\title{
Functional living biointerfaces to direct cell-material interaction
}

\author{
Thesis submitted by \\ Aleixandre Rodrigo Navarro \\ to obtain the degree of Doctor of Philosophy \\ at the Universitat Politècnica de València \\ Valencia, May 2015
}

\author{
Main supervisor \\ Prof. Manuel SALMERÓN-SÁNCHEZ
}

Co-supervisors

Dr. Patricia Rico ToRTosA Dr. Anas SAADEDDIN 



\section{Acknowledgements}

I would like to show my gratitude to all of the people with whom I have shared these last years.

I would like to express my most sincere gratitude to Manuel, for giving me the opportunity to develop this thesis, for his trust in me, his support, dedication and guidance, and for every single opportunity he gave me throughout this years. Thank you so much!

I would also like to thank, in no particular order, Anas and Patricia, for their invaluable guidance during this thesis and for teaching me countless techniques and know-how. It has been great to have you as supervisors.

My gratitude goes with all people from Center for Biomaterials and Tissue Engineering: Silvia, Úrsula, Irene, Hayk, Sara, Keila, Laura, Virginia, Pepe, Andrés, Marco, Myriam, Cristina, Ximo, Carmen, Rosa, Amparo, María, Line... for your friendship, patience, advice and know-how, not only in the lab. We have had great and not-so-great moments and you have been always there. I hope I did not forget anybody.

I would acknowledge people from MiMe group, especially Vladimira, for her great help and support with the work I did during the stay in Glasgow.

We acknowledge financial support from ERC through HealInSynergy (306990) and the Center for Biomaterials and Tissue Engineering at the Universitat Politècnica de València, through the Specialization Fellowships I was awarded.

Quiero también dar las gracias a mi familia, por su apoyo constante e infinito, su paciencia, dedicación y consejos, por animarme siempre a hacer lo que me gusta, y por aguantarme, que no es poco.

A Isabel, por estar ahí siempre. Gran parte de esta tesis también es tuya.

Y por último, a todos aquellos que, de una forma u otra, han formado parte de este trabajo. 



\section{Summary}

Abstract $\quad$ i

$\begin{array}{ll}\text { Resumen } & \text { iii }\end{array}$

Resum v v

$\begin{array}{ll}\text { Abbreviations } & \text { vii }\end{array}$

1 Introduction $\quad 1$

1.1 Biomaterials and tissue engineering $\ldots \ldots \ldots \ldots \ldots \ldots$

1.2 The need for dynamic interfaces . . . . . . . . . . 2

1.3 Interfaces based on living bacteria as a novel concept . . . . . . 4

1.4 Bacterial adhesion . . . . . . . . . . . . . . . 4

1.5 Genetic engineering and synthetic biology . . . . . . . . . 11

1.6 Cell adhesion . . . . . . . . . . . . . . . . . . . 19

The extracellular matrix . . . . . . . . . . . . . . . . 19

Cell adhesion . . . . . . . . . . . . . . . . . 20

Fibronectin structure and functions $\ldots \ldots \ldots \ldots 23$

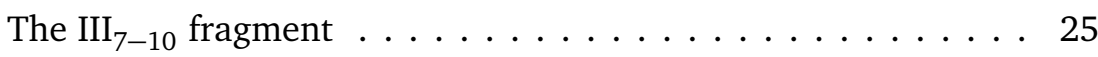

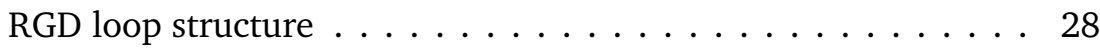

1.7 L. lactis, why and how . . . . . . . . . . . . . 30

1.8 L. lactis phylogeny, metabolism and physiology . . . . . . . . 33

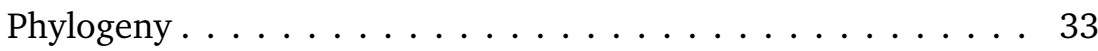

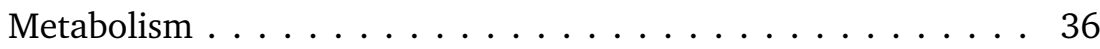

Lactic acid configuration . . . . . . . . . . . 38

2 Objectives $\quad 39$ 
3 Materials and methods $\quad 41$

3.1 Cloning protocols . . . . . . . . . . . . . . . 41

Endonuclease restriction . . . . . . . . . . . . . . 41

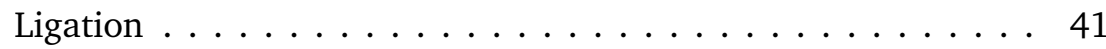

E. coli transformation . . . . . . . . . . . . . . . . . 42

E. coli culture . . . . . . . . . . . . . . . . . . . . 42

Polymerase chain reaction (PCR) . . . . . . . . . . . 42

Preparation of L. lactis electrocompetent cells . . . . . . . . . . . 43

L. lactis electrotransformation . . . . . . . . . . . . . 43

Plasmid isolation from L. lactis . . . . . . . . . . . . . . . . 43

DNA purification from PCR or enzymatic reactions . . . . . . . . 44

DNA purification from gel bands . . . . . . . . . . . . 44

Cell lysis and plasmid purification . . . . . . . . . . . . 45

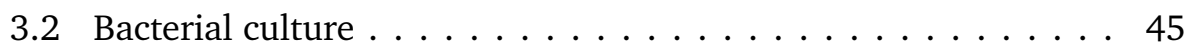

3.3 L. lactis biofilm production $\ldots \ldots \ldots \ldots \ldots \ldots$

3.4 Mammalian cell culture . . . . . . . . . . . . . . . 46

$\mathrm{Fn}^{-} / \mathrm{Fn}^{-}$murine fibroblasts . . . . . . . . . . . . 47

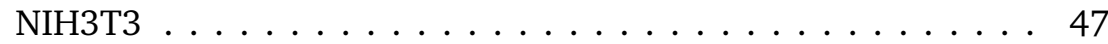

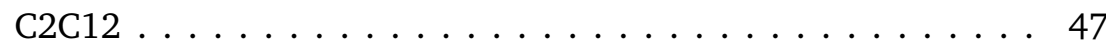

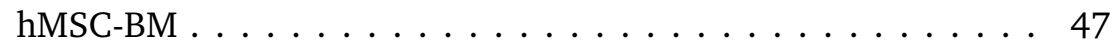

3.5 Immunofluorescence assays $\ldots \ldots \ldots \ldots \ldots$. . . . . . . 48

Cell adhesion . . . . . . . . . . . . . . . . . 48

Cell differentiation . . . . . . . . . . . . . . . . 48

3.6 Protein quantification by Western blot . . . . . . . . . . . 49

Membrane localisation of FNIII $_{7-10} \ldots \ldots \ldots$. . . . . . 49

Expressed FNIII $_{7-10}$ fragment . . . . . . . . . . . . . . . . 49

FAK phosphorylation . . . . . . . . . . . . . 50

3.7 Enzyme-linked immunosorbent assay (ELISA) . . . . . . . . . 51

Membrane-bound FNIII $_{7-10} \ldots \ldots \ldots \ldots \ldots \ldots$

ERK1/2 sandwich ELISA . . . . . . . . . . . . . . . 51

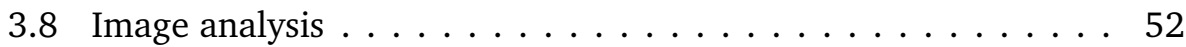

Cell morphology . . . . . . . . . . . . . . . 53

Bacterial and cell viability . . . . . . . . . . . . 53

Biofilm density . . . . . . . . . . . . . . . . . 54

Western blot quantification . . . . . . . . . . . . 54

Differentiation analysis . . . . . . . . . . . . . . 55

3.9 Materials preparation . . . . . . . . . . . . . . . 55

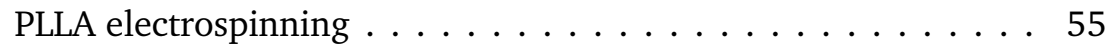


Ethyl acrylate polymerisation . . . . . . . . . . . . 56

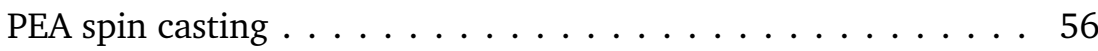

PLLA spin casting $\ldots \ldots \ldots \ldots \ldots \ldots \ldots \ldots$

4 Lactococcus lactis cloning and characterization 57

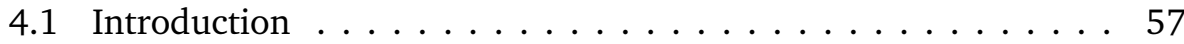

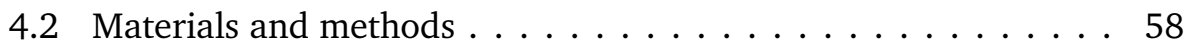

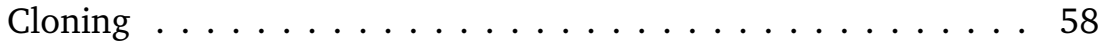

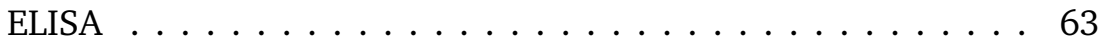

Detection of FNIII $_{7-10}$ fragment by Western blot . . . . . . . 64

Scanning electron microscopy . . . . . . . . . . . . . . 64

Atomic force microscopy . . . . . . . . . . . . . . . . 65

Confocal laser scanning microscopy . . . . . . . . . . . . . 65

Bacterial viability . . . . . . . . . . . . . . 65

Image analysis . . . . . . . . . . . . . . . 66

4.3 Results . . . . . . . . . . . . . . . . . . . 66

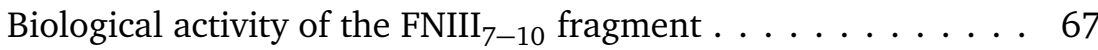

Biofilm morphology . . . . . . . . . . . . . . . . . . 71

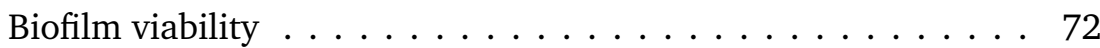

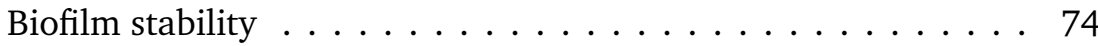

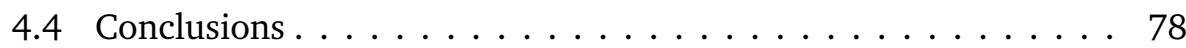

5 Cell-bacteria co-cultures and cell behaviour $\quad 81$

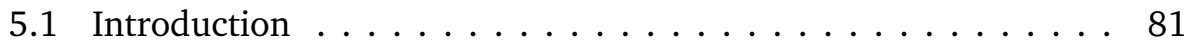

5.2 Material and Methods . . . . . . . . . . . . . . 88

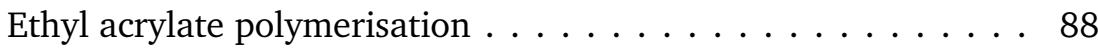

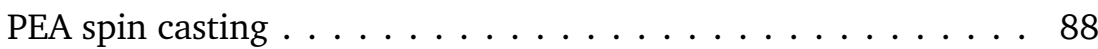

Biofilm production $\ldots \ldots \ldots \ldots \ldots$

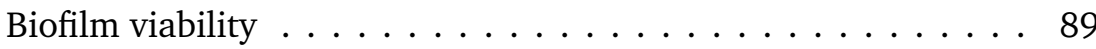

Biofilm metabolism . . . . . . . . . . . . . . . . . . . 89

Production of biofilms with tunable areal density . . . . . . . 90

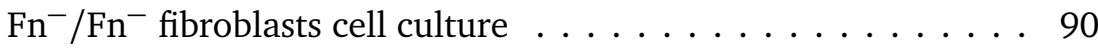

NIH3T3 cell culture . . . . . . . . . . . . . . . . . . . 90

C2C12 cell culture . . . . . . . . . . . . . . . . 90

Human mesenchymal stem cell culture . . . . . . . . . . . . . 91

Sarcomeric myosin immunostaining . . . . . . . . . . . . . . 91

Vinculin immunostaining . . . . . . . . . . . . . . . 91

Image analysis . . . . . . . . . . . . . . . . . . . 92

FAK phosphorylation analysis by Western blot . . . . . . . . . 93 
ERK1/2 phosphorylation by sandwich ELISA . . . . . . . . 93 Quantitative real-time PCR . . . . . . . . . . . . . . . 94

Statistical analysis . . . . . . . . . . . . . . . . . 994

5.3 Results . . . . . . . . . . . . . . . . . . . 96

Cell adhesion and signalling . . . . . . . . . . . . 96

Myogenic differentiation and cell signalling . . . . . . . . . . 104

Adhesion and differentation of human mesenchymal stem cells . 107 ERK1/2 phosphorylation analysis . . . . . . . . . . 108

Differentiation assessment by gene expression analysis . . . . 110

5.4 Conclusions . . . . . . . . . . . . . . . . . . . . . 112

6 Bacterial inclusion in polymeric systems 115

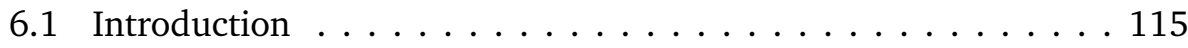

6.2 Materials and methods . . . . . . . . . . . . . . 118

Myogenic differentiation and cell signalling . . . . . . . . . . 119

6.3 Results . . . . . . . . . . . . . . . . . . . . . . . 120

Immobilisation in poly-L-lactic acid nanofibres . . . . . . . . . 120

Immobilisation in poly-L-lactic acid thin films . . . . . . . . . . 123

6.4 Conclusions . . . . . . . . . . . . . . . . . . . . . . 125

$\begin{array}{lll}7 & \text { Future work } & 127\end{array}$

8 Conclusions 131

$\begin{array}{ll}\text { Appendix } & 135\end{array}$

$\begin{array}{ll}\text { Work derived from this thesis } & 141\end{array}$

$\begin{array}{ll}\text { References } & 159\end{array}$ 


\section{Abstract}

This thesis deals with the development of a living biointerface between synthetic substrates and living cells to engineer cell-material interactions for tissue engineering purposes. This living biointerface is made of Lactococcus lactis, a non-pathogenic lactic bacteria widely used as starter in the dairy industry and, recently, in the expression of heterologous proteins in applications such as oral vaccine delivery or membrane-bound expression of proteins.

L. lactis has been engineered to display the $\mathrm{III}_{7-10}$ fragment of the human fibronectin, fused to GFP as reporter protein. Fibronectin is a ubiquitous protein present in the extracellular matrix, a complex mesh of structural and adhesive proteins which serve as mechanical support and development niche for cells of a wide variety of tissues. This fragment contains two important sequences, RGD and PHSRN. RGD is an adhesive sequence that interacts with a wide range of integrins, membrane-bound receptors that play a role in cellular processes such as adhesion, migration, proliferation and differentiation. On the other hand, PHSRN binds synergistically with RGD to some integrins such as $\alpha_{5} \beta_{1}$ and others, increasing the specificity of this interaction.

Genetically engineered $L$. lactis has been thoroughly characterized to test its capabilities as a living interface. This strain was engineered to express the FN III $_{7-10}$-GFP fragment covalently linked to the cell wall and biological activity and expression levels of this fragment were assessed with techniques such as Western blot, ELISA and immunofluorescence. Moreover, this strain still holds the ability to develop biofilms, communities of sessile, attached bacteria to abiotic surfaces which helps greatly in the generation of a stable monolayer of bacteria between synthetic substrates and mammalian cells.

Mammalian cell behaviour in response to the expressed fibronectin fragment on L. lactis membrane was also assessed. Several cell lines were tested, such as $\mathrm{Fn}^{-} / \mathrm{Fn}^{-}$and NIH3T3 fibroblasts, C2C12 myoblasts and human bone-marrow derived mesenchymal cells. This living biointerface was found to trigger cell adhesion and FAK phosphorylation, a marker for intracellular integrin-mediated 
signalling in all of the tested cell lines. It also triggered myoblast-to-myotube differentiation on C2C12 cells. In hMSCs, the cell-wall exposed fibronectin fragment was found to enhance the phosphorylation of ERK1/2, a kinase involved in the MAPK pathway, which is deeply involved in a multitude of cellular processes related to differentiation, proliferation and migration.

Nevertheless, this thesis is a proof of concept that this novel system can be further exploited to express almost any desired protein or small molecule to help in the development of new tissues from progenitor cells. These molecules can be either secreted in the medium or displayed in the membrane, and can also be constitutively expressed or in-demand, due to the great flexibility of $L$. lactis and the wide variety of expression systems available.

This interface based on living bacteria establishes a new paradigm in surface functionalization for biomedical engineering applications. 


\section{Resumen}

Esta tesis aborda el desarrollo de una biointerfase viviente entre materiales sintéticos y células vivas con el objetivo de dirigir la interacción célula-material en aplicaciones de ingeniería tisular. Esta biointerfase está formada por Lactococcus lactis, una bacteria láctica no patógena, ampliamente usada en la industria láctea como inóculo y recientemente, en la expresión heteróloga de proteínas para su uso como vacunas de administración oral o su expresión en membrana.

L. lactis ha sido modificada genéticamente para expresar el fragmento $\mathrm{III}_{7-10}$ de la fibronectina humana unida a GFP como reporter. La fibronectina es una proteína presente de forma ubicua en la matriz extracelular, una compleja red de proteínas adhesivas y estructurales cuyo propósito es servir como soporte estructural y como nicho de desarrollo para diversos tejidos. Este fragmento contiene dos secuencias importantes, RGD y PHSRN. RGD es una secuencia adhesiva de unión que interacciona con una amplia variedad de integrinas, receptores de membrana que juegan muchos e importantes papeles en diferentes procesos celulares como adhesión, proliferación, migración o diferenciación. Por otra parte, PHSRN se une a las integrinas de forma sinérgica con RGD facilitando aún más estos procesos y aumentando la especificidad de esta interacción.

Esta cepa modificada de L. lactis ha sido caracterizada para estudiar su idoneidad como interfaz funcional viviente. Se ha demostrado que L. lactis es capaz de expresar el fragmento FN $\mathrm{III}_{7-10}$-GFP covalentemente anclado a la pared celular bacteriana, habiéndose caracterizado también su actividad biológica con técnicas como Western blot, ELISA e inmunofluorescencia. Esta cepa mantiene la capacidad de desarrollo de biofilms presente en la gran mayoría de microorganismos. Los biofilms son comunidades de bacterias sésiles adheridas a un sustrato que pueden ser usadas como interfase física entre células de mamífero y sustratos abióticos.

También se ha estudiado la respuesta celular a la fibronectina expuesta en la membrana de L. lactis. Se estudiaron varias líneas celulares, como fibroblastos 
$\mathrm{Fn}^{-} / \mathrm{Fn}^{-}$y NIH3T3, mioblastos C2C12 y células mesenquimales humanas derivadas de médula ósea. Esta interfase viviente fue capaz de provocar respuesta celular en forma de adhesión en todas las líneas estudiadas, además de inducir diferenciación de mioblastos a miotubos en C2C12 y de provocar la fosforilación de FAK, un marcador de señalización celular mediada por integrinas.

En células mesenquimales humanas se demostró la capacidad del fragmento de fibronectina expuesto para fosforilar ERK1/2, una kinasa perteneciente a la ruta de señalización MAPK, ruta que forma parte de muchos procesos celulares importantes como diferenciación, proliferación y migración.

Pese a todo, esta tesis es sólo una prueba de concepto de un sistema que puede ser utilizado para expresar casi cualquier proteína o molécula pequeña deseada, que puede ser muy útil en el desarrollo de nuevos tejidos a partir de sus células progenitoras. Estas moléculas pueden ser secretadas en el medio o ancladas en la pared celular, de forma constitutiva o bajo demanda, debido a la flexibilidad y amplia variedad de sistemas de expresión disponibles para $L$. lactis.

Esta biointerfaz basada en bacterias vivas establece un nuevo paradigma en el campo de la funcionalización de superficies para aplicaciones de ingeniería biomédica. 


\section{Resum}

Aquesta tesi aborda el desenvolupament d'una interfase viva entre materials sintètics i cèl-lules vives amb l'objectiu de dirigir la interacció cèlllula-material, per al seu ús en aplicacions d'enginyeria tissular. Aquesta interfase està composta de Lactococcus lactis, un bacteri làctic, no patogènic i àmpliament utilitzat en l'industria làctica com a inòcul, $i$, recentment, en l'expressió heteròloga de proteïnes per al seu ús com vacunes d'administració oral o per a la seva expressió en membrana.

L. lactis ha sigut genèticament modificada per a expressar el fragment $\mathrm{III}_{7-10}$ de la fibronectina humana, unida a GFP com a reporter. La fibronectina és una proteïna present de forma ubiqua en la matriu extracel-lular, una complexa xarxa de proteïnes adhesives i estructurals que serveixen de suport estructural i nínxol de desenvolupament per a diversos teixits. Aquest fragment conté dos seqüències importants, RGD i PHSRN. RGD és una seqüència adhesiva d'unió a integrines, receptors de membrana que juguen molts i molt importants papers en diferents processos cel-lulars, com adhesió, proliferació, migració o diferenciació. Per altra banda, PHSRN s'uneix a les integrines de forma sinèrgica amb RGD facilitant encara més aquests processos i augmentant l'especificitat d'aquesta interacció.

Aquest cep de L. lactis ha estat àmpliament caracteritzat per estudiar les seves característiques com a interfase funcional vivent. S'ha demostrat que L. lactis és capaç d'expressar el fragment FNIII $7-10$-GFP covalentment ancorat a la paret cel-lular bacteriana, havent-se caracteritzat també la seva activitat biològica amb tècniques com Western blot, ELISA i immunofluorescència. A més, aquest cep manté la capacitat de desenvolupament de biofilms, comunitats de bacteris sèssils adherits a un substrat que poden ser utilitzades com a interfase física entre cèl-lules de mamífer i substrats abiòtics.

També s'ha estudiat la resposta cel-lular a la fibronectina expressada en la paret cel·lular de L. lactis. El estudi es va fer utilitzant diverses línies cel-lulars, com fibroblasts $\mathrm{Fn}^{-} / \mathrm{Fn}^{-}$i NIH3T3, mioblasts C2C12 i cèl-lules mesenquimals 
humanes derivades de medul-la òssia. Aquesta interfase vivent va ser capaç de provocar resposta cel·lular en forma d'adhesió a totes les línies estudiades, a més d'induir diferenciació de mioblasts a miotubs en C2C12 i de provocar la fosforilació de FAK, un marcador de senyalització cel·lular mediat per integrines, en les línies assajades. En cèl-lules mesenquimals humanes es va demostrar la capacitat del fragment de fibronectina exposat per a fosforilar ERK1/2, una kinasa pertanyent a la ruta de senyalització MAPK, ruta que forma part d'important processos cel·lulars com diferenciació, proliferació i migració.

Malgrat tot, aquesta tesi només és una prova de concepte d'un sistema que pot ser utilitzat per expressar quasi qualsevol proteïna o molècula petita desitjada, que pot ser molt útil en el desenvolupament de nous teixits a partir de les seves cèl-lules progenitores. Aquestes molècules poden ser secretades en el medi o ancorades a la paret cel-lular, de manera constitutiva o baix demanda, a causa de la flexibilitat $\mathrm{i}$ àmplia varietat de sistemes d'expressió disponibles per a L. lactis

Aquesta biointerfase basada en bacteris vius estableix un nou paradigma en el camp de la funcionalització de superfícies per a aplicacions d'enginyería biomèdica. 


\section{Abbreviations}

AFM Atomic Force Microscopy

ANOVA Analysis of variance

ATP Adenosin triphosphate

BMP Bitmap format

BMP2 Bone morphogenetic protein 2

BSA Bovine Serum Albumin

CS Calf serum

cDNA complementary DNA

cFN cellular fibronectin

Col Collagen

CWAP Cell-wall anchored protein

DAPI 4',6-diamino-2-phenylindole

DMEM Dulbecco's Modified Eagle Medium

dNTP deoxynucleotide triphosphate

DLVO Derjaguin-Landau-Verwey-Overbeek theory

DPBS Dulbecco's Phosphate Buffered Saline

ECM Extracellular matrix

EDTA Ethylenediaminetetraacetic acid 
ELISA Enzyme-linked immunosorbent assay

EPS Exopolysaccharide

ERK Extracellular regulated kinase

FA Focal adhesion

FAK Focal adhesion kinase

FBS Foetal bovine serum

FDP Fructose 1,6-diphosphate

FN Fibronectin

GAG Glycosaminoglycans

GAP Glyceraldehyde 3-phosphate

GE Genetic engineering

GFP Green fluorescent protein

GRAS Generally regarded as safe

HEPES (4-(2-hydroxyethyl)-1-piperazineethanesulfonic acid)

HFIP Hexafluoroisopropanol

hMSC Human mesenchymal stem cell

iPS induced pluripotent stem cell

LAB Lactic acid bacteria

LB Luria-Bertani broth

MCS Multiple cloning site

MAPK Mitogen-activated protein kinase

NADH Reduced nicotinamide adenine dinucleotide

$\mathrm{NAD}^{+}$Oxidized nicotinamide adenine dinucleotide

n-LDH NAD-dependent lactate dehydrogenase 
PAGE Polyacrylamide gel electrophoresis

PCR Polymerase chain reaction

PDB Protein Data Bank

PEA Poly (ethyl acrylate)

PEG Poly (ethylene glycol)

pERK Phosphorylated extracellular regulated kinase

pFAK Phosphorylated focal adhesion kinase

pFN Plasma fibronectin

PLLA Poly L-lactic acid

PTS Phosphotransferase system

qPCR Quantitative real-time polymerase chain reaction

RFLP Restriction fragment length polymorphism

RGB Red-green-blue

SB Synthetic Biology

SEM Scanning electron microscopy

SDS Sodium dodecyl sulfate

SOC Super optimal broth with catabolic repression

TIFF Tagged image file format

UMT Urogen III methyltranferase

VEGF Vascular endothelial growth factor

WB Western Blot

XDLVO Extended Derjaguin-Landau-Verwey-Overbeek theory 



\section{Chapter 1}

\section{Introduction}

\subsection{Biomaterials and tissue engineering}

Tissue engineering is defined as an interdisciplinary field that applies the principles of engineering and life sciences toward the development of biological substitutes that restore, maintain, or improve tissue function or a whole organ [1]. The loss or failure of an organ or tissue is one of the most frequent and devastating healthcare problems, and has tried to be solved using different approaches, such as transplants, autologous grafts, prostheses and tissue regeneration. [1]

Nowadays, the main purpose of tissue engineering is the repair of damaged organs and the recreation of new ones. Tissue engineering makes use of different approaches to regenerate or create a new tissue. A first approach involves the isolation of cells from the patient, followed by an in vitro expansion and their culture on suitable biomaterials with the ability to direct cellular behaviour and function, followed by their posterior implantation on the damaged site (autologous implant).

Other approach consists in the in situ liberation of growth factors and other proteins or compounds with the ability to direct cell fate. This approach relies on the regenerative ability of the already existent cells, by directing its behaviour. A third approach involves the use of polymeric scaffolds, trying to recreate and mimic the characteristics of the extracellular matrix, followed by cell seeding within the scaffold.

These approaches are complementary and require a deep understanding of the dynamics and composition of the extracellular matrix, the interaction between cells and their surroundings and the intracellular processes triggered by the cell-microenvironment bidirectional communication. 
Therefore, tissue engineering requires the use of biomaterials, which are characterized by its ability to coexist with living tissues inside the human body, without causing any rejection reaction or harm. [2]

Different inorganic materials have been used as biomaterials, such as metals, glass or synthetic polymers. Depending on their purpose, properties like biodegradability can be useful. For example, implanted patches to assist in the growth of new tissue which will eventually degrade leaving the mature tissue, or non-biodegradable materials with specific physical properties and good biocompatibility, such as titanium parts used in hip replacement. [3]

However, almost all of the tissue engineering approaches require a cell source. Stem cells, with suitable differentiation capabilities, are routinely used in research as of today, and several appropriate sources have been identified, such as bone marrow and adipose tissue. Induced pluripotent stem cells [4] (iPS) are widely used. These cells show differentiation capabilities similar to embryonic stem cells, without its ethical and legal issues. The use of iPS derived from the same patient for its use in autoimplants and alloimplants can overcome the problems derived from immune rejection. [5-7]

iPS pluripotency is a promising way to regenerate absent or damaged tissue if the adequate microenvironmental conditions are properly fulfilled. Besides iPS, other multipotent cell lineages are being used, such as stromal mesenchymal stem cells, which hold great promise in present and near-future applications for tissue engineering.

Nevertheless, growth and differentiation of stem cell lineages is unavoidable without the establishment of an adequate microenvironment where these cells can grow and differentiate in response to the biochemical, mechanical and other required stimulus in the development of a new tissue.

\subsection{The need for dynamic interfaces}

A deep understanding of cell behaviour on synthetic surfaces is of paramount interest to engineer microenvironments with the ability to direct cell adhesion, proliferation and differentiation. Surfaces of synthetic materials have been functionalized with a broad range of proteins, peptides and growth factors, including fibronectin (FN), laminin, vitronectin, synthetic peptides and others, by means of physical and chemical strategies. [8-10]

Tissue engineering is a wide knowledge area whose objective is to repair the structure and function of damaged tissues and organs through a multidisciplinary approach, by engineering advanced material-based systems. [1] 
To the date, the most used approach has consisted in the use of passive coatings such as protein or growth factors, to assist cells in the interaction with synthetic substrates. $[8,9]$

Cells interact with surfaces via integrins [11], a family of transmembrane receptors which serve as a link between the extracellular environment and the cytoskeleton. Integrins initiate several intracellular signaling pathways acting also as mechanical transducers, controlling cell motility, cytoskeleton reorganization amongst other complex cellular processes. [11-13]

However, the development of a mature tissue requires the display of a sequence of biochemical signals to the growing tissue in a highly controlled manner. Passive coatings cannot provide these dynamic stimuli, although significant efforts have focused on engineering materials that recapitulate ECM characteristics. Some examples of these coatings include cell adhesive motifs or protease degradable cross-links. Photoactivable RGD adhesive peptides have been used to investigate the effect of density and time point of ligand presentation on cell adhesion, proliferation and differentiation. [14].

Similarly, enzyme-responsive surfaces have been tested. These surfaces display cell adhesive RGD sequences on-demand, by presenting inactive RGDcontaining precursors that carry cleavable steric blocking groups, which can be later exposed to the cells by means of an enzymatic hydrolysis. [15]

Consequently, the development of a cell-material interface able to present different biochemical stimuli on demand, that is, a functional dynamic interface between stem cells and synthetic materials, has not been established yet.

Our working hypothesis is that non-pathogenic bacteria can play this role, since they are able to colonize a broad range of synthetic materials, from synthetic polymers to glass or metals and thus can establish an interfacial layer between these materials and the mammalian cells. This interfacial layer is functionally equivalent to surfaces coated with extracellular matrix components such as fibronectin, collagen and others, with the added advantage of the on-demand expression of almost any desired biochemical cue.

These bacteria can be genetically modified easily, allowing a constitutive or on-demand expression of any needed protein or growth factor, which will aid in the development of a new tissue. The aim of this work is to further investigate this hypothesis and show the feasibility of dynamic biointerfaces based on living organisms. 


\subsection{Interfaces based on living bacteria as a novel concept}

In this thesis we hypothesize that genetically modified, non-pathogenic bacteria can play the role of a living biointerface between mammalian cells and synthetic biomaterials.

Interfaces based on living bacteria have some advantages over classic biomaterials, which interact with living cells only in a limited way, or show no interaction at all [16]. Therefore, an intermediate protein layer is required to display active biochemical signals to the cells that are in contact with. These protein layers are, in most cases, a passive coating that can only provide a static stimulus, not sufficient to create a dynamic microenvironment, which is needed for the successful development of a mature tissue. To resolve these issues, we propose a living biointerface as a feasible solution to address these issues.

The proposed biointerface is composed by a monolayer of Lactococcus lactis subsp. cremoris MG1363 that express the $\mathrm{III}_{7-10}$ fragment of human fibronectin in its surface. L. lactis is a gram-positive, non-pathogenic, lactic bacteria which, since its genome has been fully sequenced, has been object of an intense research in recent years $[17,18]$. Several constitutive and inducible protein expression systems are readily available. [19-24]

Moreover, this strain has become a broadly used host for heterologous protein expression [25-30]. The heterologously expressed $\mathrm{III}_{7-10}$ fragment in its cell wall contains the adhesive RGD peptide, located on the $\mathrm{III}_{10}$ repeat, and the synergy PHSRN motif, located on the $\mathrm{III}_{9}$ repeat. Both sequences interact synergistically with the $\alpha_{5} \beta_{1}$ integrin, involved in the cellular adhesion process and in the later migration, proliferation and differentiation and plays an important role in the tissue development process. [11]

The III $_{7-10}$ fragment has been shown to induce cell response when coated on synthetic substrates [31]. The initial purpose of this work is the membranebound expression of this fragment and the assessment of the biological behaviour of a mammalian cell population cultured on top of this biointerface.

\subsection{Bacterial adhesion}

Since bacteria-based biointerfaces will be assessed throughout this work, it is important to have a good understanding of its interaction with synthetic surfaces.

Microbial adhesion is the first step in the development of a biofilm. Although biofilms can be detrimental to human life and industrial processes, due 
to its ability to colonize implants and its role in conditions such as periodontitis, caries [32] and other diseases, amongst the enhanced corrosion rates of metallic surfaces [33], they also play beneficial roles in the nature, such as degradation of environmental hazardous chemicals in soil [34, 35], in bioreactors for wastewater treatment [36] or off-gas treatment [37], in agricultural uses of root nodule bacteria in the rhizosphere [38], in the degradation of biopolymers such as cellulose [39], and in bioflocculants used for the separation of coal particles [40].

Bacterial cells have a size range from 0.5 to $2 \mu \mathrm{m}$, similar to colloids, consequently interaction between charged bacterial cells and surfaces can be described using the DLVO (Derjaguin-Landau-Verwey-Overbeek) theory [41], originally developed to describe the interaction between colloidal particles and surfaces.

The interaction between a particle and a surface can be expressed as the sum of the Van der Waals and Coulomb forces. Van der Waals are attractive, very short-ranged forces whose intensity decreases exponentially with distance, being negligible at long distances, while Coulomb or electrostatic forces can be either attractive or repulsive, with a longer interaction range [42]. Van der Waals forces become dominant below 5 nanometres, hence particles that approach to a surface at a short enough distance can attach irreversibly. This approach can be via Brownian motion or due to cell motility. Usually, natural surfaces are negatively charged [41], and that is the case for most bacteria. Surfaces in contact with an aqueous environment exhibit a net negative charge. To compensate this charge, a cationic counterion layer is formed in the immediate vicinity of the charged surface, either on the material or bacterial surface.

This counter-ion layer acts as an "electrostatic shield", resulting in an ionic double layer and a net repulsive force at medium distances (Figure 1.1). This electrostatic repulsion is highly dependent on the ionic strength of the medium. Therefore, three different scenarios can be described.

At low ionic strengths, when a charged bacterium approaches the surface, appears a repulsive energy barrier that cells cannot overcome by Brownian motion or motile forces. As ionic strength increases, the electric double layer becomes shielded by the ions present in the medium and this repulsive electrostatic interaction lessens. At intermediate ionic strengths, there is still an energy maximum, but also a shallow secondary energy minimum outside the of the energy barrier (Figure 1.2, center). At very high ionic strengths, the electrostatic energy barrier almost disappears, and theoretically, a charged particle would be able to approach to a surface and attach irreversibly. 


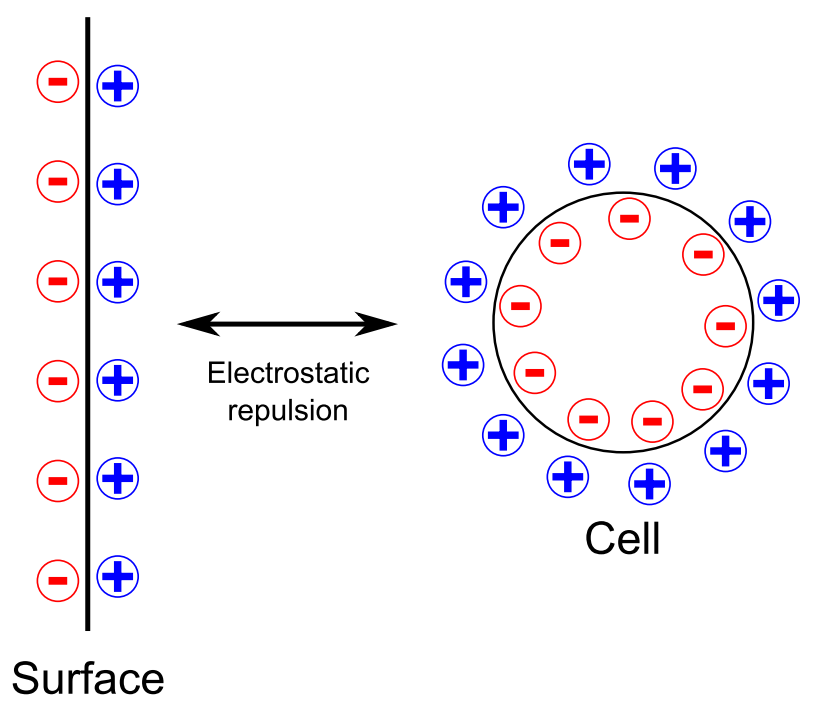

Figure 1.1 Bacteria and surfaces are, typically, negatively charged. This negative charge is counterbalanced by cations, creating a double layer that results in a net electrostatic repulsion between cells and surfaces.
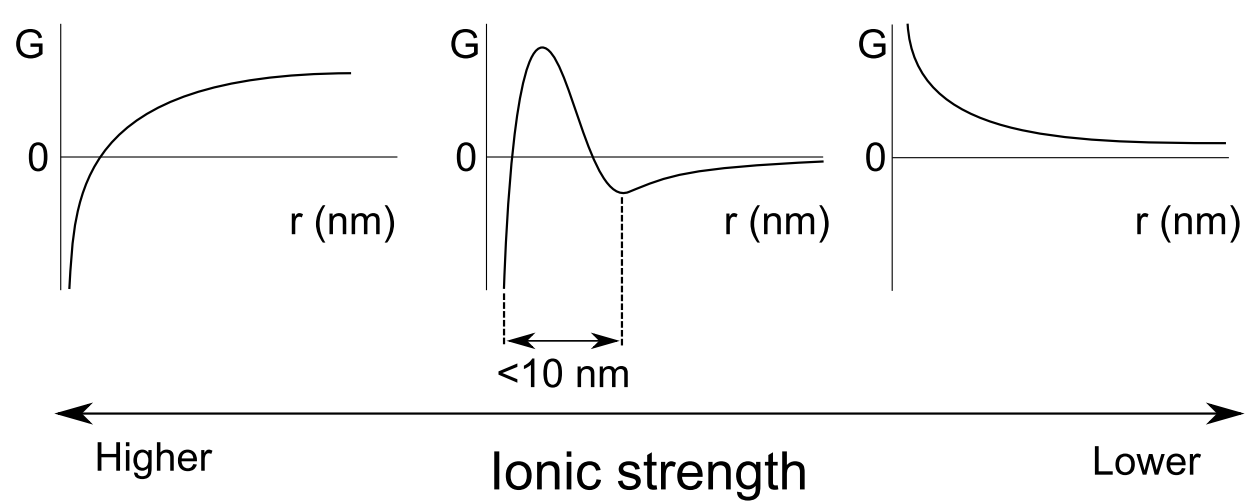

\section{lonic strength}

Lower

Figure 1.2 Free Gibbs energy (G) in three different ionic strength scenarios. From left to right, high ionic strength, where charged colloids become shielded and the maximum fades. In the middle, a shallow minimum appear and charged particles can approach to a distance close to the surface. In the low ionic strength scenario, charged particles are not shielded and the repulsive electrostatic force increases as the particle approaches to the charged surface.

In light of the above, only the intermediate ionic strength medium scenario will be taken in account, as it is the most frequent scenario for bacterial and 
cell culture medium (Figure 1.2).

The distance from the surface to the secondary minimum is usually located within several nanometres, depending on the ionic strength. A charged particle will be able to approach to this minimum and attach reversibly. This is the first step of bacterial adhesion. If we were bearing in mind only colloidal particles, this adhesion would be considered reversible, because strong enough shear forces would detach the particle from the surface.

Nevertheless, in a bacterial adhesion scenario, there is a chance that some adhered bacteria will use nanofibres, such as pili and fimbriae, with the ability to pierce the energy barrier and irreversibly attach the cell to the surface (Figure 1.3).
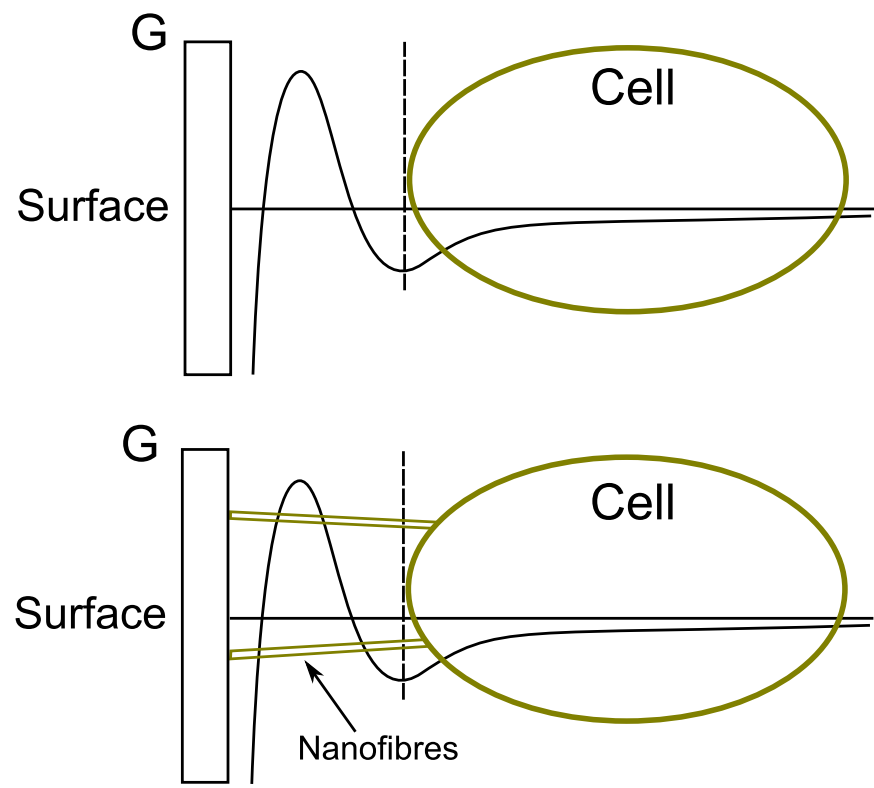

Figure 1.3 Two-step model of bacterial adhesion. In the first step, the cell approaches to the secondary minimum, attaching reversibly to the surface. In the second step, nanostructures such as pili and fimbriae are used by the cell to overcome the electrostatic potential barrier leading to an irreversible attachment.

A correlation between decreased bacterial adhesion and decreased ionic strength has been found, which is consistent with the DLVO theory [41]. However, DLVO theory is not enough to properly describe the interaction between charged cells and surfaces. Van Oss developed the extended DLVO (XDLVO) theory $[43,44]$, also known as the thermodynamic approach, based on the 
surface free energy, defined as

$$
\Delta G_{a d h}=\gamma_{S B}-\gamma_{S L}-\gamma_{L B}
$$

Where $\Delta G_{a d h}$ is the free interaction energy, $\gamma_{S B}, \gamma_{S L}$ and $\gamma_{L B}$ the surfacebacteria, surface-liquid and bacteria-liquid interfacial free energies, respectively. Negative $\Delta G_{a d h}$ values will favour the interaction.

The DLVO model describes a two-step adhesion process. Since in the first adhesion step there is not direct contact between the substrate and the bacterial surface due to the energy barrier depicted in the Figure 1.3, the minimum distance among bacteria and surface is always in the range of several nanometres. The first reversible interaction is instantaneous while the second phase is timedependent. The thermodynamic approach only takes into account interfacial energies, thus the formation of a new cell-surface interaction is at the expense of the surface-liquid and bacteria-liquid interfaces, in contrast with the DLVO theory where the interaction energy is distance-dependent.

This approach helps with the explanation of a common observation, that is, hydrophobic cell surfaces have a preference on hydrophobic materials and vice versa.

Hydrophobicity is an important factor that affects bacterial self-agglutination and adhesion [45-51]. The hydrophobic interaction is only a consequence of the water hydrogen-bonding forces surrounding the hydrophobic moieties [52], and can be viewed as a form of a more general electron-donor and accepter or Lewis acid-base interaction. [53] The surface tension $\gamma$, according to Van Oss, involves the Lifshitz-Van der Waals component and the Lewis acid-base component, $\gamma^{L W}$ and $\gamma^{A B}$ respectively.

The Lifshitz-Van der Waals component comprises the London dispersion, the Keesom dipole-dipole and the Debye dipole-induced dipole forces. Hydrophobic/hydrophilic and osmotic interactions are also included in the extended DLVO theory [54, 55], but the osmotic interaction is negligibly small in bacterial adhesion and is not taken into account. [56]

In view of these considerations, free energy can be rewritten as

$$
\Delta G^{a d h}=\Delta G^{v d W}+\Delta G^{d l}+\Delta G^{A B}
$$

where $\Delta G^{a d h}$ denotes Van der Waals, $\Delta G^{d l}$ electric double layer and $\Delta G^{A B}$ Lewis acid-base interactions. Lewis acid-base interactions includes an attractive component when hydrophobic and repulsive when hydrophilic. This acid-base interaction is much higher than the Van der Waals attractive component, but is only operative at very short distances, with the benefit that there is not a 
repulsive barrier in the vicinities of the surface. This is an advantage over the DLVO theory, but this acid-base interaction is very short ranged, 5 nanometres at most.

The energy barrier height can be calculated from the $\zeta$-potential, which can be determined using the Smoluchowsky equation [57] from the electrophoretic mobility of cells. A problem of this approach is the fact that electrophoretic mobility approaches a non-zero value at high ionic strengths $[58,59]$, in discrepancy with the value proposed in the DLVO theory. Therefore, $\zeta$-potential is not appropriate for measuring the surface potential of bacterial cells. The Smoluchowsky equation is only valid for rigid particles, but bacteria can be considered as soft particles covered with a polymer layer where ions and water can freely diffuse within. Ohshima proposed a model to determine the $\zeta$-potential with more accuracy, and Morisaki [58, 59] proposed the following formula to determine the electrophoretic mobility using the Ohshima model:

$$
\mu=\left(\frac{\varepsilon_{R} \varepsilon_{0}}{\eta}\right)\left(\frac{\frac{\Psi}{\kappa_{m}}+\frac{\Psi_{D O N}}{\lambda}}{\frac{1}{\kappa_{m}}+\frac{1}{\lambda}}\right)+\frac{z e N}{\eta \lambda^{2}}
$$

Where $\varepsilon_{R}$ is the relative permittivity of the medium, $\varepsilon_{0}$ is the permittivity of the vacuum, $\eta$ the viscosity of the medium, $\Psi$ the surface potential of the particles, $\Psi_{D O N}$ the Donnan potential of the polymer layer, $\kappa_{m}$ the Debye-Hückel parameter of the polymer layer, $z$ the valence of the charged groups in the polymers, $e$ the electron charge, $N$ the density of the charged groups and $\lambda$ the softness parameter. Bacterial cells can be described as particles coated with a soft polymer layer.

When applying the Ohshima model to bacterial cells, surface potential of bacterial cells is much smaller than the $\zeta$-potential calculated with the Smoluchowsky equation, and the energy barrier disappears when the ionic strength of the medium reaches a sufficiently high value. Only at very low ionic strength conditions, this energy potential is high enough to prevent bacterial cells adhering to a surface.

Once an initial attachment has been achieved, bacterial cells start the biosynthesis of adhesive structures, such as pili, fimbriae and lipopolysaccharides. In Lactococcus lactis, there are three major cell-wall anchored proteins or CWAP responsible of its adhesion behaviour: CluA, PrtP and NisA [60, 61]. CluA $[62,63]$ is a chromosomally-encoded sex factor. Both PrtP [64-66], a serine proteinase, and NisA, a proteinase, are plasmid-encoded proteins. In the 
plasmid-cured strain L. lactis MG1363, the only relevant adhesin is CluA, a 136 $\mathrm{kDa}$ cell-wall bound protein which plays a major role in defining its hydrophobic properties. It is involved in horizontal gene transfer by conjugation, and seems to be an important protein in bacterial clumping and aggregation, facilitating the cell-cell adhesion in the early phases of biofilm development.

Biofilms are defined as a microbially derived sessile community characterized by cells that are irreversibly attached to a substratum or interface or to each other and are embedded in a matrix of extracellular polymeric substances that they have produced, and exhibit an altered phenotype with respect to growth rate and gene transcription. [67] Biofilms can be developed on almost any abiotic or biologic surface, giving the adequate conditions. The formation and development of a biofilm is a survival strategy of the microbial cells and can be described as a four-step process.

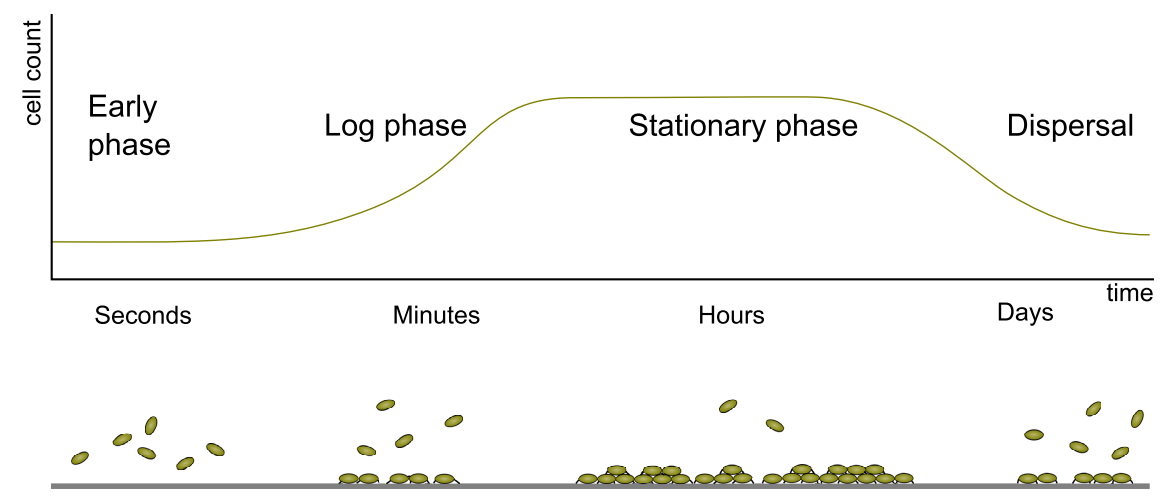

Figure 1.4 Biofilm development stages. In the early phase, some cells attach reversibly to the surface. As cell population growths, in the log phase, few of the reversibly attached cells adhere and, via the expression of adhesins and clumping proteins, more cells are recruited. In the stationary phase the biofilm is firmly established on the surface. The dispersal phase comprises the detachment and dispersal of the cells adhered within the biofilm, detachment that is caused by the depletion of the nutrients in the medium or by changes in the physiological state of these sessile cells.

In the first step, some of the free-floating bacteria, motile or not, approach the surface and, using the mechanisms described before, reversibly attach to it. Bacterial adhesion is a stochastic process, and only few of the initially attached cells will attach irreversibly. [68]

The second step [69] of this process takes place when adhesins such as CluA and secreted exopolysaccharides, although in very low amount in L. lactis, 
promotes the aggregation and attachment of more cells. This step usually takes place in the exponential growth phase, assuming that biofilm formation starts when the culture is still in the early latent phase, with very low bacterial density in the medium. In this phase, some of the attached cells detach and reattach in the vicinities.

As the optical density of culture increases, attached bacteria proliferate, getting to a maximum when the culture reaches the stationary phase, which can be considered the third phase in biofilm development [70]. In this phase, the cell division/death ratio approaches to one. Depending on the strain, a biofilm can be described as a monolayer - that is the case of L. lactis - or a multi stratified structure, mushroom-like, where cells located next to the surface display different physiological characteristics when compared to the ones in close contact with the medium. This behaviour can be attributed to the repression of genes involved in the biosynthesis of exopolysaccharides and adhesins, whose expression levels are still high in the planktonic cells.

The fourth and final stage of the biofilm development is the release and breakdown of the adhered sessile cells. Through quorum-sensing, attached cells start to express enzymes specialised in exopolysaccharide hydrolysis, resulting in cell detachment. These cells, although not adhered to a surface, are still viable and can colonize other surfaces in the vicinities (Figure 1.4). [71]

\subsection{Genetic engineering and synthetic biology}

Genetic engineering is a knowledge field that deals with the direct manipulation at a molecular level of an organism genome, by means of biotechnological and molecular biology techniques. This manipulation involves insertion, deletion or modification of the existing genetic material. This modification at the molecular level makes use of enzymes, such as restriction endonucleases, exonucleases, polymerases, ligases and others. As a result, a genetically modified organism, either unicellular or pluricellular is obtained. IUPAC defines genetic engineering as the process of inserting new genetic information into existing cells to modify a specific organism for the purpose of changing its characteristics. [72]

Several types of genetic manipulations are possible: insertion of a foreign gene from one species into another, altering a specific gene (mutagenesis), activating, silencing or changing the expression levels of one or multiple genes using multiple techniques, e.g. RNA interference [73, 74], antisense oligonucleotides [74] and riboswitches and ribozymes [75], catalytic RNA molecules with the ability to cut RNA strands at precise positions. Genetic engineering involves 
the use of recombinant nucleic acid techniques, either DNA or RNA, to create new genetic sequences into living organisms, transient or permanently, via the direct modification of the genome or using vectors.

The process of modifying the genetic material of an organism can be arbitrarily divided in several steps (Figure 1.5). The first one is the selection of the organism that will be modified, the host organism. Genetic manipulations can be carried on bacteria, yeast, fungus, mammalian cells and viruses.

One of the most important hosts used for genetic manipulations is Escherichia coli, a gram-negative bacteria. This strain has been extensively used in plasmid engineering and heterologous protein expression, but as of today, there are commercially available tools for genetic modification and engineering in grampositive strains, especially in the lactic acid bacteria clade.

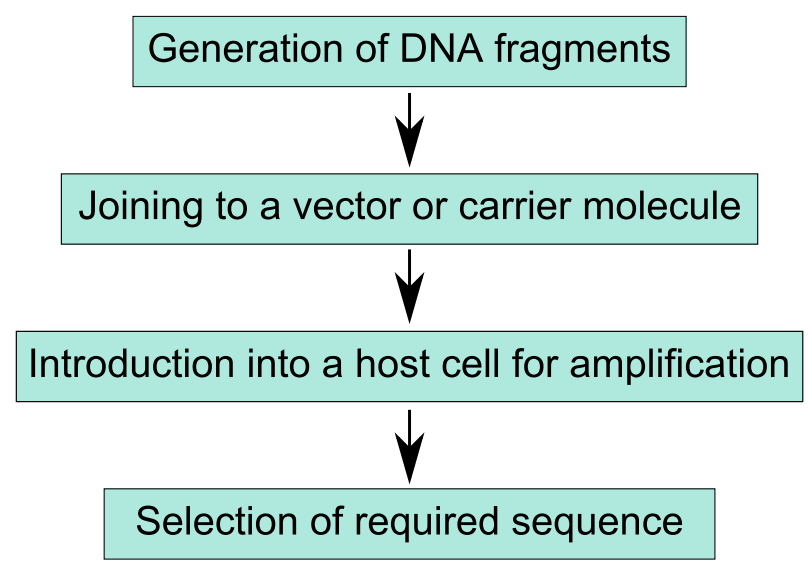

Figure 1.5 General workflow for genetic engineering.

This work deals with the genetic modification of Lactococcus lactis, a grampositive strain with industrial interest. It is also important to select the most adequate vector for our purposes. A genetic vector is a piece of circular DNA, for example plasmids, cosmids, bacterial artificial chromosomes or others that carry the desired genetic sequence. Lactococcus lactis is a strain with a wide variety of commercially available plasmids, with either inducible or constitutive promoters, several selectable genetic marker genes and multiple cloning sites (MCS) or polylinkers, where a group of restriction sequences are conveniently found and ready to use. The use of inducible or constitutive promoters depends much on the intended application; e.g., proteins toxic to the host organism cannot be constitutively expressed $[76,77]$ and must be expressed under the control of a inducible promoter. Constitutive promoters are in an "always- 
on" state, while inducible promoters require an external stimulus to initiate the transcription and induce the expression of the protein. Expression on inducible promoters can be triggered with chemical compounds, environmental conditions such as $\mathrm{pH}$ or temperature, or even light or low-frequency sound waves. Some inducible promoters show an on/off behaviour, while in others the expression can be controlled in a stimulus-dependent fashion. [21, 22, 78-80]

The next step in a classic genetic engineering workflow is the preparation of the DNA sequence to be cloned. This sequence can be obtained from multiple sources, either living or dead organisms, and amplified with the help of the polymerase chain reaction (PCR) to obtain adequate amounts of genetic material. If the source is RNA, a previous step with reverse transcriptase is required. Reverse transcriptase is an enzyme that synthesizes complementary DNA strands, or cDNA, from RNA templates. PCR is a very versatile technique and can be used to add specific restriction sequences at the $5^{\prime}$ or $3^{\prime}$ ends of sequences, helping further cloning steps. PCR can also be used to introduce single-nucleotide mutations, insertions or deletions, by using appropriate primers.

The result of a PCR reaction is a mixture of proteins (the polymerase) and nucleic acids such as the amplicon, the template, primers, dNTPs and other byproducts. Depending on the application, the amplified DNA should be subjected to a purification step. This amplicon, which should have a unique and specified length, can be separated with electrophoretic separative techniques and isolated and purified from the electrophoretic gel, generally made of agarose. Restriction endonucleases can be used to cleave in the newly introduced restriction sites and make it compatible for ligation reactions.

Those restriction enzymes can be used to cleave and linearize the destination vector. Usually, the multiple cloning site of the destination vector contains different short-length sequences that can be cleaved with appropriate restriction endonucleases, which are very useful to generate blunt or sticky ends where a foreign sequence can be ligated. A well-designed cloning planning will end with a digested vector with two different sticky ends and the amplified DNA with the same, compatible cohesive ends.

In the next step, vector and amplified DNA are joined using ligases, enzymes that covalently join two different DNA sequences by creating a phosphodiester bond in the sugar backbone of the DNA molecule, resulting in a double stranded DNA molecule with the desired sequence inserted at the exact point needed.

Besides the classic workflow that makes use of restriction endonucleases to cleave, linearize vectors and generate compatible ends, newer approaches 
does not need restriction sites at all, such as TOPO ${ }^{\circledR}$ [81], Gateway® [82], overlap extension PCR $[83,84]$ or Gibson assembly [85] techniques. These techniques make use of PCR to generate fragments with overlapping sequences that can be partially digested with an exonuclease, repaired and joined again by a polymerase and a ligase.

When the recombinant DNA molecule is ready to be inserted in the host organism, a bunch of techniques are available to help in this task. In bacterial cells, electroporation or heat-shock transformation are widely used techniques.

In gram-positive cells, electroporation is the technique of choice, because of the cell-wall structure. This transformation method consists, first, in the generation of competent cells with different methods (culture in glycine-rich medium, to obtain cells with a weakened cell wall) followed by the introduction of heterologous DNA inside the cell through the application of a very short, high voltage pulse to the cells in presence of the heterologous DNA.

This electric pulse makes the bacterial membrane permeable through the formation of temporary pores which last few nanoseconds but allow the entry of foreign DNA into the cell.

In the heat-shock transformation, cells are kept at $0{ }^{\circ} \mathrm{C}$ in presence of calcium chloride and mixed with the plasmid, which attaches to the cell wall. A quick temperature increase from 0 to $42{ }^{\circ} \mathrm{C}$ modifies the fluidity of the lipid bilayer, giving as a result the formation of temporary pores which allow the penetration of the plasmid molecules attached to the cell wall into the cytoplasmic medium through membrane invagination. Decreasing the temperature again to $0{ }^{\circ} \mathrm{C}$ returns the membrane fluidity to its original value, closing the pores and trapping the DNA inside the cell.

Other transformation techniques are also available, for exaple the gene gun or biolistic technique [86, 87], mainly used in plant biotechnology, where DNAcoated, dense tungsten microparticles are fired through intact cells, entering the cytoplasm and achieving the desired genetic transformation. For mammalian cells, lipofection $[88,89]$ is another technique which involves the generation of liposomes, usually cationic, containing the heterologous DNA to be inserted in the cells. Due to the similar structure of the cell membrane and the liposome, and favoured by their opposite charge, DNA-loaded liposomes fuse to the cell membrane, releasing the DNA inside the cell cytoplasm.

After a successful transformation, a screening step is necessary to select the transformed cells. In E. coli, the white-blue colony is the method of choice. Vectors used to transform $E$. coli cells usually contain the $\beta$-galactosidase gene, whose function is to metabolise $\beta$-galactosides into simpler monosaccharides. 
A

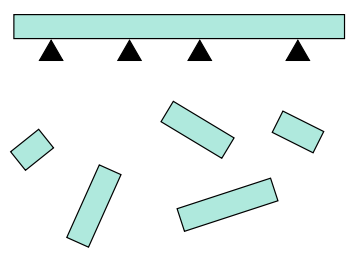

C

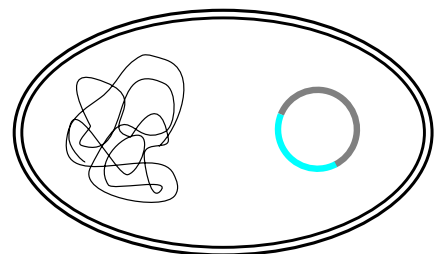

B

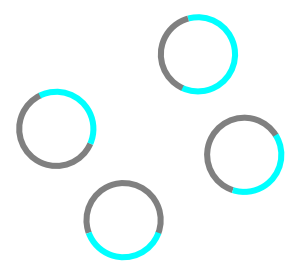

D

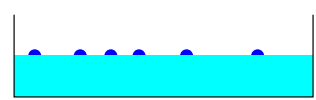

Figure 1.6 Cloning DNA fragments. a) Source DNA is fragmented through the use of restriction enzymes and b) joined to carrier molecules or vector to produce recombinant DNA molecules. c) Recombinant DNA molecules are introduced into a host cell and d) grown to propagate the clones.

Cells cultured on agar plates containing X-gal (5-bromo-4-chloro-3-indolyl- $\beta$ D-galactopyranoside), an indoxyl glycoside, form white colonies when the $\beta$-galactoside gene has been disrupted, that is to say, a heterologous sequence has been successfully cloned into the plasmid, or blue if the integrity of the gene is complete. Other selection mechanisms are based on antibiotic resistance.

In bacteria, virtually all of the engineered vectors contain one or more antibiotic resistance genes, so when a cell has been successfully transformed, it will be able to grow in medium supplemented with the proper antibiotic. This technique is not only used on bacteria. Vectors used for mammalian cell transformation usually contain a geneticin-resistance gene, an aminoglycoside antibiotic. Geneticin is very toxic to both prokaryotic and eukaryotic cells, since its mechanism of action involves the inhibition of the polypeptide chain assembly, leading to cell death. Thereby, correctly transformed cells will display geneticin resistance.

Positive clones can also be detected by the expression of reporter proteins such as the green fluorescent protein or GFP [90], a fluorescent protein originally isolated from the Aequorea victoria jellyfish. This protein displays fluorescence 
at room temperature without the need of external factors. Other commonly used reporter proteins are the urogen III methyltransferase (UMT), or luxCDABE [91], a system that comprises a five-gene cassette whose expression proteins are able to generate and sustain a bioluminescent reaction without the need of adding any external substrates.

The result of these manipulations is a genetically modified cell that carries foreign genes, has an altered nucleotide sequence or modified expression levels of the protein or gene of interest.

Genetic engineering is directly related to synthetic biology (hereinafter referred to as SB), an emerging knowledge field aimed at the design and engineering of biologically based parts, novel devices and systems as well as the redesign of existing, natural biological systems, using engineering design principles. [92]

While genetic engineering deals with the modification of existing biological systems, using a sort of copy-paste or de novo synthesis of genes and proteins, SB holds the potential to entirely develop new genes and, in the long-term, new organisms tailored to any desired application. The key engineering design principles that synthetic biologists attempt to incorporate into their experiments are modularization and standardization of biological parts, such as the BioBrick approach $[93,94]$, which is analogous to modularization and standardization of electronic parts such as inverters, switches, counters, and amplifiers. By doing so, biological parts may become reusable, and can be readily assembled to build large and complex biological systems.

Synthetic biology had emerged from genetic engineering. As of today, researchers are not limited by the naturally occurring DNA sequences that can be isolated from existing organisms. There are tools available for designing new DNA sequences, by applying engineering principles [93, 94]. Entire genes can be synthesized from scratch, and may incorporate some desirable genetic features with great flexibility. The complexity of new biological systems is boosted by the capacity of building, apart from genes, large DNA molecules such as plasmids, pathways and whole genomes. Furthermore, computational modelling tools are being used by researchers to make better predictions of the properties of a biological system prior to physical construction. Synthetic biology can be seen as a "quantum leap" in genetic engineering. [95]

The foundations of genetic engineering established in the later decades, allowing researchers to manipulate living organisms at a molecular level, have evolved into an entirely new, highly multidisciplinary discipline, where biologists and engineers work together to design from scratch, predict properties of and 
build new biological systems, either using existent biological components or designing new ones. This work focus in the use of genetic engineering to develop a modified version of $L$. lactis, by using classic GE techniques, like restriction, amplification and transformation, making use of new synthetic biology tools. A commonly used example are the genetically engineered plasmids. These small circular DNA sequences are as old as life, but when SB burst in, new plasmids, tailored to specifically designed applications were produced. Example given, the two plasmids used in this work are real examples of the application of synthetic biology to solve an actual problem.

Taking pT1NX as an example, we can see that different sequences from diverse species, with specific functionality, have been joined in order to create a useful tool for heterologous protein expression in Lactococcus. This plasmid contains the P1 putative lactococcal promoter, an isolated genetic sequence where the RNA polymerase I attaches and starts the DNA to RNA transcription.

This genetic sequence can be cloned and re-used in other applications. Other features of pT1NX are the presence of an erythromycin resistance gene isolated from Enterococcus faecalis, a gene that gives antibiotic resistance to the bacteria. The most interesting region of this plasmid is the coding sequence, formed by Usp45sp, a multiple cloning site and the spaX gene. Usp45sp is a secretion peptide originally found in Usp45, a strictly secreted protein found in L. lactis with no known biological activity; this is not an obstacle to use it as a small functional part. In between, the polylinker, a nucleotide sequence comprised of several small (5-8 nucleotides) sequences cleavable with the proper restriction endonucleases. Polylinkers are not found in the nature, and can be considered artificial constructs with a specific purpose.

Finally, the spaX gene translates into the $S$. aureus protein A, a cell-wall anchored protein used in a wide variety of plasmids to efficiently promote the membrane localization of any desired protein. pT1NX takes advantage of genes found in other species, with defined functions, to achieve the goal to promote the membrane localisation of any desired protein, so this is a small but clear example of synthetic biology applied to a specific problem.

Nevertheless, the scope of synthetic biology goes beyond the re-use of already existing parts "produced" by evolution [96]. In the long-term, once a substantially knowledge of how nature works is achieved, biologists and engineers, in collaboration with bioinformatics, mathematicians and physics, will be able to create proteins and genes, from scratch, with the desired functionality. Until the present day, SB had achieved some remarkable advances, for example new promoters with either high or low potency, inducible and combinatorial 
promoters [97] or synthetic oscillators. [98]

These oscillators share a defining characteristic: the ability to express a protein in a periodic fashion without the need of any external stimulus. They are based on repression-activation transcription factors and can be used to replicate the circadian cycle found in many organisms. Other remarkable achievements of synthetic biologists are the creation of logic gates [99] - XOR, OR, AND, NOT, and the development of a DNA-based memory, equivalent to computer memory, that is permanently integrated in the DNA sequence and lasts hundreds of generations (DNA replications).

The modified, fibronectin-expressing bacterial biofilm presented in this work can be considered as proof of concept where a living system composed of a clonal population of genetically modified bacteria has been modified to play a role replacing and enhancing another system such as the protein coatings used in cell culture and tissue engineering, allowing its use as a dynamic interface where mammalian cells are able to attach, grow, differentiate and migrate in response to the stimulus provided by the bacterial population. This modified bacteria is playing a completely different role of its intended industrial use as dairy starter.

This system can take advantage of recent developments in synthetic biology, such as the feedback loop constructs [100], which can be used for the development of a self-regulating interface that can provide a way to establish a two-way communication between the biofilm and the mammalian cells. In mesenchymal stem cells, metabolic and signalling pathways become activated as the differentiation progresses and can be used as triggers for the expression of biochemical cues in the underlying biointerface, helping cells in its differentiation process.

Moreover, this interface does not need to be strictly composed of living organisms. Some authors [101] have successfully developed micro-scale cellfree expression systems where, using the minimal required machinery, proteins can be biosynthesized and promoted to its optimal location, either exposed in a surface or secreted in the medium. The combination of feedback loop constructs with cell-free artificial expression systems enclosed in biomimetic membranes $[102,103]$, with tightly regulated protein expression, enables the development of tailored systems without the disadvantages of genetically modified organisms. For example, the presence of undesirable proteins and unwanted metabolic products such as L-lactic acid or ethanol can be avoided, and the uncontrolled bacterial proliferation or biofilm formation, establishment and breakup cycle, that could limit the long-term stability of these cultures can be surpassed.

In the long term, a fully synthetic and tightly regulated biointerface could 
be developed, based entire or partially on reusable components. In this biointerface, a constant two-way communication among the mammalian cells and the underlying protein production machinery would exist, allowing the precisely timed expression of the required signalling needed for the development of new tissues from its progenitor cells.

\subsection{Cell adhesion}

\section{The extracellular matrix}

The extracellular matrix (ECM) is a heterogeneous and dynamic mesh of fibrillar and non-fibrillar components that serve as support and provides an active microenvironment that supports cell adhesion, differentiation, migration and proliferation. It regulates a wide variety of cell functions by activating multiple signalling pathways at adhesion sites. ECM acts as a reservoir for growth factor and fluids and can be assembled into elaborated structures participating in basement membranes and providing a scaffold for tissue organization.

The main components of the ECM are structural proteins such as collagens and elastin, which provide strength and flexibility for the matrix, constituted by proteoglycans, protein-polysaccharide complexes where the structural proteins are inserted, and glycoproteins such as fibronectin and laminin, which provide adhesion cues to the cells.

ECM components are produced in situ by resident cells and secreted as nonfunctional protein units, which are assembled into functional supramolecular structures in a highly regulated manner. [104-107]

It also plays an important role in processes like growth, wound healing and fibrosis. Defects in assembly stops embryogenesis, deranged assembly promotes scarring, tumorigenesis and fibrotic disease, while delayed assembly provokes birth defects, skeletal malformations and chronic wounds. [108]

The most representative ECM proteins include proteoglycans, carbohydrate polymers that are usually attached to other proteins to form proteoglycans. Those proteins have a net negative charge that attracts cations such as $\mathrm{Na}^{+}$, which attracts water molecules via osmosis keeping the ECM cells hydrated. It also helps to trap growth factors within this matrix. The most representative proteoglycans are heparan sulphate, chondroitin sulphate and keratin sulphate. Hyaluronic acid is a special non-proteoglycan polysaccharide which retains large amounts of water, making the ECM turgent and increasing its resistance to the compressive forces usually found in tissues such as load-bearing joints. 


\section{[109]}

The fibrous protein family is composed by collagens and elastin. Collagens are the most abundant proteins of the human body [110, 111], giving structural support to resident cells. On the other hand, elastin gives elasticity to tissues, a useful characteristic found in blood vessels, lungs or skin.

Fibronectin, fibrinogen, laminin and vitronectin are a family of proteins in charge of the cell-ECM interaction. Fibrinogen is a large (328 kDa), complex and fibrous glycoprotein present in human plasma, composed of six polypeptides organized into a trinodular structure [112]. It plays an essential role in many biological functions including wound healing, haemostasis, inflammation and angiogenesis. Laminins are large $(900 \mathrm{kDa})$ multidomain proteins consisting on trimeric molecules of $\alpha, \beta$ and $\gamma$ chains [113] and are the main components of basement membranes, providing interaction sites for many other constituents including cell surface receptors. Vitronectin is an adhesive glycoprotein found in the blood and different tissues. It is a medium-sized protein $(75 \mathrm{kDa})$ involved in several physiological and pathological processes and regulates proteolysis initiated by plasminogen activation. [114]

Within the large variety of proteins that compose the ECM, this work is focused in fibronectin, a large $(220 \mathrm{kDa})$, fibrous and complex glycoprotein that exists in dimeric form. It is synthesized by adherent cells that assemble it into a fibrillar network in an integrin-binding dependent mechanism [115]. It is also the first assembled protein in the incipient formation of a mature ECM. A FN matrix is formed by fibrils that form linear, interconnected networks; in the early stages of the ECM formation only thin fibrils are found $(5 \mathrm{~nm})$, and as the ECM matures and more proteins are recruited, fibronectin fibrils become thicker $(25 \mathrm{~nm})$, as a result of the clustering of thinner fibrils.

\section{Cell adhesion}

Cell attachment to ECM or surface-grafted proteins takes place via integrins, a large family of $\alpha / \beta$ heterodimers which recognize specific sequences of ECM proteins such as the arginine-glycine-aspartic acid tripeptide (RGD), present in several proteins such as fibronectin and vitronectin, providing a trans-membrane link between the ECM and actin cytoskeleton. [12]

Although integrins are constitutively expressed, most of them are present in the cell surface in an inactive state, in which there is neither ligand binding nor signaling. Integrins can be activated by ligand binding or by intracellular signaling, due to effects in its cytoplasmic domains, leading to conformational changes which expose epitopes for specific activation antibodies. The most com- 


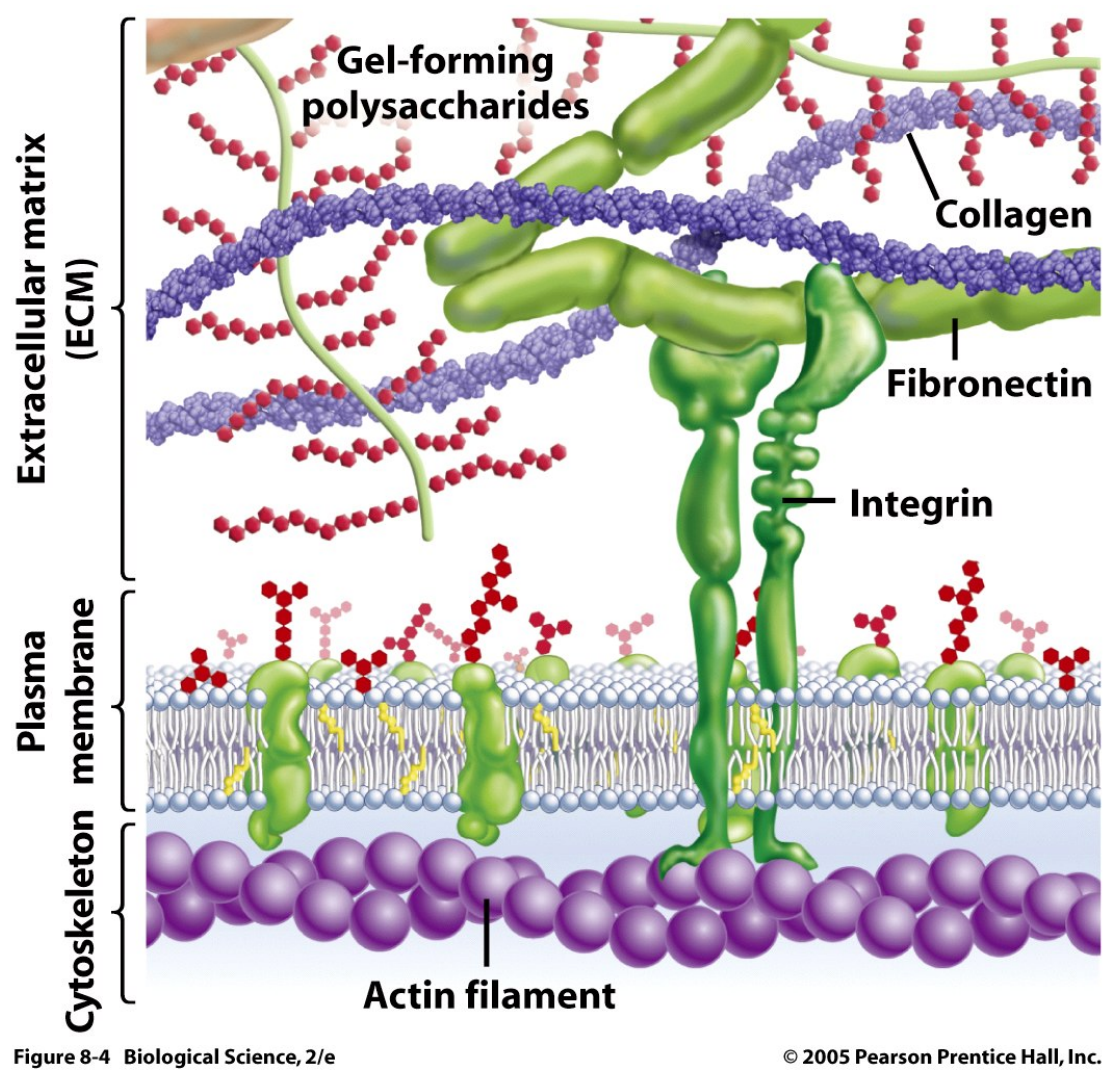

Figure 1.7 The extracellular matrix is composed by a complex mixture of structural and adhesive proteins such as fibronectin and vitronectin. Interaction between cells and the ECM takes place via integrins, membrane-bound receptors that trigger several signalling pathways and influences cell behaviour. [116]

mon integrin type found in in vitro adhesions are $\alpha_{5} \beta_{1}$, the classical fibronectin receptor, and $\alpha_{\mathrm{V}} \beta_{3}$, the vitronectin receptor.

Integrins play a dual role when activated through ligand binding: mediating cell attachment and triggering several intracellular signaling pathways, which can in turn influence growth, migration, differentiation or proliferation. [117]

When bound to its substrate, integrins cluster and develop focal adhesions, discrete supramolecular complexes that contain important structural proteins and signaling molecules, anchoring physically the cell to the substrate. Anchored cells develop a spread morphology showing a developed actin cytoskeleton, providing mechanical stability and transmitting forces to 
the intracellular regions. [118, 119]

Adhesions with the ECM act as binding bridges which link the extracellular matrix to the actin cytoskeleton. Four well-defined varieties of adhesion structures have been defined: focal adhesions, fibrillar adhesions, focal complexes (dot contacts) and podosomes.

Focal adhesions (FA) are small, flat and elongated structures that are several square microns in size and often located near the cell periphery [120-123] that mediate strong adhesion to the substrate linking bundles of actin microfilaments through a plaque formed by many different proteins such as vinculin, paxillin, talin and tyrosine phosphorylated proteins. Focal adhesion development is enhanced by the Rho-A GTPase and driven by actomyosin contractility. It is believed that focal adhesion act as mechanosensors, allowing cells to sense physical properties of the substrate such as stiffness and convert them into specific biological signals. [124]

As said, a small group of structural proteins, namely vinculin, paxillin, talin, $\alpha$-actinin, tensin and filamin can assume the role of integrin-actin linkers [121129]. Vinculin is a universal adaptor protein, due to its ability to interact with many plaque proteins, acidic phospholipids, membranes and actin.

Focal adhesions not only play the role of mechanical anchors between the ECM and the actin cytoskeleton. After integrin clustering, several signaling molecules such as the focal adhesion kinase (FAK) and the integrin-linked kinase (ILK) [130] are recruited by adapter proteins, becoming activated and triggering several intracellular signaling pathways. FAK triggers the majority of those signaling pathways [131-134] and has emerged as an important mechanotransducer, translating extracellular mechanical inputs into intracellular biochemical signals. It is a key signaling protein contributing to control cell motility, invasive phenotype, survival, cell cycle progression, proliferation and development. [135-139]

FAK is also overexpressed in a variety of human cancers and can promote invasive behaviour of tumor cells. Phosphorylation of Tyr-397 determines the activation of FAK. This activation takes place through the interaction of integrin-associated proteins and the FAT and FERM domains of FAK [140-142]. Once activated, phosphorylated Y-397 binds the SH2 domain of Src, recruiting and activating more Src molecules [143, 144]. The formation of the FAK-Src complex is the most critical event in the FAK-associated signaling. Y-397 site bound to Src phosphorylates other FAK residues, namely Y-576, Y-577 and Y-861, important for maximal FAK autophosphorylation activity [145]. Once activated and bound to Src, the signaling pathway activates other downstream pathways 
responsible for different cellular events, such as differentiation, migration and proliferation (see section 5.1).

\section{Fibronectin structure and functions}

Fibronectin is a single-gene encoded protein, with an mRNA size of $8 \mathrm{~kb}$. It can be spliced in up to 20 monomeric isoforms in human and 12 in mice [146], which may result in an even larger variety of FN isoforms if the possible combinations between monomers to form FN dimers is considered. The most common splicing mechanism generates two major different forms of $\mathrm{FN}$ - plasma or soluble FN (pFN) and cellular FN (cFN). pFN is produced by hepatocytes and secreted into the blood, where it remains in a soluble state until the activation of hematopoietic cells' integrins by a platelet-mediated mechanism allows pFN to bind and assemble into fibrils, required for thrombus growth and stability $[147,148]$. cFN is secreted by cells as a dimer in a compact globular structure and then is assembled into insoluble, fibrillar form in a cell-dependent process.

$\mathrm{FN}$ is a multidomain protein. It contains domains to interact with other ECM proteins, such as glycosaminoglycans (GAGs), integrins, other FN molecules and pathogens (bacteria) [149]. FN subunit sizes ranges from 230 to $270 \mathrm{kDa}$, depending on the alternative splicing of the mRNA, and forms dimers through two disulfide bonds at the C-terminus of the protein. Its structure is composed by three types of repeating modules, I, II and III. Both type I and II contain intramolecular disulfide bonds to stabilize the folded structure, while type III lacks these disulfide bonds. Type I and II modules are structured in beta-sheets enclosing a hydrophobic core that contains highly conserved aromatic amino acids. [108, 149]

Extra type III repeats (A and B) are produced by alternative splicing and included in cFN molecules, but are not present in $\mathrm{pFN}$; it seems that the alternative exons are unnecessary for matrix assembly, but its lack might affect matrix levels. [108, 151]

cFN subunits have a variable $\mathrm{V}$ region present, but only in one subunit of the pFN dimer. Results concerning this region suggest that this is essential for FN dimer secretion [152] and that it provides the binding site for $\alpha_{4} \beta_{1}$ integrin. [153]

FN matrix assembly is a cell-dependent process mediated by the binding of FN dimers to integrin receptors, although exist other mechanisms for FN-FN assembly in absence of cells such as the addition of reducing $[154,155]$ or oxidizing [156] agents to the protein solution; the use of denaturing [157$159]$, cationic $[160,161]$ or anionic $[162,163]$ compounds; the use of peptidic 


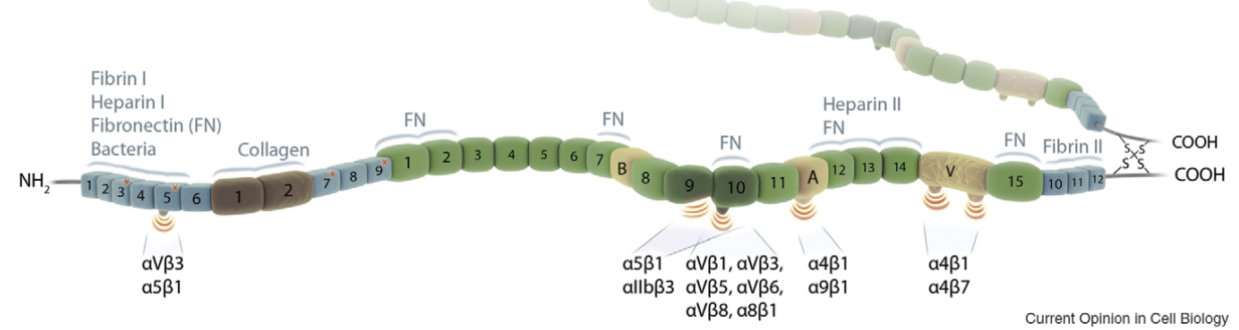

Figure 1.8 Molecular structure of the fibronectin, which consists in three different modules (type I, blue; type II, brown, and type III, green). B, A and variable region $\mathrm{V}$ (ochre) are alternatively spliced. The dimer is joined through a disulphide bond in the C-terminal region. Integrin binding sites are indicated, as well as other binding domains for FN and other proteins. [150]

fibronectin fragments [164-166]; also, the use of mechanical tension [167, 168], shear forces [169-175] or surface-initiated assembly. [176-180]

The essential domains for FN assembly include, first, FN dimerization, which depends on the covalent association of the subunits mediated by a pair of disulfide bonds at the C-terminus of the FN molecule. Second, the 70$\mathrm{kDa}$ fragment extending from $\mathrm{I}_{1}$ to $\mathrm{I}_{9}$, including the $\mathrm{N}$-terminal assembly and the collagen-gelatin binding domains. Within the 70-kDa fragment, the 40$\mathrm{kDa}$ collagen-gelatin binding modules does not appear to play a direct role in the assembly. This $70-\mathrm{kDa}$ fragment binds to cells in monolayer culture environments and blocks FN matrix assembly when added in excess. [181]

It seems that the binding activity resides only in the type $\mathrm{I}_{1-5} \mathrm{~N}$-terminal portion of the molecule, the so-called N-terminal assembly domain. FN molecules binds to each other via non-covalent interactions. [182]

Finally, the Arg-Gly-Asp (RGD) sequence located in $\mathrm{III}_{10}$ and the PHSRN synergy sequence located in the $\mathrm{III}_{9}$ modules are required for interaction with the $\alpha_{5} \beta_{1}$ integrin, which is required for the cell-mediated FN assembly [183]. Although both sites are required, synergy site does not seems to be essential since matrix levels are drastically reduced but not ablated with FN lacking this sequence [184]. RGD not only binds to $\alpha_{5} \beta_{1}$, but to several additional integrins, including all the $\alpha_{\mathrm{V}}$ subfamily, $\alpha_{8} \beta_{1}, \alpha_{9} \beta_{1}$ and the platelet-specific integrin $\alpha_{\mathrm{IIb}} \beta_{3}$. Interestingly, in absence of $\alpha_{5} \beta_{1}$ integrin expression in cells or ablation of $\alpha_{5}$ integrin gene in mice, FN can still be assembled by the other integrins, most notably the $\alpha_{V}$ subfamily $[185,186]$. However, the $\alpha_{V}$-class 
produced fibrils are shorter and thicker than the $\alpha_{5}$-produced. [150]

Summarising, the N-terminal assembly domain $\mathrm{I}_{1-5}$ is essential for FN fibrillogenesis, although other FN binding domains are implicated in matrix assembly: $\mathrm{III}_{1-2}$ and $\mathrm{III}_{12-14}$ can bind FN; additionally $\mathrm{III}_{1}$ can bind to $\mathrm{III}_{7}$ and $\mathrm{III}_{2-3}$ can also interact with $\mathrm{III}_{12-14}$ [149]. All of these domains can promote FN fibrillogenesis due to their FN binding properties, but they can also participate in intramolecular interactions which keep soluble FN in a compact form. [187]

Interaction between FN and integrins induces integrin clustering, which groups together cytoplasmic molecules such as Src kinase, focal adhesion kinase (FAK), paxillin and others, promoting the formation of focal adhesion complexes. These complexes activate the polymerization of the actin cytoskeleton and kinase cascades-mediated intracellular signaling pathways [12]. Receptor clustering by dimeric FN helps to organize FN into short fibrils.

FN fibril formation is enhanced by the contractility of the cytoskeleton [188, 189]. This contractility induces a progressive extension of the FN molecule and the exposure of binding sites that mediate lateral interactions between FN molecules.

There is also an intrinsic protein-disulfide isomerase activity in the Cterminal module $\mathrm{I}_{12}$ that may introduce intermolecular disulfide bonds within fibrils [190]. Initial thin fibrils grow in length and thickness as the matrix matures and the FN fibrils are converted in an insoluble form [108]. Proper integration of extracellular signals with active intracellular pathways plays a crucial role in the initiation, progression and regulation of the FN matrix assembly.

\section{The III $_{7-10}$ fragment}

III $_{7-10}$ comprises from 7 to 10 type III modules. These modules are the largest and the most common of the FN molecule. Depending on the splicing variant, a subunit of a fibronectin molecule can have up to 15-17 contiguous type III modules. They also occur often in pairs.

Structures of individual type III modules reveal a conserved beta-sandwich structure with one sheet containing three parallel strands and the other four strands, hiding a hydrophobic environment inside. The 10th type III repeat contains the Arg-Gly-Asp (RGD) sequence, an integrin-binding sequence [191, 192]. RGD sequences are not only found in fibronectin, but also in fibrinogen [193, 194], vitronectin [195] and Von Willebrand factor [193] mediate a wide variety of cell adhesion events [192]. That has led to the investigation of RGD peptides and its analogs as potential therapeutic agents. Apart from the 
A

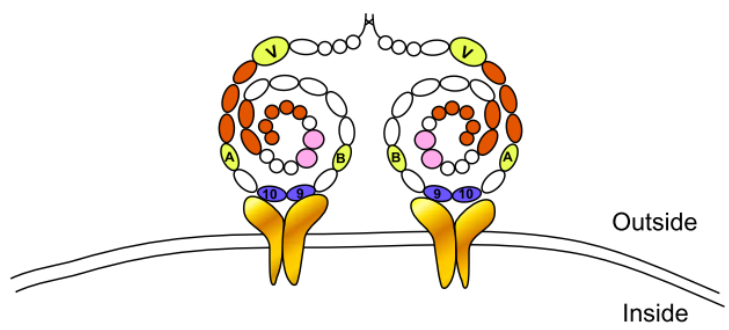

B
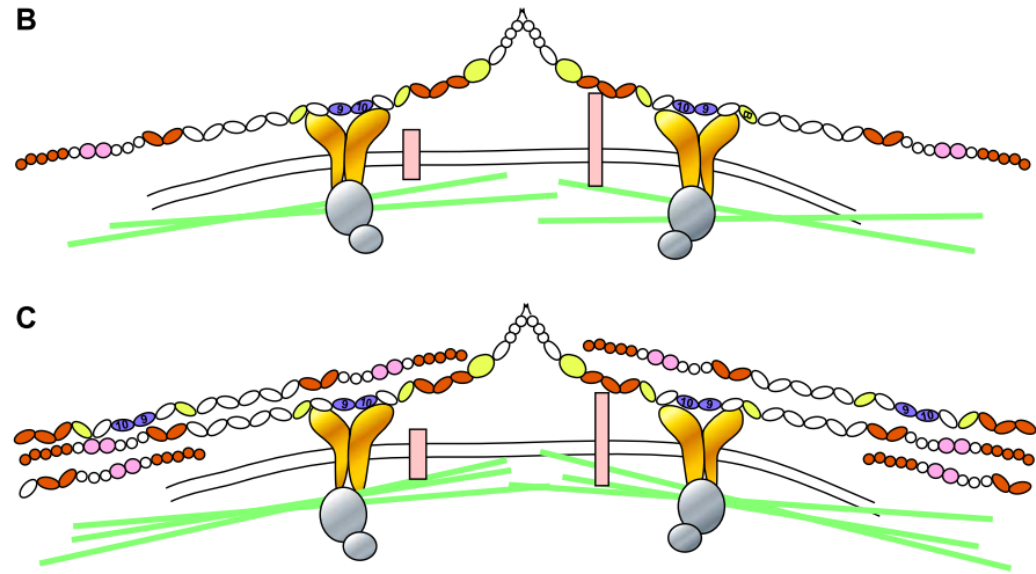

Figure 1.9 Major steps in fibronectin fibril assembly. A) cFN fibronectin binds to $\alpha_{5} \beta_{1}$ integrin (gold) via its cell binding domain. The exact organization of FN seems to depend on intramolecular interactions between $\mathrm{III}_{2-3}$ and $\mathrm{III}_{12-14}$, amongst other FN binding sites (red). B) FN binds to other receptors which induces actin cytoskeleton reorganization and activates intracellular signalling complexes (silver circles). Cell contractility aids in FN conformational changes thus exposing sequestered FN binding domains in the extended module. C) Fibrils are formed through FN-FN interactions. Alignment of FN molecules within fibrils may vary depending on which domain interact, such as $\mathrm{I}_{1-5}$ binding to $\mathrm{III}_{1-2}$ versus III $_{12-14}$ [151]. When in solution, FN does not form fibrils and keeps a globular conformation even at extremely high concentrations, due to intramolecular interactions between modules $\mathrm{III}_{2-3}$ and $\mathrm{III}_{12-14}$. [187]

prominent RGD sequence, 9th type III repetition contains the PHSRN synergy region.

The RGD loop (Figure 1.13) is found near N-terminus of $\operatorname{III}_{10}[196,197]$. Interactions with near regions or domains might be able to stabilize the RGD loop, leading to protein conformations or providing a specific context that allows recognition by specific integrins. 


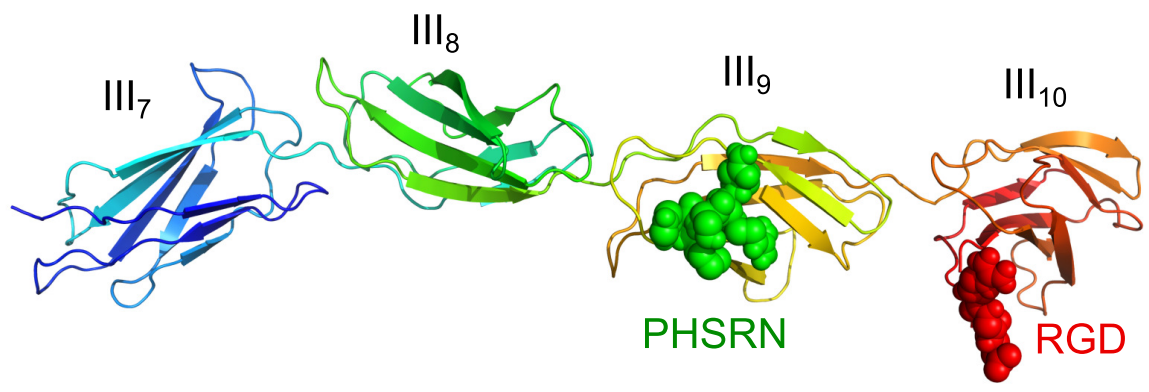

Figure 1.10 FN III $_{7-10}$ fragment structure. At the right of the molecule, the $\mathrm{III}_{10}$ domain with the RGD loop marked in red. To the left, $\mathrm{III}_{9}$ with the PHSRN synergy site colored in green and the $\mathrm{III}_{8}$ and $\mathrm{III}_{7}$ domains showing a slightly twisted conformation. PDB file id. 1FNF

This fragment features four contiguous modules in an extended array of approximately $140 \AA$ long. Domains 7 and 8 have a tilt angle of $52^{\circ}, 8$ and 9 of $48^{\circ}$ and 9 and 10 of only $12^{\circ}$. That confers a spiral-like shape to this fragment.

Individual type III modules are very similar to each other, both inside the III $_{7-10}$ and compared to other fibronectin type III modules. Each module consist of two beta sheets, one with four strands (denoted as G, F, C and $C^{\prime}$ ) and the other with three strands (A, B and E), arranged as a beta sandwich (Figure 1.11). The main differences between type III modules are mainly found in the loop regions.

Since individual type III modules share a highly conserved framework structure, [196, 198-200], many properties of the type III repeated arrays are found in the interdomain relationships. The $\mathrm{III}_{7}-\mathrm{III}_{8}$ and $\mathrm{III}_{8}-\mathrm{III}_{9}$ reveals no rules relating the orientations between adjacent domains, but the interface between $\mathrm{III}_{9}$ and $\mathrm{III}_{10}$ has some distinctive features, such as relative rotation and tilt angle, smaller than other known inter-type III interfaces, as stated previously (12 compared to 48 and 52 tilt angle degrees).

This difference is due to Ser-1417, a polar aminoacid; interfaces between domains $\mathrm{III}_{7}-\mathrm{III}_{8}$ and $\mathrm{III}_{8}-\mathrm{III}_{9}$ have a hydrophobic aminoacid that is completely buried in the interdomain. Except in $\mathrm{III}_{1}$ and $\mathrm{III}_{10}$, residues homologous to the Ser-1417 are hydrophobic. This conformational change leads to place the RGD loop on the 10th and the PHSRN on the 9th type III domains in the same side of the molecule, although they are separated by around $40 \AA$. Nevertheless, in 


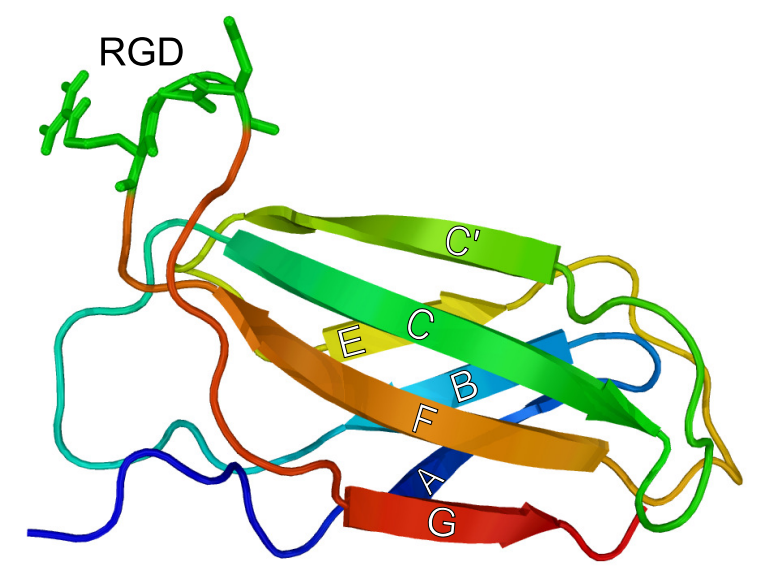

Figure 1.11 Structure of the 10th type III fibronectin module, showing a beta sandwich geometry with the RGD integrin-binding sequence loop protruding from the core of the molecule. Adapted from PDB file id. 1FNF

practice, an integrin can span this distance and interact simultaneously with the RGD and the PHSRN peptides (Figure 1.12). This simultaneous interaction adds specificity by providing an exposed array of residues that are hardly mimicked by other pairs of type III modules.

This fragment is predicted to show some structural rigidity, since can easily crystallize under the adequate conditions (i.e. for crystallographic structure determination). The $\mathrm{III}_{9-10}$ interdomain is probably the most flexible of the whole fragment, but this flexibility is limited to facilitate the simultaneous RGD-PHSRN recognition by at least two different integrins [201, 202] (Figure 1.12). The fact that $\alpha_{5} \beta_{1}$ and $\alpha_{V} \beta_{3}$ share this ability to interact with the III ${ }_{9-10}$ modules favours this hypothesis.

\section{RGD loop structure}

The RGD loop located on the 10th type III domain protrudes approximately $10 \AA$ from the core of the beta sheet and is not in close contact with any other part of the molecule (Figure 1.13). This is a satisfactory explanation on why 


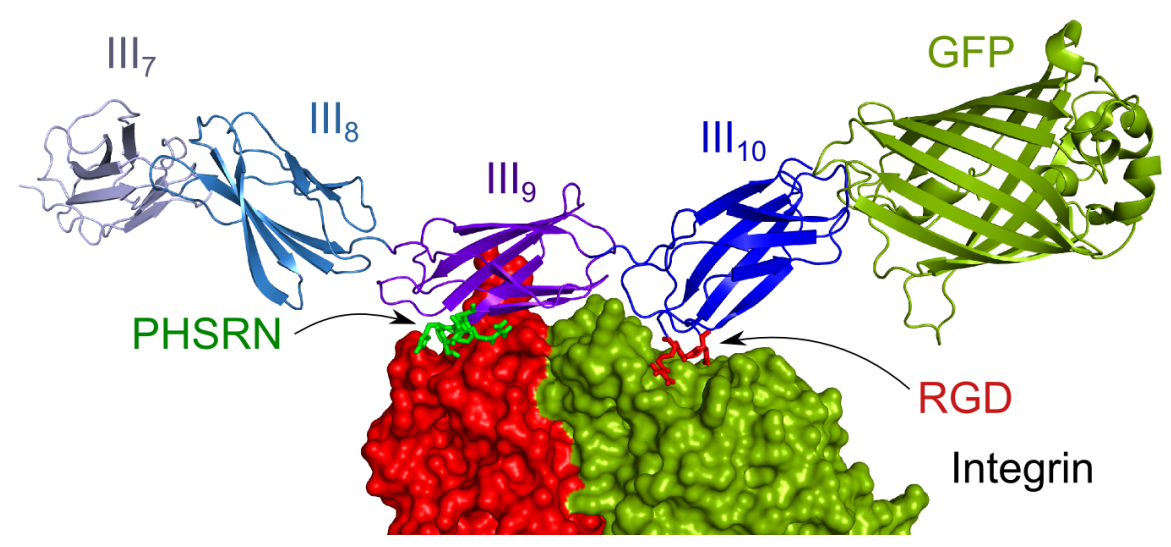

Figure 1.12 Hypothesized interaction model for the FN $\mathrm{III}_{7-10}-\mathrm{GFP}$ fragment and an integrin. The PHSRN and the RGD motifs are separated by approximately $40 \AA$, which not prevents a direct interaction with the integrin, wide enough to span this distance. GFP, although fused to the $\mathrm{III}_{10}$ fragment, does not seem to interfere with the FN-integrin interaction, a hypothesis supported by our experimental results. PDB file id. 1FNF (FNIII ${ }_{7-10}$ ), 2YOG (GFP) and 1JV2 (integrin).

small RGD-containing peptides can block interactions between FN and cells. RGD seems to be a low energy conformer of a, in principle, flexible loop, [203] showing the characteristics of a slightly deformed type $\mathrm{II}^{\prime}$ beta hairpin turn. [204]

These II' turns require a central glycine to allow this conformation with canonical values of $\phi=60^{\circ}$ and $\psi=-120^{\circ}$. A further proof of this hypothesis is that other RGD sequences which acquires an II' beta turn, either tenascin or an artificial protein made from a CRGDSC sequence inserted into lysozyme are able to interact with at least three different integrins. Tenascin's RGD interacts with $\alpha_{\mathrm{IIb}} \beta_{3}$ while fibronectin RGD interacts with $\alpha_{5} \beta_{1}, \alpha_{\mathrm{IIb}} \beta_{3}$ and $\alpha_{\mathrm{V}} \beta_{3}$.

Moreover, cyclic RGD peptides show a highly antiadhesive behaviour suggesting that this particular loop structure represents a general integrin-binding conformation. In the particular case of the fibronectin $\mathrm{III}_{10} \mathrm{RGD}$, two residues flanking both sides of the adhesive sequence are able to extend the hairpin $7 \AA$ more over the molecule core, an extension that has not been seen in any of the other FN type III domains and appears to be an adaptation to project the RGD for optimal interaction with integrins. 


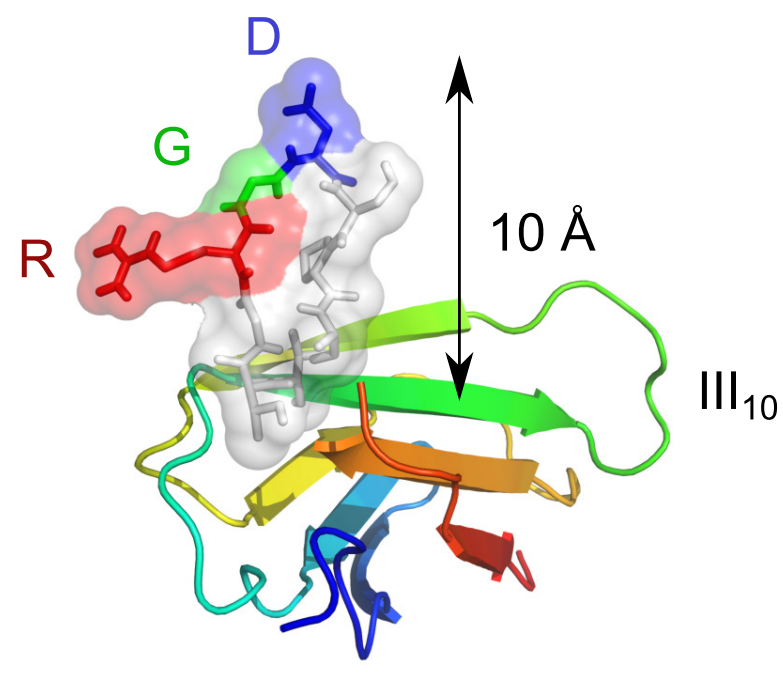

Figure 1.13 RGD loop structure of the 10th type III fibronectin domain. Arginine (red), glycine (green) and aspartic acid (blue) residues are shown as sticks inside its solvent-accessible isosurface. These three residues form the $\mathrm{II}^{\prime}$ beta hairpin loop, which extends approximately $10 \AA$ from the core of the $\mathrm{III}_{10}$ module. That distance can be extended up to $17 \AA$, depending on the molecule conformation.

\subsection{L. lactis, why and how}

Amongst the huge amount of non-pathogenic bacterial species, L. lactis has been chosen for several reasons. It features a very low production of exopolysaccharides [61, 205] (EPS), a mandatory condition for making the membraneanchored proteins accessible to cells.

In some lactic acid bacteria (LAB) strains, including the Lactococcus genus, most of the carbon obtained from glucose and other available carbon sources is metabolized to L-lactic acid through the glycolytic pathway, although researchers are developing effort in metabolic engineering to obtain EPS overexpression in LAB [205]. Here, this low EPS production [61] is needed to guarantee the accessibility of the expressed FNIII $_{7-10}$ fragments on the bacterial membrane.

L. lactis, among other LAB, are Generally Regarded as Safe (GRAS) [61] microorganisms. This classification is due to its natural presence in milk and dairy products and its contribution to a healthy mucosal microflora. [206]

Lactococcus lactis is a very well-studied strain. Its genome has been fully sequenced $[18,207]$ and has been widely used for recombinant therapeutic 
proteins production, therapeutic drug delivery and vaccine production. [27, 29, 30, 208]

Another important characteristic of this strain is its ability to spontaneously develop biofilms [64, 209, 210]. Despite its low EPS production, L. lactis adheres to and colonizes a broad range of surfaces such as synthetic polymers, glass, metals and live tissues. These biofilms remain stable for weeks and support cell adhesion, growth and differentiation [211], as will be further discussed.

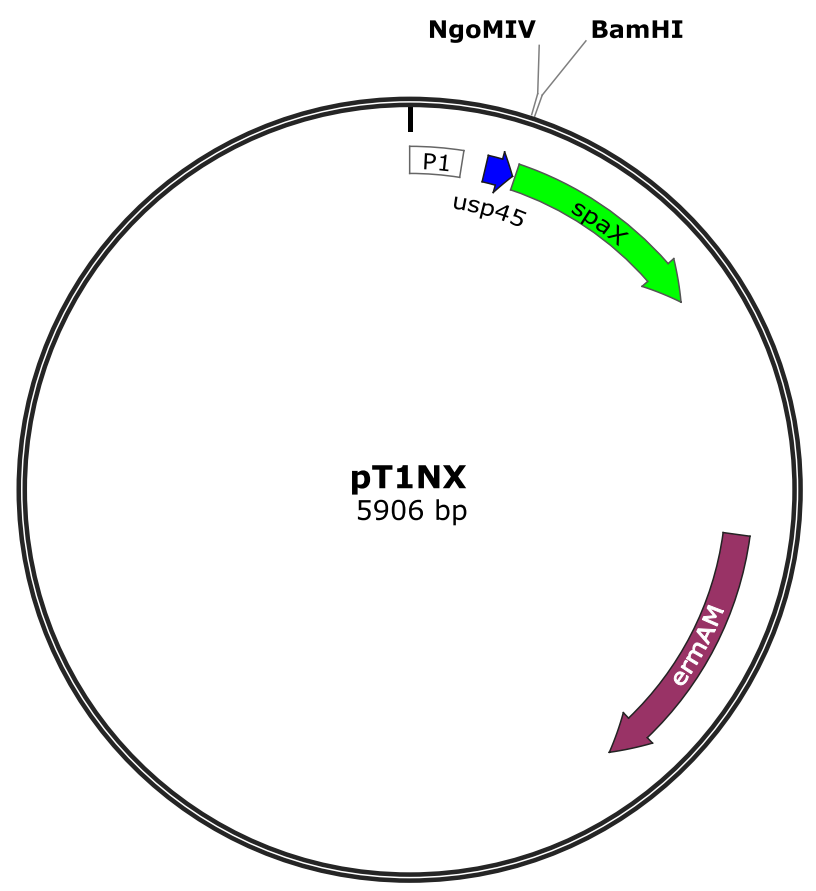

Figure 1.14 pT1NX vector map, showing the P1 lactococcal promoter, NgoMIV and BamHI restriction sites, usp 45 secretion signal, spaX protein A anchor and the ermAM erythromycin resistance gene.

pT1NX has been the chosen expression vector in this work. Originally engineered by Dr. L. Steidler, pT1NX features the P1 lactococcal promoter [212, 213], the usp 45 secretion peptide [214], the Staphylococcus aureus protein A anchor [212] and an erythromycin resistance gene. mRNA traduction is controlled by the T7g10 ribosome binding site and the T7g10 terminator from phage T7 [215]. The replicon comes from an Enterococcus faecalis plasmid $\mathrm{pAM} \beta 1$ origin, including repD and repE. With a size of $5706 \mathrm{bp}$, it has been successfully used as a membrane-anchored protein expression vector in L. lactis 
and other LAB. [61, 215, 216]

Protein A (SpA) is a $42 \mathrm{kDa}$ cell-wall anchored protein expressed by Staphylococcus aureus [212]; the anchoring mechanism includes a 35-residue sorting signal located at the C-terminal end of the protein A is required. SpA contains the LPETG motif followed by a C-terminal hydrophobic domain and tail composed of mainly positively charged residues. A signal peptidase cleaves the amino-terminal end of SpA, followed by the translocation of the protein.

The positively charged residues of the C-terminal end of SpA prevents its full secretion. Once in place, the proteolytic activity of a sortase [217-219], a prokaryotic enzyme that modifies surface proteins by recognizing and cleaving a C-terminal sorting signal, recognizes the LPETG motif, cleaving between the threonine and glycine residues and leaving the C-terminal end anchored to the lipid bilayer. Then, threonine is covalently linked to the free amino groups of the peptidoglycan cross bridge via an amide bond, before the final crosslinking is completed.

Although this anchoring mechanism is extremely efficient, some of the molecules are found in the extracellular medium, mainly due to the physiological turnover and release of peptidoglycan fragments with linked surface proteins. A model of this anchoring mechanism is depicted in the Figure 1.15. [220]

\section{Extracellular space}

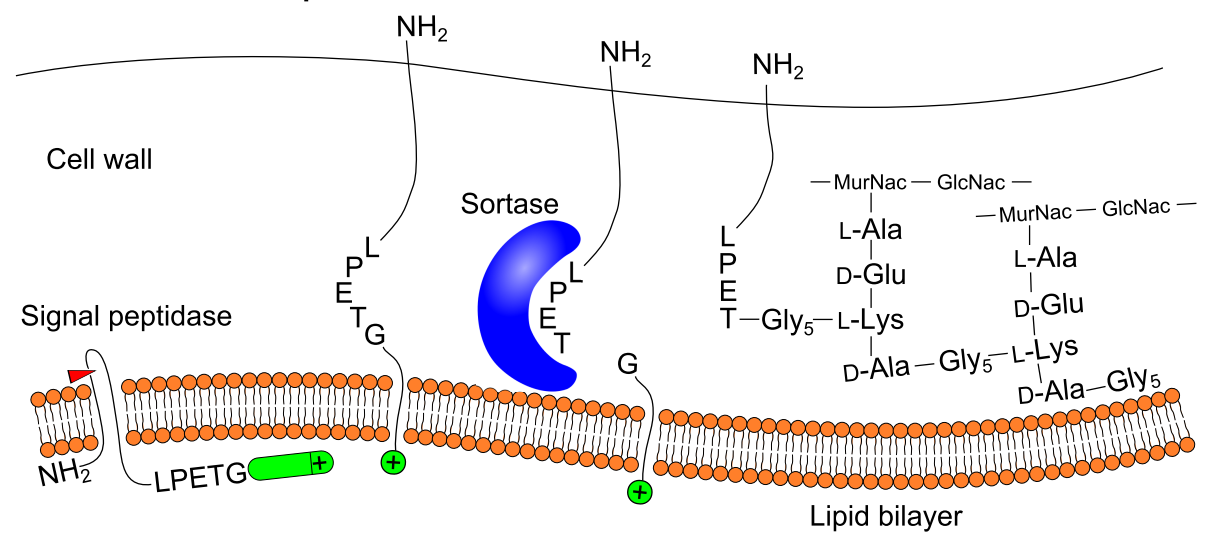

Cytoplasm

Figure 1.15 Anchoring mechanism of the LPETG motif onto the peptidoglycan layer. A signal peptidase cleaves near the N-termini of the protein, which is translocated to the outer part of the cell wall. Then, a sortase cleaves the polypeptide chain between the threonine and glycine and anchors the threonine to the tetrapeptide motif that crosslinks the peptidoglycan layer 
The Usp45sp signal peptide [214] is part of Usp45 (unknown secreted protein 45), a strictly secreted protein by mesophilic Lactococcus genus (L. lactis subsp. cremoris and L. lactis subsp. lactis) with no known biological activity, neither proteolytic nor anti-bacterial. This secretion peptide comprises the first 27 residues of the $\mathrm{N}$-terminal region. Secretion is, in principle, not limited by the protein size, since proteins up to $160 \mathrm{kDa}$ have been successfully expressed in L. lactis, but seems to be more conformation dependent. [61]

Due to these characteristics, L. lactis is currently one of the preferred vehicles for oral delivery of heterologous proteins, either secreted or membraneanchored, with a wide range of expressed proteins, from bacterial and eukaryotic antigens to interleukins, virulence factors, bacteriocins and enzymes. [19, 215, $221,222]$

\subsection{L. lactis phylogeny, metabolism and physiology}

\section{Phylogeny}

Lactic acid bacteria can be classified attending to restriction fragment length polymorfism (RFLP) or 16s rRNA sequence, obtained by reverse transcriptase or direct PCR techniques (Figure 1.16). [223]

Eubacteria are subdivided into gram-negative and gram-positive phyla. Within the gram-positive ( 2 of a total of 12), a main classification criterion is the $\mathrm{G}+\mathrm{C}$ content (molar percentage of guanine plus cytosine in the genomic DNA), where a break point can be established at 53-55 \%. High G+C content or Actinomycetes comprises the genera Bifidobacterium, Arthrobacter, Micrococcus, Propionibacterium, Microbacterium, Corynebacterium, Actinomyces, and Streptomyces. (Stackebrandt and Teuber 1988; Woese 1987). Lactic acid bacteria are included in the low- $\mathrm{G}+\mathrm{C}$ content or Clostridium subdivision, along with aerobes such as Bacillus, Staphylococcus and Listeria and anaerobes such as Clostridium, Peptococcus and Ruminococcus. L. lactis, based on this criterion, is classified within the gram-positive, low $\mathrm{G}+\mathrm{C}$ content eubacterium.

LAB is considered a supercluster (Figure 1.16)[224-232], located between facultative aerobic species (staphylococci, bacilli) and strictly anaerobic species (clostridia), although some LAB species can use oxygen if available.

Lactococcus lactis is a strain pertaining to the lactic acid bacteria (LAB hereinafter) clade, which comprises a group of roughly 20 genera, namely Aerococcus, Carnobacterium, Enterococcus, Oenococcus, Streptococcus, Tetragenococcus, Vagococcus, Weisella, Lactobacillus, Pediococcus, Leuconostoc and Lactococcus. 


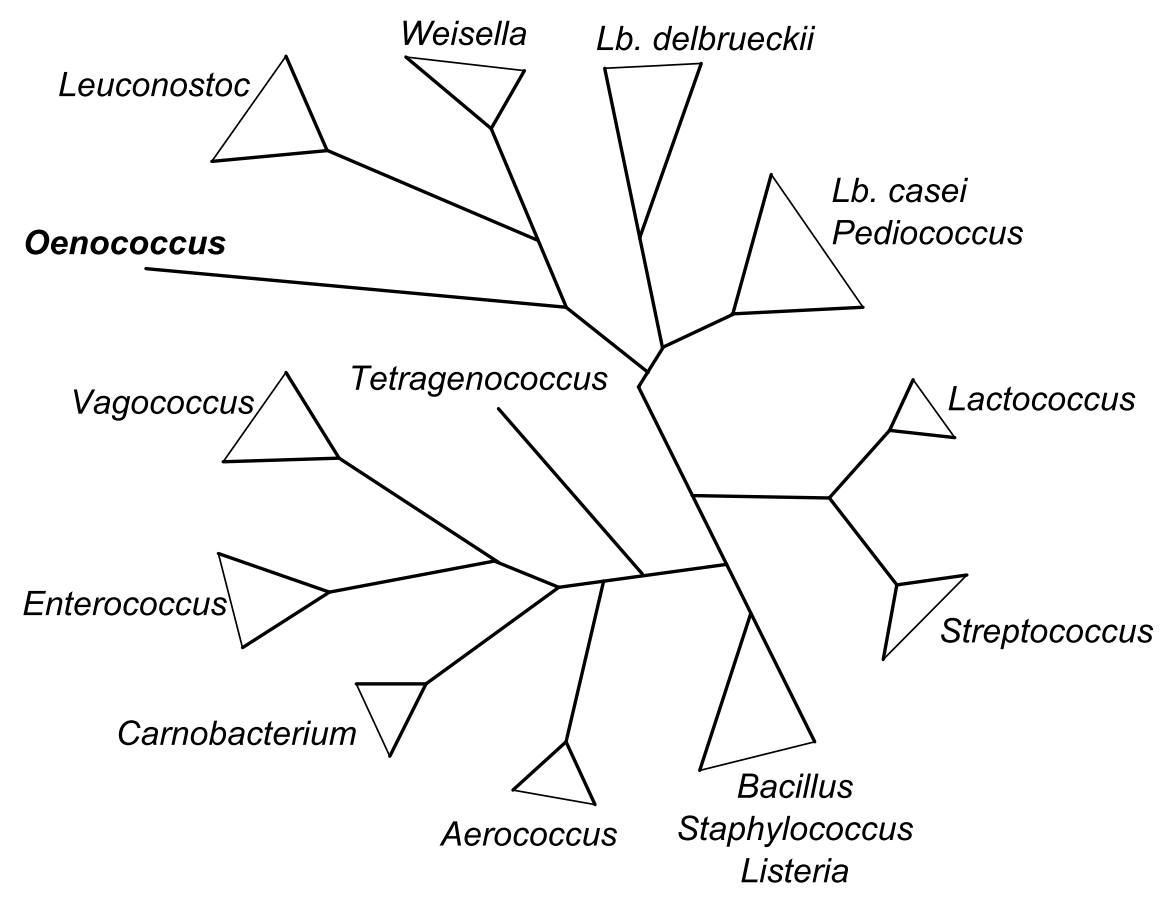

Figure 1.16 Phylogenetic tree of the lactic acid bacteria (LAB) clade [206]

It is important to note the impossibility to give an unequivocal definition of lactic bacteria [233]. A typical LAB could be defined as a gram-positive, nonspore-forming, catalase-negative - although a pseudocatalase activity, mediated by hohmene, can be found in some LAB [234] —, anaerobic but aerotolerant, devoid of cytochromes, acid-tolerant, requiring complex growth media and strictly fermentative, being the lactic acid the major end product of the sugar fermentation.

It can be further subdivided into high and low $\mathrm{G}+\mathrm{C}$ (molar percentage of guanine and cytosine in the genomic DNA) content, where L. lactis is part of the low $\mathrm{G}+\mathrm{C}$ content group. The absence of a true catalase, cytochromes and the impossibility to synthesize heme groups unless added in the growth medium is the actual physiological background of some of the defined characteristics, especially its fermentative metabolism, as heme group and hence cytochromes are required for the electron transport chain system [235-242]. Therefore, absence of cytochromes is a reliable indicator of the presence of lactic acid bacteria. [233]

Attending to its metabolism, LAB can be split in two groups. Homoferment- 
ative strains such as L. lactis metabolize glucose almost quantitatively into lactic acid. Heterofermentative strains metabolize glucose into several compounds such as lactic acid, ethanol, carbon dioxide or acetic acid.

Other LAB classification attends its shape: rods and coccis. Lactobacillus and Carnobacterium are rod-shaped while all the other genera are coccis, except Weisella that includes both cocci and rods (Figure 1.17). [226]
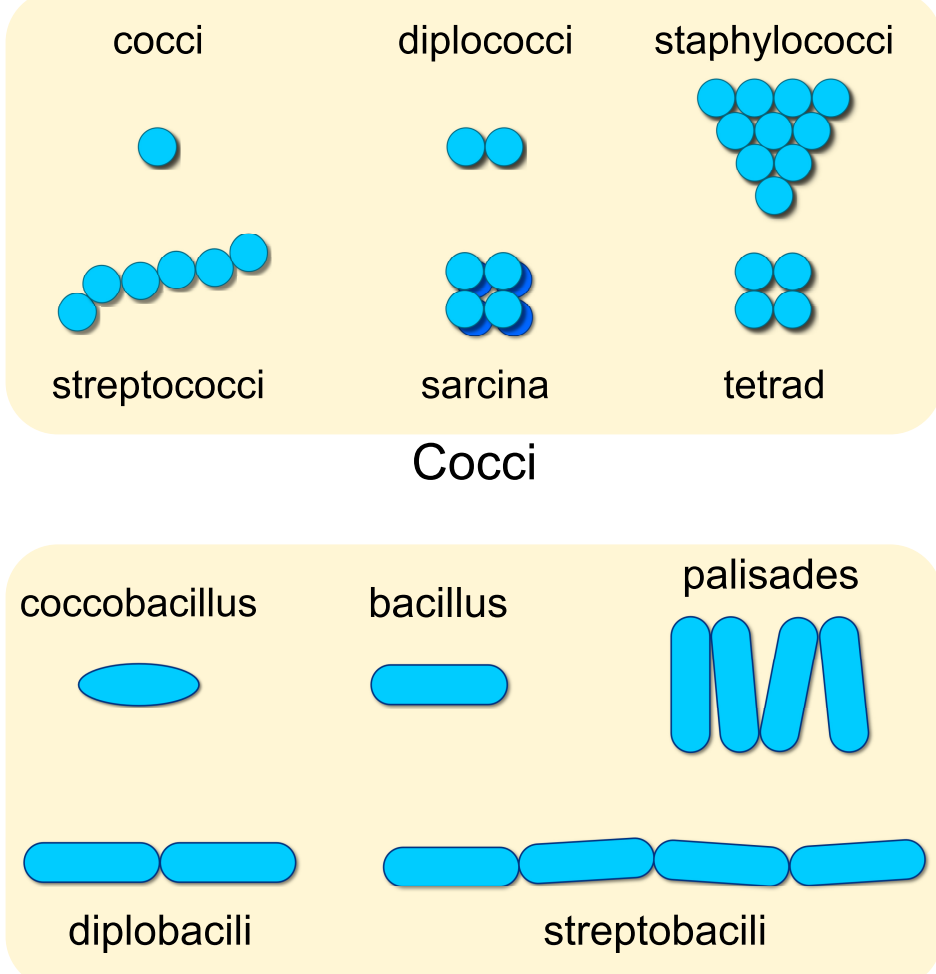

\section{Bacilli (rods)}

Figure 1.17 Lactic acid bacteria classification attending to its morphology and arrangement. L. lactis, formerly known as Streptococcus lactis, grows in a chain-like arrangement.

Lactococcus genus comprises three strains: L. lactis subsp. cremoris, L. lactis subsp. lactis and L. lactis subsp. hordniae. L. lactis subsp. cremoris can be distinguished from subsp. lactis by its inability to grow at $40{ }^{\circ} \mathrm{C}$ (the optimal growh temperature of L. lactis subsp. cremoris is $30^{\circ} \mathrm{C}$ ), in $4 \% \mathrm{NaCl}$ and to hydrolyze arginine and ferment ribose. There are also differences in DNA-DNA 
homology and in the 16S rRNA sequences.

\section{Metabolism}

The whole LAB clade shows a high carbohydrate fermentation rate coupled to substrate-level phosphorylation activity for ATP synthesis. A membranebound $\mathrm{H}^{+}$-ATPase creates a proton-motive force that drives the transport of ions and metabolites into the cell. Both permease and sugar phosphotransferase systems (PTS) makes use of this proton-motive force. There are two major ways of carbohydrate and related compounds metabolism. L. lactis, as a strict homofermentative strain, metabolizes glucose using the glycolytic (or EmbdenMeyerhof-Parnas) pathway, also known as homolactic fermentation.

Glucose, usually found in excess in the culture medium in laboratory conditions, is transformed into almost exclusively L-(+)-lactic acid, through the formation of fructose-1,6-diphosphate, which is converted into dihydroxyacetonephosphate and glyceraldehyde-3-phosphate (GAP) by a FDP aldolase. Both dihydroxyacetone-P, which is transformed to glyceraldehyde-3P, and glyceraldehyde3P is eventually converted to pyruvate.

In laboratory conditions, where there is restricted oxygen access and glucose excess, pyruvate is reduced to lactic acid by a $\mathrm{NAD}^{+}$-dependent lactate dehydrogenase, oxidizing $\mathrm{NADH}$ into $\mathrm{NAD}^{+}$produced during the earlier glycolytic steps. Usually, the only metabolic product is lactic acid, except in some cases where the complex products found in the medium can lead to the formation of acetic acid and other metabolic products [243] (Figure 1.18).

L. lactis can also metabolize sugars like mannose, fructose and galactose. In the case of mannose or fructose, a permease transport system brings the sugar into the cytoplasm, while in the case of the galactose a sugar-phosphotransferase system (PTS) converts galactose into galactose-6-P, entering the glycolytic pathway at the glyceraldehyde-3-P (GAP) level (Figure 1.18, left). In species lacking the PTS system, galactose follows the Leloir pathway (Figure 1.18, right), entering the glycolytic pathway at the glucose-6-P level.

Besides monosaccharide fermentation, L. lactis features a PTS for disaccharides. In this case, a phosphohydrolase splits the disaccharide into a free and a phosphorylated monosaccharide. Lactose is readily metabolized by $L$. lactis by using a lactose-specific PTS [244, 245]. Lactose enters the cell as lactose phosphate, which is cleaved into glucose and galactose-6-phosphate by a phospho- $\beta$-D-galactosidase ( $\mathrm{P}-\beta$-gal). Glucose is then phosphorylated into glucose-6-phosphate and enters the glycolytic pathway. Galactose-6-phosphate is metabolized via the tagatose-6-phosphate pathway (Figure 1.19). Both 


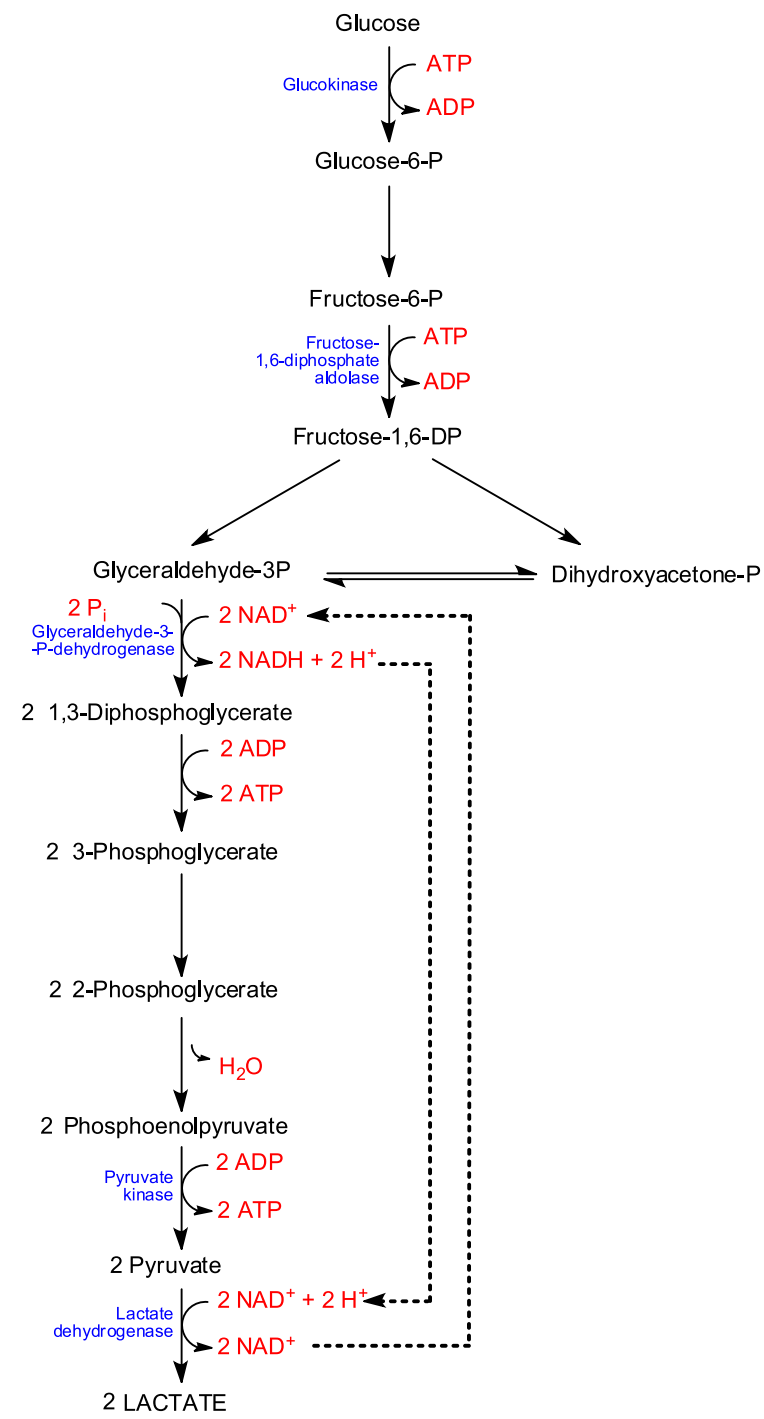

Figure 1.18 Glycolytic pathway of Lactococcus lactis, yielding L-(+)-lactate as final product.

lactose PTS and P- $\beta$-gal are inducible and repressed by glucose.

L. lactis can also metabolize pentoses, although these compounds are metabolized by the ending part of the 6-phosphogluconate/phosphoketolase pathway, which L. lactis lacks. In theory, only heterofermentative strains would be able to metabolize pentoses, but in practice all LAB strains, including L. lactis, are 

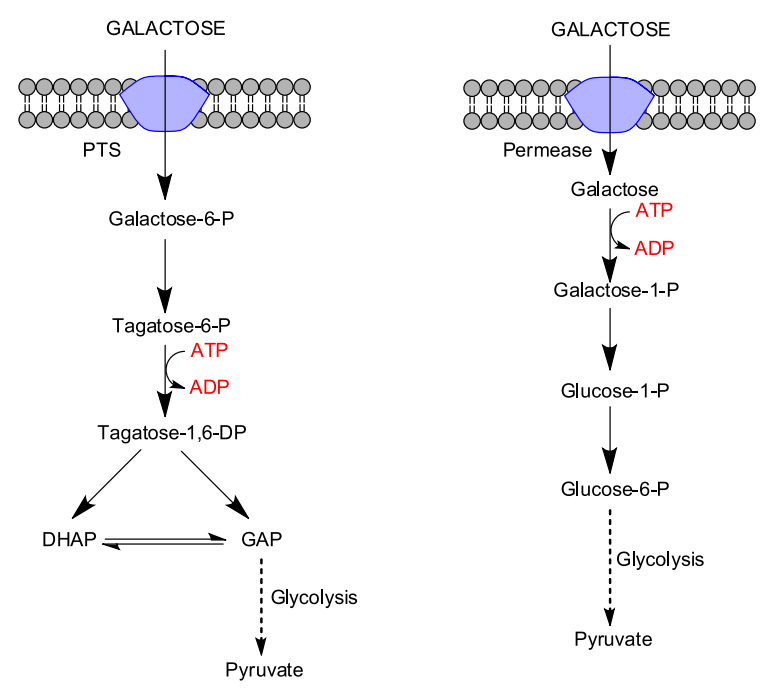

Figure 1.19 Galactose metabolism in lactic acid bacteria. Left, tagatose-6phosphate pathway; right, Leloir pathway.

pentose-positive, with the exception of group I lactobacilli.

\section{Lactic acid configuration}

The configuration of the lactic acid is strain-dependent. Some strains produce exclusively L-lactic acid, some only D-lactic acid and some others a racemic mixture of both D and L-lactic acid, either equimolar or with different ratios [206]. This configuration depends on the presence of specific $\mathrm{NAD}^{+}$-dependent lactate dehydrogenases (n-LDH) and their respective activities. L. lactis and L. casei have an allosteric L-nLDH dehydrogenase, activated by fructose-1,6diphosphate, that converts the glucose exclusively to L-lactate. 


\section{Chapter 2}

\section{Objectives}

The aim of this work is to assess the use of living, bacteria-based biointerfaces between synthetic substrates and mammalian cells, seeking to develop a new engineered interface with the ability to direct cell fate in a dynamic manner.

To play this role as a living interface, these bacteria must be genetically engineered to display active cues, specifically the $\mathrm{III}_{7-10}$ fragment of the human fibronectin.

$\mathrm{FN} \mathrm{III}_{7-10}$ enables the direct interaction between the genetically engineered bacteria and mammalian cells through integrins, membrane-bound receptors that interact with the extracellular environment and act as a link between extracellular events and the regulation of a wide variety of cellular processes, such as adhesion, proliferation, migration and differentiation, all of them involved in the development of new tissues.

The concrete objectives of this work are:

1. Identify an appropriate strain that will play the role of the living biointerface. Ideally, this strain should be able to coexist with the mammalian cells and be a suitable candidate for genetic modification. Moreover, this living biointerface will remain viable, strongly attached to the supporting substrate and ready for the expression of dynamic biochemical signals.

2. To genetically modify the bacteria to express the desired protein, FN $\mathrm{III}_{7-10}$ fused to GFP as a reporter protein.

3. To characterize the properties of the genetically engineered strain, to evaluate its localisation in the membrane and assess its biological activity. 
4. Develop immobilisation methods to ensure that a proper physical bacterial layer between synthetic materials and cells can be produced, and characterize this interface.

5. To investigate and characterize the cellular response of mammalian cells cultured onto the living biointerface.

6. Engineer technologies for the robust incorporation of the bacteria within material systems. 


\section{Chapter 3}

\section{Materials and methods}

In this chapter, a general description of each protocol is described, going in depth in the pertinent materials and methods section of the following chapters.

\subsection{Cloning protocols}

\section{Endonuclease restriction}

Endonuclease restriction reactions were carried out according to the manufacturers protocol. A typical reaction mix contained $1 \mu \mathrm{L}$ of the restriction enzyme, $1 \mu \mathrm{g}$ of DNA, $2 \mu \mathrm{L}$ of $10 \times$ reaction buffer and nuclease-free sterile ultrapure water to complete $20 \mu \mathrm{L}$. The reaction was carried out for $1 \mathrm{~h}$ at $37^{\circ} \mathrm{C}$ in a thermostatic block.

\section{Ligation}

Purified DNA from the digestion step of both insert and plasmid were mixed in a 5:1 molar ratio, with a typical mass of $50 \mathrm{ng}$ of insert and $30 \mathrm{ng}$ of plasmid. Then, $2 \mu \mathrm{L}$ of $10 \times \mathrm{T} 4$ ligase buffer, $1 \mu \mathrm{L}$ of T4 DNA ligase and nuclease-free water were added to complete $20 \mu \mathrm{L}$. The reaction was gently mixed by pipetting up and down one time. The reaction was completed in 15 minutes at room temperature. Reaction products were purified using the Illustra GFX DNA and gel band purification kit (GE Healthcare). 


\section{E. coli transformation}

A $50 \mu \mathrm{L}$ aliquot of E. coli NEB5 $\alpha$ high-efficiency competent cells (New England Biolabs) stored at $-80{ }^{\circ} \mathrm{C}$ was kept on ice for 10 minutes for thaw the cells. Then, $5 \mu \mathrm{L}$ with a maximum of $100 \mathrm{ng}$ of plasmid DNA of the purified reaction mixture from the ligation reaction was added to the competent cells and gently mixed by inversion, while avoiding vortexing.

This mix was left 30 minutes on ice, heated at $42{ }^{\circ} \mathrm{C}$ for 30 seconds and placed on ice for 5 minutes, followed by the addition of $950 \mathrm{~mL}$ of SOC medium (New England Biolabs). The tube was kept in a shaking incubator for one hour at $37^{\circ} \mathrm{C} .100 \mu \mathrm{L}$ of the resulting culture was spread in several Luria-Bertani agar plates supplemented with $50 \mu \mathrm{g} / \mathrm{mL}$ kanamycin and left overnight at $37^{\circ} \mathrm{C}$ to screen the positive clones, based on the incorporation of the kanamycin resistance gene in the pGFP-C2 plasmid.

\section{E. coli culture}

Escherichia coli is a gram-negative aerobic strain which grows in Luria-Bertani medium [246] (LB), composed of $10 \mathrm{~g} / \mathrm{L}$ tryptone, $5 \mathrm{~g} / \mathrm{L}$ yeast extract and $10 \mathrm{~g} / \mathrm{L} \mathrm{NaCl}$. This medium is then sterilised at $121{ }^{\circ} \mathrm{C}$ for 30 minutes. Its optimal growth temperature is $37^{\circ} \mathrm{C}$ with shaking, in aerobic conditions (open container). LB-agar plates were prepared by adding $1.5 \% \mathrm{w} / \mathrm{v}$ agar, sterilised at $121^{\circ} \mathrm{C}$ for 20 minutes and poured into Petri dishes. Freshly prepared LB-agar plates can be stored at $4{ }^{\circ} \mathrm{C}$ for several weeks in closed containers.

\section{Polymerase chain reaction (PCR)}

PCR reactions were carried on an Eppendorf Personal Thermal Cycler (Eppendorf, Germany), using AmpliTAQ Gold polymerase (Applied Biosystems). The same PCR program was used for each amplicon:

1. 1st denaturation step: 10 minutes at $95{ }^{\circ} \mathrm{C}$

2. 35 amplification steps:

Denaturation, 40 seconds at $95^{\circ} \mathrm{C}$

Annealing, 45 seconds at $56^{\circ} \mathrm{C}$

Extension, $1: 45$ minutes at $72{ }^{\circ} \mathrm{C}$

3. Final extension step, $72{ }^{\circ} \mathrm{C}$ for 10 minutes. 


\section{Preparation of $L$. lactis electrocompetent cells}

$2 \mathrm{~mL}$ of an overnight $L$. lactis culture was inoculated into $200 \mathrm{~mL}$ of M17 medium with $1 \%$ glycine and grown at $30{ }^{\circ} \mathrm{C}$. When the culture reached an optical density (OD) of 0.6-0.8, measured at $660 \mathrm{~nm}$, cells were harvested by centrifugation at $4000 \mathrm{~g}$ for 5 minutes at $4{ }^{\circ} \mathrm{C}$, and thoroughly washed in an sterile ice-cold solution of sucrose $0.5 \mathrm{M}$ and glycerol $10 \% \mathrm{v} / \mathrm{v}$.

Then, cells were resuspended in the same solution, aliquoted in volumes of $50 \mu \mathrm{L}$ and frozen at $-80^{\circ} \mathrm{C}$. These cells keep their electrocompetent capabilities for up to three months.

\section{L. lactis electrotransformation}

Electrotransformation of $L$. lactis cells was performed using a BTX electroporator (Harvard Apparatus). The electrotransformation protocol involved a prior desalting and purification of the DNA with the Illustra GFX DNA and gel band purification kit (GE Healthcare). Frozen electrocompetent cells were thawed on ice for 10 minutes. $5 \mu \mathrm{L}$ of the purified plasmid DNA was gently mixed with competent cells with the pipette and transferred to a sterile electroporation cuvette with $1 \mathrm{~mm}$ gap between electrodes. A $2.5 \mathrm{kV}$ pulse with a typical time constant of 4.5 was applied, followed by the addition of $5 \mathrm{~mL}$ of recuperation medium containing M17, sucrose $0.5 \mathrm{M}, \mathrm{MgCl}_{2} 20 \mathrm{mM}$ and $\mathrm{CaCl}_{2} 2 \mathrm{mM}$. Cells were allowed to recover for $2 \mathrm{~h}$ at $30^{\circ} \mathrm{C}$.

Cells were then harvested at $3000 \mathrm{~g}$ for $5 \mathrm{~min}$. The resulting pellet was resuspended in $500 \mu \mathrm{L}$ of the same medium, seeded on M17-agar plates supplemented with $0.5 \% \mathrm{w} / \mathrm{v}$ glucose and $10 \mu \mathrm{g} / \mathrm{mL}$ erythromycin and incubated at $30{ }^{\circ} \mathrm{C}$ for $24-48 \mathrm{~h}$ to select positive (erythromycin resistant) clones.

\section{Plasmid isolation from $L$. lactis}

Plasmid extraction was carried over using a combination of a standard protocol [247] and the GenElute five-minute plasmid miniprep kit (Sigma). Stationary phase cultures grown overnight at $30{ }^{\circ} \mathrm{C}$ in sterile M17 medium supplemented with $0.5 \% \mathrm{v} / \mathrm{v}$ glucose and $10 \mu \mathrm{g} / \mathrm{mL}$ erythromycin (hereinafter GM17-E) were harvested by centrifugation at $3000 \mathrm{~g}$ for 10 minutes. The pellet was resuspended in $25 \%$ sucrose containing $30 \mathrm{mg} / \mathrm{mL}$ lysozyme and $1 \mathrm{mg} / \mathrm{mL}$ RNase, to a final volume of $200 \mu \mathrm{L}$, and incubated at $37^{\circ} \mathrm{C}$ for 15 minutes.

Lysozyme helps in the hydrolysis of the peptidoglycan cell wall, while the resulting protoplasts become lysed by the osmotic shock induced by sucrose at 
high concentrations. Then, $400 \mu \mathrm{L}$ of $3 \%$ SDS in $0.2 \mathrm{~N} \mathrm{NaOH}$ solution were added, mixing by inversion, to solubilize the lipid bilayer and the DNA.

After a 7-minute incubation at room temperature, $300 \mu \mathrm{L}$ of ice-cold $3 \mathrm{M}$ sodium acetate solution ( $\mathrm{pH} 4.8$ ) was added, vortexing the resulting solution. This solution was then centrifuged at $18000 \mathrm{~g}$ for 15 minutes at $4^{\circ} \mathrm{C}$. The supernatant was recovered, further purifying the plasmidic DNA with the GenElute five-minute miniprep kit from Sigma.

\section{DNA purification from PCR or enzymatic reactions}

Purification of PCR or enzymatic restriction products were carried on using the Illustra GFX DNA and gel band purification kit (GE Healthcare).

Briefly, $500 \mu \mathrm{L}$ of capture buffer were added to up to $100 \mu \mathrm{L}$ of reaction sample (containing PCR or enzymatic products) and spun to collect the liquid at the bottom of the tube. This mix was transferred to a silica column and centrifuged at $16000 \mathrm{~g}$ for 30 seconds, discarding the eluted liquid.

Then, $500 \mu \mathrm{L}$ of the washing buffer was loaded onto the column and centrifuged at $16000 \mathrm{~g}$ for 30 seconds, discarding the eluted liquid.

Finally, $40 \mu \mathrm{L}$ of the eluted buffer was loaded onto the column, followed by a 1 minute incubation at room temperature and centrifuged at $16000 \mathrm{~g}$ for 1 $\min$.

\section{DNA purification from gel bands}

DNA gel bands from agarose gel electrophoresis were purified using the Illustra GFX DNA and gel band purification kit (GE Healthcare).

Bands containing the desired DNA from the gel electrophoresis were carefully cut with a scalpel under UV transiluminator visualization and transferred to a reaction microtube. Then, $10 \mu \mathrm{L}$ of capture buffer per $10 \mathrm{mg}$ of gel were added and incubated at $60{ }^{\circ} \mathrm{C}$ in a thermostatic block for $15-30$ minutes, until agarose was completely dissolved.

The microtube was subjected to a short spin to collect the liquid at the bottom of the tube and the resulting liquid was transferred to a silica column included in the kit, followed by a 1 minute incubation step at room temperature. The column was centrifuged at $16000 \mathrm{~g}$ for 30 seconds, discarding the flow-through. Then, $500 \mu \mathrm{L}$ of washing buffer was added followed by a $30 \mathrm{~s}$ centrifugation at $16000 \mathrm{~g}$.

Finally, $40 \mu \mathrm{L}$ of elution buffer was carefully loaded onto the silica column, incubated for 1 minute and centrifuged at $16,000 \mathrm{~g}$ for 1 minute, to recover 
the purified DNA. Purified DNA was stored at $-20^{\circ} \mathrm{C}$ or immediately used.

\section{Cell lysis and plasmid purification}

Plasmidic DNA was extracted and purified according to the manufacturer's protocol. Briefly, $500 \mu \mathrm{L}$ of column preparation solution were centrifuged at maximum speed for 15 seconds, discarding the flow-through.

Then, the lysed bacterial solution, up to $780 \mu \mathrm{L}$, was centrifuged again at maximum speed for 20 seconds, discarding the flow-through. The column was twice washed using 700 and $200 \mu \mathrm{L}$ of washing buffer, also discarding the flow-through.

Finally, elution solution was used to recover the plasmid DNA, by centrifugation at maximum speed a $1.5 \mathrm{~mL}$ microtube. This purified DNA was later used for cloning or transformation.

\subsection{Bacterial culture}

L. lactis strain was cultured in GM17-E medium to ensure the positive selection of the pT1NX plasmid, which carries an erythromycin resistance gene. The composition of the M17 medium is [248]:

- Tryptone (5 g/L)

- Soya peptone $(5 \mathrm{~g} / \mathrm{L})$

- "Lab-lemco" powder (5 g/L)

- Yeast extract $(2.5 \mathrm{~g} / \mathrm{L})$

- Ascorbic acid (0.5 g/L)

- Magnesium sulphate $(250 \mathrm{mg} / \mathrm{L})$

- Di-sodium glycerophosphate (19 g/L)

The reconstituted medium has a pH of $6.9 \pm 0.2$ measured at $25^{\circ} \mathrm{C}$. This medium is commercially sold as a highly hygroscopic, dehydrated powder that was reconstitued at $37.25 \mathrm{~g} / \mathrm{L}$ in ultrapure or distilled water and sterilized at $121^{\circ} \mathrm{C}$ for 20 minutes. Once cooled down, it was supplemented with $0.5 \% \mathrm{v} / \mathrm{v}$ sterile glucose and $10 \mu \mathrm{g} / \mathrm{mL}$ erythromycin, to avoid glucose caramelisation or erythromycin degradation during the sterilization process. 
L. lactis grows optimally at $30{ }^{\circ} \mathrm{C}$ in anaerobic conditions as a standing culture. When cultures reaches the stationary phase, bacteria slowly settles forming a pellet in the bottom of the container. We observed that L. lactis-FN produces compact pellets whilst the L. lactis-empty strain produces a turbid medium with a smaller pellet. Brightfield microscopic imaging of the stationary phase cultures shows that $L$. lactis-FN grows in chains of 5 to 15 cells in contrast to L. lactis-empty, which grows in short chains of 4-5 cells at most.

\subsection{L. lactis biofilm production}

The protocol to establish a biofilm on a material surface has been adapted from elsewhere [209, 249]. A frozen glycerinate of L. lactis-FN kept at $-80^{\circ} \mathrm{C}$ was used to streak a fresh GM17-E $1 \%$ agar plate. The plate was kept at $30{ }^{\circ} \mathrm{C}$ for 18-24 h until 1-2 mm colonies grew up. Then, a single colony was inoculated in $10 \mathrm{~mL}$ of fresh GM17-E medium and grown until the optical density, measured at $600 \mathrm{~nm}$, reached a value between 0.3 and 0.5 . Then, the bacterial culture was poured into a multiwell plate, sealed with adhesive tape or parafilm and kept in the incubator at $30{ }^{\circ} \mathrm{C}$ for at least $18-24 \mathrm{~h}$.

Once the stationary point was reached, the culture was removed, washing the wells with sterile ultrapure water to remove the non-attached (planktonic) bacteria. After three gentle washes, a monolayer of adhered bacteria remained attached on the material surface. The same protocol was used for L.lactis-empty and L. lactis-FN.

\subsection{Mammalian cell culture}

Several mammalian cell lines have been used in this work, human and murine. The first assays were done with murine fibronectin null $\left(\mathrm{Fn}^{-} / \mathrm{Fn}^{-}\right)$fibroblasts. The rationale for using these cells was to ensure that cell behavior was only affected by the fibronectin displayed in the L. lactis membrane, since fibroblasts secrete fibronectin that could interfere with the adhesion assays.

Morphology studies on different densities biofilms were carried using two different cell lines, the murine C2C12 myoblastic cell line and L929 fibroblastic cell line. Finally, human bone-marrow derived mesenchymal stem cells were used to assess the differentiation capabilities of the FNIII $_{7-10}$ fragment in long-term cultures. In the bacterial biofilm co-cultures, the $1 \%$ penicillinstreptomycin antibiotic mix was substituted with $10 \mu \mathrm{g} / \mathrm{mL}$ tetracycline, to 
inhibit the growth of bacteria and prevent the medium acidification due to lactate production.

\section{$\mathrm{Fn}^{-} / \mathrm{Fn}^{-}$murine fibroblasts}

Cells were maintained at $37{ }^{\circ} \mathrm{C}, 5 \% \mathrm{CO}_{2}$ in a humidified atmosphere. The culture medium was composed of Dulbecco's modified Eagle medium (DMEM) supplemented with $4.5 \mathrm{~g} / \mathrm{L}$ glucose, $100 \mathrm{U} / \mathrm{mL}$ penicillin-streptomycin and $10 \%$ calf serum. Cells were passaged twice a week using standard techniques.

\section{NIH3T3}

NIH3T3 is a commercial fibroblastic cell line developed from NIH Swiss mouse embryo cultures. Its growth properties are similar to those of 3T3 and BALB/ 3T3. Cells were maintained at $37{ }^{\circ} \mathrm{C}$ in a humidified atmosphere with $5 \% \mathrm{CO}_{2}$. The culture medium contained DMEM with $4.5 \mathrm{~g} / \mathrm{L}$ glucose, $20 \%$ calf serum and $1 \%$ (equivalent to $100 \mathrm{U} / \mathrm{mL}$ ) penicillin-streptomycin. Cells were passaged twice a week using standard techniques.

\section{C2C12}

This is a murine myoblastic cell line with the ability to differentiate to myotubes. Cells were maintained in the usual conditions, $37{ }^{\circ} \mathrm{C}, 5 \% \mathrm{CO}_{2}$ humidified atmosphere. The medium contained DMEM (Dulbecco's modified eagle medium) with $4.5 \mathrm{~g} / \mathrm{L}, 1 \%$ penicillin-streptomycin and $20 \%$ Foetal Bovine Serum (FBS). It is not advised to let cultures reach confluence in order to maintain its differentiation capabilities, as the myoblastic population quickly depletes when confluence is reached, due to paracrine interactions.

\section{hMSC-BM}

Human bone-marrow derived mesenchymal stem cells were kept in DMEM supplemented with $100 \mu \mathrm{M}$ pyruvate (Sigma), $1.1 \mathrm{mM}$ L-glutamine (Sigma), $10 \% \mathrm{FBS}$ and $1 \%$ penicillin-streptomycin. The culture conditions were the same as the other cell lines, $37{ }^{\circ} \mathrm{C}$ in a humidified atmosphere with $5 \% \mathrm{CO}_{2}$. 


\subsection{Immunofluorescence assays}

\section{Cell adhesion}

Cell adhesion to the biofilm and control substrates was characterized by vinculin immunostaining. After culture times, cells were washed with Dulbecco's phosphate buffered saline (DPBS, Invitrogen) and fixed in $10 \%$ formalin solution (Sigma) at $4{ }^{\circ} \mathrm{C}$ for $30 \mathrm{~min}$. Formalin was rinsed three times with DPBS, incubating the samples with permeabilising buffer (0.1\% Triton X-100 in DPBS) at room temperature for $5 \mathrm{~min}$.

Then, samples were incubated in $1 \%$ bovine serum albumin (Sigma) in DPBS at room temperature for $30 \mathrm{~min}$, in order to block reactive sites and reduce the background signal. Samples were then hybridized with a monoclonal antivinculin antibody (Sigma) diluted 1:400 in 1\% BSA / DPBS for 1 hour at room temperature and washed three times in $0.5 \%$ Tween 20 / DPBS. A Cy3-conjugated polyclonal rabbit anti-mouse IgG secondary antibody (Jackson Immunoresearch), diluted 1:200 in 1\% BSA / DPBS, with 1:40 BODIPY FLconjugated phallacidin (Invitrogen) was added and incubated for 1 hour at room temperature in absence of light.

Samples were washed three times with $0.5 \%$ Tween 20 / DPBS and mounted in Vectashield containing DAPI (Vector Laboratories, Peterborough, UK) mounting medium and imaged using a Nikon Eclipse 80i fluorescence microscope.

\section{Cell differentiation}

Myoblastic differentiation of the $\mathrm{C} 2 \mathrm{C} 12$ cell line was assessed using sarcomeric myosin immunostaining. Cultures were fixed at $4{ }^{\circ} \mathrm{C}$ with a mixture of $70 \%$ ethanol, $37 \%$ formaldehyde and glacial acetic acid (mixing ratio of 20:2:1 respectively) for $15 \mathrm{~min}$ and blocked with $5 \%$ goat serum in DPBS for $1 \mathrm{~h}$ at RT. Samples were incubated with MF-20 antibody against sarcomeric myosin (Developmental Studies Hybridoma Bank, University of Iowa, USA) at 1:250 dilution in $5 \%$ goat serum / DPBS, followed by two washes with $0.5 \%$ Tween 20 / DPBS and another blocking step with $5 \%$ goat serum in DPBS for 10 min at RT.

Samples were washed twice with $0.5 \%$ Tween 20 / DPBS and incubated with polyclonal rabbit anti-mouse Cy3-conjugated secondary antibody (Jackson Immunoresearch) diluted 1:200 in $5 \%$ goat serum / DPBS, rinsed three times with $0.5 \%$ Tween 20 / DPBS and mounted with Vectashield-DAPI (Vector 
Laboratories, Peterborough, UK). Samples were imaged under a Nikon Eclipse 80i epifluorescence microscope.

\subsection{Protein quantification by Western blot}

\section{Membrane localisation of FNIII $_{7-10}$}

Cells corresponding to $10^{9} \mathrm{cfu}$ were washed and resuspended in $50 \mu \mathrm{L}$ of lysis buffer composed of Tris- $\mathrm{HCl}(50 \mathrm{mM}, \mathrm{pH} 7.5)$, sucrose $0.5 \mathrm{M}$ and lysozyme 50 $\mathrm{mg} / \mathrm{mL}$, incubated for $2 \mathrm{~h}$ at $37^{\circ} \mathrm{C}$ and centrifuged at maximum speed.

Supernatant (cytosolic fraction) and pellet (membrane fraction) were separated and resuspended in Laemmli loading buffer $(50 \mu \mathrm{L})$, boiled for 5 min and separated by $10 \%$ SDS-PAGE gels. Proteins were transferred to positively charged PVDF membranes (GE Healthcare) using the Bio-Rad semidry transfer cell system. Membranes were blocked using $5 \%$ skimmed milk in DPBS for 1 hour at RT and then incubated with the MAB1937 antibody (Millipore), directed against the 8th type III human FN domain, diluted 1:1000 in DPBS with $0.1 \%$ Tween 20 and $2 \%$ skimmed milk (Sigma). Incubation was carried out overnight at $4{ }^{\circ} \mathrm{C}$.

After several washes with $0.1 \%$ Tween 20 / DPBS, the blot was incubated using anti-mouse antibody conjugated to HRP (GE Healthcare) in a dilution of 1:50,000 in $0.1 \% \mathrm{v} / \mathrm{v}$ DPBS / Tween 20 and $2 \%$ skimmed milk for $1 \mathrm{~h}$ at RT. Membranes were washed with $0.1 \%$ Tween 20 / DPBS.

Immunoreactive bands were visualized using the ECL Plus Western blot kit (GE Healthcare) after developing the photographic films.

\section{Expressed $\mathrm{FNIII}_{7-10}$ fragment}

Three aliquots of $0.5,1$ and $1.5 \mathrm{~mL}$ from a $24 \mathrm{~h}$ standing culture of L. lactis-FN and $L$. lactis empty strains in GM17-E were lysed using a modified acetone/SDS protocol [250]. Briefly, cells were harvested by centrifugation at 7,000 $\mathrm{g}$ for 5 min, washed twice with DPBS++ (DPBS supplemented with $\mathrm{Ca}^{2+}$ and $\mathrm{Mg}^{2+}$ ) and centrifuged again.

The bacterial pellet was treated with $1 \mathrm{~mL}$ of acetone at $-20{ }^{\circ} \mathrm{C}$ for $10 \mathrm{~min}$, with occasional vigorous vortexing. This extract was centrifuged at 7,000 $\mathrm{g}$ for 5 min and carefully dried under a gentle stream of $\mathrm{N}_{2}$ until a porous, dry white powder was obtained. Proteins were solubilised by incubating the previously obtained powder in $100 \mu \mathrm{L}$ of $1 \%$ SDS in ultrapure water for $20 \mathrm{~min}$ at RT, with occasional vortexing. Debris were pelleted by centrifugation at 7,000 g 
for $5 \mathrm{~min}$. $20 \mu \mathrm{L}$ of the supernatant was mixed with $20 \mu \mathrm{L}$ of $2 \times$ Laemmli buffer, boiled for $5 \mathrm{~min}$ at $95{ }^{\circ} \mathrm{C}$ and subjected to $10 \%$ SDS-polyacrylamide gel electrophoresis (PAGE).

Simultaneously, 750, 500 and 250 ng of purified FNIII $_{7-10}$ fragment were loaded in the same gel as controls. Proteins were transferred to a positively charged PVDF membrane (GE Healthcare) using a semidry transfer cell system (Bio-Rad).

Membranes were blocked using $5 \%$ skimmed milk in DPBS for 1 hour at RT and then incubated with the MAB1937 antibody (Millipore), directed against the 8th type III human FN domain, diluted 1:1000 in DPBS with $0.1 \%$ Tween 20 and $2 \%$ skimmed milk (Sigma). Incubation was carried out overnight at $4{ }^{\circ} \mathrm{C}$.

After several washes with $0.1 \%$ Tween 20 in DPBS, the blot was incubated using horseradish peroxidase-conjugated anti-mouse antibody (GE Healthcare) diluted 1:50,000 in DPBS / Tween $20(0.1 \% \mathrm{v} / \mathrm{v})$ and $2 \%$ skimmed milk for 1 $\mathrm{h}$ at RT. Membranes were washed several times with $0.1 \%$ Tween 20 in DPBS. The immunoreactive bands were visualized using the ECL Plus Western blot kit (GE Healthcare) after developing the photographic films.

\section{FAK phosphorylation}

After a 3-hour culture, C2C12 or $\mathrm{Fn}^{-} / \mathrm{Fn}^{-}$fibroblasts were lysed with RIPA buffer (Tris-HCl $50 \mathrm{mM}, 1 \%$ Nonidet P-40, $0.25 \%$ sodium deoxycholate, $150 \mathrm{mM} \mathrm{NaCl}, 1 \mathrm{mM}$ EDTA) supplemented with protease inhibitor cocktail tablets (Complete, Roche). Proteins were concentrated using Microcon YM-30 Centrifugal Filter devices (Millipore) following manufacturer instructions.

To determine FAK protein expression and its Tyr397 phosphorylated form (pFAK), concentrated samples were subjected to $7 \%$ SDS-polyacrylamide gel electrophoresis (PAGE). Proteins were transferred to a positively charged PVDF membrane (GE Healthcare) using a semidry transfer cell system (Bio-Rad) and blocked by immersion in $5 \%$ skimmed milk / DPBS for $1 \mathrm{~h}$ at room temperature.

The blot was incubated with anti-FAK antibody (Upstate) and anti-pFAK antibody (Millipore) diluted 1:2,500 in 2\% skimmed milk / $0.1 \%$ Tween 20 / DPBS. After several washes with $0.1 \%$ Tween 20 / DPBS, the blot was incubated in horseradish peroxidase-conjugated antibody (GE Healthcare) diluted 1:50,000 in $2 \%$ skimmed milk / $0.1 \%$ Tween 20 / DPBS for 1 hour at room temperature.

After several washes with $0.1 \%$ Tween 20 / DPBS, immunoreactive bands were visualized using Supersignal West-femto Maximum Sensitivity Substrate 
(Thermo Scientific) after developing the photographic films.

\subsection{Enzyme-linked immunosorbent assay (ELISA)}

\section{Membrane-bound FNIII $_{7-10}$}

Enzyme-linked immunosorbent assays were used to quantify the biological activity of the exposed FNIII $_{7-10}$ fragment displayed on the L. lactis surface. Three mililitres from a $24 \mathrm{~h}$ standing culture of L. lactis-FN and L. lactis-empty grown in sterile GM17-E, with a bacterial density of $10^{7} \mathrm{cfu} / \mathrm{mL}$, were filtered through a porous polycarbonate membrane with a mean pore size of $0.8 \mu \mathrm{m}$ (Isopore, Millipore).

The membrane was twice washed with DPBS++ to remove non-trapped bacterial cells. Another set of identical membranes were coated with 20, 10, 5 and $2.5 \mu \mathrm{g} / \mathrm{mL}$ of human plasma fibronectin (Sigma) dissolved in DPBS++ for $1 \mathrm{~h}$ at RT, and washed twice with PBS++. Uncoated membranes were used to assess the absence of any background signal in the polycarbonate membranes. Membranes were then blocked with $1 \%$ bovine serum albumin (Sigma) in DPBS ++ for $1 \mathrm{~h}$ at RT, and incubated for $1 \mathrm{~h}$ at $37^{\circ} \mathrm{C}$ with mouse monoclonal HFN7.1 anti-fibronectin antibody. The primary antibody dilution was 1:4,000 from a $32 \mu \mathrm{g} / \mathrm{mL}$ stock.

After that, samples were washed twice with DPBS++ / Tween $20(0.5 \%$ $\mathrm{v} / \mathrm{v}$ ) and incubated with alkaline phosphatase-conjugated donkey anti-mouse secondary antibody (Jackson Immunoresearch) for $1 \mathrm{~h}$ at RT. Samples were washed again twice with DPBS++ / Tween $20(0.5 \% \mathrm{v} / \mathrm{v})$. Then, $400 \mu \mathrm{L}$ of a $0.6 \mathrm{mM}$ 4-methylumbelliferyl phosphate solution in a $\mathrm{pH} 10$ borax $/ \mathrm{NaOH}$ buffer was added.

After an incubation time of $45 \mathrm{~min}$ at $37^{\circ} \mathrm{C}$, the supernatant was transferred to a P96 multiwell plate. Fluorescence was measured at $\lambda_{e x}=365 \mathrm{~nm}$ and $\lambda_{e m}=460 \mathrm{~nm}$ in a Perkin-Elmer Victor3 Multilabel Counter (Perkin Elmer).

\section{ERK1/2 sandwich ELISA}

ERK 1/2 phosphorylation was assessed with the DuoSet ERK 1/2 sandwich ELISA kit (RnD Systems, Minneapolis, USA).

Human bone marrow-derived mesenchymal stem cells, passage 2 (Promocell) were maintained in DMEM supplemented with $1 \% \mathrm{P} / \mathrm{S}, 1.1 \mathrm{mM} \mathrm{L-}$ glutamine, $100 \mu \mathrm{M}$ pyruvate and $10 \%$ FBS. Then, cells were seeded over maximum-density L. lactis-empty and L. lactis-FN biofilms produced on PEA 
thin films, FN-coated PEA and bare polystyrene surfaces in the same medium, but replacing $\mathrm{P} / \mathrm{S}$ by $10 \mu \mathrm{g} / \mathrm{mL}$ tetracycline, without FBS, at 25,000 cells $/ \mathrm{cm}^{2}$.

After 30 minutes, culture medium was removed and cells were lysed with $50 \mu \mathrm{L}$ of lysis buffer ( $1 \mathrm{mM}$ EDTA, $0.5 \%$ Triton X-100, $5 \mathrm{mM} \mathrm{NaF}, 6 \mathrm{M}$ urea, $10 \mu \mathrm{g} / \mathrm{mL}$ leupeptin, $10 \mu \mathrm{g} / \mathrm{mL}$ pepstatin, $100 \mu \mathrm{M}$ PMSF, $3 \mu \mathrm{g} / \mathrm{mL}$ aprotinin, $2.5 \mathrm{mM}$ sodium pyrophosphate and $1 \mathrm{mM}$ activated sodium orthovanadate in DPBS, pH 7.2-7.4) for $15 \mathrm{~min}$ in ice. Lysate was stored at $-80^{\circ} \mathrm{C}$. Assay plates were coated with capture antibody at $8 \mu \mathrm{g} / \mathrm{mL}$ in DPBS, overnight at room temperature.

The following day, the plate was washed three times using washing buffer (0.5 \% Tween 20 in DPBS, pH 7.2-7.4) and blocked with blocking buffer (1 \% BSA, $0.05 \% \mathrm{NaN}_{3}$ in DPBS, $\mathrm{pH}$ 7.2-7.4) for $1-2 \mathrm{~h}$ at room temperature, rinsing twice with washing buffer. Then, a standard curve covering from $30 \mathrm{ng} / \mathrm{mL}$ to $0.23 \mathrm{ng} / \mathrm{mL}$ of pERK1/2, with eight two-fold dilutions (in $1 \mathrm{mM}$ EDTA, $0.5 \%$ Triton X-100, $5 \mathrm{mM}$ NaF, $1 \mathrm{M}$ urea in DPBS, pH 7.2-7.4), was prepared. Samples were diluted six-fold in the same buffer and incubated for two hours at room temperature.

Then, wells were washed twice with the washing buffer. Immediately, the detection antibody, with a final concentration of $400 \mathrm{ng} / \mathrm{mL}$ diluted in $1 \%$ BSA in DPBS, was added, allowing a two-hour incubation. Wells were twice washed again, adding streptavidin-HRP (1/400 in $1 \%$ BSA in DPBS, $\mathrm{pH}$ 7.2-7.4) and incubating for 20 minutes at room temperature. Wells were twice washed, adding immediately the substrate solution (1:1 mix of $\mathrm{H}_{2} \mathrm{O}_{2}$ and tetramethylbenzydine).

After a $20 \mathrm{~min}$ at room temperature, while protecting the plate from the light, $1 / 2$ volume of stop solution $\left(\mathrm{H}_{2} \mathrm{SO}_{4} 2 \mathrm{~N}\right)$ was added. Absorbance of the samples was measured at $\lambda=450 \mathrm{~nm}$. The obtained standard calibration curve was adjusted to a third-degree polynomial equation, interpolating the sample concentration values from this curve.

\subsection{Image analysis}

Image analysis procedures were conducted using the Fiji-ImageJ software [251]. Images were acquired using a Nikon Eclipse 80i epifluorescence microscope, fitted with a monochromatic Nikon 90i camera with a 12-bit analog-to-digital converter. 10, 20, 40 and $60 \times$ objectives were used in conjunction with binocular 10× eyepieces. Images were saved in 8-bit per channel RGB BMP format. 


\section{Cell morphology}

Cell morphology was determined by capturing images of the vinculin channel of the immunofluorescence, in our experiments stained with a Cy3-conjugated secondary antibody.

RGB BMP images were converted to 8-bit grayscale images with Fiji-ImageJ and binarized with the Otsu algorithm. The resulting binary mask was subjected to a watershed algorithm to isolate the contiguous, touching cells. Finally, cell area and roundness was calculated using the Particle Analysis command. Roundness is defined as the inverse of the aspect ratio and is calculated with the following expression:

$$
\text { roundness }=\frac{4 \text { area }}{\pi(\text { major axis })^{2}}
$$

\section{Bacterial and cell viability}

Bacterial viability was determined using the BacLight live/dead bacterial viability kit (Life Technologies). This kit contains two dyes, SYTO9 and propidium iodide (PI). SYTO9 is an intercalant, green-fluorescent permeant stain that stains the DNA of the cells in a given population. Propidium iodide is an intercalant, red-fluorescent and non-permeant stain that only enter cells whose membrane is structurally compromised. When used together in an appropriate mixture ratio, 1:1 in this case, PI quenches most of SYTO9 fluorescence. As a result, viable bacteria show green and non-viable bacteria red fluorescence.

For mammalian cell viability, the mammalian live/dead viability kit (Life Technologies) was used. This kit comprises two different probes, calcein AM and ethidium homodimer-2. In viable cells, calcein AM permeates the intact membrane and, once in the cytoplasm, is hydrolyzed by the ubiquitous cytoplasmic esterase activity, giving as a result calcein, a bright green fluorescent dye. On the other hand, ethidium homodimer-2 is a non-permeant DNA stain that only enters cells with compromised membrane. After the staining, viable cells show a bright green cytoplasmic fluorescence while non-viable cells show red fluorescent nuclei, which are easily distinguishable by fluorescence microscopy.

The same protocol was used to assess bacterial and cell viability. In either mammalian cells or bacteria, the live/dead kit stains non-viable cells in red and viable cells in green. Two-channel images from each microscope field were recorded and saved. Then, each image was processed the same way: green and red channels were separately converted to 8-bit grayscale images, binarized 
using the Otsu algorithm [252] and the resulting binary mask were subjected to the particle analysis command of Fiji-ImageJ. Nuclei of non-viable cells showed red fluorescence while viable cells displayed green fluorescence.

Percentage of viable cells was calculated as the number of cells counted in the green channel divided by the total number of cells, i.e. the viable cells plus the non-viable cells. For bacteria, since individual nucleus could not be resolved, coverage percentage was calculated from the total stained area in the red and green channels.

\section{Biofilm density}

Biofilm density was calculated from either DAPI or live/dead stained biofilms. For DAPI, single-channel images of the blue channel were converted from RGB BMP (bitmap format) to 8-bit grayscale images and binarized using the Otsu [252] algorithm or the Trainable Weka Segmentation machine-learning algorithm [253] where needed, mainly in images with low contrast or with uneven background. Total area covered by bacteria was calculated using the Image Analysis command. The coverage of the bacterial cells with respect to the total image area was calculated as follows:

$$
\% \text { coverage }=\frac{\text { stained pixel count }}{\text { total pixel count }} \cdot 100
$$

When live/dead protocol was used to stain bacteria, the red (non-viable) and green (viable) channels were combined in an RGB BMP image that was later converted to an 8-bit grayscale image. This image was binarized using the Otsu thresholding algorithm or the abovementioned Weka machine-learning algorithm, calculating the total area. Coverage percentage was calculated using the latter equation.

\section{Western blot quantification}

Chemiluminiscence films from the Western blot assays were digitized using a flatbed scanner with a resolution of 600 dots per inch and 8-bit per pixel sampling in a single channel grayscale TIFF image.

Images were quantified with Fiji-ImageJ. To do so, individual membrane images were cropped from the whole image. Vertical lanes of each sample were selected and processed with the Gel Analysis tool of Fiji-ImageJ. This tool computes, for each different lane, a pixel intensity profile. A baseline indicating the background is drawn for each lane, and the software returns a pixel count 
value. This pixel count is considered as the number of pixels contained in each band. From this value, relative or absolute quantifications can be performed.

In FAK and pFAK, the $\alpha$-tubulin bands were used as internal controls, normalising the intensity of each band against $\alpha$-tubulin bands.

\section{Differentiation analysis}

For differentiation analysis, two images for each field were taken. One from the nuclei (DAPI channel), and the other from the myotubes (red channel), stained with Cy3. Images were acquired at 10× magnification, transformed to an 8-bit grayscale bitmap and segmented using the Trainable Weka Segmentation plugin to create a binary mask for both Cy3 and DAPI channels.

Total nuclei per image were counted using the Particle Analysis command. Then, the binarized DAPI channel was multiplied by the binarized Cy3 channel image, leaving as a result an image containing only nuclei co-located with the tubes.

Nuclei in this resulting image were counted using the Particle Analysis command. The fraction of differentiated cells was calculated dividing differentiated by total nuclei count.

\subsection{Materials preparation}

\section{PLLA electrospinning}

$50 \mathrm{~mL}$ of an overnight culture of L. lactis-FN and L. lactis-empty in GM17-E were pelleted by centrifugation at 3,000 $\mathrm{g}$ for $10 \mathrm{~min}$. The pellet was twice washed with $2 \mathrm{~mL}$ of sterile $\mathrm{NaCl} 0.85 \% \mathrm{w} / \mathrm{v}$ to remove traces of the growth medium. Bacteria were harvested by centrifugation at 3,000 $\mathrm{g}$ for 10 minutes, and resuspended in a $10 \% \mathrm{w} / \mathrm{v}$ sucrose solution, that was immediately frozen at $-80{ }^{\circ} \mathrm{C}$ and freeze-dried. Freeze-dried bacteria were resuspended in $750 \mu \mathrm{L}$ of hexafluoroisopropanol (HFIP, $>99 \%$ pure, Sigma) and filtered through a 75 $\mu \mathrm{m}$ metallic sieve to remove the precipitated sucrose. This solution was mixed with $750 \mu \mathrm{L}$ of an $8 \% \mathrm{w} / \mathrm{v}$ poly-L-lactic acid solution in HFIP and electrospun using an electric potential of $22 \mathrm{kV}$, a flow rate of $500 \mu \mathrm{L} / \mathrm{h}$ and a distance between the extruding needle and the collector of 18 centimeters. The needle had an internal diameter of $0.15 \mathrm{~mm}$. As a result, a nonwoven mat of PLLA filaments with trapped bacteria was obtained. 


\section{Ethyl acrylate polymerisation}

Poly (ethyl acrylate) (PEA) films were prepared by radical polymerization of pure liquid ethyl acrylate (Sigma) using $0.35 \% \mathrm{w} / \mathrm{v}$ benzoin (98 \% pure, Scharlau) as photoinitiator. The polymerization was carried out for 24 hours in a UV oven. After polymerization, a second post-polymerization step was performed at $90^{\circ} \mathrm{C}$ for 24 hours. Low molecular mass substances were extracted from the material by in vacuum drying at $60^{\circ} \mathrm{C}$ for two days.

\section{PEA spin casting}

Poly (ethyl acrylate) sheets were dissolved in toluene to a final $2.5 \% \mathrm{w} / \mathrm{v}$ concentration. The solution was stirred for two days until all the polymer was properly dissolved, obtaining a viscous solution as a result. Spin casting was performed on 12 or $25 \mathrm{~mm}$ glass coverslips at 2,000 rpm for 30 seconds. Samples were dried in vacuum at $60{ }^{\circ} \mathrm{C}$ to remove solvent traces before biofilm preparation.

\section{PLLA spin casting}

A similar protocol was applied to prepare PLLA thin films with trapped bacteria. L. lactis-FN and L. lactis-empty were cultured overnight on GM17-E in a total volume of $50 \mathrm{~mL}$. Cells were harvested at 3,000 g for 5 minutes, washed twice with sterile $0.85 \% \mathrm{NaCl}$ and centrifuged again at 3,000 g for 5 minutes. The pellet was mixed with $1 \mathrm{~mL}$ of an $8 \%$ PLLA solution in HFIP. Each 12 mm-coverslip was coated with $100 \mu \mathrm{L}$ of this solution.

The spin-coater program consisted on a 30-second run at 3,000 rpm, drying afterwards the coated coverslips in the air, at room temperature, for 1 hour. Those PLLA thin films with included L. lactis were used for the subsequent cell cultures. 


\section{Chapter 4}

\section{Lactococcus lactis cloning and characterization}

\subsection{Introduction}

Understanding the behaviour of cells on synthetic surfaces is of foremost interest to engineer microenvironments that mimics and summarise the characteristics of the extracellular cell matrix. In most cases, direct interaction of cells and synthetic materials, polymers, glass or metals is not possible without the presence of an intermediate protein layer. [12, 119]

A wide variety of materials have been functionalised with a broad range of proteins, peptides and growth factors, such as fibronectin, laminin, collagen, fibrin and others, by using physical or chemical strategies [8-10]. This protein layer provides biochemical cues where cells can attach, adhere, proliferate and differentiate. However, the assembly of cells into tissues is a highly orchestrated set of events that requires time scales ranging from seconds to days or weeks and dimensions ranging from microns to centimetres, and it is clear that passive coatings cannot provide this dynamic microenvironment. [9]

The extracellular matrix is a complex network of proteoglycans and glycoproteins, including fibronectin, laminin, fibrin, elastin, collagen and others that provide a well-ordered environment which support cell proliferation, migration, survival and differentiation. Extracellular enzymes, mainly proteases, constantly reorder ECM; therefore, the natural niche of these cells is a highly dynamic environment.

Significant efforts have focused on engineering materials that recapitulate the characteristics of the ECM, such as the presentation of cell adhesive mo- 
tifs protected by enzymatic cleavable moieties [254], or photoactivable RGD peptides [14]. In both scenarios, cell behaviour can be controlled to a certain extent, obtaining as a result a sort of dynamic interface but still far away from the requirements for a true ECM substitute.

In this chapter, the use of Lactococcus lactis as a living biointerface [216] is presented. This bacterium has been genetically modified to express the FNIII $_{7-10}$ repeats of the human fibronectin, taking advantage of its low exopolysaccharide production, to make it accessible to the extracellular environment. Although with a low polysaccharide production, this strain exhibits the ability to develop stable biofilms [209] in the proper environment, so a stable monolayer between the synthetic material and the living cells can be produced.

The expressed fibronectin fragment contains the RGD adhesion and the PHSRN synergy motifs, both involved in the interaction with integrins, mainly through the $\alpha_{5} \beta_{1}$ integrin [201]. Integrins [11] are transmembrane receptors linked to cell adhesion, spreading, migration, proliferation and differentiation. [14]

\subsection{Materials and methods}

\section{Cloning}

A summary of the whole cloning protocol is as follows. First, the FNIII $_{7-10}$ fragment from the pET-15b-FNIII $7-10$ plasmid, kindly donated by Dr. Mercedes Costell from the Universitat de València, was amplified by PCR and subcloned downstream to GFP in the pGFP-C2 (Clontech) GFP-containing plasmid. The FNIII $_{7-10}$-GFP fragment was amplified via PCR and subcloned into the pT1NX lactococcal plasmid using proper restriction enzymes. Finally, competent $L$. lactis cells were prepared and transformed with the pT1NX-FNIII ${ }_{7-10}$-GFP plasmid. The protocol is detailed below.

The first step comprised the amplification of the FNIII $_{7-10}$ from the pET15bFNIII $_{7-10}$ plasmid [255] using PCR.

The following primers were used:

- F1 (with HindIII restriction site, lowercase)

5' -aagcttaCCATTGTCTCCACCAACAAAC

- R1 (with SalI restriction site, lowercase) 5' -gtcgacttaTTCTGTTCGGTAATTAATGGAAA 
The PCR product was subjected to electrophoresis in a $0.7 \%$ agarose gel in order to isolate the amplified DNA. This band was carefully cut from the gel under transilluminator UV light, isolating the DNA with the Illustra GFX DNA and gel band purification kit (GE Healthcare). Once purified, FNIII ${ }_{7-10}$ amplified fragment was sequentially digested with HindIII (New England Biolabs) and SalI (New England Biolabs) in order to generate sticky ends. The same restriction reaction was carried on the PGFP-C2 plasmid (Clontech). This E. coli plasmid contains a neomycin/kanamycin resistance gene, the GFP gene and a MCS downstream to GFP containing HindIII and SalI restriction sites, in frame with the GFP ORF (Figure 4.1).

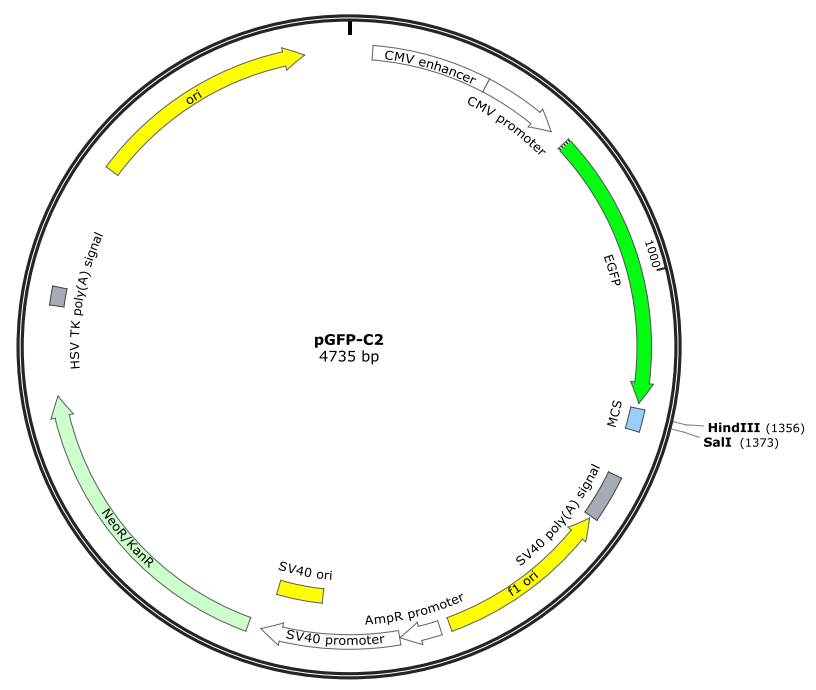

Figure 4.1 pGFP-C2 map. FNIII ${ }_{7-10}$ fragment was subcloned downstream to GFP using the HindIII and SalI restriction sites.

Once purified, both pGFP-C2 plasmid and FNIII $_{7-10}$ fragment were ligated using T4 ligase (New England Biolabs). The reaction mix was further purified using the Illustra GFX DNA and gel band purification kit (GE Healthcare).

Ligated and purificated product were used to transform $E$. coli NEB $5 \alpha$ strain (New England Biolabs) following manufacturer's protocol. A $50 \mu \mathrm{L}$ aliquot of frozen cells kept at $-80{ }^{\circ} \mathrm{C}$ was thawed on ice for 10 minutes. Then, $5 \mu \mathrm{L}$ of the purified ligation product was added to the competent bacteria and gently shaken while avoiding vortexing.

Competent bacteria were transformed by heat shock method in which the mix was left 30 minutes on ice followed by a 30-second heat-shock at $42{ }^{\circ} \mathrm{C}$, 
then placed on ice for 5 minutes. $950 \mu \mathrm{L}$ of super-optimal growth (SOC) medium (New England Biolabs) was immediately added to the reaction tube and incubated for 1 hour at $37^{\circ} \mathrm{C}$, while shaking the tube at $250 \mathrm{rpm}$.

$100 \mu \mathrm{L}$ of the resulting culture was spread in several LB-agar plates supplemented with $50 \mu \mathrm{g} / \mathrm{mL}$ kanamycin and left overnight at $37^{\circ} \mathrm{C}$, to select the kanamycin-resistant positive clones. Four of the grown colonies were picked up and cultured at $37^{\circ} \mathrm{C}$ for 18 hours in LB medium supplemented with 50 $\mu \mathrm{g} / \mathrm{mL}$ kanamycin.

Then, cultures were harvested at 10,000 g for 5 minutes, isolating and purifying the plasmidic DNA with the GenElute Five-minute miniprep kit from Sigma. To check the correct insertion of the FNIII $_{7-10}$ fragment into the pGFPC2 plasmid, the obtained DNA was consecutively digested with HindIII and SalI.

As shown in Figure 4.2, the enzymatic digestion of one of the clones (marked with the arrow) followed by electrophoretic separation in a $0.7 \%$ agarose gel showed two bands, one corresponding to the pGFP-C2 plasmid, with a size of $4.7 \mathrm{~kb}$, and the FNIII $_{7-10}$ fragment with a size of $1.1 \mathrm{~kb}$ (Figure 4.2)

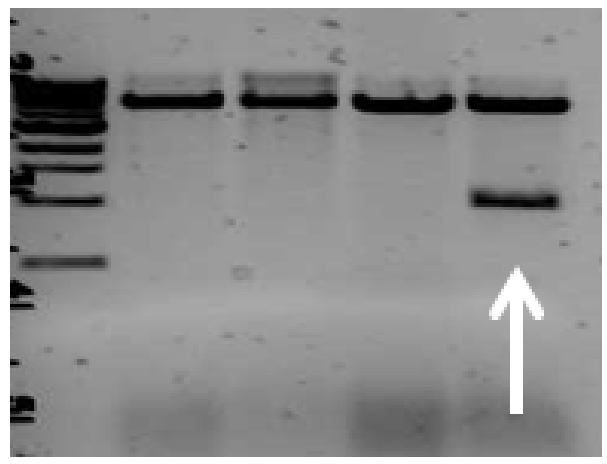

Figure 4.2 Electrophoresis of the digested pGFP-C2 plasmid with HindIII and Sall showing two bands, corresponding to the backbone vector and the insert, in the fourth lane (white arrow).

The E. coli strain transformed with the positive clone was grown in LB medium supplemented with $50 \mu \mathrm{g} / \mathrm{mL}$ of kanamycin, overnight, at $37{ }^{\circ} \mathrm{C}$. Plasmid DNA was then purified using the GenElute Five-minute miniprep kit (Sigma). This DNA was used to amplify the whole FNIII $7-10$-GFP fragment by PCR. To do so, the following primers were used: 
- F1 (with NgomIV restriction site in lowercase)

5' -gccggcATGGGTAAAGGAGAAGAACTTT

- R1 (without restriction sites)

5' -TTCTGTTCGGTAATTAATGGAAA

The resulting PCR product, with a size of $1.7 \mathrm{~kb}$, was subjected to a $0.7 \%$ agarose gel electrophoresis and purified from the gel (Figure 4.3).

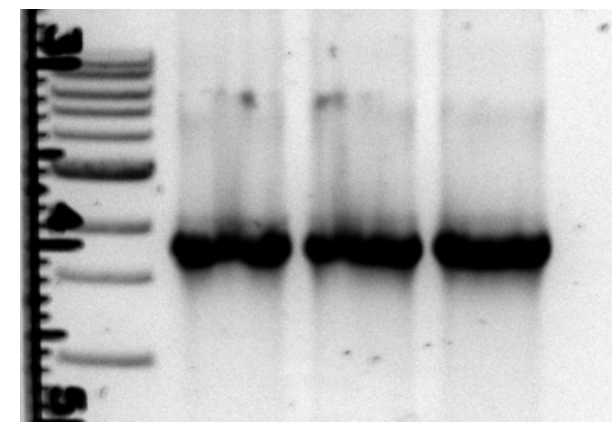

Figure 4.3 Agarose electrophoresis of the amplified PCR product, showing three different lanes with the same product, with a molecular size of $1.7 \mathrm{~kb}$

This fragment contains the FNIII $7-10$ gene downstream to GFP, with an NgoMIV restriction site in $5^{\prime}$. The Lactococcal pT1NX plasid was the chosen vector to transform $L$. lactis. This vector contains the constitutive P1 promoter, the ermM erythromycin resistance gene, the secretion peptide Usp45 and the Staphylococcus aureus protein A (SpA) spaX gene to covalently bind the fusion protein into the $L$. lactis peptidoglycan layer.

A multiple cloning site containing BamHI and NgoMIV, amongst other restriction sequences, is located between usp 45 and spaX, in frame with the usp45-spaX ORF (see Figure 4.4).

pT1NX was amplified from the bacterial pT1NX-containing strain L. lactis MG1363-pT1NX. The amplification procedure involved the overnight culture of this strain in M17 medium supplemented with $10 \mu \mathrm{g} / \mathrm{mL}$ erythromycin and 0.5 $\% \mathrm{v} / \mathrm{v}$ glucose. Plasmidic DNA was isolated using a combination of a manual protocol and the Five-minute miniprep kit (Sigma).

Cloning of FNIII $7-10$-GFP into pT1NX was performed by linearizing pT1NX with BamHI (New England Biolabs), obtaining a linear DNA with two BamHI sticky ends.

Then, the Klenow fragment of the DNA polymerase I (New England Biolabs) was used to convert the sticky ends to blunt ends. The resulting pT1NX plasmid 


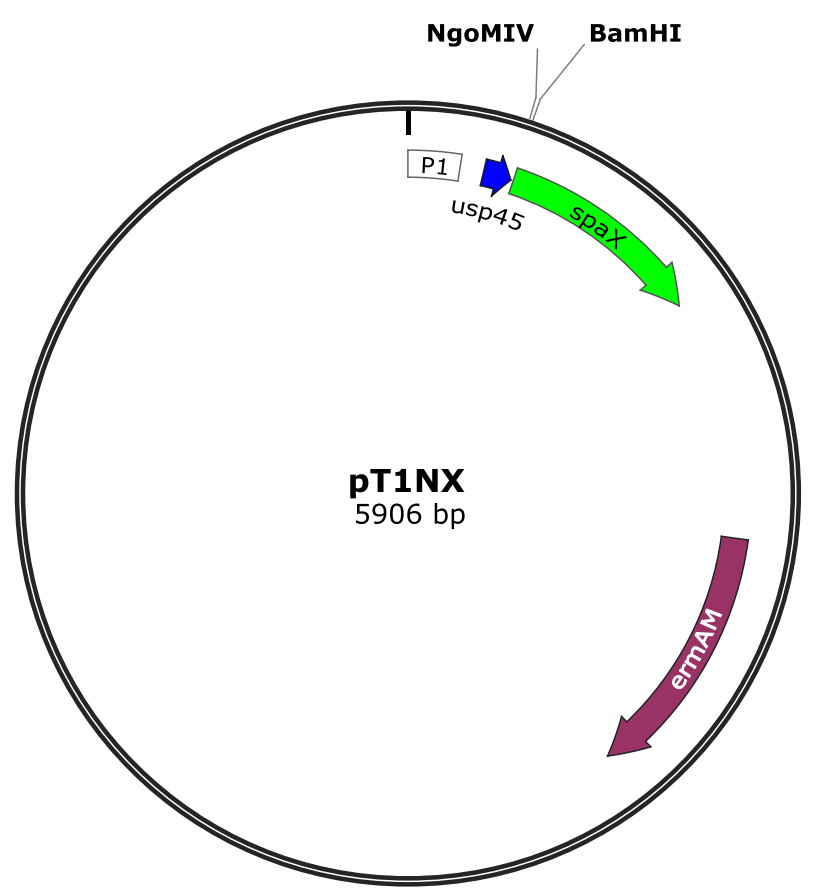

Figure 4.4 pT1NX plasmid map, showing the NgoMIV and BamHI restriction sites used in the cloning protocol.

with blunt ends and an NgoMIV restriction site, along the FNIII $7-10$-GFP fragment (carrying an NgoMIV restriction site in $5^{\prime}$ ) were digested with NgoMIV, in separate reactions.

NgoMIV restriction products were purified using the Illustra GFX DNA and gel band purification kit (GE Healthcare) and mixed in a 5:1 (insert:plasmid) ratio, joining the DNA chains with T4 ligase (New England Biolabs). Reaction product of ligation was purified with the kit and used to transform electrocompetent L.lactis.

Grown colonies were screened to check the presence of the correct clone. To do so, 25 colonies were picked up and cultured in $5 \mathrm{~mL}$ of M17 medium supplemented with $0.5 \% \mathrm{v} / \mathrm{v}$ glucose and $10 \mu \mathrm{g} / \mathrm{mL}$ erythromycin. $1 \mu \mathrm{L}$ of the resulting cultures were subjected PCR with the same primers used to amplify the FNIII $_{7-10}$-GFP sequence. From these PCR, three positive clones were detected and sequenced to ensure the correct in-frame insertion of the FNIII ${ }_{7-10}$-GFP fragment into the pT1NX plasmid (Figure 4.5) 


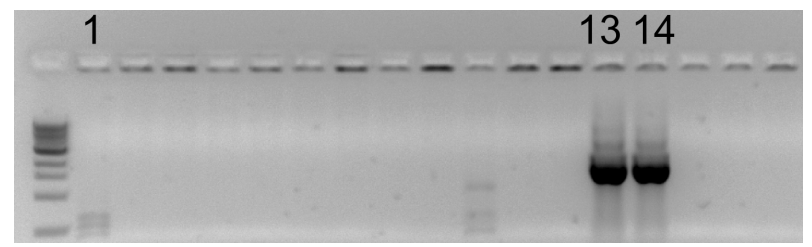

Figure 4.5 Agarose gel electrophoresis showing two of the three positive clones carrying the pT1NX-FNIII $7-10$-GFP plasmid. After sequencing, clone 14 was found to carry the inserted fragment in frame. This is the clone used in this work, hereinafter L. lactis-FN. The L. lactis strain containing the empty pT1NX plasmid is stated as L. lactis-empty.

\section{ELISA}

An enzyme-linked immunosorbent assay (ELISA) was used to quantify the biological activity of the exposed FNIII $_{7-10}$ fragment displayed on the L. lactis surface. $3 \mathrm{~mL}$ from a $24 \mathrm{~h}$ standing culture of L. lactis-FN and L. lactis-empty grown in sterile GM17-E, with a bacterial density of $10^{7} \mathrm{cfu} / \mathrm{mL}$, were filtered through a porous polycarbonate membrane with a mean pore size of $0.8 \mu \mathrm{m}$ (Isopore, Millipore).

The membrane was twice washed with DPBS ++ to remove the non-trapped bacterial cells. Another set of membranes was coated with 20, 10, 5 and 2.5 $\mu \mathrm{g} / \mathrm{mL}$ of human plasma fibronectin (Sigma) in PBS++, for $1 \mathrm{~h}$ at RT, and washed twice with PBS++. Uncoated membranes were used to assess the absence of any background signal in the polycarbonate membranes.

Membranes were blocked with $1 \%$ bovine serum albumin (Sigma) in PBS++ for $1 \mathrm{~h}$ at RT to reduce the background signal, and incubated for $1 \mathrm{~h}$ at $37^{\circ} \mathrm{C}$ with monoclonal mouse HFN7.1 anti-fibronectin antibody at 1:4000 from a 32 $\mu \mathrm{g} / \mathrm{mL}$ antibody stock. After that, samples were washed twice with PBS++ / Tween $20(0.5 \% \mathrm{v} / \mathrm{v})$ and incubated with alkaline phosphatase-conjugated donkey anti-mouse secondary antibody (Jackson Immunoresearch) for $1 \mathrm{~h}$ at RT.

Samples were washed again twice with PBS++ / Tween $20(0.5 \% \mathrm{v} / \mathrm{v})$, followed by the addition of $400 \mu \mathrm{L}$ of 4-methylumbelliferyl phosphate $(0.6$ $\mathrm{mM}$, Sigma) in borax $/ \mathrm{NaOH} \mathrm{pH} 10$ buffer. After a $45 \mathrm{~min}$ incubation at $37^{\circ} \mathrm{C}$, the supernatant was transferred to a P96 multiwell plate. Fluorescence was measured at 365/460 nm (excitation/emission wavelengths) with a PerkinElmer Victor3 Multilabel Counter (Perkin Elmer).

The same protocol was used to assess the influence of the antibiotic-containing 
medium used to check whether the biological activity of the expressed FNIII $7-10$ fragment would be altered. In this case, polycarbonate membranes with trapped bacteria were transferred to 24 well plates and incubated for $24 \mathrm{~h}$, in a humidified atmosphere at $37{ }^{\circ} \mathrm{C}$ with $5 \% \mathrm{CO}_{2}$, with the corresponding medium, namely DMEM, DMEM supplemented with $1 \% \mathrm{P} / \mathrm{S}$ and DMEM supplemented with $10 \mu \mathrm{g} / \mathrm{mL}$ tetracycline.

\section{Detection of FNIII ${ }_{7-10}$ fragment by Western blot}

From an overnight culture of L. lactis-FN strain, cells corresponding to $10^{9} \mathrm{cfu}$ were washed and resuspended in $50 \mu \mathrm{L}$ of lysis buffer composed of Tris- $\mathrm{HCl}$ $50 \mathrm{mM}, \mathrm{pH} 7.5$, with $0.5 \mathrm{M}$ sucrose and $50 \mathrm{mg} / \mathrm{mL}$ lysozyme. The bacterial suspension was incubated $2 \mathrm{~h}$ at $37^{\circ} \mathrm{C}$ in and centrifuged at $16,000 \mathrm{~g}$ for 5 minutes. Supernatant and pellet were separated and resuspended in $50 \mu \mathrm{L}$ of Laemmli loading buffer, denatured at $100^{\circ} \mathrm{C}$ for 5 minutes and separated by $10 \%$ SDS-polyacrylamide gel electrophoresis (PAGE).

Protein were then transferred to a positively charged PVDF membrane (GE Healthcare) using a BioRad semidry transfer system cell, followed by immersion in $5 \%$ skimmed milk in PBS as a blocking buffer. The blocking step lasted $1 \mathrm{~h}$ at room temperature.

Membrane was then incubated with mouse mAb1937 antibody (Merck Millipore), diluted 1:1000 in a $2 \%$ skimmed milk in PBS / Tween $200.5 \%$ solution. This antibody is directed against the 8th type III domain of the human fibronectin. Incubation lasted 2 hours at room temperature. The primary antibody was washed several times with PBS / Tween $200.5 \%$ and incubated $2 \mathrm{~h}$ at room temperature with rabbit anti-mouse horseradish peroxidase-linked antibody, diluted 1:50,000 in $2 \%$ skimmed milk / PBS / Tween $200.5 \%$.

After several washes with PBS / Tween $200.5 \%$, immunoreactive bands were visualized with the ECL Plus kit (GE Healthcare) in a photographic film.

\section{Scanning electron microscopy}

Freshly prepared biofilms were washed twice with sterile ultrapure water, to remove traces of the culture medium, and then were fixed with $2.5 \%$ glutaraldehyde in phosphate buffer (PB) $0.1 \mathrm{M}, \mathrm{pH} 7.3$, for $14 \mathrm{~h}$ at $4{ }^{\circ} \mathrm{C}$.

Fixed biofilms were twice washed with $\mathrm{PB}$ and dehydrated in ethanol/water mixtures of $50 \%, 70 \%, 80 \%, 90 \%$ and $100 \%$, repeating the $100 \%$ step three times, for 10 minutes each step. Finally, samples were dried using hexamethyldisilazane (Sigma) and air-dried for 10 minutes. [256] Prior to imaging, 
samples were sputter coated with a $1 \mathrm{~nm}$ layer of platinum and imaged in a Zeiss Ultra55 Field Emission SEM (Zeiss Microscopy, Germany) with an electron gun acceleration voltage of $1 \mathrm{kV}$.

\section{Atomic force microscopy}

$10 \mathrm{~mL}$ of L. lactis-FN and L. lactis-empty stationary-phase cultures were centrifuged at 3,000 $\mathrm{g}$ for 10 minutes and twice washed with $100 \mathrm{mM}$ sodium acetate buffer (Sigma) with a pH of 4.8. The resulting pellet was resuspended in the same volume with the same buffer and filtered through a porous hydrophilic polycarbonate membrane (Isopore, Merck-Millipore) with an average pore size of $0.8 \mu \mathrm{m}$.

Untrapped bacteria were gently washed with the sodium acetate buffer. Membranes with trapped bacteria were kept in a P24 multiwell plate while avoiding dewetting [257]. These samples were imaged in a Multimode AFM fitted with a NanoScope IIIa controller from Veeco (Manchester, UK) in QNM PeakForce mode. Silicon nitride cantilevers, with a force constant of $0.7 \mathrm{~N} / \mathrm{m}$ were used. Drive amplitude was set to $100 \mathrm{mV}$ and amplitude setpoint to 250 $\mathrm{mV}$.

\section{Confocal laser scanning microscopy}

Biofilms from viability assays, after its quantification in a standard fluorescence microscopy, were mounted with Fluorsave mounting medium and imaged in a Leica MI8 confocal microscope, using a $63 \times$ oil immersion objective. 39 z-planes were scanned and the final image was reconstructed in Fiji - Image J using the $3 \mathrm{D}$ viewer plugin.

\section{Bacterial viability}

To assess bacterial viability, samples were twice washed with sterile $\mathrm{NaCl} 0.85 \%$ solution to remove traces of the growth medium. Then was added a mixture of SYTO9 $(5 \mu \mathrm{M})$ and propidium iodide $(30 \mu \mathrm{M})$ in $\mathrm{NaCl} 0.85 \%$, incubating the biofilms for 15 minutes at room temperature, in absence of light. Afterwards, biofilms were washed twice with $\mathrm{NaCl} 0.85 \%$ to remove the incubation medium. Samples were mounted using Fluorsave medium, kept at $4{ }^{\circ} \mathrm{C}$ for 15 minutes to allow its solidification and imaged in a Nikon Eclipse 80i epifluorescence microscope. 


\section{Image analysis}

Four different fields for each sample were captured using a Nikon Eclipse 80i fluorescence microscope, at 40× magnification, in the green (FITC) and red (Cy3) channels. Both channels were treated separately. Images, in a RGB BMP format, were first converted to 8-bit grayscale format and thresholded using the Otsu algorithm to create binary masks of the stained bacteria. Total area was calculated using the Particle Analysis command of ImageJ.

Since it was not possible to resolve individual bacteria, and taking in account that the only fluorescent pixels present in the images were due to bacterial fluorescence, viability was calculated as the ratio between areas of the stained pixels in the green channel (viable bacteria) and areas of the stained pixels in the merged green and red channels (viable plus non-viable bacteria). Results were averaged and expressed as mean \pm SD.

\subsection{Results}

\section{Membrane localisation of the FNIII $_{7-10}$-GFP fragment}

Expression and membrane localisation of FNIII $_{7-10}$ fused to GFP in the L. lactis-FNIII $7-10$-GFP modified strain (hereinafter L. lactis-FN) was confirmed by several methods. The first confirmation came from the sequencing of one of the clones obtained after the electrotransformation. Sequencing confirmed the in-frame inclusion of a $1.8 \mathrm{~kb}$ fragment corresponding to the $\mathrm{FNIII}_{7-10^{-}}$GFP sequence amplified from the pGFP-C2-FNIII ${ }_{7-10}$ plasmid.

The combination of Usp45 and Staphylococcus aureus protein A anchor signals efficiently promoted the localization of FNIII $_{7-10}$ to the bacterial membrane, as confirmed by fluorescence microscopy. L. lactis-FN cells showed rings delimiting the bacterial perimeter (Figure 4.6).

Further confirmation of the FNIII $7-10$-GFP membrane anchoring was obtained with a Western blot analysis. As described in the materials and methods section, a sample volume of the L. lactis-FN culture was lysed with lysozyme, analyzing the membrane and cytoplasmic fractions with Western blot. The fraction corresponding to the membrane showed presence of the fragment, without detectable FNIII $7-10$ signal in the cytoplasmic fraction (Figure 4.6).

This result suggests the adequate anchoring mechanism provided by the Staphylococcus aureus protein A featured in the pT1NX plasmid, and that a large fusion protein such as FNIII ${ }_{7-10}$-GFP can be successfully expressed and promoted to this localization, without affecting L. lactis viability. 


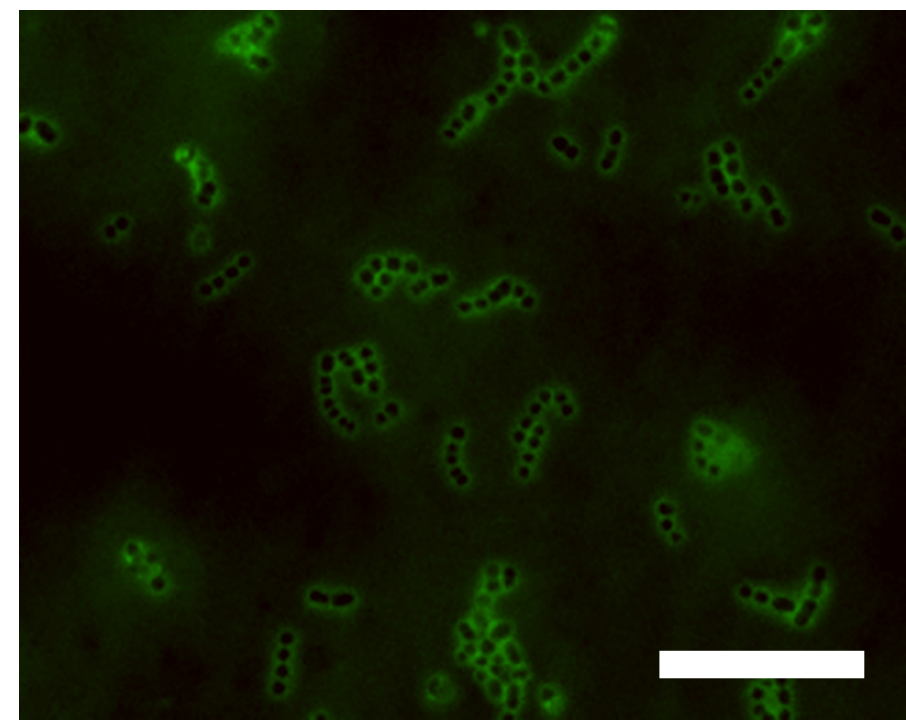

Figure 4.6 Fluorescence image of a stationary-phase L. lactis-FN culture grown overnight in M17 medium. Scale bar size is $10 \mu \mathrm{m}$

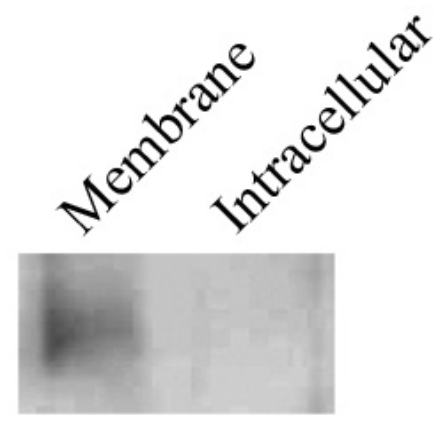

Figure 4.7 Western blot analysis of the membrane and intracellular fractions of L. lactis. FNIII ${ }_{7-10}$ fragment is only found in the membrane fraction, with no detectable levels in the intracellular pool.

\section{Biological activity of the FNIII $_{7-10}$ fragment}

The amount of expressed FNIII ${ }_{7-10}$ fragment was assessed with a Western blot analysis. Three different volumes of 25, 50 and $75 \mu \mathrm{L}$ were taken from an $L$. lactis-FN culture in stationary phase, lysed and subjected to a $10 \%$ SDS-PAGE gel electrophoresis (Figure 4.7). $75 \mu \mathrm{L}$ of L. lactis-empty was used as negative 
control. Three different amounts of a purified FNIII $_{7-10}$ fragment, 250, 500 and $750 \mathrm{ng}$ were used to make a calibration curve. Figure 4.8 shows that the amount of FNIII $\mathrm{F}_{7-10}$ increases monotonically with the sample volume.

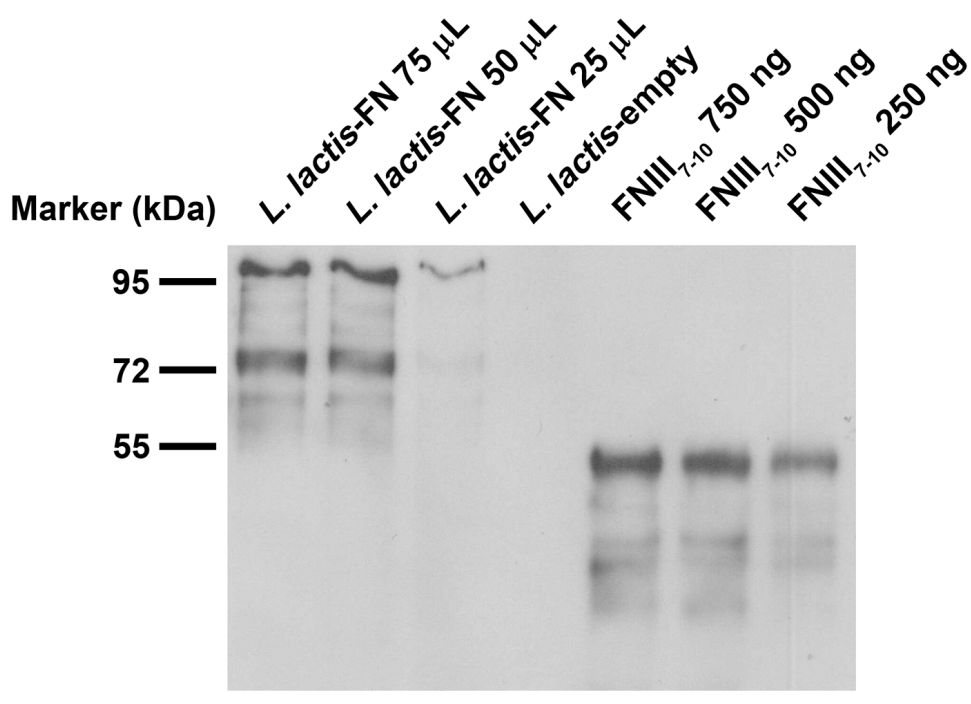

Figure 4.8 Representative membrane used in the quantification of the expressed amount of FNIII $_{7-10}$ in the bacterial membrane.

Bands from the cultured bacteria showed higher molecular mass values due to their structure, since FNIII ${ }_{7-10}$ is fused to GFP, Usp45 and SpA. The three bands on the right, used as standards, showed lower molecular weight, since they proceed from purified FNIII ${ }_{7-10}$ fragment without GFP or signal or anchoring motifs. The negative L. lactis-empty control showed undetectable amounts of FN.

The amount of the FNIII $_{7-10}$ fragment was quantified using the calibration curve calculated from the standards by band densitometry analysis, finding a linear relationship between band density and protein amount.

Based on this, the approximate density of FN fragment per unit volume of bacteria in a culture in stationary phase was estimated to be around 980 $\mathrm{ng} / \mathrm{mL}$, which corresponds to approximately $980 \mathrm{ng} / 10^{9} \mathrm{cfu}$, roughly $7 \cdot 10^{4}$ FNIII $_{7-10}$-GFP molecules per cell assuming that the fragment has a molecular weight of $83.1 \mathrm{kDa}$.

These values depict the total FNIII $_{7-10}$ mass expressed by the bacteria, but considering its role in interacting with mammalian cells, is also important to 


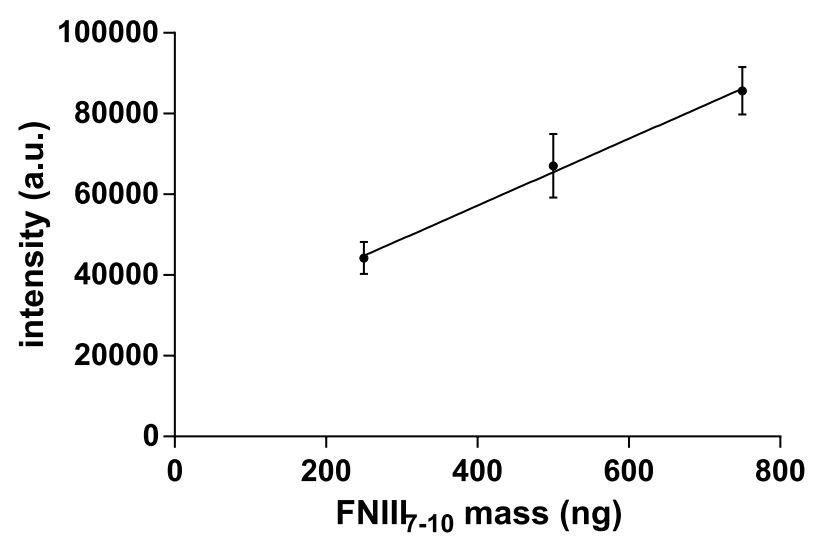

Figure 4.9 Linear regression analysis of the control bands used in the quantification of FNIII $_{7-10}$ expressed by the L. lactis-FN strain.

assess the FNIII $_{7-10}$ availability and biological activity after its immobilization on a synthetic substrate. This was assessed through an enzyme-linked immunosorbent assay (ELISA).

A bacterial culture grown until stationary phase was washed to remove traces of the culture medium and filtered through a porous polycarbonate membrane with a mean pore size of $0.8 \mu \mathrm{m}$, washing the membranes after filtering to remove unattached bacteria.

Membranes were blocked with BSA to reduce background signal and hybridized with HFN7.1, a monoclonal antibody directed against the flexible linker between the $\mathrm{III}_{9}$ and $\mathrm{III}_{10}$ repeats of the expressed fragment. ELISA is a well-established method to probe structural or conformational changes in adsorbed proteins [258, 259].

Identical polycarbonate membranes were coated with solutions of human plasma fibronectin at 20,10,5 and $2.5 \mu \mathrm{g} / \mathrm{mL}$. Results showed that the FNIII $_{7-10}$ fragment displayed on the L. lactis-FN has a similar biological activity compared to the membranes coated with a $20 \mu \mathrm{g} / \mathrm{mL}$ fibronectin solution.

Since tetracycline-containing medium was be used to keep a stable biofilm over the surface while cultures were performed with mammalian cells, another ELISA was performed to assess tetracycline influence on the biological activity of the biofilms. The rationale behind this assay is that tetracycline might inhibit bacterial protein expression due to its action mechanism.

Three different conditions were tested, a fresh biofilm made in M17 medium, a biofilm incubated for one day in DMEM supplemented with tetracycline 


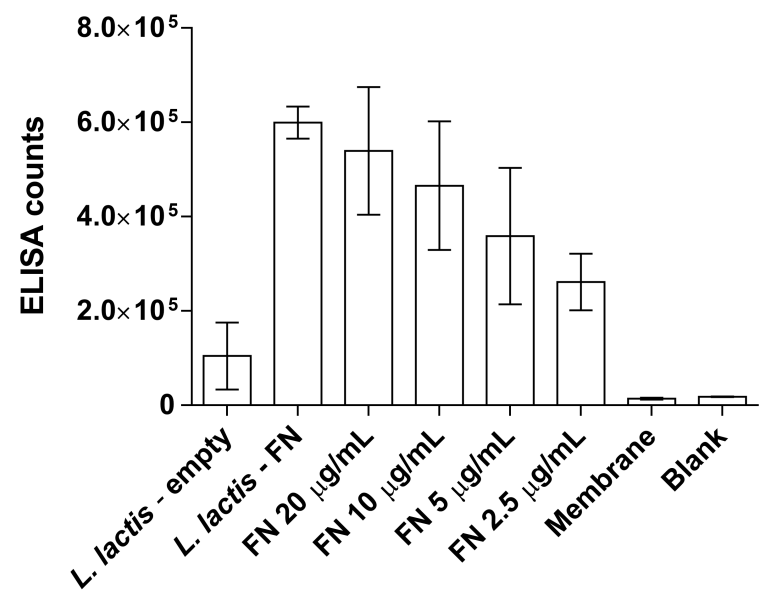

Figure 4.10 Comparable activity values of the membrane-expressed $\mathrm{FNIII}_{7-10}$ fragment in L. lactis-FN and the membrane coated with FN from a $20 \mu \mathrm{g} / \mathrm{mL}$ solution. Both L. lactis-empty biofilm and uncoated membranes showed negligible biological activity. Data shown as mean $\pm \mathrm{SD}, \mathrm{N} \geq 9$

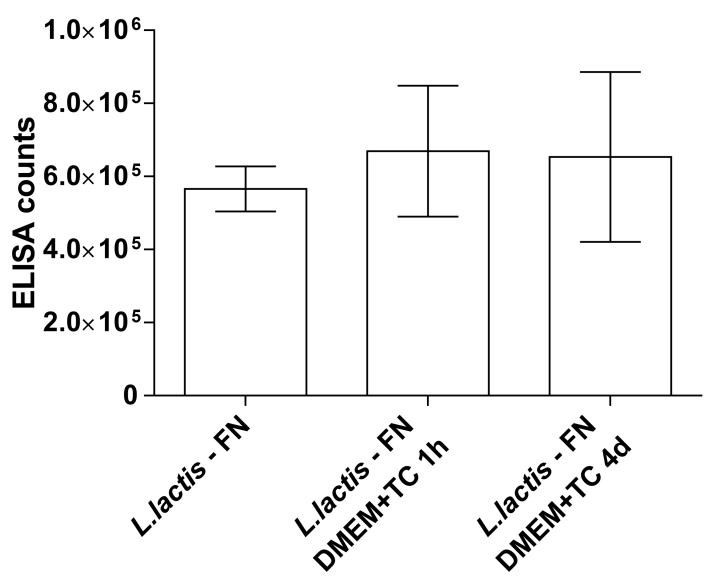

Figure 4.11 ELISA of bacterial biofilms (L. lactis-FN) produced from fresh GM17E medium and incubated in DMEM supplemented with tetracycline $10 \mu \mathrm{g} / \mathrm{mL}$ for 1 and 4 days respectively. ANOVA showed no statistically significant differences between samples. Data presented as mean $\pm \mathrm{SD}, \mathrm{N} \geq 9$ 
at $10 \mu \mathrm{g} / \mathrm{mL}$, and a biofilm incubated in the same conditions for 4 days. Results showed a similar biological activity, so we can dismiss any influence of tetracycline on the $\mathrm{FNIII}_{7-10}$ activity.

This is an expected result, since the FNIII $_{7-10}$ fragment is constitutively expressed in the biofilm formation phase and there is no new protein synthesis after biofilm development.

\section{Biofilm morphology}
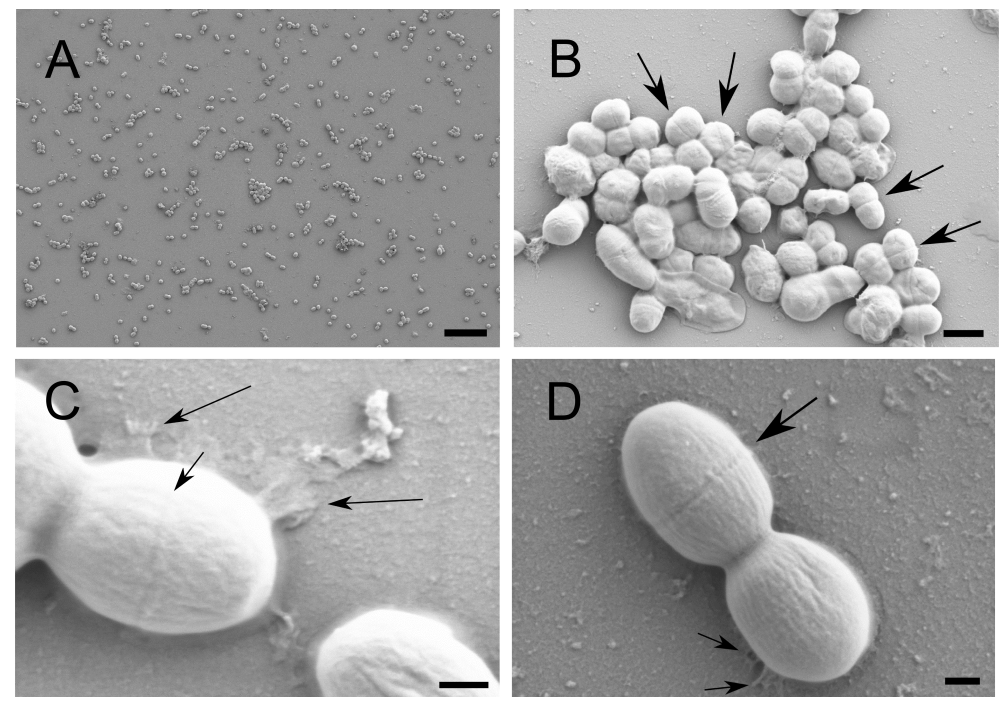

Figure 4.12 Low-magnification FESEM image of an L. lactis-FN (a and c) and L.lactis-empty (b and d) biofilm. a) bacterial clusters appear strongly attached to the surface, creating a scattered non-continuous layer; b) magnified view of a bacterial cluster. Cells appear joined through a thin exopolysaccharide layer. In some cells, the glycocalyx, the region where the peptidoglycan layer is synthesized, is marked by black arrows; c) and d) close-up views of individual diplococcus showing the glycocalyx and some adhesion fimbriae, proving the presence of bacterial-secreted extracellular structures that provide an irreversible attachment to the surface. Images of a 24-hour-old biofilm developed on glass. Scale bar sizes are $10 \mu \mathrm{m}, 1 \mu \mathrm{m}, 100 \mathrm{~nm}$ and $200 \mathrm{~nm}$ respectively.

Biofilm morphology was assessed through scanning electron microscopy (SEM), atomic force microscopy (AFM), fluorescence microscopy and confocal laser scanning microscopy (CLSM) in order to check whether the presence of the expressed fragment would affect the shape or the superficial appearance of 

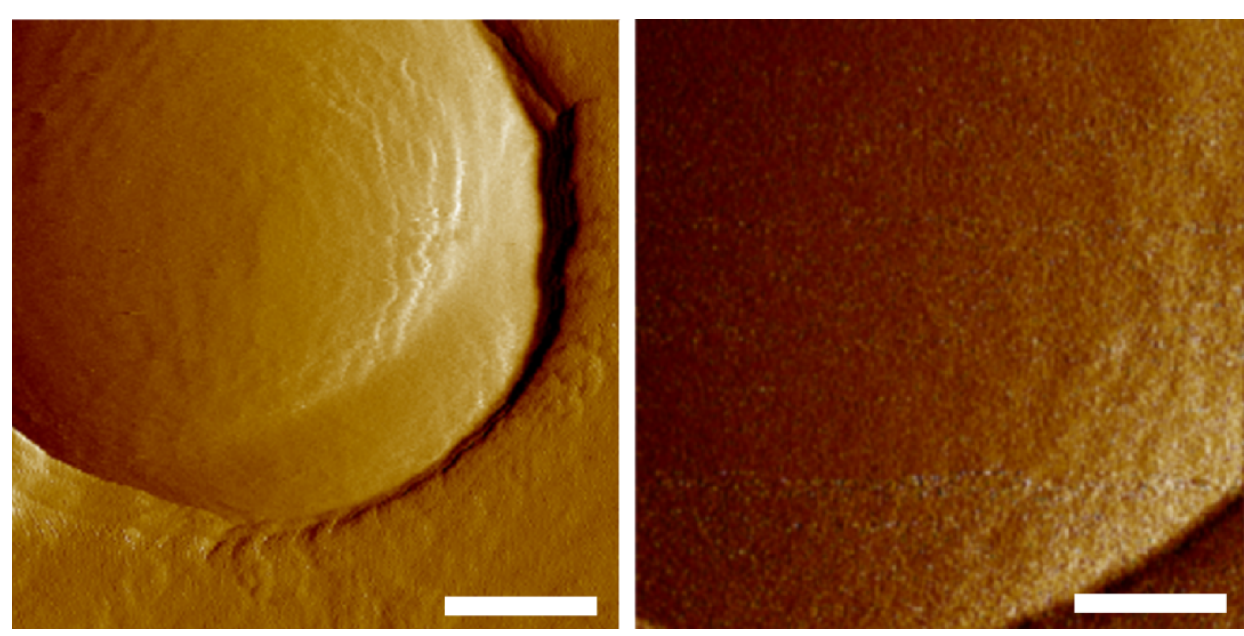

Figure 4.13 AFM images of the polar area of an L. lactis-emtpy (left) and $L$. lactis-FN cell (right). These peak-force error images were taken in QNM PeakForce mode. Both surfaces have a smooth appearance, without defining characteristics, and almost identical in both strains. Scale bar size is $250 \mathrm{~nm}$ (left) and $125 \mathrm{~nm}$ (right)

the bacterial cell wall and the biofilm macrostructure.

SEM images were taken from an L. lactis-FN and a L. lactis-empty biofilm, showing a non-continuous monolayer of attached bacteria with a morphology very similar to the one found in the fluorescence images (Figure 4.12).

High-magnification images of the L. lactis-empty strain showed no morphological differences at single-cell level between both strains. In the lowmagnification images, L. lactis-FN strain appears to grow in longer chains compared to the L. lactis-empty strain, where only diplococcus of at most six or seven cells appear joined.

AFM images from bacteria trapped in a porous polycarbonate membrane were also taken. Atomic force microscopy allows higher magnification values than SEM, so it was possible to image membrane close-ups. No significant morphological features were detected, in line with the SEM images. Surfaces showed a smooth appearance with no noticeable differences between strains.

\section{Biofilm viability}

Viability and stability of the living interface on the material substrate was also studied. First step was to check bacterial viability after the biofilm is established, 
using the BacLight (Invitrogen) viability kit. As described in section 3.8, freshly prepared biofilms were incubated with this kit, which contains two different stains, a green, permeant one and a red, non-permeant one. These stains are able to discriminate between viable bacteria, with uncompromised membrane integrity, and non-viable bacteria, stained in green and red respectively.
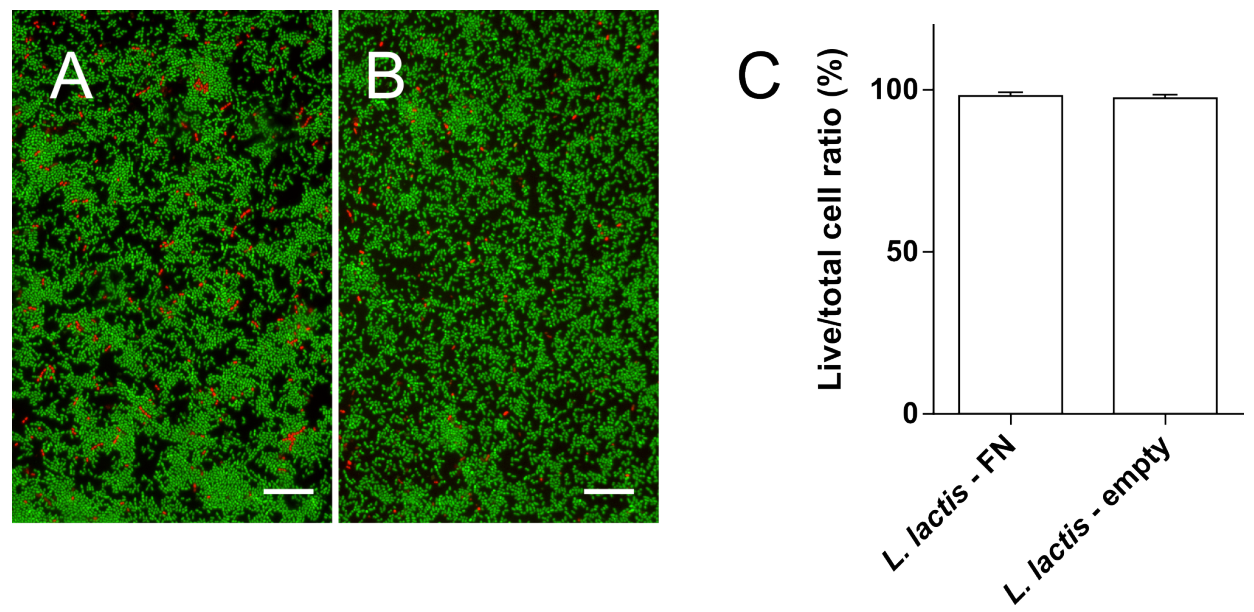

Figure 4.14 Bacterial viability in a 24-hour biofilm. a) for L. lactis-FN biofilm, viability is $98.1 \pm 1.1 \%$; b) for L. lactis-emtpy biofilm, with a viability of $97.1 \pm$ $1.1 \%$; c) calculated viability by image analysis, from at least five different fields taken at $40 \times$. Data is shown as mean $\pm \mathrm{SD}, \mathrm{N}=4$, scale bar size is $20 \mu \mathrm{m}$. ANOVA showed no statistically significant differences between strains

In the Figure 4.14, viability results of 24-hour biofilms of both strains grown in GM17-E are shown. Cells were washed and its viability was tested using the BacLight live/dead kit. No statistically significant differences between strains were found. This fact suggests that $L$. lactis is able to synthesize and promote the FNIII $_{7-10}$-GFP fragment to its membrane while keeping its viability.

Figure 4.15 shows the 3D reconstruction obtained with a confocal laser scanning microscope of a maximum-density biofilm developed over glass and subjected to a viability staining; non-viable cells appear in red and viable cells in green. Bacterial cells appear as an almost flat biofilm.

Biofilms used in the Figure 4.16 were produced by pouring $1000 \mu \mathrm{L}$ of an exponentially growing culture in P24 multiwell plates. Lower density biofilms were successfully produced using lower volumes, namely 300, 500 and $700 \mu \mathrm{L}$, using the $1000 \mu \mathrm{L}$ biofilm as the one maximum density. Viability assessment on these biofilms was also performed, with identical results compared to the 


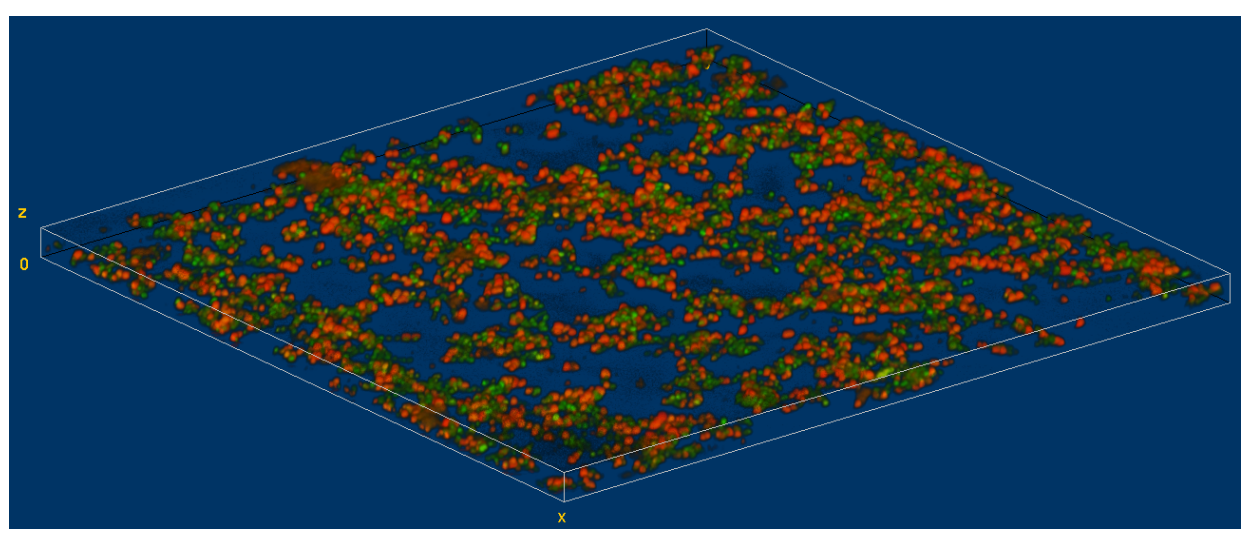

Figure 4.15 3D reconstruction of a 39-slice stack of a SYTO9 and propidium iodide-stained biofilm. Bounding box size is 116.4 x 116.4 x $7.8 \mu \mathrm{m}$. Since both strains were able to develop biofilms and taking into account that these biofilms display remarkably high viability values, an experiment was performed to determine whether different areal densities could be obtained

maximum density ones, that is to say higher than $97 \%$ for the two assessed strains. Our hypothesis was confirmed since we obtained different coverage percentages, and those percentages were directly related to the initial culture volume.

\section{Biofilm stability}

Biofilm stability of the living interface developed on the material surface is discussed in this section. This strain, once the biofilm has been established, is able to proliferate as long as there is a sufficient supply of nutrients, mainly glucose or other suitable carbon source. As a result, there is a production of $\mathrm{L}$ lactic acid from from homolactic fermentation of glucose that leads to a decrease in the $\mathrm{pH}$ of the culture medium up to $\mathrm{pH} \approx 4.5$, seriously compromising the viability of the co-cultured mammalian cells.

Therefore, it is imperative to minimize the metabolic activity of L. lactis without affecting their viability. We found that tetracycline used at low concentrations, $10 \mu \mathrm{g} / \mathrm{mL}$, is enough to inhibit bacterial replication without impacting mammalian cell metabolism [260, 261]. Tetracycline is a broad-spectrum bacteriostatic antibiotic that binds to the $30 \mathrm{~S}$ subunit of the bacterial ribosome, inhibiting the protein synthesis by blocking the attachment of the charged aminoacyl-tRNA to the ribosomal A site. [262] 

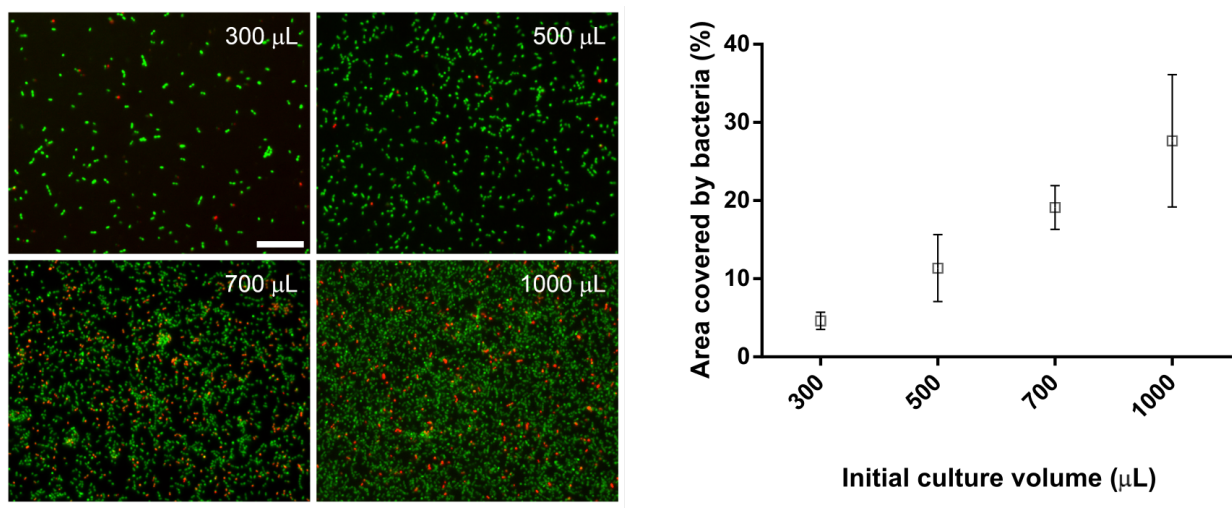

Figure 4.16 Fluorescence image of biofilms obtained from different starting culture volumes. Images from the L. lactis-FN biofilm, although both strains showed an almost identical areal density and viability. Viability was nearly identical to the one calculated in the previous figure in both strains. There is a linear correlation between both variables, with a maximum of $27 \%$ coverage from an initial volume of $1000 \mu \mathrm{L}$. Data shown as mean $\pm \mathrm{SD}, \mathrm{N}=6$. Scale bar size is 20 $\mu \mathrm{m}$.

Although other antibiotics were considered, mainly penicillin-streptomycin because it is routinely used in cell biology, tetracycline is preferred due to its mechanism of action. Instead of inhibiting protein synthesis, which does not affect the membrane integrity, the action mechanism of penicillin involves the inhibition of the synthesis of new crosslinks between peptidoglycans inhibiting the responsible enzyme of this process, DD-transpeptidase.

If we consider that the cell wall is subjected to a constant reorganization state that involves hydrolysis and transpeptidation, inhibition of this last step will eventually lead to the breakdown of the peptidoglycan layer, leaving as a result a cell without the outer cell wall - a protoplast, which lacks the ability to adhere to any surface as lacks all the components required to develop a stable biofilm, primarily exopolysaccharides and adhesins. Another harmful effect is the loss of the FNIII $_{7-10}$ fragment, which is covalently linked to the peptidoglycan layer.

Tetracycline seemed to control the bacterial metabolism more effectively than penicillin-streptomycin. Biofilm stability and viability was assessed in mammalian cell culture medium (DMEM) supplemented with tetracycline and penicillin-streptomycin for up to 4 days, the minimum time needed for myogenic differentiation. Three time points were selected, 1, 2 and 4 days. The 
experiment was conducted by preparing fresh biofilms in GM17 and changing the medium to high-glucose DMEM ( $4.5 \mathrm{~g} / \mathrm{L})$ without antibiotics, supplemented with $10 \mu \mathrm{g} / \mathrm{mL}$ tetracycline or $1 \%$ penicillin-streptomycin $(100 \mathrm{U} / \mathrm{mL})$, and incubating the samples at $30{ }^{\circ} \mathrm{C}$ and $37^{\circ} \mathrm{C}$ in a humidified atmosphere with 5 $\% \mathrm{CO}_{2}$.

Viability was tested at the selected time points tested using the Invitrogen BacLight kit (section 3.8). Overall viability values seems to be independent of the used antibiotic, at either 30 or $37^{\circ} \mathrm{C}$. The viability value for biofilms incubated at $30{ }^{\circ} \mathrm{C}$ was $78.1 \pm 5.2 \%$, while for $37^{\circ} \mathrm{C}$ was $52.4 \pm 5.6 \%$. This decrease could be attributed to the temperature increase, since there not seems to be influence of the strain, incubation time or antibiotic, and the optimal growth temperature of L.lactis is $30^{\circ} \mathrm{C}$.

An unpaired Student's t test performed over the $30^{\circ} \mathrm{C}$ and $37^{\circ} \mathrm{C}$ overall mean values showed statistically significant differences with $\mathrm{p}=0.0001$. Nevertheless, since mammalian cells are routinely cultured at $37^{\circ} \mathrm{C}$, biofilm viability seems good enough for our purposes.

Biofilms treated with penicillin-streptomycin did not showed viability losses may be attributed to the mechanism of action of streptomycin, identical to tetracycline. It may explain why viability is almost the same in all the assessed time points and antibiotics. Streptomycin inhibits bacterial metabolism, so no ATP is newly synthesized and enzymes like DD-transpeptidase, needed for the cell wall reorganization process, are effectively inhibited, keeping the cell wall as-is.
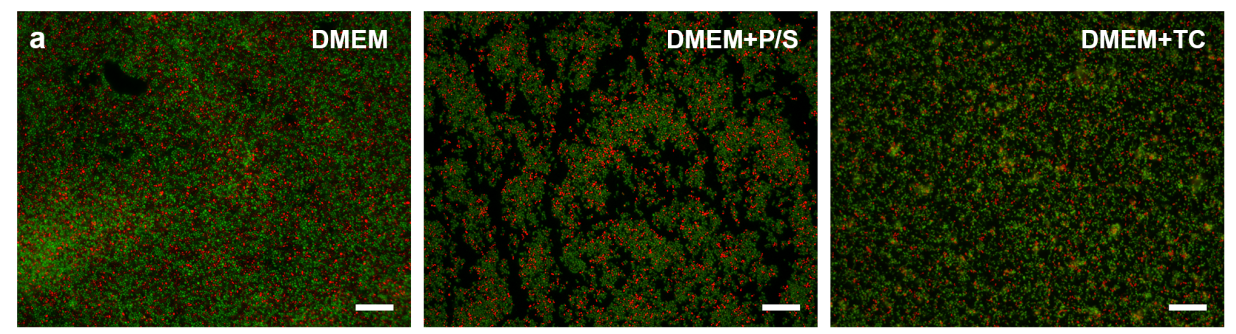

Figure 4.17 Fluorescence microscopy images of DMEM, DMEM + PS and DMEM + tetracycline-treated biofilms at $\mathrm{t}=4$ days. Viable bacteria is shown in green and non-viable in red. Scale bar size is $25 \mu \mathrm{m}$

Metabolic activity of the biofilm was indirectly assessed as a function of the $\mathrm{pH}$, due to the L-lactic acid production that results from the glucose metabolism. Temporal evolution of the $\mathrm{pH}$ was measured using a $\mathrm{pH}$ meter. Fresh biofilms 

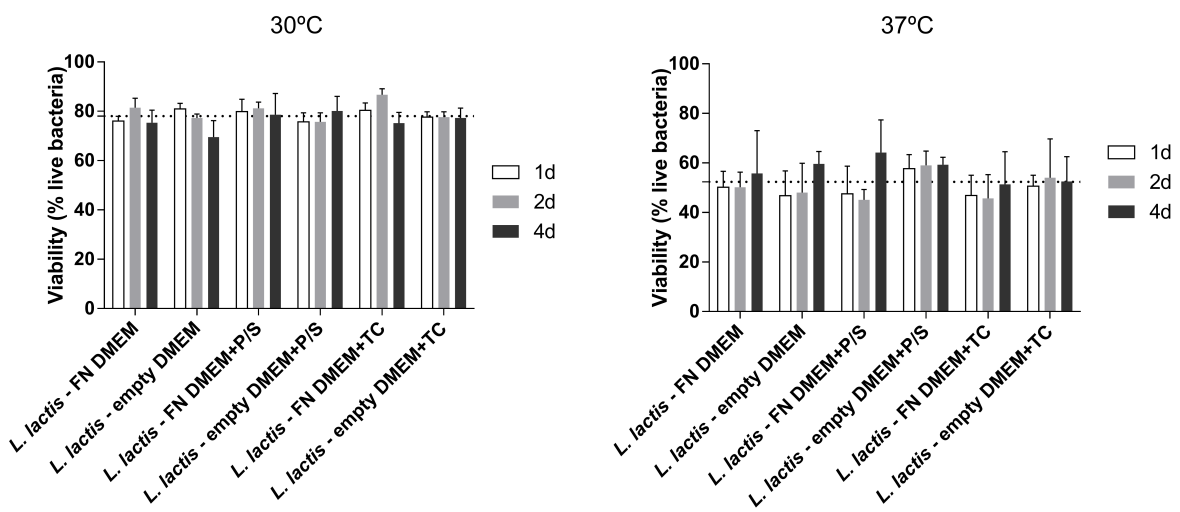

Figure 4.18 Viability values after 1, 2 and 4 days on L. lactis-FN and L. lactisempty biofilms incubated at 30 and $37^{\circ} \mathrm{C}$ with DMEM, DMEM supplemented with $1 \%$ penicillin-streptomycin (P/S) or $10 \mu \mathrm{g} / \mathrm{mL}$ tetracycline (TC). There are no statistically significant differences between strains, antibiotics or incubation time, with an overall mean value of $78.1 \pm 5.2 \%$ at $30^{\circ} \mathrm{C}$ and $52.4 \pm 5.6 \%$ at $37^{\circ} \mathrm{C}$, value shown as a dotted line. An unpaired Student's t test with the two overall means showed statistically significant differences with a significance level of $\mathrm{p}<$ 0.0001

were incubated at $37^{\circ} \mathrm{C}$ in a humidified atmosphere with $5 \% \mathrm{CO}_{2}$, using the same medium as in the preceding assay.

Attending to the results showed in the Figure 4.19, tetracycline was the only antibiotic that maintained the $\mathrm{pH}$ of the medium above 7 , a mandatory condition to culture mammalian cells over the biofilms without risking its viability.

The use of antibiotics in the culture medium decreased the density of bacteria on the material surfaces, as inferred from Figure 4.20. However, even if it is the case, the bacterial layer that remains in the surface shows a viability higher than $50 \%$, enough to support cell adhesion and differentiation, as will be later discussed. That is to say, even if the biofilm is not perfectly homogeneous, the bacterial biofilm still shows adequate expression levels of $\mathrm{FN}$ for mammalian cell interactions. 


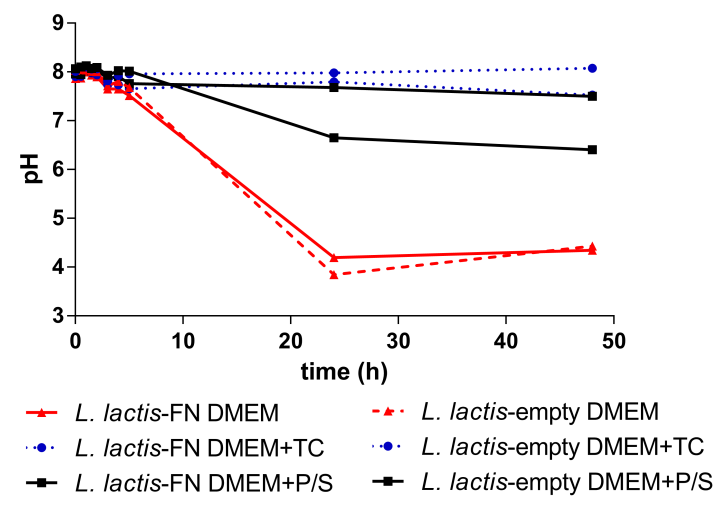

Figure 4.19 Bacterial metabolism inferred from the $\mathrm{pH}$ of the medium. Strains incubated with DMEM supplemented with tetracycline $10 \mu \mathrm{g} / \mathrm{mL}$ (blue lines) maintained its $\mathrm{pH}$ above seven in every moment, while incubation with DMEM $+\mathrm{P} / \mathrm{S}$ led to a slight $\mathrm{pH}$ decrease, mainly in the L. lactis-empty strain. With no antibiotics, $\mathrm{pH}$ quickly dropped to a value below 5 , as a result of the glucose conversion into L-(+)-lactic acid.

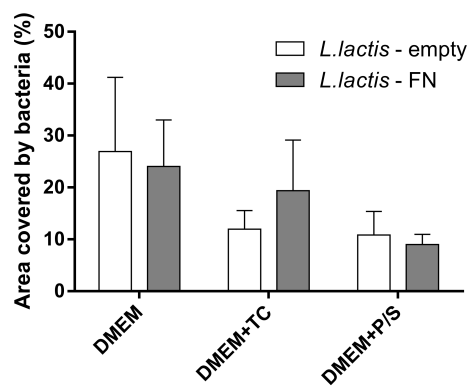

Figure 4.20 Antibiotic influence on the biofilm areal density. Starting from maximum density biofilms, $\mathrm{P} / \mathrm{S}$ seems to have a greater influence than tetracycline, and L. lactis-emtpy seems also to be more affected than L. lactis-FN. Data shown as mean $\pm \mathrm{SD}, \mathrm{N}=4$

\subsection{Conclusions}

In this chapter has been described the genetic modification of Lactococcus lactis subsp. cremoris to express the $\mathrm{III}_{7-10}$ domains of the human fibronectin, which contains two the adhesive RGD and the synergy PHSRN sequences. Both are involved in the interaction with integrins, a wide family of transmembrane 
proteins that plays an important role in cell-ECM and cell-cell interactions. [12]

Genetic engineering of this strain has been made with standard techniques. A fusion protein composed of FNIII $7-10$ and GFP has been cloned and expressed. Green fluorescent protein is a widely used expression reporter originally isolated from the Aequorea victoria jellyfish [90], and displays a bright green fluorescence when exposed to ultraviolet light.

With the help of a secretion peptide, Usp45, and the membrane-anchoring peptide LPETG from the SpA protein membrane of Staphylococcus aureus, this fusion protein efficiently localizes the expressed protein on the peptidoglycan layer of this strain, becoming exposed to the extracellular medium and thus available for interaction with mammalian cells through integrins.

Genetically engineered $L$. lactis strain has been characterised in order to analyse the expression levels and biological activity of the expressed FNIII ${ }_{7-10}$ fragment, using two different but complementary techniques, Western blot and ELISA. By using Western blot has been possible to determine the total amount of the expressed fragment, and the ELISA technique has been useful to determine its biological activity, which has been found to be roughly equivalent to a surface coated with a solution of $20 \mu \mathrm{g} / \mathrm{mL}$ fibronectin, roughly $300 \mathrm{ng} / \mathrm{cm}^{2}$. [263]

L. lactis develops stable biofilms, while keeping high viability values [216]. Bacteria shows high viability levels even with low concentrations of tetracycline, a bacteriostatic antibiotic.

The use of tetracycline is important when culturing mammalian cells on the biofilm, in order to avoid an excessive medium acidification due to L-lactic acid production.

However, as low $\mathrm{pH}$ values can compromise the viability of mammalian cells, it is clear that a metabolic control system is required. L. lactis, regardless its genetic modification, still showed the ability to develop biofilms.

As shown in the SEM images, L. lactis makes use of some extracellular proteins, mostly CluA [62, 264], to attach to abiotic surfaces. These biofilms are strong enough to support the growth of mammalian cells, as will be later discussed.

Moreover, biofilm density, expressed as number of cells per square centimetre or covered area, in percentage, is an easily adjustable parameter. Starting from different volumes of exponential-phase liquid cultures, thus different amounts of total biomass, the resulting biofilm shows an increasing coverage percentage dependent on the initial culture volume.

Summarising, genetically modified Lactococcus lactis to express biologically active FNIII $_{7-10}$ fragment on its membrane retains remarkable ability to develop 
biofilms much like the strain without membrane-bound heterologous proteins. These biofilms can be adjusted to different coverage densities, with the exposed fragment showing proper biological activity. 


\section{Chapter 5}

\section{Cell-bacteria co-cultures and cell behaviour}

\subsection{Introduction}

Phenomena occurring at the cell-material interface are of fundamental importance in biotechnological and biomedical strategies to direct cell behaviour on biomaterials, including cell adhesion, proliferation, migration and differentiation $[8,9]$. The interaction of cells with abiotic surfaces such as synthetic polymers, metals or glass usually takes place via an adsorbed protein layer.

Extracellular matrix proteins such as vitronectin, laminin or collagen have been used to establish this intermediate layer of proteins at the materials interface, using physical and chemical methods, in order to mimic to a certain extent the ECM characteristics. However, a static protein layer is not enough to provide the dynamic stimuli required to orchestrate cell responses and organise the formation of a new tissue at the cell-material interface.

Several approaches have been proposed to introduce a dynamic cell/material interface. Photoactivable RGD adhesive peptides [14] have been engineered, where RGD is blocked with 3-(4,5-dimethoxy-2-nitrophenyl)-2-butyl (DMNPB), rendering it unreachable to integrins. When irradiated with light of the proper wavelength, the capping molecule is cleaved and RGD becomes accessible to integrins, starting a cellular response. The effect of density and time-point ligand presentation on cell adhesion, proliferation and differentiation has been studied.

Other proposed solution has been enzyme-responsive surfaces that presents RGD sequences on demand [15]. By enzymatic hydrolysis, inactive RGD- 


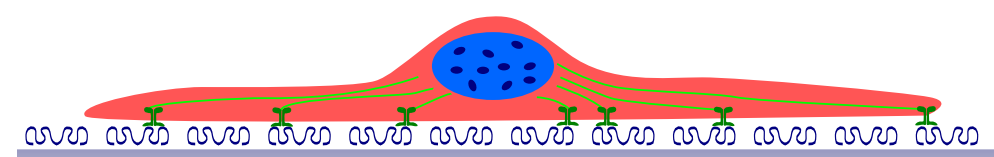

Figure 5.1 Simplified sketch of the cell-protein-material interaction. Cells interact with the adsorbed protein layer through integrins, transmembrane receptors involved in multiple cellular processes such as adhesion, migration, differentiation or proliferation. Integrins also play a role in the organisation of the cytoskeleton (light green, actin) and interactons with the extracellular matrix (blue, adsorbed proteins).

containing precursors become active enabling integrin-mediated cell response on these surfaces. These two approaches rely in chemical modifications of synthetic peptides, which are previously grafted on the surface. They are present from the beginning of the assays and activated on demand. This approach goes one step further from classic passive coatings, but a major issue is that all the signalling cues should be present since the beginning. Our approach tries to address this problem by using living organisms with the ability to produce, on demand, any desired biochemical signal.

This work proposes the use of genetically modified L. lactis, a lactic acid bacteria with the ability to develop biofilms on most surfaces, enabling the development of an interfacial layer between synthetic materials and mammalian cells. L. lactis has been extensively used in genetic engineering, being, as of today, the most versatile LAB host for protein expression [80]. Its genome has been fully sequenced $[17,207]$ and is publicly available with a wide variety cloning vectors commercially available.

In this chapter, we describe the development of a model system based on $L$. lactis cells expressing $\mathrm{FN}^{-\mathrm{III}_{7-10}}$ fused to GFP. This protein is efficiently located in the bacterial cell-wall. Expressed $\mathrm{III}_{7-10}$ fragment contains RGD and PHSRN sequences which interact $\alpha_{5} \beta_{1}$ and other related integrins.

Integrin-mediated adhesion is a complex process that involves the organization of focal adhesion (FA) clusters, whose commitment is to link ECM proteins with the actin cytoskeleton. Focal complexes are mature adhesion sites that contains structural and signalling proteins, such as focal adhesion kinase (FAK) and Src. These signalling proteins play the initial step in the organization of mid- and long-term processes such as differentiation and migration.

The main signalling protein involved in focal adhesion development is the 


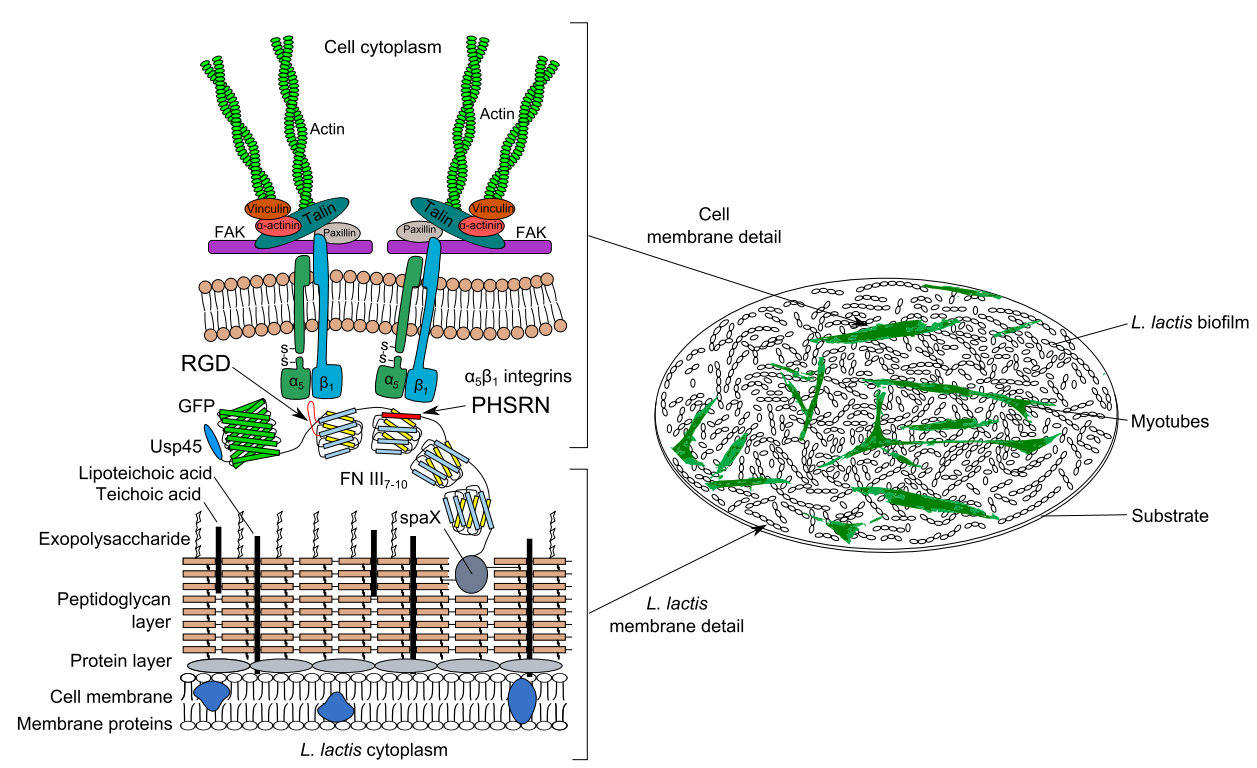

Figure 5.2 Conceptual sketch of the membrane localisation of the expressed $\mathrm{III}_{7-10}$ fragment in L. lactis and the proposed interaction model with the $\alpha_{5} \beta_{1}$ integrin, the main fibronectin receptor. Actually, a single integrin molecule is wide enough to simultaneously interact with the RGD and the PHSRN sequences.

focal adhesion kinase (FAK), a non-receptor tyrosine kinase that activates in response to cell-ECM adhesion and inactivated by dephosphorylation after detachment or trypsinization. [131, 132]

FAK triggers a wide variety of signalling pathways involved in cell motility, invasion, proliferation, cell cycle and development [135-139] and contributes to integrin activation directed towards the generation and enhancement of cellECM adhesive forces [137]. FAK is also overexpressed in a variety of human cancers [133], promoting their invasive behaviour. [134, 265]

The activation of FAK via phosphorylation involves FAT and FERM domains interacting with other integrin-associated proteins [140, 142]. Its activation is mainly dictated by Tyr-397 autophosphorylation. This phosphorylation creates a high-affinity site for the SH2 domain of Src, recruiting and activating Src in the focal adhesion complexes [266]. When Src binds to phosphoTyr-397, other FAK residues are also phosphorylated [143, 144], including Tyr-576 and Tyr-577 in the kinase domain activation loop and Tyr-861, involved in the FAK autophosphorylation process. [145]

Besides triggering adhesion through focal adhesion development, both 
integrins and signalling proteins such as FAK are deeply involved in other cellular processes. In this chapter, we assess the ability of the bacterially expressed $\mathrm{III}_{7-10}$ fragment to induce cell differentiation, in particular myogenic differentiation in the well-established C2C12 in vitro model.

We first examine myogenic differentiation, a complex process that involves committed myoblastic cells, which undergo polar alignment and fusion, yielding, first, differentiated multinucleated myotubes and, second, mature muscular fibres [13]. It is a tightly controlled process orchestrated by several transcription factors, namely MyoD, myogenin, Myf5 and MRF4 [267]. The initial regulation of myogenic differentiation involves the p38 mitogen activated protein kinase (MAPK), a member of the MAPK signalling cascades that can be activated by multiple stressors including ultraviolet light, cytokines or osmotic stress. Once activated, p38 MAPK activates other proteins via phosphorylation and initiates the downstream transcriptional signalling pathway. [268-270]

Myogenic differentiation involves withdrawal from cell cycle through expression of MyoD and Myf5, which are activated through the p38 MAPK. These two transcription factors are involved in the change from somites to committed myoblasts, fusion-competent cells that undergo cytoplasmic fusion in subsequent differentiation stages. Under the influence of these two transcription factors, somites withdraw from cell cycle starting the differentiation process, which involves morphological changes that eventually leads to formation of competent myotubes.

The second step in the muscle fibre formation is the activation of other two transcription factors, myogenin and Myf5. Under their influence, competent myoblasts acquire the ability to fuse together, developing multinucleated myotubes. Focal adhesion kinases, which are activated under the influence of extracellular signals, i.e. interactions of integrins with ECM molecules such as fibronectin, also play an important role in the myogenic process [271].

Activated FAK interacts with signalling and adaptor proteins, including p130Cas, Grb2, paxillin, Shc and PI-3k kinase, thereby initiating intracellular signal transduction cascades [272-274] that, in turn, regulate cellular processes such as proliferation, migration, survival, and differentiation. FAK inhibition via siRNA or by expression of dominant negative form results in impaired myoblast function in both in vitro and in vivo. [275] (Figure 5.3)

In short, myogenic differentiation is a complex process influenced by both cellular reprogramming via 38 MAPK pathway, which is responsible of MyoD and Myf5 upregulation. However, FAK activation produced by integrin dimerization also plays an important role in the development of mature myoblasts. 


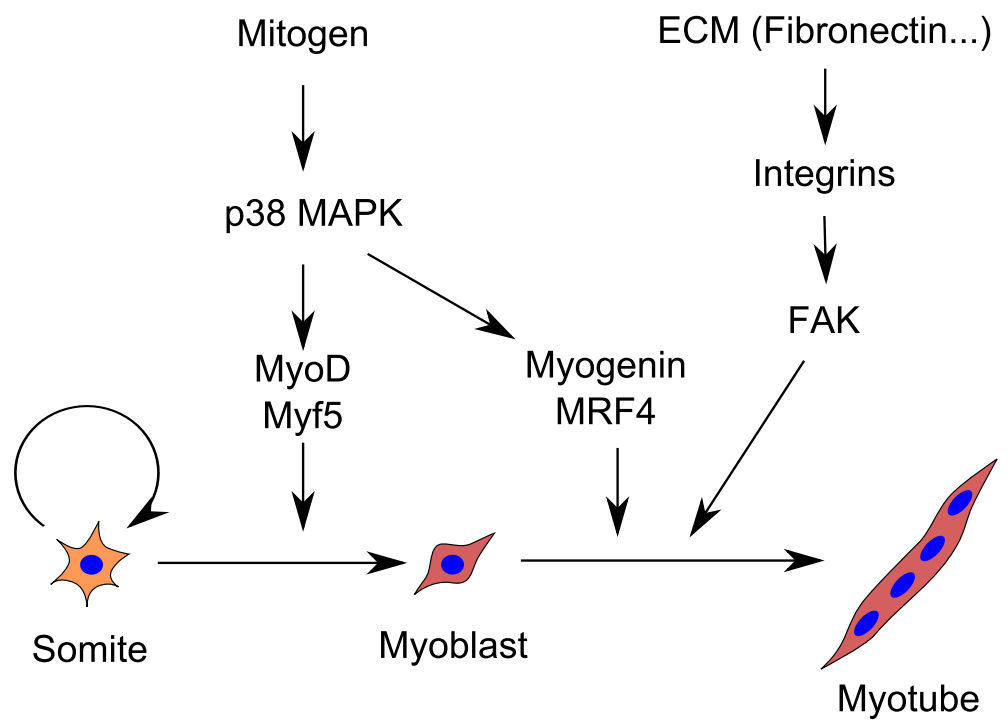

Figure 5.3 Simplified sketch of the myogenic differentiation process, influenced by both p38 MAPK signalling pathway and FAK activation, the last one triggered by the interaction of integrins with the ECM. It has been demonstrated the influence of fibronectin in the enhancement of myoblast migration, alignment and fusion into myotubes.

Myotube fusion, migration and alignment is greatly enhanced when cultured on fibronectin-coated substrates. [13]

Myogenic differentiation is only one amongst the wide variety of cellular processes directed by the MAPK signalling pathway [276]. MAPK superfamily includes ERK1/2 amongst hundreds of kinases [277], and is involved in an amplificatory cascade where an initial trigger, which can be integrin-mediated signalling, activates a series of kinases which substrates are other kinases. This signalling cascade can be divided into three tiers; the first tier is comprised of MAP3K or MAPK kinases kinases, which phosphorylates MAP2K (MAPK kinases, second tier). Substrates of MAP2K are MAPK or mitogen-activated protein kinases (third tier), namely ERK1/2/1c, p38 $\alpha / \beta / \gamma / \delta$ and JNK1/2/3. [269, 278]

Activation of the MAPK signalling pathway is used in this thesis to assess the influence of $\mathrm{III}_{7-10}$ in cell behaviour. Both FAK and ERK1/2 phosphorylation are assessed using several techniques such as Western blot and ELISA.

Cell proliferation is one of the most important events related to newly developed tissue, and is tightly controlled by the Ras-Raf-MEK-ERK pathway 
[278]. This pathway can be triggered by integrin dimerization, in response to extracellular events such as interaction with ECM components (fibronectins, collagen, laminin and others) [11]. Dimerization of integrin subunits leads to Ras activation, via exchange of GDP by GTP, the active form. Ras-GTP is responsible for the subsequent activation of the Raf kinase family (Raf-A, B and C), in an complex multistage process involving homo- and heterodimer formation [279]. Raf activates MEK1/2 (MAP/ERK kinases), whose only substrates are ERK1 and ERK2. MEK1/2 are Tyr-Thr kinases, phosphorylating Thr202/Tyr204 in ERK1 and Thr185/Tyr187 in ERK2. Active ERK1/2 are promiscuous kinases, with 175 known substrates [280]. One of these substrates is paxillin, a protein that plays a prominent role in focal adhesion complexes.

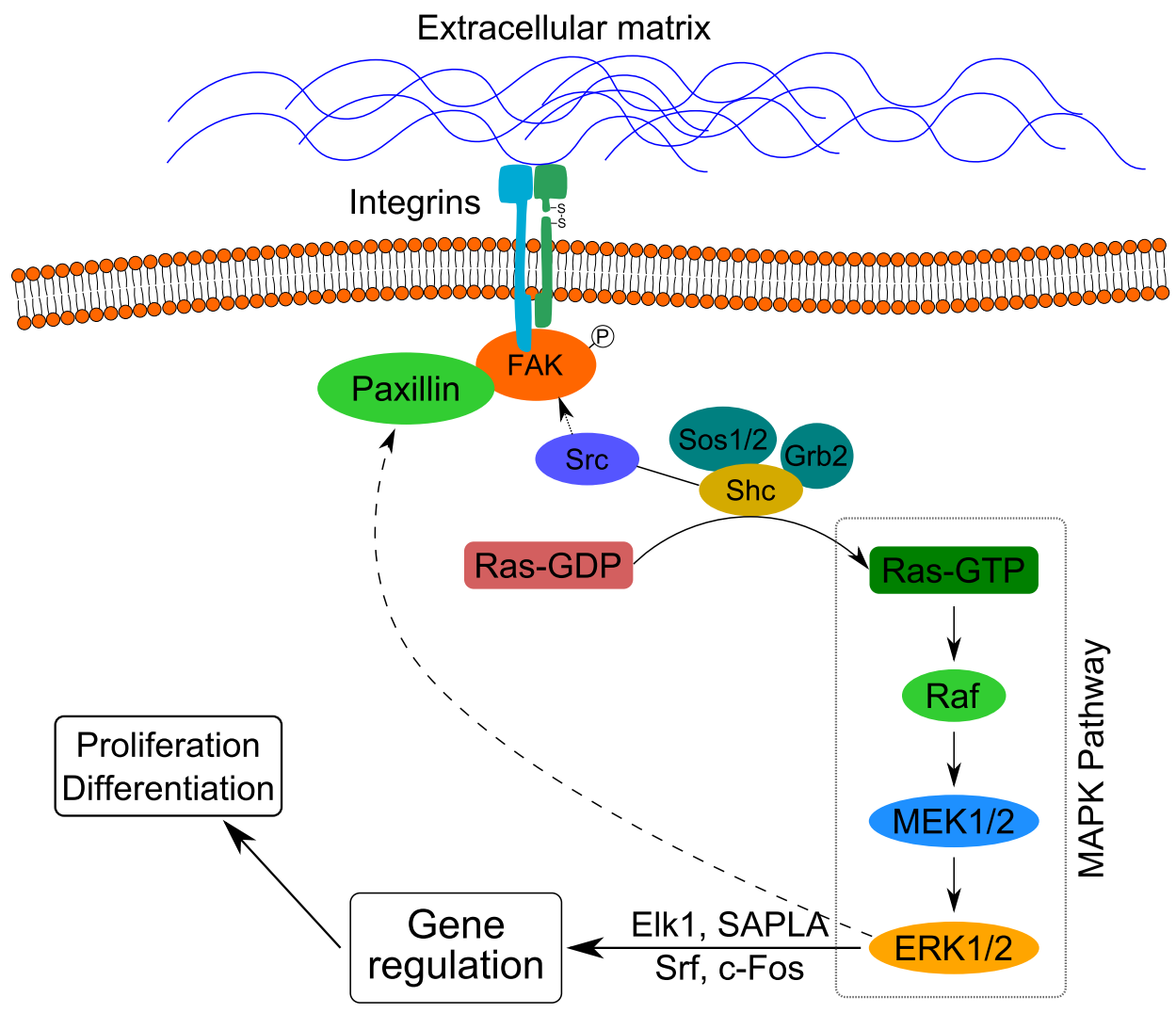

Figure 5.4 Integrin dimerization activates the MAPK pathway signalling cascade, which results in enhanced focal adhesion formation and maturation via paxillin phosphorylation. MAPK signalling pathway also activates several genes involved in cell proliferation and migration. 
ERK1/2 is also responsible for further paxillin activation via phosphorylation $[280,281]$. This activation helps in the formation of mature adhesion complexes.

Besides FAK and ERK1/2 phosphorylation in response to integrin activation, human bone marrow-derived mesenchymal stem cells were used to assess the influence of the bacterially expressed fibronectin on the cell fate. hMSCs are multipotent cells that reside within the bone marrow and have the ability to differentiate into cells of the mesodermal lineage such as osteoblasts, chondrocytes, myoblasts or adipocytes [282], amongst other lineages such as neurons [283], cardiomyocites [284] and vascular endothelial cells. [285]

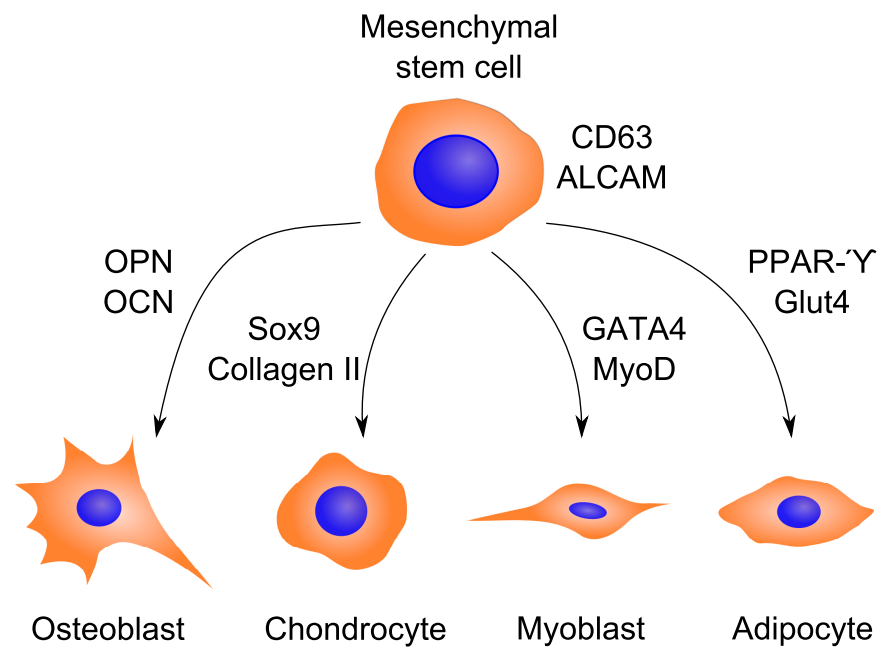

Figure 5.5 Mesenchymal stem cells can undergo osteoblastic, chondrogenic, myoblastic, adipogenic or fibroblastic differentiation (not shown). Differentiation was assessed by quantitative real-time PCR.

Experiments on the influence of the $\mathrm{FNIII}_{7-10}$ on mesenchymal stem cell [286] showed that polymer brushes coated with multimeric units of this fragment induced osteoblastic differentiation, measured through alkaline phosphatase activity, of human mesenchymal stem cells cultured in osteogenic media.

To assess the influence of the $\mathrm{III}_{7-10}$ fragment on hMSC differentiation, 15-day cultures of hMSC on L. lactis-FN and L. lactis-empty biofilms were performed, analysing the gene expression profile to check whether osteoblastic, chondrogenic, myoblast or adipocyte differentiation took place, without using differentiation inducers. Gene expression analysis was performed using 
quantitative real-time PCR, a technique that gives quantitative information about the relative expression of a selected gene over a constitutive expressed gene, GAPDH in our experiments. The selected genes for each lineage were osteopontin (OPN) and osteocalcin (OCN) for osteoblasts; SOX9 and Collagen type II for chondrocytes; GATA4 and MyoD for myoblasts and PPAR- $\gamma$ and Glut4 for adypocites. CD63 and ALCAM were analysed for self-renewal or stemness maintenance.

\subsection{Material and Methods}

\section{Ethyl acrylate polymerisation}

Poly (ethyl acrylate) (PEA) sheets were prepared by radical polymerization of pure liquid ethyl acrylate (Sigma) using $0.35 \%$ benzoin (98\% pure, Scharlau) as photoinitiator. Polymerization was carried out for 24 hours under UV light. Then, a second post-polymerization step was performed at $90{ }^{\circ} \mathrm{C}$ for 24 hours. Low molecular mass substances were extracted from the material by in vacuo drying for 48 hours at $60{ }^{\circ} \mathrm{C}$.

\section{PEA spin casting}

PEA sheets were dissolved in toluene to a final concentration of $2.5 \% \mathrm{w} / \mathrm{v}$. The solution was stirred at room temperature until all the polymer was properly dissolved, obtaining a viscous solution as a result. Spin casting was performed on 12 or $25 \mathrm{~mm}$ glass coverslips at $2000 \mathrm{rpm}$ for 30 seconds. Samples were dried in vacuo at $60{ }^{\circ} \mathrm{C}$ for at least 4 hours in order to remove solvent traces before biofilm preparation.

\section{Biofilm production}

The protocol used to produce biofilms has been described elsewhere [209, 249]. In this work, we use a modified protocol based on the referenced ones. Lactococcus lactis MG1363 carrying the PT1NX-III ${ }_{7-10}$-GFP plasmid (L. lactisFN) and the empty PT1NX plasmid (L. lactis-empty) were grown from a frozen glycerinate in GM17E-agar Petri dishes, for $24 \mathrm{~h}$ at $30^{\circ} \mathrm{C}$.

Grown colonies were inoculated in fresh GM17-E, using one colony for each $10 \mathrm{~mL}$ of culture, and kept at $30{ }^{\circ} \mathrm{C}$ in closed containers. When the optical density of the culture reached a value of $0.2-0.3$, measured at 600 $\mathrm{nm}$, cultures were transferred to 24-well plates containing clean and sterile 
glass coverslips (for short-term cultures) or PEA-coated glass coverslips (for long-term cultures). Plates were sealed with adhesive plate sealers to guarantee an anaerobic environment and minimize evaporation, and left at $30^{\circ} \mathrm{C}$.

After $24 \mathrm{~h}$, plates were gently shaken at $150 \mathrm{rpm}$ for 3 minutes. Then, plate sealer was removed and non-adhered bacteria were twice washed with sterile ultrapure water, until adhered bacteria were exposed. These washing steps were controlled with a phase-contrast optical microscope. In the last washing step, ultrapure water was substituted with a phosphate-buffered saline solution.

\section{Biofilm viability}

Biofilm viability was assessed using the same conditions as in cell cultures. Fresh biofilms were incubated at $37{ }^{\circ} \mathrm{C}, 5 \% \mathrm{CO}_{2}$ humidified atmosphere with three different media - DMEM (DMEM), DMEM with $1 \%$ penicillin-streptomycin (DMEM+PS) and DMEM with $10 \mu \mathrm{g} / \mathrm{mL}$ tetracycline (DMEM+TC). DMEM contained in all cases $4.5 \mathrm{~g} / \mathrm{L}$ of glucose. Plates were kept for one, two and four days and after each time point were subjected to a viability assay. Medium was removed and the biofilms were washed twice with $\mathrm{NaCl} 0.85 \%$.

Samples were imaged in a Nikon Eclipse 80i epifluorescence microscope and up to 10 fields per sample were used to calculate the viability, defined as the ratio between viable and total cell number. Image analysis was performed with Fiji - ImageJ as described in the Bacterial and cell viability section.

\section{Biofilm metabolism}

Biofilm metabolism was indirectly inferred from the decrease of the $\mathrm{pH}$ of the medium. As described in the introduction, L. lactis is a homolactic fermentative strain that metabolises glucose to L-lactic acid.

Fresh biofilms were prepared following the protocol described in the biofilm production section. Afterwards, to assess the influence of tetracycline and penicillin-streptomycin, medium was changed to DMEM (DMEM), DMEM with 1 $\%$ penicillin-streptomycin (DMEM+PS) and DMEM with $10 \mu \mathrm{g} / \mathrm{mL}$ tetracycline (DMEM+TC). DMEM contained in all cases $4.5 \mathrm{~g} / \mathrm{L}$ of glucose. Samples were then incubated at $37{ }^{\circ} \mathrm{C}, 5 \% \mathrm{CO}_{2}$ in a humidified atmosphere, and the $\mathrm{pH}$ was monitored as a function of time $(0,0.5,1,1.5,2,3,4,5,24$ and $48 \mathrm{~h})$ with a $\mathrm{pH}$-meter (Eutech Instruments). 


\section{Production of biofilms with tunable areal density}

Single colonies of L. lactis-FN grown overnight in GM17-E agar plates were inoculated in $10 \mathrm{~mL}$ of GM17-E and when optical density measured at $600 \mathrm{~nm}$ reached a value of $0.2-0.3$, liquid cultures were transferred to P24 multiwell plates.

Volumes of 300, 500, 700 and $1000 \mu \mathrm{L}$ respectively were used for obtaining increasing areal density. After that, the multiwell plate was sealed and kept at $30{ }^{\circ} \mathrm{C}$ for $24 \mathrm{~h}$. Then, non-adhered bacteria were washed three times with ultrapure water, with a fourth wash with PBS to avoid autolysis derived from osmotic shock.

\section{$\mathrm{Fn}^{-} / \mathrm{Fn}^{-}$fibroblasts cell culture}

Fibronectin-null mutant fibroblasts were maintained in DMEM with $4.5 \mathrm{~g} / \mathrm{L}$ glucose, $10 \%$ FBS and $1 \%$ penicillin-streptomycin. After washing and trypsinizing, were cultured on the bacteria in DMEM with $4.5 \mathrm{~g} / \mathrm{L}$ glucose without FBS, with a seeding density of 7500 cells $/ \mathrm{cm}^{2}$, kept at $37{ }^{\circ} \mathrm{C}$ in $5 \% \mathrm{CO}_{2}$ in a humidified atmosphere for 4 hours and then washed twice with PBS++. Then were fixed with $10 \%$ formalin at $4{ }^{\circ} \mathrm{C}$ for 30 minutes.

\section{NIH3T3 cell culture}

NIH3T3 cells were maintained in DMEM with $4.5 \mathrm{~g} / \mathrm{L}$ glucose and supplemented with $10 \%$ calf serum and $1 \% \mathrm{P} / \mathrm{S}$. Afterwards, they were cultured on freshly prepared biofilms of different densities, in DMEM with $4.5 \mathrm{~g} / \mathrm{L}$ glucose without calf serum, and kept at $37{ }^{\circ} \mathrm{C}$ in $5 \% \mathrm{CO}_{2}$ in a humidified atmosphere, then were washed twice with PBS++ and fixed with $10 \%$ formalin, at $4{ }^{\circ} \mathrm{C}$, for 30 minutes.

\section{C2C12 cell culture}

C2C12 cells maintained in DMEM with $4.5 \mathrm{~g} / \mathrm{L}$ glucose, 20\% FBS and $1 \% \mathrm{P} / \mathrm{S}$ were cultured on different substrates with an initial density of 10,000 cells $/ \mathrm{cm}^{2}$ for adhesion assays and 20,000 cells $/ \mathrm{cm}^{2}$ for differentiation assays.

For adhesion assays, after three hours of culture in FBS-free medium supplemented with $10 \mu \mathrm{g} / \mathrm{mL}$ tetracycline, cells were fixed in formalin $10 \%$ at 4 ${ }^{\circ} \mathrm{C}$ for 30 minutes. For differentiation cultures, the first three hours of culture were conducted in FBS-free medium supplemented with $10 \mu \mathrm{g} / \mathrm{mL}$ tetracycline, 
which was removed and substituted with medium containing $1 \%$ insulintransferrin-selenium and $10 \mu \mathrm{g} / \mathrm{mL}$ tetracycline. Cultures were kept at $37^{\circ} \mathrm{C}$ in a humidified atmosphere with $5 \% \mathrm{CO}_{2}$, changing the medium every two days. Cells were then fixed with $70 \%$ ethanol, $37 \%$ formaldehyde and glacial acetic acid $(20: 2: 1)$ for 10 minutes at $4{ }^{\circ} \mathrm{C}$.

\section{Human mesenchymal stem cell culture}

Bone marrow-derived hMSCs were acquired from PromoCell Inc. Cells were maintained in DMEM supplemented with $1 \% \mathrm{P} / \mathrm{S}$, L-glutamine $1.1 \mathrm{mM}$, pyruvate $100 \mu \mathrm{M}$ and $10 \%$ foetal bovine serum. Afterwards, cells were cultured on freshly prepared biofilms or control solutions in DMEM supplemented with $10 \mu \mathrm{g} / \mathrm{mL}$ tetracycline, $1.1 \mathrm{mM}$ L-glutamine and $100 \mu \mathrm{M}$ pyruvate and without FBS. These cultures were used for vinculin immunostaining, ERK1/2 ELISA assays and quantitative PCR for gene profiling.

\section{Sarcomeric myosin immunostaining}

Fixed cells were washed twice with PBS++ and blocked with $5 \%$ goat serum in $\mathrm{PBS}++$ for $1 \mathrm{~h}$ at RT. Samples were then incubated with MF20 anti-sarcomeric myosin antibody (Developmental Studies Hybridoma Bank, University of Iowa, USA) at 1:250 dilution in PBS++ with $5 \%$ goat serum, for 1 hour at RT. After two washes with Tween $200.5 \%$ in PBS++, were blocked again with $5 \%$ goat serum in $\mathrm{PBS}++$ for 10 minutes at RT, then washed twice again with Tween $200.5 \%$ in PBS++. Rabbit anti-mouse conjugated with Cy3 (Jackson Immunoresearch) was used as secondary antibody, with a dilution of 1:200 in PBS++ with $5 \%$ goat serum.

After 1 hour at RT in absence of light, samples were washed three times with Tween $200.5 \%$ in PBS++ and mounted with Vectashield-DAPI (Vector Laboratories).

\section{Vinculin immunostaining}

C2C12, $\mathrm{Fn}^{-} / \mathrm{Fn}^{-}$fibroblasts and NIH3T3 Cells were fixed with $10 \%$ formalin were washed twice with PBS++ and blocked with a solution of $1 \%$ BSA in PBS++. Monoclonal anti-vinculin antibody produced in mouse (Sigma), diluted 1:400 in BSA $1 \%$ in PBS++ was used as primary antibody. Incubation lasted 1 hour at RT. Then, cells were washed twice with Tween $200.5 \%$ in PBS++ and incubated with rabbit anti-mouse Cy3-conjugated secondary antibody (Jackson 
Immunoresearch), diluted 1:200 in 1\% BSA / PBS++. The secondary antibody was incubated for 1 hour at RT in absence of light and with FITC-conjugated phallacidin 1:100. Cells were then washed three times with Tween $200.5 \%$ in PBS++ and mounted with Vectashield-DAPI (Vector Laboratories)

Human mesenchymal stem cells (hMSC) Cells were fixed in $4 \%$ formaldehyde and $2 \% \mathrm{w} / \mathrm{v}$ glucose in PBS for $15 \mathrm{~min}$ at $37^{\circ} \mathrm{C}$. The fixative solution was removed and cells were permeabilised with $10.3 \% \mathrm{w} / \mathrm{v}$ sucrose, $0.292 \% \mathrm{w} / \mathrm{v}$ $\mathrm{NaCl}, 0.06 \% \mathrm{MgCl}_{2} \cdot 10 \mathrm{H}_{2} \mathrm{O}, 0.476 \% \mathrm{w} / \mathrm{v}$ HEPES and $0.5 \% \mathrm{v} / \mathrm{v}$ Triton X-100 in PBS, pH 7.2, at $4{ }^{\circ} \mathrm{C}$ for 5 minutes.

Then, cells were blocked with $1 \% \mathrm{BSA}$ in PBS at $37^{\circ} \mathrm{C}$ for $30 \mathrm{~min}$, removing the blocking solution and incubating with mouse anti-vinculin monoclonal antibody (Sigma) diluted 1:400 in BSA $1 \%$ in PBS++, at $37^{\circ} \mathrm{C}$, for $1 \mathrm{~h}$. Cells were washed three times with Tween $200.5 \% \mathrm{v} / \mathrm{v}$ in PBS++.

Then, the secondary antibody, Cy3-conjugated rabbit anti-mouse (Jackson Immunoresearch) diluted 1:200 in BSA $1 \%$ in PBS was added and incubated for $1 \mathrm{~h}$ at $37^{\circ} \mathrm{C}$. Afterwards, this solution was removed, adding BODIPY-PL phallacidin diluted 1:40 in BSA $1 \%$ in PBS++ for $30 \mathrm{~min}$ at RT. Cells were washed three times with Tween $200.5 \% \mathrm{v} / \mathrm{v}$ in PBS and mounted with Vectashield-DAPI (Vector Laboratories).

\section{Image analysis}

Differentiation cultures were analyzed from fluorescence images taken in a Nikon Eclipse 80i epifluorescence microscope. Two different channels were acquired, red for Cy3 (sarcomeric myosin) and blue for DAPI (nuclei), at 10x magnification, with at least 10 different fields per sample. Images were transformed to an 8-bit grayscale bitmap (ImageJ - Fiji software) and segmented with the help of the Trainable Weka Segmentation plugin where needed or the Otsu thresholding algorithm, to get a binarized mask for both channels.

Total nuclei per image were counted using the Particle Analysis command of Image J on the DAPI images. Then, the binarized DAPI channel image was multiplied by the Cy3 (sarcomeric myosin) binarized image. After image multiplication, only nuclei under myotubes (assigned to differentiated cells) were displayed and counted. Differentiation percentage was calculated dividing the differentiated nuclei and the total nuclei count. 


\section{FAK phosphorylation analysis by Western blot}

After a 3 hour-culture, cells were washed with PBS++ and lysed with RIPA buffer (Tris-HCl $50 \mathrm{mM}$, Nonidet P-40 $1 \%$, Na deoxycholate $0.25 \%, \mathrm{NaCl}$ $150 \mathrm{mM}$, EDTA $1 \mathrm{mM}$ ) supplemented with protease inhibitor cocktail tablets (Complete, Roche). Proteins were concentrated using Microcon YM-30 Centrifugal Filter devices (Millipore) as manufacturer described. After two consecutive centrifugations at $10,000 \mathrm{~g}$ for 10 minutes, proteins were recovered with a mixture of $7 \mathrm{M}$ urea, $2 \mathrm{M}$ thiourea, $4 \% \mathrm{w} / \mathrm{v}$ CHAPS (3-[(3cholamidopropyl)dimethylammonio]-1-propanesulfonate) and $200 \mathrm{mM}$ ditiothreitol.

To determine FAK protein expression and its Tyr397 phosphorylated form (pFAK), concentrated samples were subjected to $7 \%$ SDS-PAGE gel electrophoresis. Proteins were transferred to a positively charged PVDF membrane (GE Healthcare) using a semidry transfer cell system (Bio-Rad) and blocked by immersion in $5 \%$ skimmed milk in PBS for $1 \mathrm{~h}$ at room temperature.

The blot was incubated with anti-FAK antibody (Upstate), diluted 1:2500 and anti-pFAK antibody (Millipore), diluted 1:250, in $2 \%$ skimmed milk and $0.1 \%$ Tween 20 in PBS, and left overnight at $4{ }^{\circ} \mathrm{C}$ in an airtight container. After several washes with $0.1 \%$ Tween 20 in PBS, the blot was incubated in horseradish peroxidase-conjugated antibody (GE Healthcare) diluted 1:50,000 in $2 \%$ skimmed milk, $0.1 \%$ Tween 20 in PBS, for 1 hour at room temperature.

After several washes with $0.1 \%$ Tween 20 in PBS, immunoreactive bands were developed with the Supersignal West-femto Maximum Sensitivity Substrate (Thermo Scientific). After a 5-minute incubation, chemiluminiscent bands were visualized with Amersham high sensitivity chemiluminiscence photographic film (GE Healthcare).

\section{ERK1/2 phosphorylation by sandwich ELISA}

ERK1/2 phosphorylation was assessed with the DuoSet ERK1/2 sandwich ELISA kit (RnD Systems, Minneapolis, USA), as described in Section 3.7. Cells from a 30-minute culture were lysed using the protocol described in the kit and subjected to the ELISA protocol. Briefly, the ELISA plate was coated with the capture antibody overnight, adding the lysate immediately. After hybridisation, the biotinylated detection antibody was added and then the streptavidin-conjugated horseradish peroxidase, which was used to catalyse the oxidation of tetramethylbenzidine with hydrogen peroxide. The reaction was stopped with sulphuric acid, measuring the optical density at $450 \mathrm{~nm}$ in a multiplate reader. 


\section{Quantitative real-time PCR}

hMSC-BM cells were cultured at 20,000 cells $/ \mathrm{cm}^{2}$ and cultured for 15 days on freshly prepared L. lactis-empty and L. lactis-FN maximum density biofilms produced on PEA-coated, FN-coated PEA and bare glass coverslips. Culture medium was composed of high-glucose DMEM supplemented with $10 \mu \mathrm{g} / \mathrm{mL}$ tetracycline, $100 \mu \mathrm{M}$ sodium pyruvate, $1.1 \mathrm{mM}$ L-glutamine and $1 \% \mathrm{FBS}$. Total RNA was extracted and purified with a Qiagen RNeasy kit (Qiagen, Venlo, Netherlands), which included a previous DNase treatment to remove genomic DNA. Total RNA amount and quality was checked with a Nanodrop 1000 (Thermo Scientific). After extraction, RNA purity was checked using the $A_{260} / A_{280}$ ratio with values between 1.8 and 2.0, showing that total RNA was succesfully purified with the kit.

200 ng of total RNA, when possible, were reverse transcribed to cDNA with the Qiagen QuantiTect Reverse Transcription kit.

Real Time qPCR was carried out in an Applied Biosystems 7500 Real Time PCR system, normalizing the gene expression to GAPDH and then to two different control conditions, L. lactis-emtpy biofilm and FN-coated PEA coverslips. Reaction was carried out in a final volume of $20 \mu \mathrm{L}$.

The following equation was used to quantify the relative expression of the genes showed in the Table 5.1:

$$
\text { relative expression }=2^{-\Delta \Delta \mathrm{CT}}
$$

Where

$$
\begin{gathered}
\Delta \Delta \mathrm{CT}=\Delta \mathrm{CT}_{1}-\Delta \mathrm{CT}_{2} \\
\Delta \mathrm{CT}_{1}=\mathrm{CT}_{\text {sample gene }}-\mathrm{CT}_{\mathrm{GAPDH}} \quad \text { (sample 1) } \\
\Delta \mathrm{CT}_{2}=\mathrm{CT}_{\text {sample gene }}-\mathrm{CT}_{\mathrm{GAPDH}} \quad \text { (sample 2) }
\end{gathered}
$$

and $\mathrm{C}$ т is the threshold cycle, where the exponential amplification phase begins.

Absolute expression values were obtained using the expression absolute expression $=$ $\Delta \mathrm{C}$. Threshold values decreased in a linear fashion with the increase of initial RNA amounts present in the sample. Reaction efficiencies were tested before qPCR with values close to $100 \%$ for each primer pair (data not shown).

\section{Statistical analysis}

Data is shown as mean \pm SD. One-way ANOVA analysis was performed with the help of GraphPad Prism software, with several p values and a previous 


\begin{tabular}{|c|c|c|}
\hline Gene & Pair & $\bar{S}$ \\
\hline \multirow{2}{*}{$\begin{array}{c}\text { ALCAM } \\
\text { (self-renewal) }\end{array}$} & Forward & 5'-ACG ATG AGG CAG CAG AGA TAA GT-3' \\
\hline & Reverse & 5'-CAG CAA GGA GGA GAC CAA CAA C-3' \\
\hline \multirow{2}{*}{$\begin{array}{c}\text { CD63 } \\
\text { (self-renewal) }\end{array}$} & Forward & 5'-GCT GTG GGG CTG CTA ACT AC-3' \\
\hline & Reverse & 5'-ATC CCA CAG CCC ACA GTA AC-3' \\
\hline \multirow{2}{*}{$\begin{array}{c}\text { PPAR- } \gamma \\
\text { (adipogenic) }\end{array}$} & Forward & 5'-TGT GAA GCC CAT TGA AGA CA-3' \\
\hline & Reverse & 5'-CTG CAG TAG CTG CAC GTG TT-3' \\
\hline \multirow{2}{*}{$\begin{array}{c}\text { GLUT4 } \\
\text { (adipogenic) } \\
\end{array}$} & Forward & 5'-ATG TTG CGG AGG CTA TGGG-3' \\
\hline & Reverse & 5'AAA GAG AGG GTG TCC GGT GG-3' \\
\hline \multirow{2}{*}{$\begin{array}{c}\text { MyoD } \\
\text { (myogenic) }\end{array}$} & Forward & 5'-CAC TAC AGC GGC GAC TCC-3' \\
\hline & Reverse & 5'-TAG GCG CCT TCG TAG CAG-3' \\
\hline \multirow{2}{*}{$\begin{array}{c}\text { GATA4 } \\
\text { (myogenic) }\end{array}$} & Forward & 5'-GGA AGC CCA AGA ACC TGA AT-3' \\
\hline & Reverse & 5'-GTT GCT GGA GTT GCT GGA A-3' \\
\hline \multirow{2}{*}{$\begin{array}{c}\text { OPN } \\
\text { (osteogenic) }\end{array}$} & Forward & 5'-AGC TGG ATG ACC AGA GTG CT- 3' \\
\hline & Reverse & 5'-TGA AAT TCA TGG CTG TGG AA -3' \\
\hline \multirow{2}{*}{$\begin{array}{c}\text { OCN } \\
\text { (osteogenic) }\end{array}$} & Forward & 5'-CAG CGA GGT AGT GAA GAG ACC-3' \\
\hline & Reverse & 5'TCT GGA GTT TAT TTG GGA GCA G-3' \\
\hline \multirow{2}{*}{$\begin{array}{c}\text { SOX9 } \\
\text { (chondrogenic) }\end{array}$} & Forward & 5'AGA CAG CCC CCT ATC GAC TT-3' \\
\hline & Reverse & 5'-CGG CAG GTA CTG GTC AAA CT-3' \\
\hline \multirow{2}{*}{$\begin{array}{c}\text { Collagen II } \\
\text { (chondrogenic) }\end{array}$} & Forward & 5'-GTG AAC CTG GTG TCT CTG GTC-3' \\
\hline & Reverse & 5'-TTT CCA GGT TTT CCA GCT TC-3' \\
\hline \multirow{2}{*}{$\begin{array}{c}\text { GAPDH } \\
\text { (house-keeping) }\end{array}$} & Forward & 5'ACC CAG AAG ACT GTG GAT GG-3' \\
\hline & Reverse & 5'-TTC TAG ACG GCA GGT CAG GT-3' \\
\hline
\end{tabular}

Table 5.1 Primers used in the qPCR gene expression analysis.

data normality check before analysis of variance. A post-hoc Tukey multiple comparison test was used to assess differences between samples.

Where data did not to follow a Gaussian distribution, checked with the D'Agostino-Pearson omnibus normality test, a non-parametric analysis was performed, comparing the mean rank of each column with the post-hoc Dunn test. Statistically significant differences were indicated with $* \mathrm{p}<0.05,{ }^{* *} \mathrm{p}<0.01$, $* * * \mathrm{p}<0.001$ and $* * * * \mathrm{p}<0.0001$ 


\subsection{Results}

\section{Cell adhesion and signalling}

Cell adhesion and signalling on L. lactis biofilms Murine fibronectin-null fibroblasts $\left(\mathrm{Fn}^{-} / \mathrm{Fn}^{-}\right)$were cultured on L. lactis-FN and L. lactis-empty biofilms, used as interphase between the material surface and the fibroblasts, in FBS-free medium, to rule out the presence of any external FN influence on the material surface other than the FN fragment anchored in the bacterial membrane. After 4 hours, cells cultured on L. lactis-FN displayed well-developed focal adhesion complexes, showing accumulation of vinculin at focal adhesion sites (figure 5.6).

Glass surfaces coated with a $20 \mu \mathrm{g} / \mathrm{mL}$ fibronectin solution and glass surfaces were used as control. Fibroblasts cultured on L. lactis-FN showed a similar behaviour to that found on fibronectin-coated glass. On the other hand, cells cultured on L. lactis-empty remained in a rounded shape, without spreading or focal adhesion plaques development, as on the uncoated glass surface. This was an expected result since there is no fibronectin at the cell-bacteria-material interface to trigger cell adhesion.

Focal adhesion kinase (FAK) are part of the focal adhesion complexes and activate multiple signalling pathways which regulate cell migration, survival, proliferation and differentiation [287-289]. We examined phosphorylation of Tyr-397, the autophosphorylation site in FAK and a binding site for Src and PI-3 kinase $[266,290]$ by Western blotting.

FAK band intensity remained approximately constant, whereas the pFAK band integrated intensity value was significantly higher for cells cultured on $L$. lactis-FN, with levels similar to the ones found in the fibroblasts cultured on FN-coated glass. Fibroblasts cultured on L. lactis-empty and bare glass exhibited minimal FAK phosphorylation. This result demonstrates that the $\mathrm{III}_{7-10}$ fragment located in the bacterial membrane triggers the adhesion signalling pathway in contiguous cells.

Cell viability on this living interface was assessed. Fibronectin-null fibroblasts were cultured on L. lactis-FN and L. lactis-emtpy monolayers, FN-coated glass and bare glass, and cultured for 4 hours in serum-free medium. Then, a viability analysis was performed, using the Invitrogen viability kit for mammalian cells. This kit provides a two-colour fluorescence assay using two probes that measure recognized parameters of cell viability: cytoplasmic esterase activity and cell membrane integrity.

Live cells have ubiquitous intracellular esterase activity, which is required 

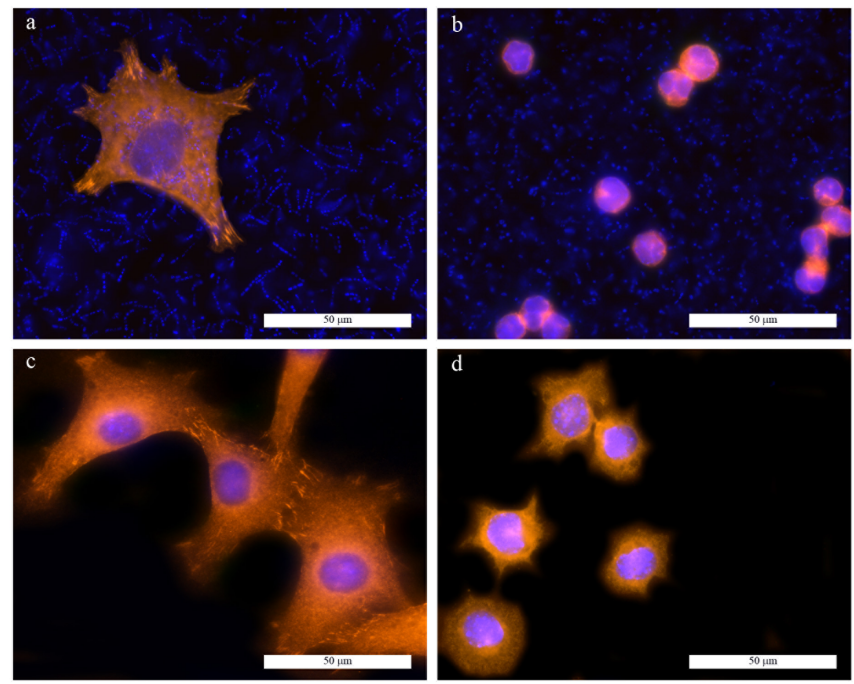

Figure 5.6 a) Cells cultured on L. lactis-FN displayed well-developed focal adhesion complexes, while in b) L. lactis-empty remained in a rounded shape. Cells cultured on fibronectin-coated glass, in c), displayed a similar behaviour to the ones cultured on L. lactis-FN, remaining unattached and without focal adhesion plaques on bare glass, shown in d). This behaviour suggest the role of the membrane-displayed fibronectin fragment as an adhesion trigger. Scale bar size is $50 \mu \mathrm{m}$

for the conversion of the non-fluorescent, cell permeant dye calcein-AM into calcein, a polyanionic and intensely fluorescent dye that is well retained within live cells, producing an intense green fluorescence. On the other hand, ethidium homodimer- 1 is a non-permeant dye that only enters cells with compromised membrane integrity and binds strongly to nucleic acids, with a 40 -fold fluorescence enhancement. A fluorescence microscope was used to image the cells tested with this kit.

Cells showed viability values higher than $93 \%$ for each surface, and up to $99.5 \pm 0.7 \%$ in the cells cultured on the L. lactis-FN monolayer. This result is consistent with the formation of focal adhesion complexes and FAK phosphorylation behaviour.

Cell morphology and adhesion are controlled by biofilm density As previously stated, biofilms of different areal density or bacterial coverage were obtained from different volumes of bacterial culture. Murine NIH3T3 fibro- 

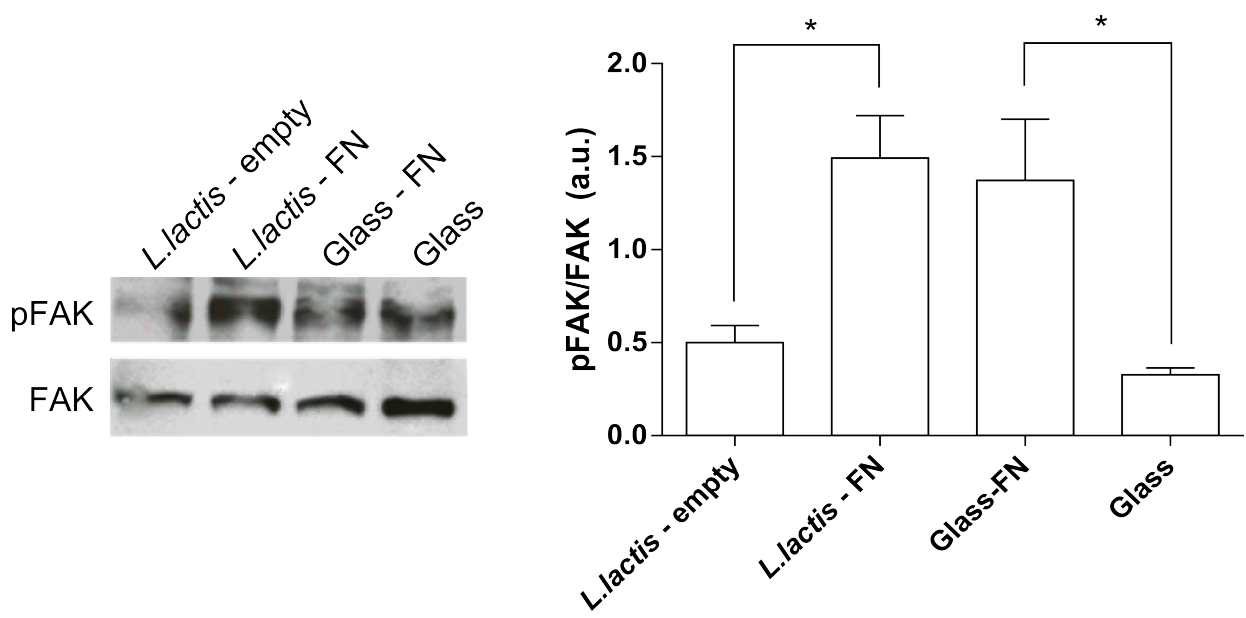

Figure 5.7 FAK phosphorylation analysis with Western blot. Fibronectin-null murine fibroblasts cultured on FN-expressing L. lactis showed a pFAK/FAK ratio higher than fibroblasts cultured on control L. lactis and comparable to cells cultured on FN-coated glass surface. Phosphorylation ratio was similar in the cells cultured on glass and on L. lactis-empty. Data was analysed with an ANOVA test, $\mathrm{N}=3$, and statistically significant differences between L. lactis-FN, L. lactis-empty, and glass-FN and glass were found. * $\mathrm{p}<0.05$

blastic and $\mathrm{C} 2 \mathrm{C} 12$ cells were used to assess the influence of this different bacterial density, and hence different amount of exposed III 7-10 $_{\text {fragment. }}$

Four different density biofilms were prepared from four volumes of logphase bacterial cultures, namely 300, 500, 700 and $1000 \mu \mathrm{L}$, which were poured on P24 multiwell plates and left for 24 hours at $30{ }^{\circ} \mathrm{C}$. Biofilm densities, expressed as percentage of area covered by bacteria, were $4.6 \pm 1.1 \%$ for 300 $\mu \mathrm{L}, 11.4 \pm 4.3 \%$ for $500 \mu \mathrm{L}, 19.1 \pm 2.8 \%$ for $700 \mu \mathrm{L}$ and $27.6 \pm 8.4 \%$ for $1000 \mu \mathrm{L}$.

Cells were seeded at an initial density of 5,000 cells $/ \mathrm{cm}^{2}$ in DMEM with 4.5 $\mathrm{g} / \mathrm{L}$ glucose supplemented with $10 \mu \mathrm{g} / \mathrm{mL}$ tetracycline. After three hours, cells were immunostained for vinculin and FITCconjugated phallacidin to stain focal adhesion complexes and actin cytoskeleton respectively. Area and roundness values were calculated from binary masks segmented from the actin (Сy3, red channel) as this stain, while much more intense in focal adhesions than in the cytoplasm and nuclei area, is bright enough to discriminate the whole cell shape from the non-fluorescent background.

Results obtained from the NIH3T3 cell culture are shown in Figure 5.9. 

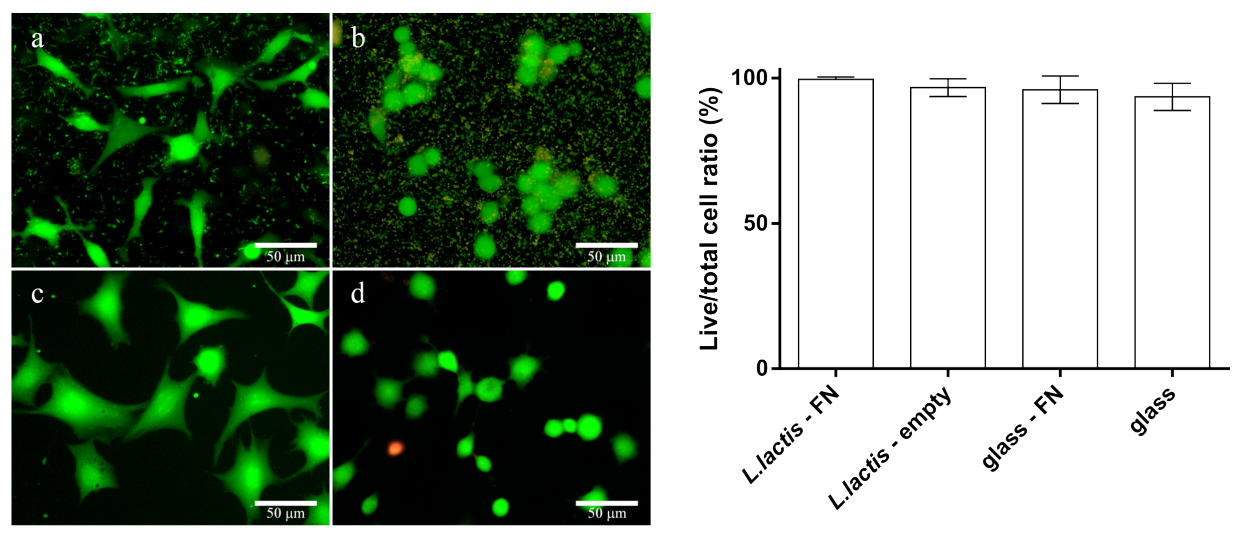

Figure 5.8 Viability test of $\mathrm{Fn}^{-} / \mathrm{Fn}^{-}$fibroblasts cultured on a) L. lactis-FN, b) L. lactis-empty , c) FN-coated glass and d) bare glass. Cells were cultured for 4 hours in serum-free medium. The highest viability value corresponded to the cell population cultured on L. lactis-FN, with a mean value of $99.5 \pm 0.7 \%$, while on L. lactis-emtpy was $96.7 \pm 3.0 \%, 96.0 \pm 4.7 \%$ for FN-coated glass and $93.5 \pm 4.6$ $\%$ for bare glass. ANOVA analysis of the data showed no statistically significant differences. $\mathrm{N} \geq 6$ for all data, represented as mean $\pm \mathrm{SD}$

Cell area increased with biofilm density, which is directly related to the amount of $\mathrm{III}_{7-10}$ available to the cultured cells. ANOVA revealed statistically significant differences between three groups of samples, L. lactis-emtpy, L. lactisFN biofilms, including FN-coated glass and the bare glass surface. Cells cultured on L. lactis-emtpy and glass presented smaller areas than cells cultured on $L$. lactis-FN biofilms and FN-coated glass.

Despite the fact that statistically non-significant differences were found between areas values of the cells cultured on different density L. lactis-FN biofilms, data represented in the Figure 5.9 showed an increase in an areal density-dependent manner, which was expected due to the higher amount of FN available to develop focal adhesion complexes. The highest value was found in the cells cultured on FN-coated glass, with very similar values compared to cells cultured on maximum density L. lactis-FN biofilm.

Data obtained from image analysis allowed the calculation of cell roundness in the same samples. Cell roundness is defined as the inverse of the aspect ratio of the ellipse that fits best on the cell shape, and is calculated as

$$
\text { roundness }=\frac{4 \text { area }}{\pi \text { (major semiaxis })^{2}}
$$


A
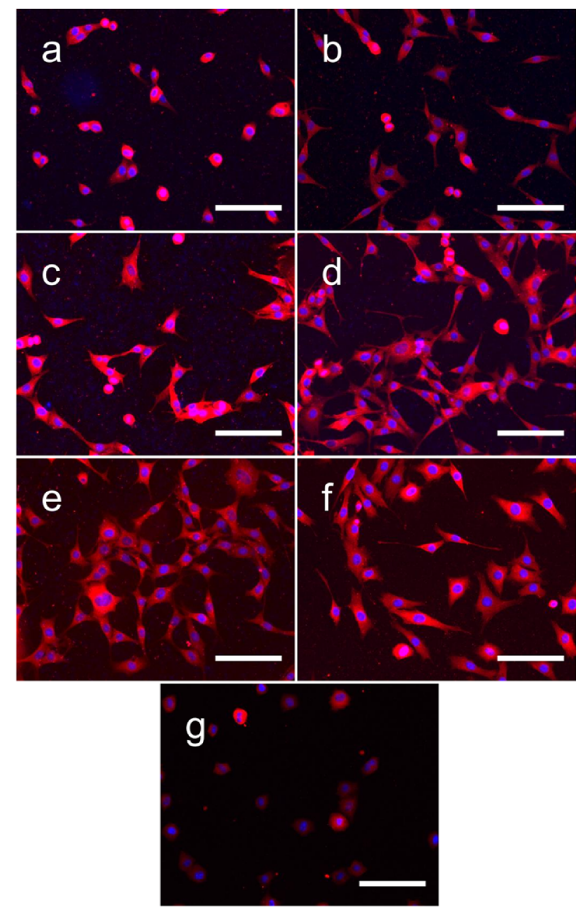

B
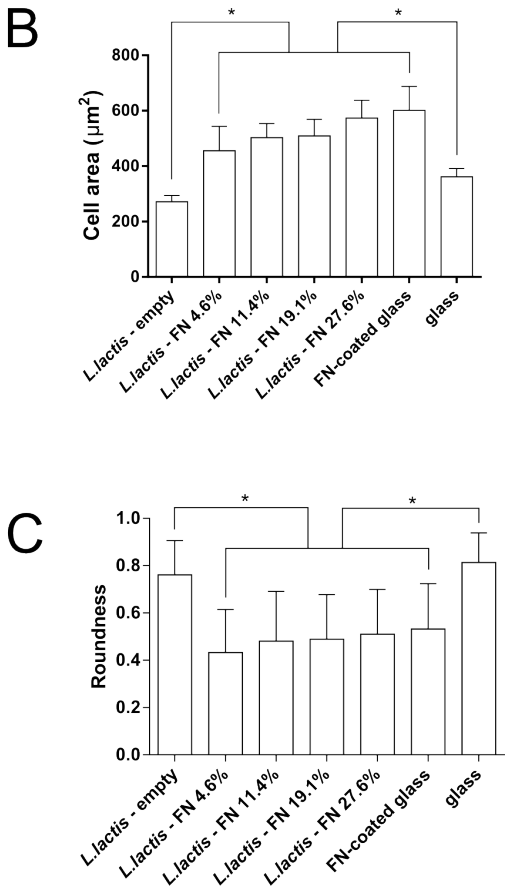

Figure 5.9 Adhesion behaviour of NIH3T3 cells cultured on a) L. lactis-emtpy $27.6 \%$; b) L. lactis-FN $4.1 \%$; c) L. lactis-FN $11.4 \%$; d) L. lactis-FN $19.1 \%$; e) L. lactis-FN $27.6 \%$ coverage biofilm; f) FN-coated glass from a $20 \mu \mathrm{g} / \mathrm{mL}$ fibronectin solution and g) bare glass. Vinculin is shown in red and nuclei in blue. Cell area increases as the biofilm density does. ANOVA (*p < 0.05) reveals statistically significant differences between L. lactis-emtpy, glass and the L. lactis-FN biofilms, including cells cultured on FN-coated glass. Roundness values were also found to behave differently on the different surfaces. Data presented as mean \pm SD, with $\mathrm{N} \geq 35$

Obtained values are shown in Figure 5.9.

Roundness values were found to be inversely related to area values. That is to say, cells that showed poor spreading and small area values stayed in a rounder shape than cells cultured on L. lactis-FN biofilms or FN-coated glass. NIH3T3 is a fibroblastic cell line, so cell spreading involves the development of an elongated shape, with major/minor semi axis ratio increasing as the cell spreads. In a similar way to data shown in Figure 5.9, two different categories were extracted from the ANOVA analysis, one corresponding to cells on $L$. lactis-empty biofilm and glass, and the L. lactis-FN biofilms and FN-coated glass. 
Higher area values showed an inverse correlation with roundness values. The biological meaning is the influence of the $\mathrm{III}_{7-10}$ fragment on the development of focal adhesions, and via intracellular signalling, cell behaviour related to spreading and actin cytoskeletal reorganization, which is ultimately one of the most important factor that defines the shape of a cell in the initial adhesion stages. Cells were cultured in serum-free medium to avoid the interference and to ensure that the only fibronectin available was the fragment displayed on the bacterial membrane, although these cells are not fibronectin null and in the mid-term will secrete, create and eventually reorganize a fibronectin network.

To check whether this behaviour was due to the NIH3T3 fibroblastic phenotype or if it was only an effect of the different amount of available fibronectin, the same experiment, under the same conditions, was performed using murine C2C12 myoblasts. These cells can differentiate and fuse into myotubes, which eventually leads to a polar alignment and cytoplasmic fusion, but in short term assays, 3 hours, adhesion behaviour is much like in fibroblasts. Cells were cultured at the same density on the same L. lactis-empty, L. lactis-biofilms, FN-coated glass and bare glass, stained with an anti-vinculin antibody and FITC-conjugated phallacidin, to visualize the actin cytoskeleton, followed by image analysis and extraction of the morphological features (area, roundness) from the segmented images.

Figure 5.10 shows the results of the vinculin and phallacidin immunostaining of a 3-hour culture. Cells cultured on L. lactis-empty biofilm remained in a round shape, without spreading or focal adhesion development, while in the L. lactis-FN biofilms there is an increase in the cell area which seems to be correlated to the areal density of the underlying biofilm. Cell shape is very similar in L. lactis-empty and bare glass, due to the lack of any adhesion protein. Cell area and roundness were quantified like in the NIH3T3 culture, that is to say, fluorescence images of the red channel (vinculin) were segmented and binarized to obtain the shape of each cell, which where analysed with Image J Fiji.

A good correlation between cell area and L. lactis-FN biofilm density was found. Surprisingly, cells cultured on L. lactis-FN biofilm with $27.6 \%$ coverage showed higher area values than cells cultured on FN. This result agrees with NIH3T3 results, and is a good support that biofilm density, and thus III $_{7-10}$ amount available to mammalian cells, is key to direct the early cell response, specifically cell adhesion and morphology, which is a first step before considering other long-term processes such as cell differentiation.

However, roundness values in C2C12 were less affected by biofilm density, 

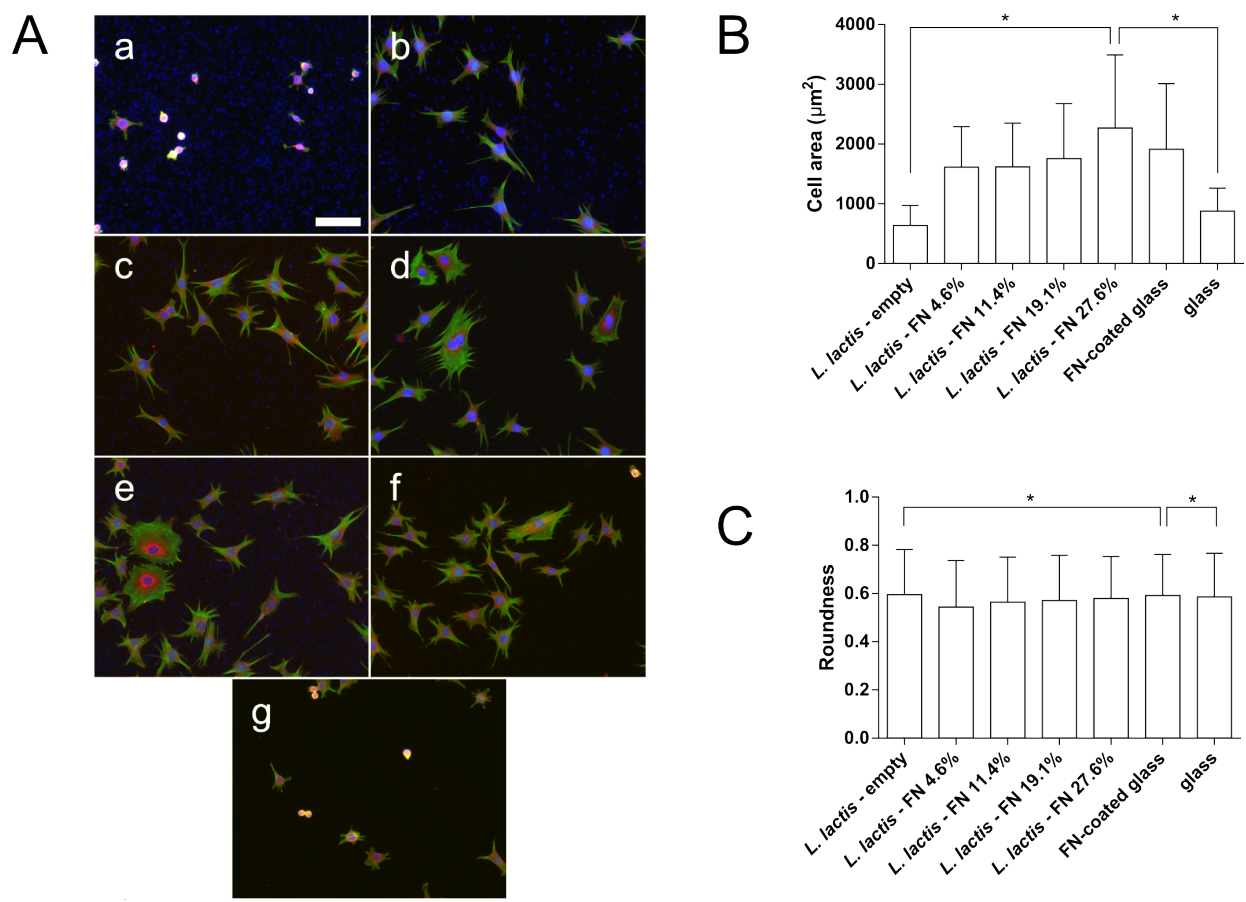

Figure 5.10 Vinculin (red) and actin (green) immunostaining of C2C12 cells cultured on a) L. lactis-emtpy $27.6 \%$; b) L. lactis-FN $4.1 \%$; c) L. lactis-FN 11.4 \%; d) L. lactis-FN $19.1 \%$; e) L. lactis-FN $27.6 \%$ coverage biofilm; f) FN-coated glass from a $20 \mu \mathrm{g} / \mathrm{mL}$ solution and g) bare glass. DAPI-stained nuclei shown in blue. An area increase related to L. lactis-FN biofilm areal density was found, with a maximum corresponding to the L. lactis-FN biofilm with a coverage of $27.6 \%$. Cell roundness was calculated using the same images. Results were very similar as the NIH3T3 cell cultures, with highest roundness values corresponding to $L$. lactis-emtpy and glass, due to the lack of spread and focal complexes development, and lower values corresponding to the L. lactis-FN biofilms and FN-coated glass. Scale bar size is $100 \mu \mathrm{m}$. Data shown as mean $\pm \mathrm{SD}, \mathrm{N} \geq 400$

which is likely due to the phenotype of these cells, since they exhibit a star-like and not an elongated shape like NIH3T3. Best-fit ellipse had closer major- and minor- semi axis values. Nevertheless, a variance analysis performed on these data showed statistically significant differences between L. lactis-empty, glass and the group composed of L. lactis-FN biofilms and FN-coated glass.

Focal adhesion complexes from the same culture were counted and compared to L. lactis-FN biofilm surface coverage. In vinculin immunostaining, focal adhesions appeared as bright spots, mainly in the cell boundaries. To avoid 
altered area and roundness values that cell overlapping would have produced, only isolated cells were used.
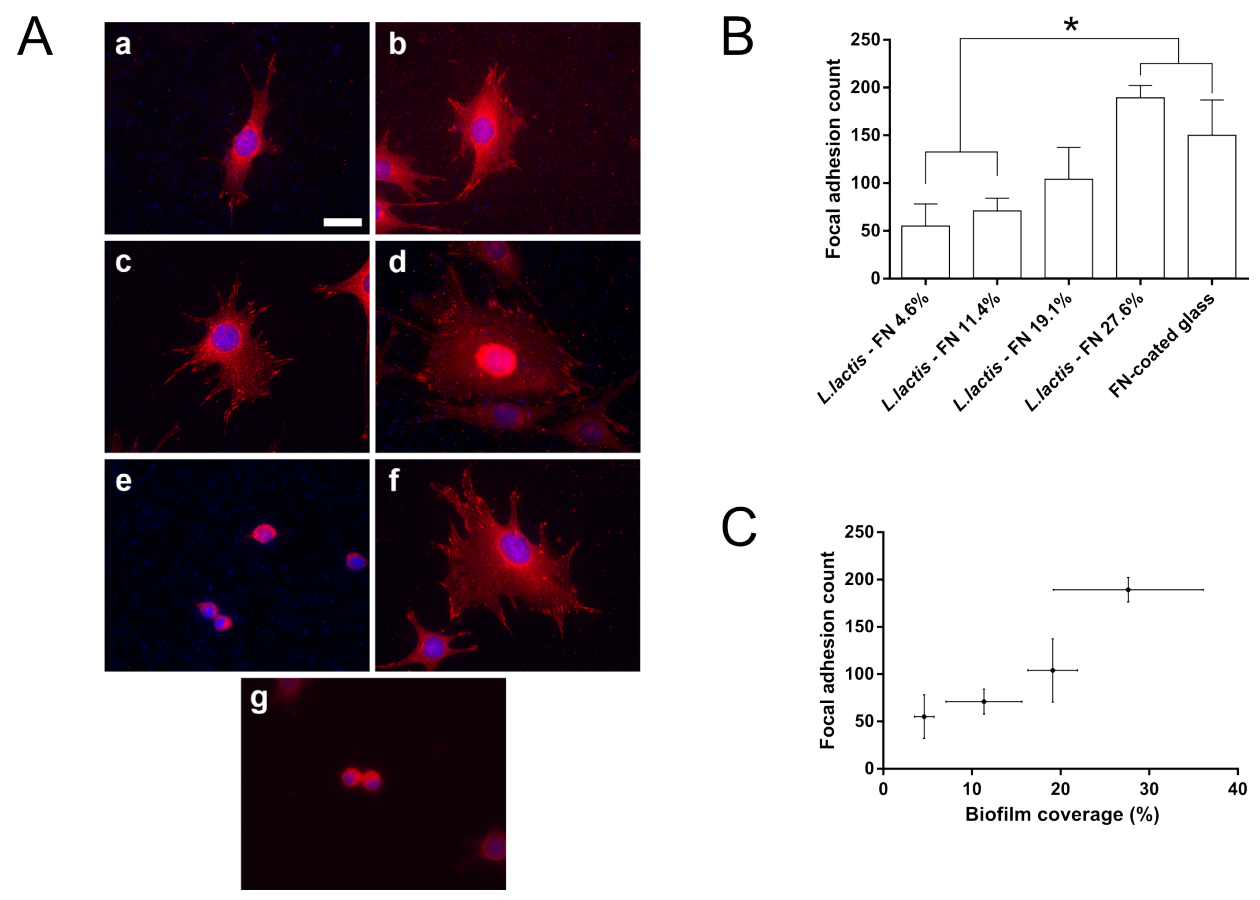

Figure 5.11 C2C12 cells cultured on a) L. lactis-FN 4.6\%; b) L. lactis-FN $11.4 \%$; c) L. lactis-FN $19.1 \%$ and d) L. lactis-FN $27.6 \%$ biofilms; e) L. lactis-emtpy biofilm, f) FN-coated glass and g) bare glass surfaces were used to measure the number of focal adhesion complexes in at least five different cells. B) Focal adhesion count of C2C12 cells cultured on L. lactis-FN biofilms and FN-coated glass. We found statistically significant differences between two groups, L. lactis-FN biofilms with 4.6 and $11.4 \%$ coverage and L. lactis-FN $27.6 \%$ and FN-coated glass. C) There is an approximate linear relationship between both variables, suggesting an increase in focal adhesion count that directly relates to the available amount of fibronectin displayed to C2C12 cells. ANOVA ( ${ }^{*} \mathrm{p}<0.05$ ) analysis performed on $\mathrm{N} \geq 5$ representative cells, values displayed as mean $\pm \mathrm{SD}$

Vinculin-stained cells cultured on different biofilms, shown in Figure 5.11, were analysed with Image - Fiji to segment and isolate focal adhesions, which appeared as bright spots in the boundaries of each cell. These values were compared between each condition, finding that focal adhesion count is also depends on the amount of displayed $\mathrm{III}_{7-10}$.

Although area values were similar for cells cultured on the lower density $L$. 
lactis-FN biofilms, focal adhesion analysis revealed that cell area does not need to be necessarily related to focal adhesion development, as shown in Figure 5.11. The same data is represented in a scatter plot in the same figure.

Figure 5.11 shows a direct relationship between focal adhesion count and biofilm density, i.e. avilable amount of $\mathrm{III}_{7-10}$ expressed a bacterial membrane protein. Since cells were cultured in serum-free medium, focal adhesion development can be only attributed to this bacterially expressed fibronectin.

\section{Myogenic differentiation and cell signalling}

As previously shown, L. lactis modified to express the $\mathrm{III}_{7-10}$ fragment carrying the RGD adhesion and PHSRN synergy motifs promotes focal adhesion formation and development as well as FAK signalling at similar levels as native FN in fibroblasts. It was assessed the ability of this living interface, built on synthetic surfaces, to support cell differentiation by examining myogenic differentiation.

Integrin-mediated cell adhesion through $\alpha_{5} \beta_{1}$ and other integrins triggers a cascade of intracellular signals such as the p38 mitogen-activated protein kinase (p38 MAPK) pathway, which is involved in the myoblast differentiation process, by promoting the activity of several transcription factors and regulating cell cycle withdrawal. The RGD motif on the 9th type III repeat is responsible for the early interaction with $\alpha_{5} \beta_{1}$.

Lack of this interaction, by either blocking the RGD adhesion motif or by inhibiting the expression of $\alpha_{5}$ subunit in knockout cells, prevents early adhesion to the substrate. Focal adhesion kinase phosphorylation is an intermediary step between adhesion and downstream targets, including MAPK pathways. As a result, Tyr-397 autophosphorylation of FAK plays a central role during myoblast differentiation in 2D cultures. Although Tyr-397 phosphorylation of FAK is transiently reduced, contributing to trigger the myogenic genetic program, is later activated, as it is central to terminal differentiation into myotubes.

Fibronectin also accelerates cell alignment and elongation compared to other standard substrates like laminin or gelatin [13]. Although C2C12 cells will eventually grow until confluence and then fuse and differentiate into myotubes, the presence of the RGD peptide speeds up this process, leading to myotube formation without the need to reach confluence.

To assess the competence of $L$. lactis-FN biofilms to induce differentiation, C2C12 cells were cultured on maximum-density, i.e. $27.6 \%$ coverage L. lactisFN biofilms, maximum-density L. lactis-empty biofilms, glass coated with a 20 $\mu \mathrm{g} / \mathrm{mL}$ solution of fibronectin, and collagen type I $(1 \mathrm{mg} / \mathrm{mL})$ coated glass the gold-standard substrate for myogenic differentiation. [291] 
Cells were cultured at 20,000 cells $/ \mathrm{cm}^{2}$ in FBS-free medium and allowed to attach for three hours. Then, medium was then changed to differentiation medium, containing $1 \%$ insulin-transferrin-selenium without FBS. The culture was kept four days and a immunostaining for sarcomeric myosin was performed at the end of the culture. Strikingly, myogenic differentiation values were higher on the L. lactis-FN biofilms than on native fibronectin and collagen I-coated substrates. It is important to emphasize that these differences in myogenic differentiation are not due to cell density differences.

Although a direct correlation between the number of cells on the surface and the level of myogenic differentiation has been found, the number of cells in the L. lactis-FN biofilm is slightly lower than in the FN and collagen I controls (Figure 5.12).
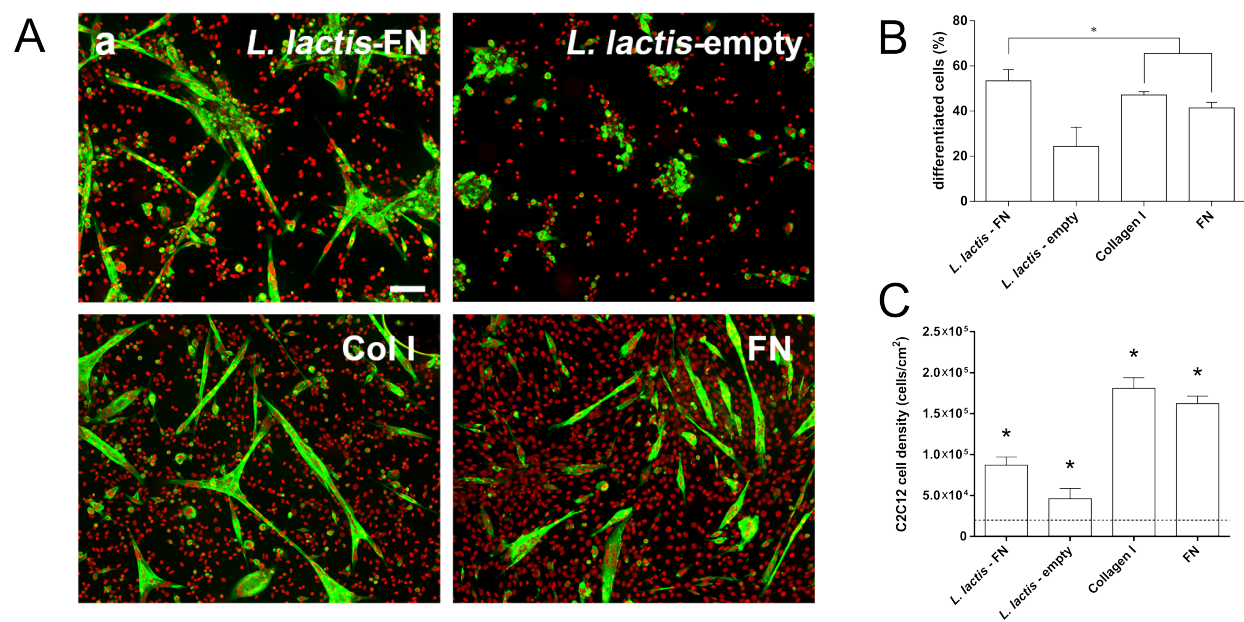

Figure 5.12 A) Myogenic differentiation on L. lactis-emtpy, L. lactis-FN, Collagen I and fibronectin substrates. Differentiated myotubes were immunostained against anti-sarcomeric myosin, in green. Nuclei shown in red. B) Higher differentiation values were found on L. lactis-FN compared to collagen I and FN-coated glass. C) Cell density on different substrates after 4 days of culture. Dashed line points out initial seeding density $\left(20,000\right.$ cells $\left./ \mathrm{cm}^{2}\right)$. All columns showed statistically significant differences between each other. Values are presented as mean $\pm \mathrm{SD}$, while the analysis of variance was conducted with $N \geq 10$ and *p $<0.05$. Data presented as mean \pm SD. Scale bar size is $25 \mu \mathrm{m}$

Figure 5.12 shows myotubes developed on the four tested substrates. Differentiation levels found in L. lactis-FN biofilm were higher than in collagen I and FN, whereas in L. lactis-emtpy no myotubes were found. 
Differentiation degree values were calculated by image analysis. At least 10 fields at $10 \times$ magnification were taken in two channels, red for nuclei and green for sarcomeric myosin-stained myotubes.

To calculate the differentiation degree, a total nuclei count was performed using Image J - Fiji, after binarizing the image. Green channel was also binarized using the Otsu thresholding algorithm and, where needed, a semiautomatic machine-learning algorithm to obtain properly binarized masks. Both binary images were multiplied to calculate the number of nuclei below myotubes (differentiated cells). The ratio between differentiated and total cells can be seen in Figure 5.12B.

Cells cultured on L. lactis-FN and L. lactis-empty proliferated to a lesser extent compared to collagen I and FN, but as shown in the Figure 5.12, that did not have an effect on differentiation values.

Activation of FAK via Tyr-397 autophosphorylation was examined with Western blot. C2C12 myoblasts were cultured with at 20,000 cells $/ \mathrm{cm}^{2}$ in FBS-free medium, for three hours. Then, cells were lysed and the protein extract was purified and subjected to a $7 \%$ SDS-PAGE electrophoresis. Bands corresponding to FAK and pFAK were visualized and quantified by densitometry with the help of the Image J - Fiji software.
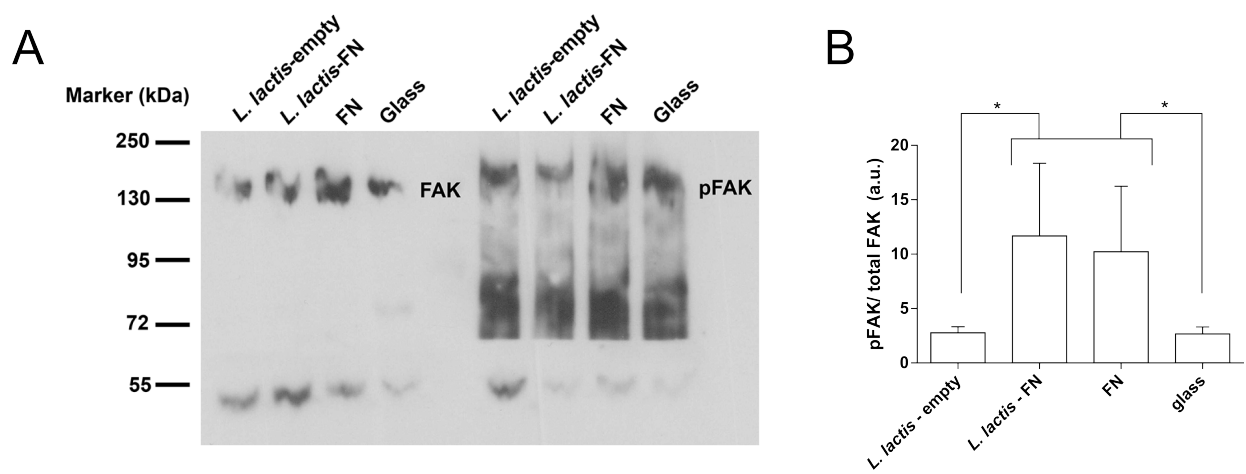

Figure 5.13 A) Representative Western blot bands for pFAK and FAK on the different biointerfaces. $\alpha$-tubulin was used as housekeeping protein for normalization of the analysed values. Quantification of Western blot bands. ANOVA test showed statistically significant differences between each column, *p $<0.05$. Data presented as mean $\pm \mathrm{SD}$

pFAK/FAK ratio was found to be higher in the cells cultured on L. lactis-FN biofilm and FN-coated glass compared to the ones cultured on L. lactis-emtpy 
and bare glass surfaces. This result supports the previous results, since the bacterially expressed $\mathrm{III}_{7-10}$ fragment is interacting with the cellular fibronectins and leading to the activation of the FAK via phosphorylation.

\section{Adhesion and differentation of human mesenchymal stem cells}

Behaviour of bone marrow-derived human mesenchymal stem cells (hMSC-BM) was also studied on L. lactis-empty and L. lactis-FN biofilms. Maximum density biofilms were produced on PEA-coated glass coverslips, using FN-coated (from a solution of $20 \mu \mathrm{g} / \mathrm{mL}$ ) PEA on glass coverslips as a positive control. After $3 \mathrm{~h}$, cells were immunostained against vinculin, using FITC-conjugated phallacidin to stain the actin cytoskeleton.

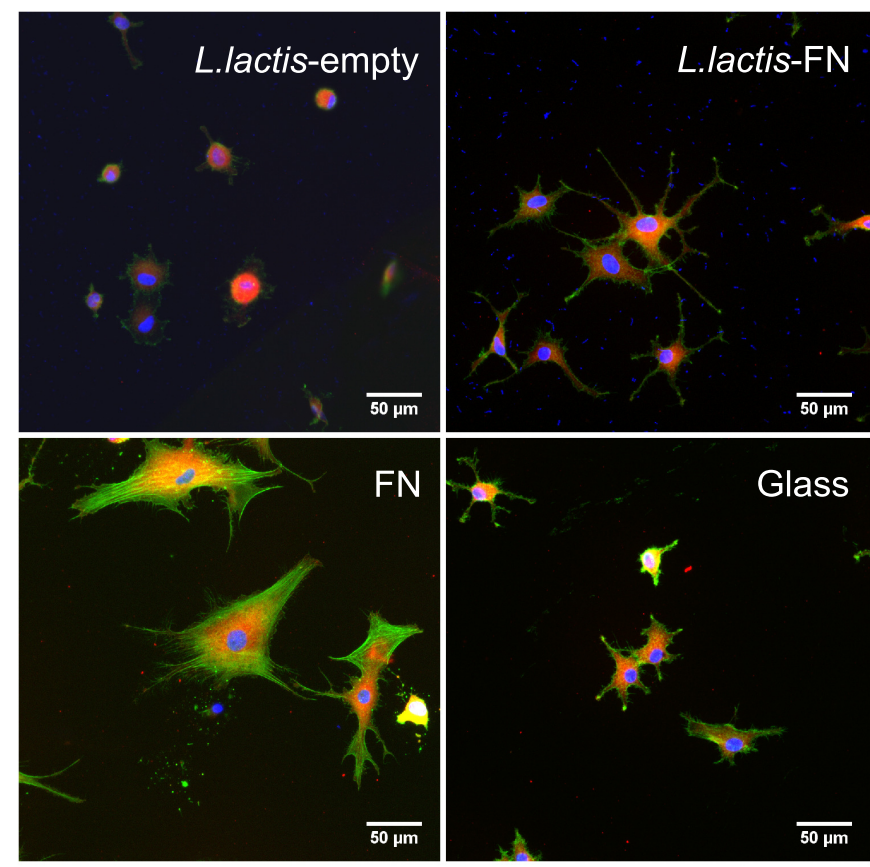

Figure 5.14 Adhesion behaviour of hMSC-BM cells on L. lactis-emtpy and $L$. lactis-FN biofilms, FN-coated PEA coverslips and bare glass. hMSC behaviour is very similar to $\mathrm{C} 2 \mathrm{C} 12$, NIH3T3 and $\mathrm{Fn}^{-} / \mathrm{Fn}^{-}$fibroblasts.

Much like in the previous adhesion assays, hMSC-BM cells cultured on $L$. lactis-emtpy biofilms remained in a rounded shape without any signs of actin cytoskeleton development. On L. lactis-FN biofilm, a developing cytoskeleton is 
clearly visible, although is less developed than in the FN-coated PEA coverslip. In glass, as expected, cells showed no adhesion, keeping a rounded shape at the end of the culture time.

Cell area and roundness were quantified using Fiji-ImageJ software. The green channel, corresponding to the actin staining, was used to determine cell area and shape, since in these images the cell silhouette is clearly visible and easy to segment from the background (Figure 5.14).

A

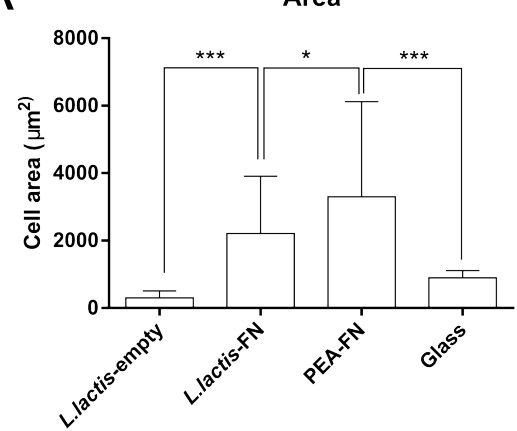

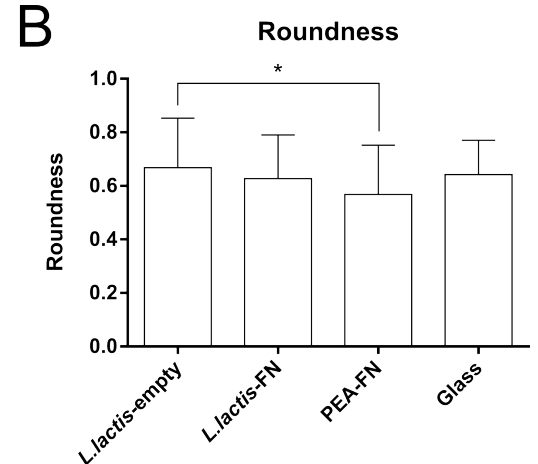

Figure 5.15 hMSC-BM cell area $\left(\mu \mathrm{m}^{2}\right)$ (A) and roundness (B) after a 3-hour culture. Highest area values were found on FN-coated PEA coverslips, although statistical significance between hMSC cells cultured on L. lactis-empty and L. lactisFN biofilms were also found. As expected, cells cultured on L. lactis-empty and glass showed lowest area values. Higher roundness values were present on cells cultured on L. lactis-empty biofilm and uncoated glass. Statistical significance was found for cells cultured on L. lactis-empty and PEA-FN. * stands for p $<0.05$ and $* * *$ for $\mathrm{p}<0.001$. Results are presented as mean $\pm \mathrm{SD}$. Parametric ANOVA was performed on $\mathrm{N} \geq 15$ cells.

Roundness values were found to be very similar across the different tested conditions, although this can be attributed to the shape of the adhered cells, as they did not show an elongated, fibroblast-like morphology.

\section{ERK1/2 phosphorylation analysis}

Early adhesion behaviour was also assessed via ERK1/2 phosphorylation analysis. As previously described in the materials and methods section, a 30-minute culture of hMSC-BM cells on L. lactis-empty, L. lactis-FN biofilms produced on PEA-coated glass coverslips, FN-coated PEA and bare polystyrene was used to quantify the amount ERK1/2 phosphorylated on Thr-202/Tyr-204. Results are shown in Figure 5.16 


\section{ERK1/2 phosphorylation}

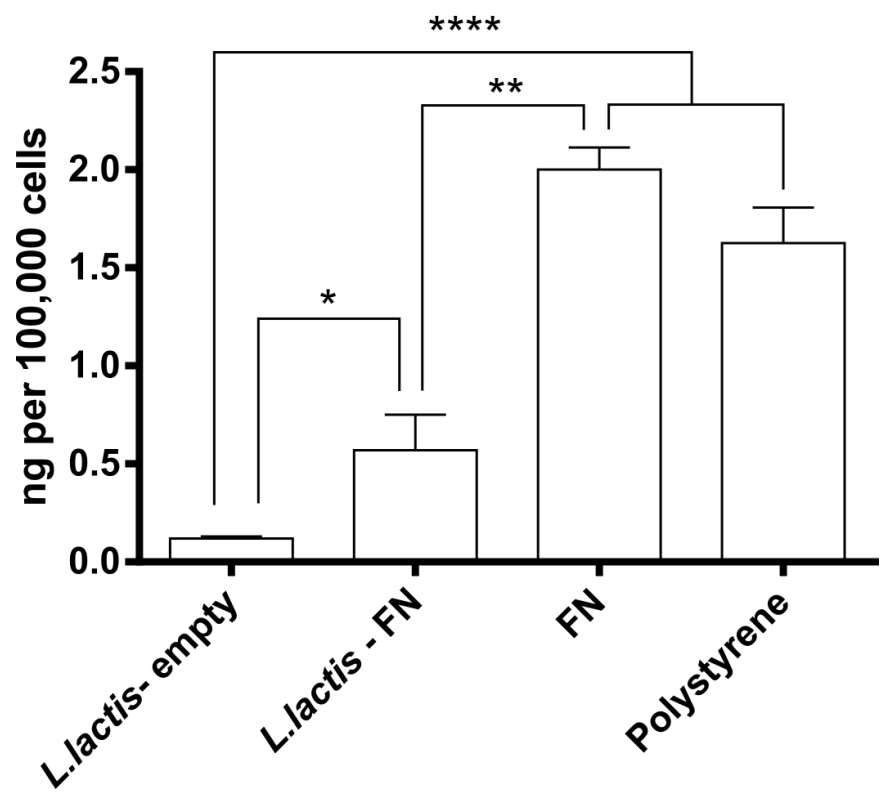

Figure 5.16 ERK1/2 phosphorylation on hMSC-BM cells cultured on L. lactis-empty and L. lactis-FN biofilms developed on PEA, FN-coated PEA and bare polystyrene. Phosphorylation analysis was assessed with sandwich ELISA after a 30-minute culture. Statistically significant differences were found between phosphorylation levels of cells cultured on L. lactis-emtpy and L. lactis-FN biofilms (*p $<0.05)$, L. lactis-emtpy and FN and polystyrene (****p < 0.0001) and between $L$. lactis-FN and FN-coated PEA (**p $<0.01) . \mathrm{N} \geq 3$, data shown as mean $\pm \mathrm{SD}$

As shown in the introduction of this chapter, ERK1/2 are two isoforms of the extracellular regulated kinase, a kinase pertaining to the MAPK regulatory pathway, involved in proliferation and migration processes. As expected $\mathrm{III}_{7-10}$ triggers the activation, via dimerization, of the $\alpha_{5} \beta_{1}$ integrin, leading to the activation of this pathway. Cells cultured on the L. lactis-empty biofilm showed negligible phosphorylation levels, whereas cells cultured on FN-coated PEA and cell-culture treated polystyrene showed the highest phosphorylation levels.

It is interesting to note that cell area, a variable greatly influenced by the presence of adhesive cues that allow cells to adhere and spread, and ERK1/2 phosporylation, an event taking place upstream to the formation of focal adhesion complexes and the subsequent activation of the MAPK signalling pathway, 
are related. In the assays done in this cell line, these two variables seemed to be related, much like in the results obtained in the other cell lines, notably C2C12. It looks like biological activity of bacterially expressed $\mathrm{III}_{7-10}$ fragment is affecting hMSC-BM cells to a lesser extent if compared to the other tested cell lines. Another explanation could be the fact that this cells require longer times than the other tested cell lines to fully adhere and develop focal adhesion complexes.

\section{Differentiation assessment by gene expression analysis}

Differentiation analysis was performed in hMSCs cultured at 20,000 cells $/ \mathrm{cm}^{2}$ on surfaces covered with L. lactis-empty and L. lactis-FN biofilms (developed on PEA) FN-coated PEA and bare polystyrene. Cells were maintained in DMEM supplemented with $10 \mu \mathrm{g} / \mathrm{mL}$ tetracycline.

After 14 days, total RNA was extracted and retrotranscripted to cDNA, which was used to quantify the relative expression levels of the genes depicted in Table ?? for each lineage.

\begin{tabular}{|c|c|}
\hline Lineage & Differentiation markers \\
\hline Self-renewal & ALCAM, CD63 \\
\hline Chondrogenic & SOX9, Collagen II \\
\hline Osteogenic & OPN, OCN \\
\hline Myogenic & MyoD, GATA4 \\
\hline Adipogenic & PPAR- $\gamma$ \\
\hline
\end{tabular}

Table 5.2 Summary of the differentiation markers used for qPCR analysis.

$\Delta \mathrm{CT}$ results are shown in Figure 5.17.

Results from the qPCR analysis, with the exception of SOX9 gene, for which no detectable expression was found in any condition, showed the lowest $\triangle \mathrm{CT}$ values for self-renewal markers, ALCAM and CD63. No significant differences were found across the different assessed conditions.

The other studied genes, related to adipogenic, osteogenic, chondrogenic and myogenic differentiation showed similar values with, again, statistically non-significant differences between conditions or genes in the same condition. A subsequent $\Delta \Delta \mathrm{CT}$ analysis was done, using two different conditions as controls, as shown in the Figure 5.18

Relative expression levels, expressed as $\Delta \Delta \mathrm{CT}$, were found not to be statistically significant across conditions, taking two different conditions as controls, 


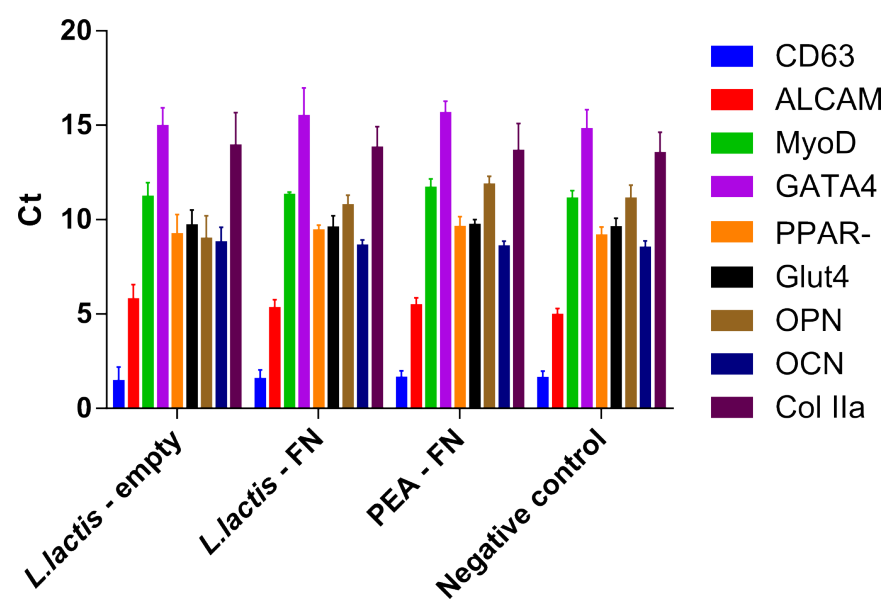

Figure 5.17 $\Delta \mathrm{CT}$ values for each studied gene. Lowest values were found in the self-renewal genes, CD63 and ALCAM, compared to the rest. This result suggest that hMSCs are maintaining its self-renewal capabilities after 14 days of culture.
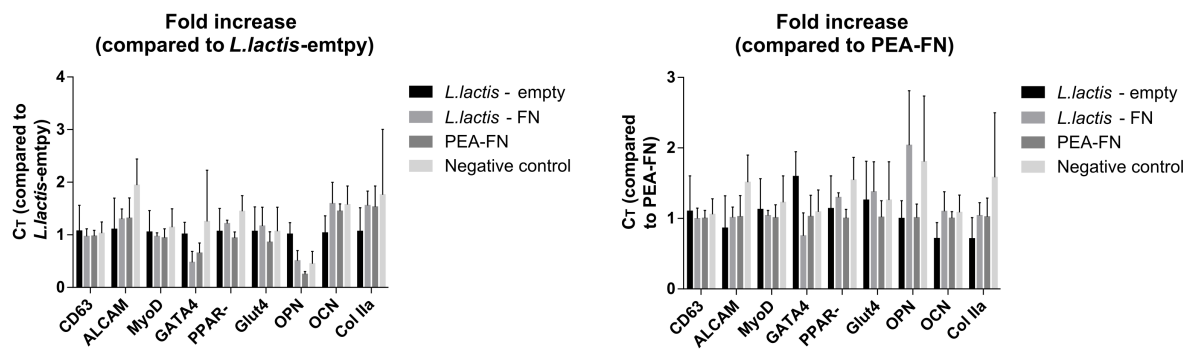

Figure 5.18 Relative expression (fold increase) compared to two different control conditions, that is to say, L. lactis-empty and FN-coated PEA. Again, no statistically significant differences were found between conditions for each studied gene.

that is to say, cells cultured on L. lactis-empty biofilm and on FN-coated PEA.

As seen throughout this work, cell behaviour on L. lactis-emtpy biofilms was found to be very similar to the one found on non-functionalised surfaces such as glass or polystyrene. FN-coated PEA was also used as a kind of positive control, since FN is known to induce cell adhesion and intracellular signalling for a multitude of processes.

The conclusion that can be drawn from these results is that, since the cultures were made in a medium supplemented with $1 \%$ foetal bovine serum, 
the influence of both bacterially expressed $\mathrm{III}_{7-10}$ and adsorbed FN has been superseded by the protein mixture present in the FBS. Since FBS is vital to ensure the viability of the hMSCs in long-term cultures, the effect of the bacterially expressed fibronectin should be assessed by using fibronectin-depleted FBS. [292]

\subsection{Conclusions}

Engineering microenvironments to provide cells with dynamic cues, as occurs in the natural extracellular matrix, is a field of intensive research seeking to direct the differentiation of stem cells and advance in strategies for tissue repair and regeneration [293].

Several approaches have been explored, spanning from functionalisation of material surfaces with cell adhesive motifs to the incorporation of proteasedegradable fragments in polymer hydrogels that allow changes in the material structure as cells secrete proteases to remodel the ECM [15, 291, 294]. Dynamic surfaces have also been engineered to present cell adhesive RGD sequences on-demand. [14, 15, 295]

From a different perspective, dynamic cell microenvironments have been engineered to present and release growth factors in a sustainable and controlled way to stimulate and support cell differentiation. [16, 296-301]

As seen in Chapter 4, we have engineered [216] Lactococcus lactis to display the $\mathrm{III}_{7-10}$ domains of human fibronectin as a membrane-bound protein. III $_{7-10}$ contains the RGD and PHSRN synergy sequences which promote cell adhesion and differentiation [31, 302]. Several cell lines, namely fibronectin-null fibroblasts $\left(\mathrm{Fn}^{-} / \mathrm{Fn}^{-}\right)$, NIH3T3 and $\mathrm{C} 2 \mathrm{C} 12$ adhere, spread and develop focal adhesion complexes on the engineered L. lactis biofilm, behaving in a similar way as when cultured directly on a FN-coated surface. [216]

This strain produces stable biofilms that support cellular growth, adhesion and differentiation [211]. The formation of the biofilm starts when some individual cells adhere to the surface, a process governed by weak non-specific forces - Van der Waals and polar Lewis acid-base interactions [43, 303]. This initial, reversible attachment becomes irreversible after bacteria make use of several cell-wall anchored proteins (CWAP) known as adhesins. In L. lactis, the most prominent ones are the CluA $[62,264]$ sex factor and the PrtP and NisP proteinases. [62, 64, 66]

These adhesins modify the bacterial surface properties and ultimately lead to its irreversible attachment to the surface. After this attachment becomes 
irreversible, the required force to detach additional bacteria increases and more bacteria are recruited and co-aggregated to the existing ones. Afterwards, bacteria proliferate and develop the biofilm itself. In this phase, few hours after the initial irreversible attachment, a co-continuous and stable layer is formed.

L. lactis subsp. cremoris MG1363 is a strain with a low production of exopolysaccharides, so biofilms usually show a monolayered morphology, lacking the horizontal stratified structure found in other strains. [211, 304, 305]

Hence, the formation of $L$. lactis biofilms seems limited to a monolayer [306] of strongly attached bacteria, in almost any abiotic surface such as polymers, glass or metallic surfaces. Usually, the adhesion of the bacterium to the substrate is mediated by the bacterial fimbriae, also called adhesion pili [307]. These fimbriae are also involved in the formation of the bacterial aggregates, as shown in the results section.

Once the biofilm has been successfully established, a need to control its proliferation arises. We found that the biofilm behaviour can be controlled to remain in a stationary phase, using low concentrations of tetracycline, up to 15 days. The amount of $\mathrm{FNIII}_{7-10}$ available on the membrane of the bacteria has been quantified; it promotes cell adhesion, signalling and cell differentiation [211]. Overall, this living interface based on non-pathogenic bacteria enhances the myogenic differentiation process. Selecting the proper substrate is also important due to the nature of the bacterial-surface interactions; it seems that the use of hydrophobic substrates such as PEA is needed for the establishment of a stable biofilm that remains stable for at least two weeks.

Further genetic modification of this living interface will be done to engineer a dynamic system able to provide cells different temporal stimuli beyond cell adhesion, such as the delivery of growth factors and other molecules upon external demand. By engineering non-pathogenic bacteria to produce proteins and growth factors upon external stimuli, we aim at control the interface between synthetic biomaterials and stem cells to control self-renewal and differentiation, which can be then applied to several strategies to promote tissue repair and regeneration [1]. 



\section{Chapter 6}

\section{Bacterial inclusion in polymeric systems}

\subsection{Introduction}

Cell immobilisation is a simple, cheap and effective way to maintain viable eukaryotic or prokaryotic cells trapped within a polymer, while retaining its functional properties. It is a common technique used in applications such as bioreactors, where whole cells or enzymes are immobilised within a polymeric substrate and act as live biocatalysts for complex reactions in mild conditions, or biosensors, where live cells or enzymes are able to sense the external environment generating a signal in response to these stimulus. [308-310]

Cells can be immobilised in several ways: attachment or adsorption on solid carrier surfaces; entrapment within a porous matrix; self-aggregation by natural flocculation or artificially with crosslinking agents; or in cell containment behind barriers [308]. In previous chapters, a natural immobilisation method, biofilm formation, has been described. L. lactis cells spontaneously attach to surfaces as a response to environmental stresses, getting as a result a stable layer of adhered bacteria. In this chapter, our objective is to further investigate the possibility of physical entrapment within natural and biodegradable polymers, to ensure good compatibility between the bacterial cells and the polymeric matrix.

Amongst the wide variety of commercially available polymers, poly-L-lactic acid (PLLA) has been selected due to its physical and biocompatibility properties. Poly-L-lactic acid is a natural polymer obtained from renewable sources such as corn starch, tapioca roots or sugarcane [311]. High molecular weight PLLA is 
produced through catalytic ring opening polymerization of cyclic lactides, which are derived from the lactic acid, the final product of lactic homofermentation of the abovementioned sugar sources [312]. Higher molecular weights can be achieved through the polycondensation method, where short oligomeric units react in anhydrous conditions to favour condensation over transesterification. The PLLA used in this work (Cargill Dow) is a brittle, non-crosslinked and thermoplastic polymer soluble in tetrahydrofuran (THF), chloroform, benzene, 1,4-dioxane and hexafluoroisopropanol (HFIP) and insoluble in toluene, pxylene, water, ethanol and other solvents. [313]

Polylactic acid is widely used as medical biomaterial, due to its good biocompatibility properties [314]. PLLA degrades naturally through either chemical or enzymatic hydrolysis [315], yielding nontoxic degradation products that are easily reabsorbed by the body. As of today, PLLA is being used in various biomedical devices including degradable sutures, drug releasing micro and nanoparticles, and porous scaffolds for cellular applications. [316]

In this work, we have used a whole-cell entrapment approximation to immobilise L. lactis cells within a PLLA matrix. Two different techniques were used, electrospinning and spin-casting.

Electrospinning is a technique used to produce polymeric fibres with diameters comprised between micro- and nanometres. By using an electric potential in the range of the kilovolts, a charged jet emerges from an extruded molten polymer or a polymeric solution, leading to the formation of long and very thin fibres. [317]

Three main components are needed: a direct current high-voltage power source, a capillary tube from where the solution or molten polymer is extruded and a conductive, earthed collector [318]. The high-voltage direct current power source is set-up for a potential difference of several kilovolts with a very low current intensity, typically in the range of the microamperes. The extruder is usually a non-bevelled needle directly connected to the power source. A syringe connected to a syringe pump feeds the extruding needle with a constant flow of a polymer solution or molten polymer. [319]

An electric field applied on the extruding droplet gives as a result an accumulation of charges of the same sign in its surface. Repulsive electrostatic forces accumulate in the air-liquid interface until the accumulated repulsive forces equal surface tension. As a result, a charged jet emerges from the droplet creating the Taylor cone. The jet flies to the collector, creating a long and very thin fibre that collides with the collector. [320, 321]

As the jet leaves the needle, solvent quickly evaporates, resulting in a vis- 


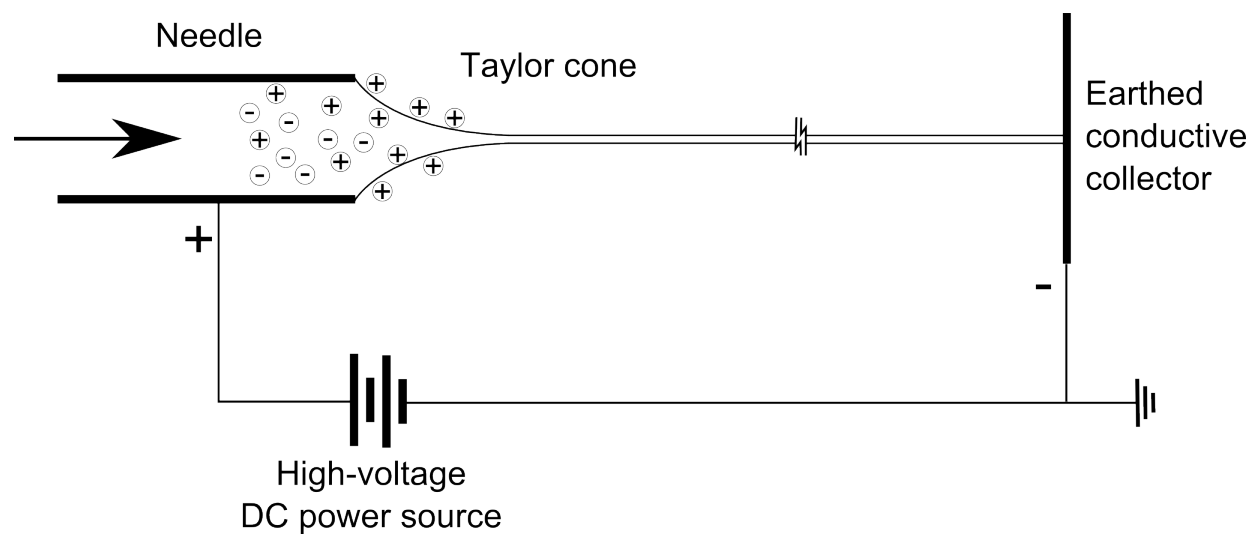

Figure 6.1 Sketch of the electrospinning process and the Taylor cone created at the end of the needle.

cosity increase of the solution. Polymer chains start to align until a very thin fibre is formed. This fibre shows a constant and uniform diameter. With the proper solvent, flying time, polymer concentration and applied voltage, a nonwoven mat of randomly aligned fibres is obtained in the collector. Nevertheless, the morphology of the collected fibres depends on the geometry of the collector; aligned nanofibres can be easily obtained with a rotating drum with the adequate linear speed. [318, 322-326]

Other technique used to immobilise bacterial cells in PLLA involves the production of thin films by using spin casting. A drop of the polymer solution with the dispersed bacterial wells is deposited onto the centre of the substrate and spin at high speed. Centripetal acceleration forces the polymer solution to spread to the edge of the surface. During the high-speed spinning, the solvent is quickly evaporated leaving a thin polymer film. Film thickness depends on the nature of the polymer (surface tension, viscosity, drying rate, percent solids, etc.), the substrate surface and the parameters of the spin process, such as rotational speed, acceleration and time. [327-329]

Thin PLLA films with trapped L. lactis cells were prepared this way and further characterised to assess the viability of the included cells and the availability of the FN III ${ }_{7-10}$ fragment expressed in the bacterial cell wall. 


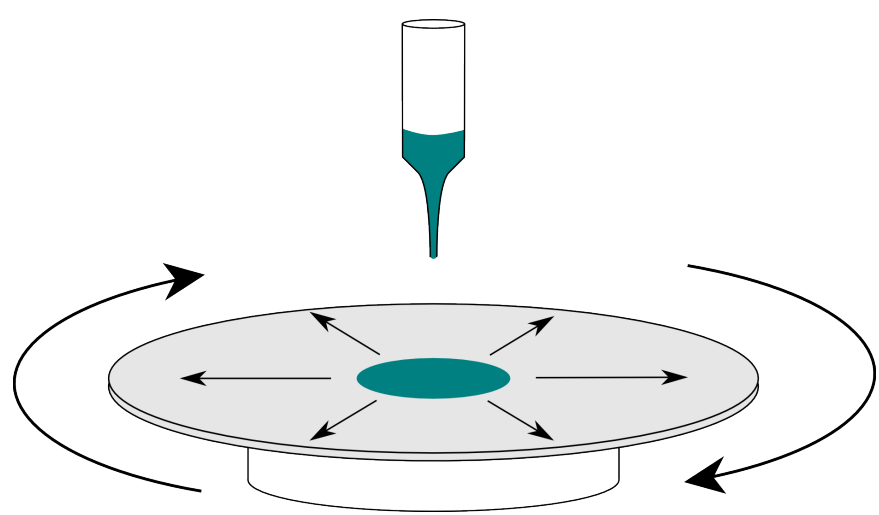

Figure 6.2 Spin casting process. A drop of the polymer solution is quickly spun and, once the solvent has evaporated, a thin polymer film remains on the surface of the substrate.

\subsection{Materials and methods}

\section{Preparation of PLLA nanofibres with trapped L. lactis cells}

$50 \mathrm{~mL}$ of an overnight culture of L. lactis-FN and L. lactis-empty in GM17-E was pelleted by centrifugation at 3,000 $\mathrm{g}$ for $10 \mathrm{~min}$. The pellet was twice washed with $2 \mathrm{~mL}$ of sterile $\mathrm{NaCl} 0.85 \% \mathrm{w} / \mathrm{v}$ to remove traces of the growth medium, harvested again by centrifugation at 3,000 $\mathrm{g}$ for 10 minutes and resuspended in a $10 \% \mathrm{w} / \mathrm{v}$ solution of sucrose in distilled water. This suspension was immediately frozen at $-80{ }^{\circ} \mathrm{C}$ and freeze-dried to remove the water while keeping cell viability.

Freeze-dried bacteria were resuspended in $750 \mu \mathrm{L}$ of hexafluoroisopropanol (HFIP, $>99 \%$ pure, Sigma) and filtered through a $75 \mu \mathrm{m}$ metallic sieve to remove the precipitated sucrose. The resulting solution was mixed with $750 \mu \mathrm{L}$ of an $8 \%$ of poly-L-lactic acid solution in HFIP. This suspension was electrospun using an electric potential of $22 \mathrm{kV}$, a flow rate of $500 \mu \mathrm{L} / \mathrm{h}$ and a distance between the extruding needle and the collector of 18 centimetres. The needle had an internal diameter of $0.15 \mathrm{~mm}$.

As a result, a nonwoven mat of PLLA filaments with included bacteria was obtained. This mat was left two hours at room temperature to properly dry the fibres and immediately used in either viability assays, immunostainings or cell cultures. 


\section{PLLA spin casting}

A similar protocol was applied to prepare PLLA thin films with included bacteria. L. lactis-FN and L. lactis-empty strains were grown in $50 \mathrm{~mL}$ of GM17-E. Cells were harvested at 3,000 $\mathrm{g}$ for 5 minutes and washed twice with sterile 0.85 $\% \mathrm{NaCl}$ and centrifuged again at 3,000 $\mathrm{g}$ for 5 minutes. The pellet was mixed with $1 \mathrm{~mL}$ of an $8 \%$ PLLA solution in HFIP. $100 \mu \mathrm{L}$ of this solution was used to prepare each $12 \mathrm{~mm}$ glass coverslip.

The spin-coater program consisted on a 30-second run at 3,000 rpm, drying afterwards the coated coverslips in the air, at room temperature, for 1 hour. These PLLA thin films with included L. lactis were used for the subsequent viability assays and cell cultures.

\section{Cell adhesion and immunostaining}

Adhesion of NIH3T3 fibroblasts to the PLLA-immobilised L. lactis was assessed through an anti-vinculin immunostaining. After culture times, cells were washed with Dulbecco's phosphate buffered saline (DPBS, Invitrogen) and fixed in formalin solution $10 \%$ (Sigma) at $4{ }^{\circ} \mathrm{C}$ for $30 \mathrm{~min}$. The formalin was washed three times with DPBS and the samples were incubated with permeabilising buffer ( $0.1 \%$ Triton X-100 in DPBS) at room temperature for $5 \mathrm{~min}$.

Then, the samples were incubated in $1 \%$ bovine serum albumin (Sigma) in DPBS at room temperature for $30 \mathrm{~min}$, in order to reduce the background signal. The samples were then incubated with monoclonal anti-vinculin antibody (Sigma) diluted 1:400 in 1\% BSA / DPBS for 1 hour at room temperature. Samples were washed in $0.5 \%$ Tween 20 / DPBS three times. Cy3-conjugated polyclonal rabbit anti-mouse secondary antibody (Jackson Immunoresearch), diluted 1:200 in 1\% BSA/PBS, with 1:40 BODIPY FL-conjugated phallacidin (Invitrogen) was added to the samples and incubated 1 hour at room temperature.

Samples were washed three times with $0.5 \%$ Tween 20 / PBS and mounted with Vectashield-DAPI mounting medium (Vector Laboratories, Peterborough, UK). Samples were imaged using a Nikon Eclipse 80i epifluorescence microscope.

\section{Bacterial viability}

Bacterial viability was assessed using the protocol depicted in the Bacterial and cell viability section. 


\section{Scanning electron microscopy}

Samples were imaged using a Jeol JSM 6300 system (Jeol Ltd., Tokyo, Japan) operating at $20 \mathrm{kV}$. Previously to imaging, samples were sputtered with gold and visualized. Images were acquired using the TIFF raster format with 512 lines of horizontal resolution.

\subsection{Results}

\section{Immobilisation in poly-L-lactic acid nanofibres}

Nonwoven random mats made of poly-L-lactic acid (PLLA) nanofibres were electrospun according to the protocol described in the materials and methods section. Cell pellets from L. lactis-FN and L. lactis-emtpy overnight cultures were washed and resuspended in hexafluoroisopropanol (HFIP) and mixed with equal volumes of either $8 \%$ or $4 \%$ PLLA solution in HFIP. The resulting bacterial dispersion, in $4 \%$ or $2 \%$ PLLA in HFIP, was electrospun to produce random nonwoven mats, with a mean fibre diameter of $0.49 \pm 0.07 \mu \mathrm{m}$.

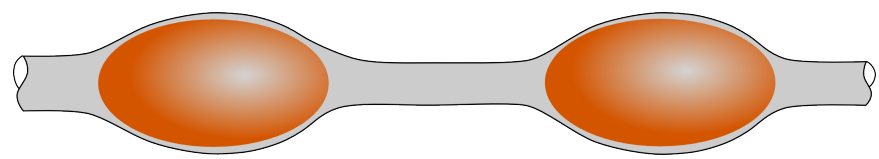

Figure 6.3 Proposed model of L. lactis cells (brown) trapped within PLLA fibres (gray)

Bacterial cells appear as bulges with a mean diameter of $0.96 \pm 0.06 \mu \mathrm{m}$, trapped within the individual fibres.

Fibres with immobilised L. lactis cells, along with control PLLA and FNcoated PLLA, were immunostained with the HFN7.1 antibody to assess the availability and biological activity of the FNIII $_{7-10}$ fragment. This antibody is directed against the flexible linker between the $\mathrm{III}_{9}$ and $\mathrm{III}_{10}$ fragments.

As expected, fibronectin immunostaining showed almost no signal in the fibres with included L. lactis-empty strain cells. Fibres with L. lactis-FN cells showed fluorescence to a certain extent, while in the FN-coated membrane, individual fibres were clearly distinguishable. The negative control, raw PLLA, showed no fluorescence at all.

According to this result, it seems to be a lower FNIII $_{7-10}$ exposure in the fibres with trapped L. lactis-FN membrane than in the fibronectin-coated PLLA nanofibres. This result suggests that immobilised bacterial cells are not correctly 

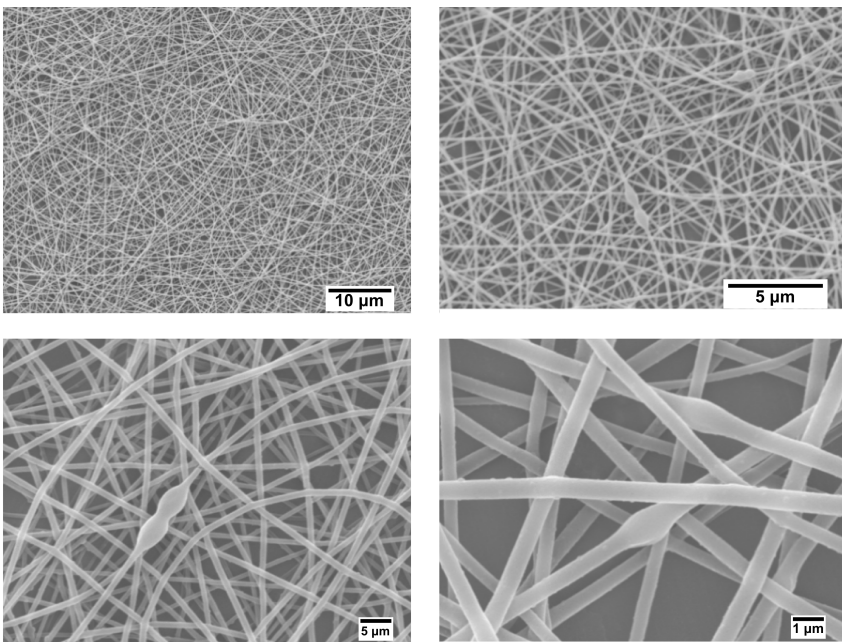

Figure 6.4 Scanning electron microscopy images of the trapped L. lactis cells in the electrospun poly-L-lactic acid fibres. Cells appear as bulges trapped in the fibres.
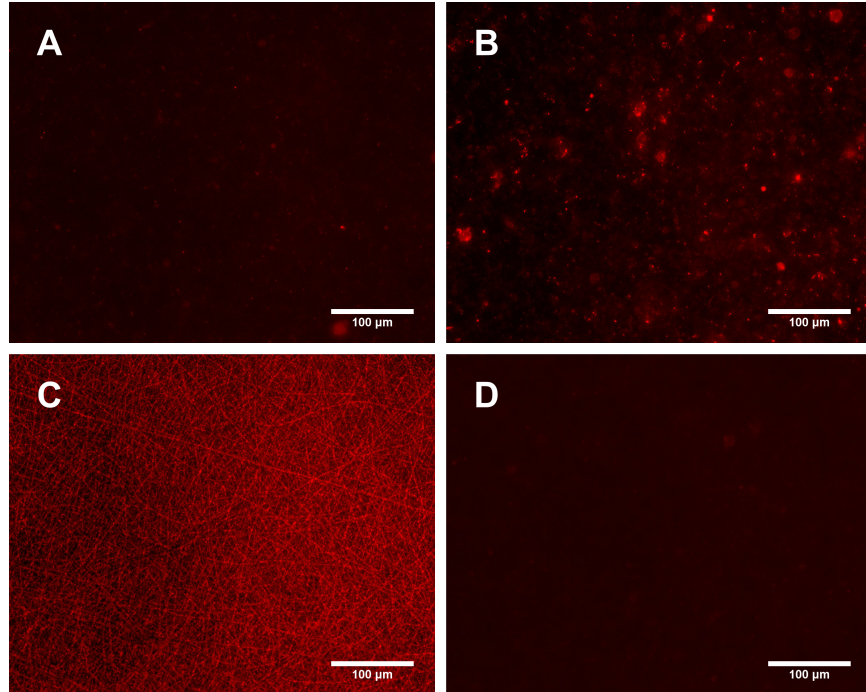

Figure 6.5 Fibronectin immunostaining in the electrospun membranes. A), ESPLLA membrane with L. lactis-empty bacteria included; B) with L. lactis-FN strain; C) ES-PLLA membrane coated with fibronectin from a $20 \mu \mathrm{g} / \mathrm{mL}$ solution, and D) uncoated ES-PLLA membrane. 
exposing the FNIII $_{7-10}$ fragment, probably due to the thin PLLA layer that covers the whole cell, while in the FN-coated fibres the fibronectin domains are located in the surface of the PLLA, being more accessible to the cultured cells.

To assess the influence of the FNIII $_{7-10}$ fragment in the cellular behaviour, NIH3T3 fibroblasts were cultured in serum-free medium for a total culture time of three hours, and then immunostained for vinculin (red) and actin (green). Nuclei were counter-stained with DAPI (blue).
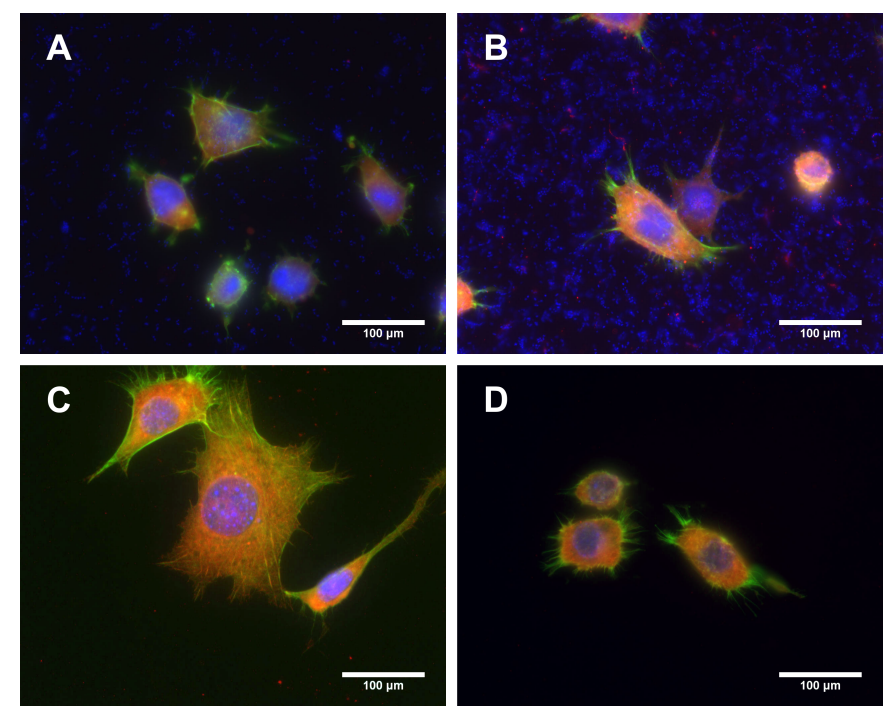

Figure 6.6 Vinculin (red) and actin (green) immunocytochemistry on NIH3T3 cells seeded on the electrospun membranes containing A) L. lactis-empty cells, B) L. lactis-FN cells, C) fibronectin-coated fibres and D) bare PLLA fibres.

This adhesion assay is coherent with the previous anti-FN immunostaining. Cells seeded on L. lactis-empty and L. lactis-FN trapped cells and on bare PLLA fibres showed almost no actin cytoskeleton or focal adhesion development, with an overall smaller size than the ones seeded on FN-coated PLLA electrospun fibres.

It can be concluded that the lower accessibility of the fibronectin fragment had a negative effect on the initial adhesion and cytoskeleton development behaviour, thus this approach seems to be less effective than immobilisation with biofilm presented in the previous chapters. 


\section{Immobilisation in poly-L-lactic acid thin films}

Starting from cell pellets from stationary phase cultures, thin PLLA films were produced using spin casting, a widely used technique for producing thin and uniform polymer films. The polymer solution containing bacteria was deposited in the centre of the substrate and spun at high speed, forcing the solution to spread on the substrate by means of the centripetal force. As a result, a thin film was obtained, while the solvent evaporated during the spinning process.

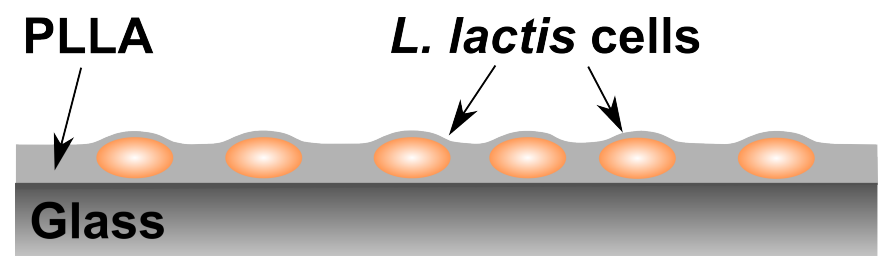

Figure 6.7 Proposed model of a PLLA thin film prepared on glass with trapped L. lactis cells.

Unfortunately, although great effort was put in the maintenance of a homogeneous suspension, bacterial cells eventually clumped leading to the formation of minuscule droplets, a kind of phase separation due to the aqueous nature of the cells, in contrast to the non-polar nature of the chloroform.

Although some phase-separation was observed, a very thin and transparent with included bacteria PLLA film was produced. A viability test was performed on the trapped bacterial cells, as seen in Figure 6.8.

In both strains, bacterial cells clumped, creating small droplets, while the rest of the PLLA remained virtually bacteria-free. The yellowish tint of the images, a composite of the green and red channel, could be due to the fact that both channels showed similar fluorescent intensity under the microscope. No definitive conclusion can be obtained from these images, as the viability results are not clear and cells appear clumped.

Both cell trapping in electrospun PLLA fibres and spin-coated PLLA does not seem to be suitable techniques for cell immobilisation, due to unresolved issues such as the low biological availability of the FNIII $_{7-10}$ fragment and inconclusive results from the viability assay. In fact, the use of organic solvents like chloroform or hexafluoroisopropanol are very likely to affect cell integrity and viability.

Further approaches based in polymer-immobilised cells will need to consider the high sensitivity of these bacterial cells to organic solvents and the need to ensure the availability of the expressed FNIII $_{7-10}$ fragment to the mammalian 

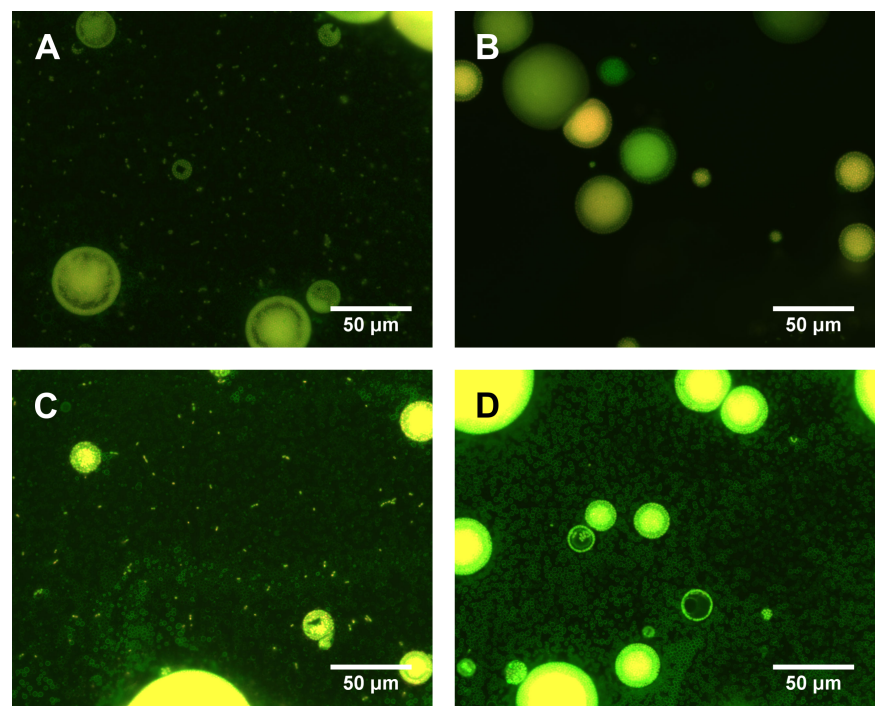

Figure 6.8 Fluorescence images of the bacterial viability test. L. lactis cells were trapped in a thin film of PLLA produced using the spin casting technique. In A) and B), L. lactis-empty cells; in C) and D), L. lactis-FN cells.

cells that will be in direct contact with bacteria. 


\subsection{Conclusions}

Although bacteria-based dynamic biointerfaces based on bacterial immobilisation through spontaneous biofilm formation hold great promises, immobilisation in polymeric supports opens a wide range of applications for this bacteria-based biointerfaces.

For example, immobilisation in water-based, porous polymers such as alginate, chitosan, gelatin, agar or agarose could enhance the bacterial stability and lifespan of these supports, provided proper environmental culture conditions.

This is a competitive advantage over biofilms, which are subjected to a finite and well established life cycle, while cells immobilised within a polymer can be maintained in an almost-stationary state, much like in the bioreactors used for industrial production of products such as bacteriocins, lactic acid and other products.

Nevertheless, immobilisation within a polymeric matrix also entails disadvantages. The most obvious one is the fact that membrane surface-exposed biochemical signals, such as the FNIII ${ }_{7-10}$ fragment assessed throughout in this work, become less accessible to mammalian cells.

The biggest disadvantage faced in this work has been the need to use non-polar solvents when working with water-insoluble polymers such as PLLA, and is clear that is preferable the use of water-soluble polymers for bacterial cells immobilisation; the use of stringent environmental conditions should be avoided in order to maintain bacterial viability and structural integrity of the expressed proteins.

Anyway, the use of membrane-bound biochemical cues is only one amongst the range of potential uses of genetically engineered bacteria for tissue engineering. The development of a new tissue is driven by static and dynamic biochemical signals, being fibronectin only one in the wide variety of signals needed for the development of a mature tissue.

Depending on the chosen tissue, soluble factors and small molecules play an important role, and in this point is where immobilised cells within hydrophylic polymers can play an important role, since a direct, physical contact between bacteria and mammalian cells is not strictly needed and the inclusion within a porous polymer can be enough to allow passive diffusion within the culture medium.

This newly developed biointerface can be used not only for expressing static cues (proteins, small molecules or growth factors), in resemblance to the passive protein coatings used until today, but to express on-demand cues in either membrane-exposed or soluble form. 



\section{Chapter 7}

\section{Future work}

In this work, a new model for surface functionalisation based on live organisms has been established, specifically the lactic bacteria Lactococcus lactis. This strain has been engineered to express the $\mathrm{III}_{7-10}$ fragment of the human fibronectin, which carries the RGD adhesion and the PHSRN synergy motifs, both involved in the integrin-ECM interaction.

The extracellular matrix is a complex and dynamic system that cannot be mimicked using a simple, passive coating. Although this work presents a functional living interface, it does not show any functional characteristics beyond the presentation of a constitutively expressed recombinant protein to the aboveground cell layer. Is at this point where this system can show its full potential, and can be modified to act as a truly dynamic interface with the ability to display almost any desired biochemical cue in response to user-selectable triggers.

Lactococcus lactis is one of the most studied gram-positive microorganisms; is the model organism for the lactic acid bacteria clade with many genetic tools available. Lactococcus lactis has already been used as a vehicle for recombinant protein expression with uses such as oral vaccine delivery and other heterologous proteins.

There is a wide variety of available constitutive and inducible expression systems, for example NICE, a nisin-induced promoter; the acid-inducible P170 promoter; Pgad, a chloride-inducible system or Zirex, a zinc-regulated expression system, amongst others. These inducers can be of the on-off type or regulated, such as the NICE system. With these tools readily available to the researcher, the logical next step is the development of biointerfaces with a) single constitutive or inducible expression systems that will allow a tightly con- 
trolled spatio-temporal control of protein expression, and b) the combination of two or more of these expression systems in a single bacterial population, enabling protein expression control and allowing the expression of more than one protein in a single biointerface.

In the context of tissue engineering, there are several proteins and growth factors of special interest, due to its role in the development and growth of specific tissue types. Bone morphogenetic protein-2 (BMP2) is a growth factor pertaining to the TGF-beta superfamily involved in the development of bone tissue. Bone is the tissue with the highest regeneration potential, and, given an appropriate microenvironment and the proper cell line, the presence of BMPs is essential for the biological reaction chain that leads to the development of mature bone tissue. Nowadays, the most used source of BMPs for research and clinical purposes is the expression of recombinant versions of this proteins; the use of an inducible, in-situ BMP2 source will enable the possibility to trigger the signalling induced by this protein family in a more controlled fashion.

Not only bone regeneration could be favoured by this new type of dynamic interface. Vascular endothelial growth factor-2 (VEGF2) is another example of recombinant protein that is being currently used in research. VEGF2 is a diffusible mitogen with vasculogenic and angiogenic properties that plays an important role in the de novo development of blood vessels and in hypoxic conditions. Since wound healing often require the presence of angiogenic factors, VEGF2 can be used for the development of new blood vessels in growing tissues.

Although cell immobilisation through the formation of biofilms seems to be suitable for most purposes, inclusion in polymeric systems should be further explored. Several hydrophylic polymers, mostly polysaccharides such as agarose, pullulans and alginate have been used in bioreactors and other applications. The disadvantage of using polymers only soluble in organic solvents (polycaprolactone, poly-L-lactic acid and others) is the foreseeable loss of bacterial viability, so using water-based polymers is a must.

Nevertheless, since it can be difficult to obtain bacterial inclusion without blocking the extracellular exposure of membrane-expressed proteins, hybrid systems could be a suitable solution. In these hybrid systems, a bacterial strain whose only objective is to express soluble factors such as growth factors or small molecules could be immobilised within a water-based polymer and the same strain, with membrane-anchored expression, could be immobilised as a biofilm in the surface of the polymer.

This is a system that would be easy to develop and test in the short-term 
and would help in issues such as the need to control the bacterial proliferation and lactic acid production.

Summarising, functional living bionterfaces presented in this thesis could be developed, with a minimum effort, to include several strains in the same system and express many, either on-demand or constitutively, proteins, soluble factors, small molecules and almost any needed biochemical cue to assist in the development of new tissues. 



\section{Chapter 8}

\section{Conclusions}

1. The lactic bacteria strain Lactococcus lactis subsp. cremoris has been genetically engineered to display the $\mathrm{III}_{7-10}$ fragment of the human fibronectin in its cell wall. This fragment contains two important sequences, RGD and PHSRN, involved in the cell-ECM interaction via integrins.

2. This genetic modification has been done using standard techniques, that is to say, PCR and restriction site cloning. Fibronectin fragment has been cloned as a fusion protein with GFP as reporter protein, using the Usp45 signal peptide as secretion signal and $S$. aureus protein A to covalently anchor the fragment to the peptidoglycan layer of $L$. lactis.

3. The modified strain, stated as L. lactis-FN throughout the work, has been characterized to ensure that the fragment is correctly expressed in the bacterial cell wall by using different techniques: western blot for assessing the cell wall localization of the protein and fluorescence microscopy to detect the green fluorescent protein. Both techniques have given the expected results, since the $\mathrm{FNIII}_{7-10}$ fragment is covalently linked to the bacterial peptidoglycan layer.

4. L. lactis, much like the vast majority of the bacterial species, has the ability to develop biofilms, communities of sessile bacteria attached to a surface in order to increase its survival rate. Development of biofilms, although detrimental to most applications, can be exploited in our favour to produce a physical, monolayer of bacterial cells strongly attached to a surface, which play the role of the interfacial layer between the synthetic substrate and the mammalian cell population that can grow and develop on this biofilm. 
5. Biofilm areal density, or number of bacterial cells per area unit, can be finely tuned by using different volumes of a bacterial culture in the log phase. Since total bacterial biomass depends on the initial volume, larger volumes will lead to denser biofilms.

6. Biological activity of the expressed fibronectin fragment was assessed with several techniques. ELISA was used to quantify the exposure of the fragment and its availability to mammalian cells. Biological activity was found to be practically identical to a fibronectin-coated surface with an approximate density of $300 \mathrm{ng} / \mathrm{cm}^{2}$.

7. To further confirm the biological availability and activity of the expressed fibronectin fragment, several mammalian cell lines were cultured on the L. lactis-FN biofilm. Adhesion behaviour and integrin-mediated signalling through focal adhesion kinase (FAK) phosphorylation was confirmed on NIH3T3 fibroblasts, $\mathrm{Fn}^{-} / \mathrm{Fn}^{-}$fibroblasts and $\mathrm{C} 2 \mathrm{C} 12$ myoblasts. Myogenic differentiation was also found to be higher on the cells cultured on the $L$. lactis-FN biofilm than in the L. lactis-emtpy biofilm, with differentiation degrees similar to the ones found in the standard differentiation substrate, Collagen I and fibronectin.

8. Human mesenchymal stem cell response to the L. lactis-FN biofilm was also assessed. hMSCs showed focal adhesion development and ERK1/2 phosphorylation. ERK is an enzyme involved in the MAPK pathway, responsible for a wide variety of cellular processes such as differentiation, adhesion, migration and proliferation. MAPK activity is induced by integrin dimerization amongst other factors, so we can infer that the FNIII $_{7-10}$ fragment is responsible for activating several intracellular signalling pathways.

9. Differentiation analysis of hMSCs by qPCR showed that no differentiation was taking place on these cells after a two-week culture. mRNA expression levels of the two studied self-renewal genes ALCAM and CD63 were significantly higher than other differentiation markers, but this result has to be further verified since the fibronectin present in the serum used in the culture could be outgrowing the influence of the bacterially expressed fragment.

10. Finally, bacterial inclusion into polymeric systems such as PLLA was assessed, although no improvement over the biofilm model was found. 
Trapping bacterial cells within PLLA requires the use of organic solvents which are detrimental to bacterial viability; moreover, polymer surrounding bacterial cells hides the fibronectin fragment from mammalian cells. Cultures done on L. lactis-FN trapped within electrospun nanofibres and spin-coated PLLA thin films showed no difference between a bare polymer surface and the same surface with included bacteria. Nevertheless, bacterial inclusion within polymers is very promising and other approaches should be tested. 



\section{Appendix}

\section{pT1NX-FNIII ${ }_{7-10}$-GFP sequence}

After cloning, plasmid pT1NX-FNIII ${ }_{7-10}-\mathrm{GFP}$ was sequenced to ensure the inframe insertion of the FNIII ${ }_{7-10}$-GFP fragment. Plasmid map and annotated sequence is as follows.

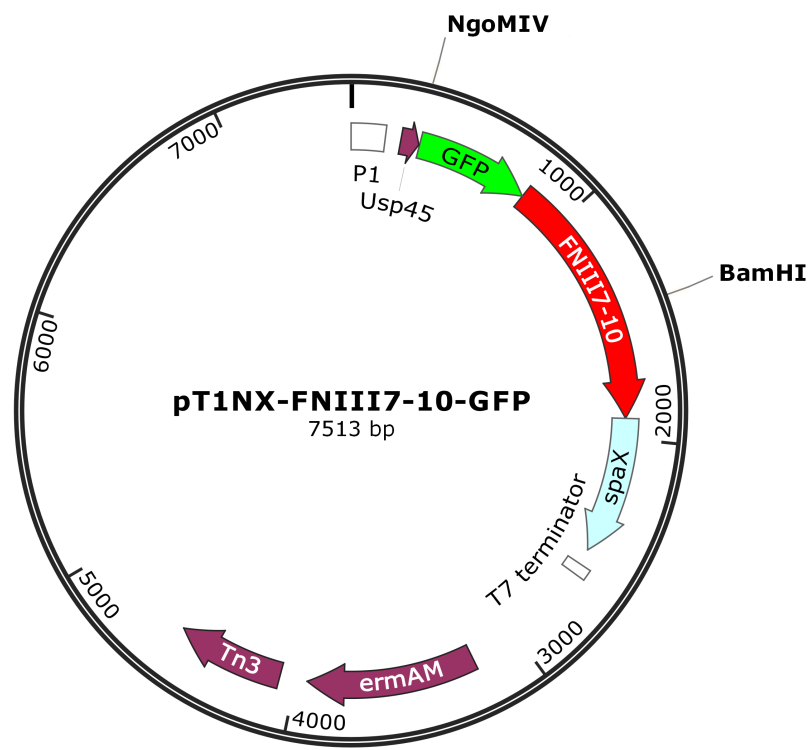

Figure 8.1 Map of the pT1NX-FNIII ${ }_{7-10}$-GFP plasmid developed in this thesis 


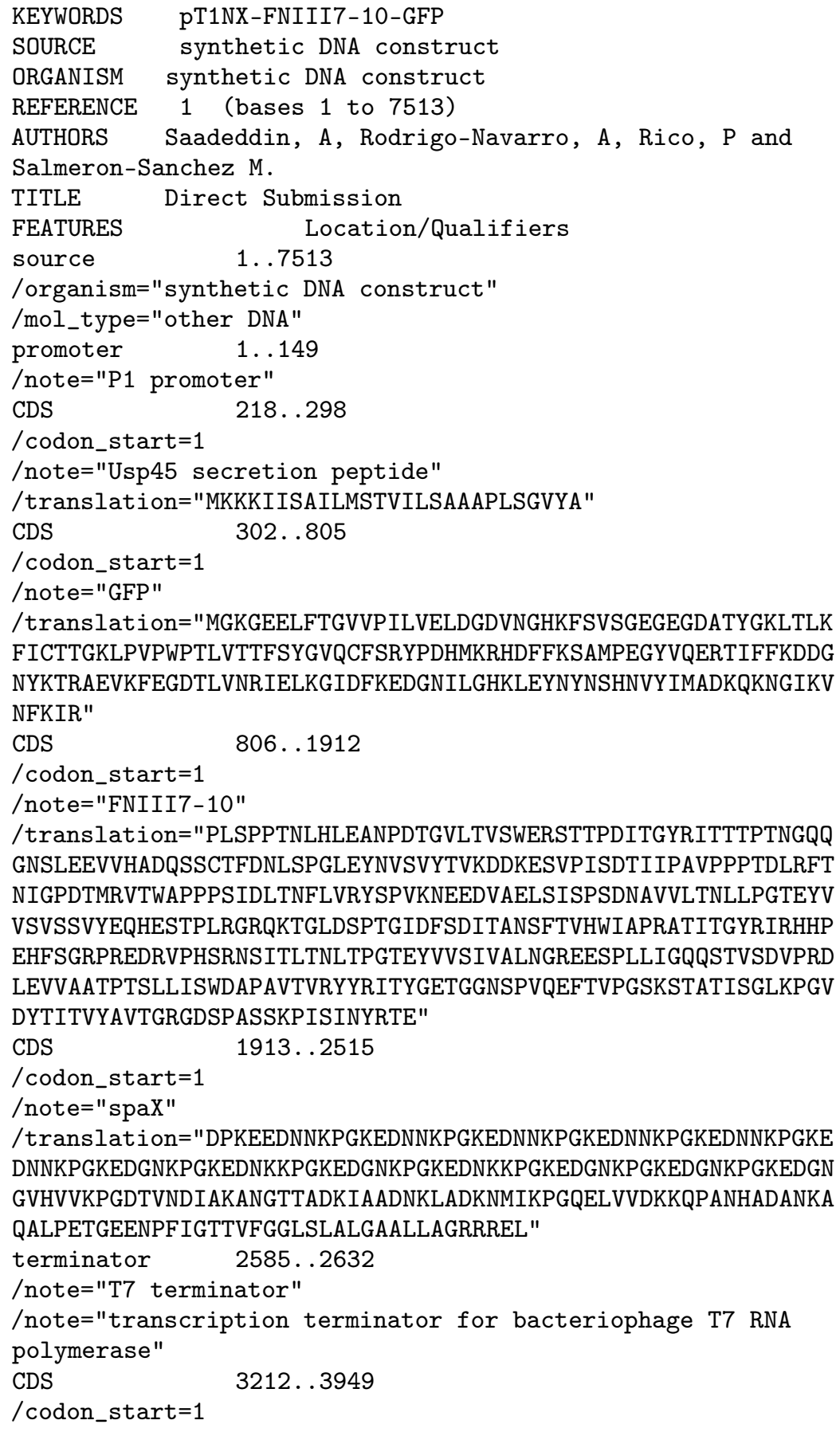


$/$ note $=$ "ermAM"

/translation="MNKNIKYSQNFLTSEKVLNQIIKQLNLKETDTVYEIGTGKGHLTT KLAKISKQVTSIELDSHLFNLSSEKLKLNTRVTLIHQDILQFQFPNKQRYKIVGSIPYH LSTQIIKKVVFESHASDIYLIVEEGFYKRTLDIHRTLGLLLHTQVSIQQLLKLPAECFH PKPKVNSVLIKLTRHTTDVPDKYWKLYTYFVSKWVNREYRQLFTKNQFHQAMKHAKVNN LSTVTYEQVLSIFNSYLLFNGRK"

CDS 4070 . 4540

/ codon_start $=1$

$/$ note $=" \operatorname{Tn} 3 "$

/translation="MGKLGSYARQNKLATALGEMGRIEKTLFTLDYISNKAVRRRVQKG LNKGEAINALARTIFFGQRGEFRERALQDQLQRASALNIIINAISVWNTVYMEKAVEEL KARGEFREDLMPYAWPLGWEHINFLGEYKFEGLHDTGQMNLRPLRIKEPFYS" ORIGIN

1 gaattcgatt aagtcatctt acctctttta ttagtttttt cttataatct aatgataaca 61 tttttataat taatctataa accatatccc tctttggaat caaatttat tatctactcc 121 tttgtagata tgttataata caagtatcag atctgggaga ccacaacggt ttcccactag 181 aaataatttt gtttaacttt agaaaggaga tatacgcatg aaaaaaaga ttatctcagc 241 tattttaatg tctacagtga tactttctgc tgcagccccg ttgtcaggtg tttacgccgg 301 catgggtaaa ggagaagaac ttttcactgg agttgtccca attcttgttg aattagatgg 361 tgatgttaat gggcacaaat tttctgtcag tggagagggt gaaggtgatg caacatacgg 421 aaacttacc cttaaattta tttgcactac tggaaacta cctgttccat ggccaacact 481 tgtcactact ttctcttatg gtgttcaatg cttttcaaga tacccagatc atatgaaacg 541 gcatgacttt ttcaagagtg ccatgcccga aggttatgta caggaaagaa ctatattttt 601 caaagatgac gggaactaca agacacgtgc tgaagtcaag tttgaaggtg atacccttgt 661 taatagaatc gagttaaaag gtattgattt taaagaagat ggaacattc ttggacacaa 721 attggaatac aactataact cacacaatgt atacatcatg gcagacaaac aaaagaatgg 781 aatcaaagtt aacttcaaaa ttagaccatt gtctccacca acaacttgc atctggaggc 841 aaccctgac actggagtgc tcacagtctc ctgggagagg agcaccaccc cagacattac 901 tggttataga attaccacaa cccctacaaa cggccagcag ggaaattctt tggaagaagt 961 ggtccatgct gatcagagct cctgcacttt tgataacctg agtcccggcc tggagtacaa 1021 tgtcagtgtt tacactgtca aggatgacaa ggaaagtgtc cctatctctg ataccatcat 1081 cccagctgtt cctcctccca ctgacctgcg attcaccaac attggtccag acaccatgcg 1141 tgtcacctgg gctccacccc catccattga tttaaccaac ttcctggtgc gttactcacc 1201 tgtgaaaaat gaggaagatg ttgcagagtt gtcaatttct ccttcagaca atgcagtggt 1261 cttaacaaat ctcctgcctg gtacagaata tgtagtgagt gtctccagtg tctacgaaca 1321 acatgagagc acacctctta gaggaagaca gaaaacaggt cttgattcc caactggcat 1381 tgacttttct gatattactg ccaactcttt tactgtgcac tggattgctc ctcgagccac 1441 catcactggc tacaggatcc gccatcatcc cgagcacttc agtgggagac ctcgagaaga 1501 tcgggtgccc cactctcgga attccatcac cctcaccaac ctcactccag gcacagagta 1561 tgtggtcagc atcgttgctc ttaatggcag agaggaaagt cccttattga ttggccaaca 1621 atcaacagtt tctgatgttc cgagggacct ggaagttgtt gctgcgaccc ccaccagcct 1681 actgatcagc tgggatgctc ctgctgtcac agtgagatat tacaggatca cttacggaga 1741 aacaggagga aatagccctg tccaggagtt cactgtgcct gggagcaagt ctacagctac 1801 catcagcggc cttaaacctg gagttgatta taccatcact gtgtatgctg tcactggccg 1861 tggagacagc cccgcaagca gcaagccaat ttccattaat taccgaacag aagatccaaa 1921 agaggaagac aataacaagc ctggcaaaga agacaataac aagcctggca aagaagacaa 1981 taacaagcct ggcaaagaag acaacaacaa gcctggcaaa gaagacaaca acaagcctgg 
2041 taaagaagac aacaacaagc ctggcaaaga agacggcaac aagcctggta aagaagacaa 2101 caaaaaacct ggtaaagaag atggcaacaa gcctggtaaa gaagacaaca aaaacctgg 2161 taaagaagac ggcaacaagc ctggcaaaga agatggcaac aaacctggta aagaagatgg 2221 taacggagta catgtcgtta aacctggtga tacagtaaat gacattgcaa aagcaaacgg 2281 cactactgct gacaaaattg ctgcagataa caaattagct gataaaaca tgatcaaacc 2341 tggtcaagaa cttgttgttg ataagaagca accagcaaac catgcagatg ctaacaaagc 2401 tcaagcatta ccagaaactg gcgaagaaaa tccattcatc ggtacaactg tatttggtgg 2461 attatcatta gccttaggtg cagcgttatt agctggacgt cgtcgcgaac tataactagt 2521 agatccggct gctaacaaag cccgaaagga agctgagttg gctgctgcca ccgctgagca 2581 ataactagca taaccccttg gggcctctaa acgggtcttg aggggttttt tgctgaaagg 2641 aggaactata tccggatgac ctgcaggcaa gctctagaat cgatacgatt ttgaagtggc 2701 aacagataaa aaaagcagt ttaaattgt tgctgaactt ttaaacaag caaatacaat 2761 cattgtcgca acagatagcg acagagaagg cgaaacatt gcctggtcga tcattcataa 2821 agcaaatgcc ttttctaaag ataaaacgta taaaagacta tggatcaata gtttagaaaa 2881 agatgtgatc cgtagcggtt ttcaaaattt gcaaccagga atgaattact atccctttta 2941 tcaagaagcg caaaagaaaa acgaaatgat acaccaatca gtgcaaaaaa agatataatg 3001 ggagataaga cggttcgtgt tcgtgctgac ttgcaccata tcataaaat cgaaacagca 3061 aagaatggcg gaaacgtaaa agaagttatg gaaataagac ttagaagcaa acttaagagt 3121 gtgttgatag tgcagtatct taaattttg tataatagga attgaagtta aattagatgc 3181 taaaaatttg taattaagaa ggagtgatta catgaacaaa aatataaaat attctcaaaa 3241 ctttttaacg agtgaaaaag tactcaacca aataataaaa caattgaatt taaagaaac 3301 cgataccgtt tacgaaattg gaacaggtaa agggcattta acgacgaaac tggctaaaat 3361 aagtaaacag gtaacgtcta ttgaattaga cagtcatcta ttcaacttat cgtcagaaaa 3421 attaaaactg aatactcgtg tcactttaat tcaccaagat attctacagt ttcaattccc 3481 taacaaacag aggtataaaa ttgttgggag tattccttac catttaagca cacaaattat 3541 taaaaagtg gtttttgaaa gccatgcgtc tgacatctat ctgattgttg aagaaggatt 3601 ctacaagcgt accttggata ttcaccgaac actagggttg ctcttgcaca ctcaagtctc 3661 gattcagcaa ttgcttaagc tgccagcgga atgctttcat cctaaaccaa aagtaaacag 3721 tgtcttaata aaacttaccc gccataccac agatgttcca gataaatatt ggaagctata 3781 tacgtacttt gtttcaaaat gggtcaatcg agaatatcgt caactgttta ctaaaatca 3841 gtttcatcaa gcaatgaaac acgccaaagt aacaattta agtaccgtta cttatgagca 3901 agtattgtct atttttaata gttatctatt atttaacggg aggaaataat tctatgagtc 3961 gcttttgtaa atttggaaag ttacacgtta ctaaagggaa tgtagataaa ttattaggta 4021 tactactgac agcttccaag gagctaaaga ggtccctagc gctcttatca tggggaagct 4081 cggatcatat gcaagacaaa ataaactcgc aacagcactt ggagaaatgg gacgaatcga 4141 gaaaccctc tttacgctgg attacatatc taataaagcc gtaaggagac gggttcaaaa 4201 aggtttaaat aaaggagaag caatcaatgc attagctaga actatatttt ttggacaacg 4261 tggagaattt agagaacgtg ctctccaaga ccagttacaa agagctagtg cactaaacat 4321 aattattaac gctataagtg tgtggaacac tgtatatatg gaaaagccg tagaagaatt 4381 aaaagcaaga ggagaattta gagaagattt aatgccatat gcgtggccgt taggatggga 4441 acatatcaat tttcttggag aatacaaatt tgaaggatta catgacactg ggcaaatgaa 4501 tttacgtcct ttacgtataa aagagccgtt ttattcttaa tataacggct cttttatag 4561 aaaaatcct tagcgtggtt tttttccgaa atgctggcgg taccccaaga attagaaatg 4621 agtagatcaa attattcacg aatagaatca ggaaatcag atccaaccat aaaacacta 4681 gaacaaattg caaagttaac taactcaacg ctagtagtgg atttaatccc aaatgagcca 4741 acagaaccag agccagaaac agaatcagaa caagtaacat tggatttaga aatggaagaa 4801 gaaaaagca atgacttcgt gtgaataatg cacgaaatcg ttgcttattt ttttttaaaa 
4861 gcggtatact agatataacg aaacaacgaa ctgaatagaa acgaaaaaag agccatgaca 4921 catttataaa atgtttgacg acattttata aatgcatagc ccgataagat tgccaaacca 4981 acgcttatca gttagtcaga tgaactcttc cctcgtaaga agttatttaa ttaactttgt 5041 ttgaagacgg tatataaccg tactatcatt atatagggaa atcagagagt tttcaagtat 5101 ctaagctact gaatttaaga attgttaagc aatcaatcgg aaatcgtttg attgcttttt 5161 ttgtattcat ttatagaagg tggagtttgt atgaatcatg atgaatgtaa aacttatata 5221 aaaatagtt tattggagat aagaaatta gcaaatatct atacactaga aacgtttaag 5281 aaagagttag aaaagagaaa tatctactta gaacaaaat cagataagta tttttcttcg 5341 gagggggaag attatatata taagttaata gaaataaca aataattta ttcgattagt 5401 ggaaaaaat tgacttataa aggaaaaaa tctttttcaa aacatgcaat attgaaacag 5461 ttgaatgaaa aagcaaacca agttaattaa acaacctatt ttataggatt tataggaaag 5521 gagaacagct gaatgaatat cccttttgtt gtagaaactg tgcttcatga cggcttgtta 5581 aagtacaaat ttaaaaatag taaaattcgc tcaatcacta ccaagccagg taaaagcaaa 5641 ggggctattt ttgcgtatcg ctcaaatca agcatgattg gcggtcgtgg tgttgttctg 5701 acttccgagg aagcgattca agaaatcaa gatacattta cacattggac acccaacgtt 5761 tatcgttatg gaacgtatgc agacgaaaac cgttcataca cgaaaggaca ttctgaaaac 5821 aatttaagac aaatcaatac cttctttatt gattttgata ttcacacggc aaaagaaact 5881 atttcagcaa gcgatatttt aacaaccgct attgatttag gttttatgcc tactatgatt 5941 atcaaatctg ataaaggtta tcaagcatat tttgttttag aaacgccagt ctatgtgact 6001 tcaaaatcag aatttaaatc tgtcaaagca gccaaataa tttcgcaaaa tatccgagaa 6061 tattttggaa agtctttgcc agttgatcta acgtgtaatc attttggtat tgctcgcata 6121 ccaagaacgg acaatgtaga attttttgat cctaattacc gttattcttt caaagaatgg 6181 caagattggt ctttcaaaca aacagataat aagggcttta ctcgttcaag tctaacggtt 6241 ttaagcggta cagaaggcaa aaaacaagta gatgaaccct ggtttaatct cttattgcac 6301 gaaacgaaat tttcaggaga aaagggttta atagggcgta ataacgtcat gtttaccctc 6361 tctttagcct actttagttc aggctattca atcgaaacgt gcgaatataa tatgtttgag 6421 tttaataatc gattagatca acccttagaa gaaaagaag taatcaaaat tgttagaagt 6481 gcctattcag aaaactatca aggggctaat agggaataca ttaccattct ttgcaaagct 6541 tgggtatcaa gtgatttaac cagtaaagat ttatttgtcc gtcaagggtg gtttaaattc 6601 aagaaaaaa gaagcgaacg tcaacgtgtt catttgtcag aatggaaaga agatttaatg 6661 gcttatatta gcgaaaaaag cgatgtatac aagccttatt tagtgacgac caaaaagag 6721 attagagaag tgctaggcat tcctgaacgg acattagata aattgctgaa ggtactgaag 6781 gcgaatcagg aaattttctt taagattaaa ccaggaagaa atggtggcat tcaacttgct 6841 agtgttaaat cattgttgct atcgatcatt aaagtaaaaa aagaagaaaa agaaagctat 6901 ataaaggcgc tgacaaattc ttttgactta gagcatacat tcattcaaga gactttaaac 6961 aagctagcag aacgccctaa aacggacaca caactcgatt tgtttagcta tgatacaggc 7021 tgaaataaa acccgcacta tgccattaca tttatatcta tgatacgtgt ttgttttttc 7081 tttgctgttt agcgaatgat tagcagaaat atacagagta agattttaat taattattag 7141 ggggagaagg agagagtagc ccgaaaactt ttagttggct tggactgaac gaagtgaggg 7201 aaaggctact aaaacgtcga ggggcagtga gagcgaagcg aacacttgat tttttaattt 7261 tctatctttt ataggtcatt agagtatact tatttgtcct ataactatt tagcagcata 7321 atagatttat tgaataggtc atttaagttg agcatattag aggaggaaa tcttggagaa 7381 atatttgaag aacccgatta catggattgg attagttctt gtggttacgt ggtttttaac 7441 taaaagtagt gaatttttga tttttggtgt gtgtgtcttg ttgttagtat ttgctagtca 7501 aagtgattaa ata

/1 



\section{Work derived from this thesis}

The following publications were derived from this thesis:

- Anas Saadeddin et al. Functional living biointerphases. Advanced Healthcare Materials 2.9 (Sept. 2013), pp. 1213-8. DOI: 10.1002/adhm. 201200473

- Aleixandre Rodrigo-Navarro et al. Living biointerfaces based on non-pathogenic bacteria to direct cell differentiation. Scientific reports 4 (Jan. 2014), p. 5849. DOI: 10.1038/ srep05849 


\title{
Functional Living Biointerphases
}

\author{
Anas Saadeddin, Aleixandre Rodrigo-Navarro, Vicente Monedero, Patricia Rico, \\ David Moratal, María Luisa González-Martín, David Navarro, Andrés J. García, \\ and Manuel Salmerón-Sánchez*
}

\begin{abstract}
Phenomena occurring at the biological/non-biological interface are of fundamental importance in biotechnological and biomedical strategies to direct cell behavior on biomaterials, including cell adhesion, proliferation and differentiation..$^{1-2}$ The interaction of cells with synthetic materials takes place via a layer of proteins, such as fibronectin (FN), either adsorbed or grafted on the material surface. ${ }^{[1-3]}$ Synthetic biomaterials have been functionalized with a broad range of proteins and growth factors seeking to provide (static) cues to direct cell behavior. However, the interactions of cells with their surroundings are exquisitely dynamic processes which comprise different spatiotemporal stimuli at different stages. Therefore the simple functionalization of material surfaces can by no means provide the required dynamic environment for these processes to occu in a biomimetic way. Here we show that genetically modified non-pathogenic bacteria can be engineered to play the role of functional living biointerphases between synthetic materials and living cells. As a proof of concept, we have modified Lactococcus lactis to express a fibronectin fragment that incorporates both the PHSRN synergy sequence and the RGD binding motifs $\left(\mathrm{FNIII}_{7-10}\right)$ and display this ligand as a membrane
\end{abstract}

\section{Dr. A. Saadeddin \\ Abengoa Research}

Abengoa, Campus Palmas Altas, Sevilla, Spain

A. Rodrigo-Navarro, [i]] Dr. P. Rico, Prof. D. Moratal,

Prof. M. Salmerón-Sánchez

Center for Biomaterials and Tissue Engineering

Universitat Politècnica de València

Valencia, Spain

E-mail: masalsan@fis.upv.es

Dr. V. Monedero

Laboratorio de Bacterias Lácticas y Probióticos
Instituto de Agroquímica y Tecnología de Alimentos-CSIC

Instituto de Agroquímica

Dr. P. Rico, Prof. M. Salmerón-Sánchez, Prof. M. Luisa González-Martín CIBER de Bioingeniería, Biomateriales y Nanomedicina, Spain

Prof. M. Luisa González-Martín

Departamento de Física Aplicada

Facultad de Ciencias

Universidad de Extremadura, Badajoz, Spain

Prof. D. Navarro

Servicio de Microbiología. Hospital Clínico Universitario, Valencia, Spain

Prof. A. J. García

Prof. A. J. García
Woodruff School of Mechanical Engineering

Petit Institute for Bioengineering and Bioscience

Petit Institute for Bioengineerin
Georgia Institute of Technology

Georgia Institute of Tech
Atlanta, GA 30332, USA

[†] These authors contributed equally to this work

DOI: 10.1002/adhm.201200473 protein. We found that Lactococcus lactis expressing FNIII $_{7-10}$ is able to enhance cell adhesion and signaling, leading to the development of focal adhesion plaques and phosphorylation of focal adhesion kinase (FAK). Our results demonstrate that modified bacteria can colonize the surface of an implant and provide the adequate stimuli to direct the behavior of mammalian cells. This functional interphase between synthetic biomaterials and cells consist of living organisms could be further modified to express any desired protein upon external request, which constitutes a new paradigm to direct cell behavior in regenerative medicine and several biotechnological and biomedical problems.

The cell-material interaction is a complex bi-directional and dynamic process that mimics to a certain extent the natural interactions of cells with the extracellular matrix (ECM). The interaction of cells with synthetic materials is not a direct one but occurs via a layer of proteins such as fibronectin (FN), vitronectin, and fibrinogen, which are immobilized on the material surface.$^{[3]}$ Cells primarily interact with these proteins via integrins, a family of transmembrane cell adhesion receptors. ${ }^{[4]}$ Integrin-mediated adhesion is a complex process that involves integrin association with the actin cytoskeleton and clustering into focal adhesions: supramolecular complexes that contain structural proteins (vinculin, talin, tensin, etc.) and signaling molecules (focal adhesion kinase-FAK, etc.). ${ }^{[5]}$ FAK is a nonreceptor tyrosine kinase that becomes activated in response to cell-matrix adhesion and is a key signaling protein involved in regulating cell motility, invasion, survival, and proliferation. ${ }^{[6]}$

Significant efforts have focused on engineering materials that recapitulate characteristics of ECM, such as the presentation of cell adhesive motifs or protease degradable cross-links, in order to direct cellular responses. ${ }^{[7,8]}$ Similarly, various approaches have been made in order to provide cells with dynamic-like environments able to provide proteins and factors using controlled delivery strategies. Direct loading, electrostatic interaction, covalent binding, and the use of carriers are the main strategies used, including the incorporation of proteasedegradable sites, adhesive ligands to direct protein and growth factors release. ${ }^{[9-15]}$ However, the development of a cell-material interphase able to provide biological stimuli upon demand, a functional dynamic interphase between living cells and synthetic materials, has not been established yet. We hypothesized that non-pathogenic bacteria can provide such a role, since they can colonize the surface of a broad range of synthetic materials and be genetically modified to express or secrete the desired adhesive proteins and factors to a living cell population.

Among the broad range of non-pathogenic bacteria, we have selected food-grade Lactococcus lactis, a gram-positive bacterium 
with very low production of lipopolysaccharides (LPS), a mandatory condition to preserve the accessibility of cells to the expressed proteins in the bacteria membrane. Moreover Lactococcus lactis has been widely used for recombinant therapeutic proteins production, therapeutic drug delivery and vaccine production. ${ }^{[16-20]}$

L. lactis was grown overnight at $30{ }^{\circ} \mathrm{C}$ in M17 medium supplemented with $0.5 \%$ glucose in static conditions. After adding the grown culture over the material surface at $30{ }^{\circ} \mathrm{C}$ we observed that L. lactis adhered, colonized and formed a cocontinuous, stable bacteria multilayer on different material surfaces (polymers, glass, etc.) after $3 \mathrm{~h}$. To assess the interaction of seeded cells with the layer of bacteria in direct contact with the synthetic biomaterial, the material surface was coated with gelatin $(0.1 \%)$ and the excess of bacteria was washed with PBS (phosphate buffered saline) before cell seeding.

Figure 1 shows a diagram of the living interphase developed in this work as a functional linker between synthetic materials and cells. We genetically modified L. lactis (MG1363) to expres FNIII $_{7.10}$ in their membrane. After cloning FNIII $_{7 \cdot 10}$ fused to GFP in pGFP-C2, then GFP-FNIII ${ }_{7-10}$ fragment was subcloned (NgomIV/Klenow BamHI) in pT1NX vector ${ }^{[21]}$ which contains P1 lactococcal promoter, ${ }^{[22]}$ usp45 lactococcal secretion signal sequence, and spax Staphylococcus aureus anchor signal (Figure 2a). GFP-FNIII ${ }_{7-10}$ was cloned in frame with both signals and the resultant construct was electroporated in L. lact MG1363. The secretion and anchor signals efficiently promoted the localization of GFP-FNII ${ }_{710}$ on bacteria wall. Figure 2 shows bacteria aggregates displaying green fluorescence rings, which show cell-surface display of the fibronectin fragment
Further, to provide more evidence for the membrane expression of $\mathrm{FNIII}_{7-10}$, fractionation and western blot analysis for bacterial membrane proteins were performed (Figure $2 \mathrm{c}$ ). $\mathrm{FNIII}_{7-10}$ was detected only on the part of the bacteria lysate ascribed to membrane proteins (Figure 2c, lane 1) but without any trace of the fragment in the intracellular fraction (Figure 2c, lane 2).

L. lactis expressing $\mathrm{FNIII}_{7 \cdot 10}$ in their membrane colonize the surface of the synthetic material forming a homogeneous and viable layer of bacteria (Figure 2d, left). Afterwards, fibroblasts were seeded on this layer of bacteria in serum free medium. In order to avoid adhesion mediated by proteins secreted by the mammalian cells, we used FN-null fibroblasts (FN - / - ) to rule out the presence of any external FN on the material surface other than the FN fragment anchored in the bacteria membrane. FN -/- fibroblasts were seeded over a layer of GFP. $\mathrm{FNIII}_{7.10}$ bacteria and control bacteria (empty pT1NX vector) as an interphase between the material surface and fibroblasts. Cells were allowed to attach and spread for 4 hours, and remain viable during the experiment without significant differences between L. lactis expressing $\mathrm{FNIII}_{7.10}$ and surfaces covered with plasma FN (Figure 3). Subsequently, cells werefixed and stained for the focal adhesion protein vinculin (Figure 3a).

Strikingly, cells seeded on bacteria expressing $\mathrm{FNIII}_{7-10}$ displayed well-developed focal adhesions plaques, showing accumulation of vinculin at focal adhesion sites (Figure 3a, image 1). This result indicates that FNIII $_{7-10}$ anchored in the membrane of $L$. lactis is able to provide the adequate functionalities to direct cell adhesion and spreading. This behavior is similar to that found when fibroblasts are seeded on a layer of adsorbed FN on the same material surface, as it is shown in Figure 3a,

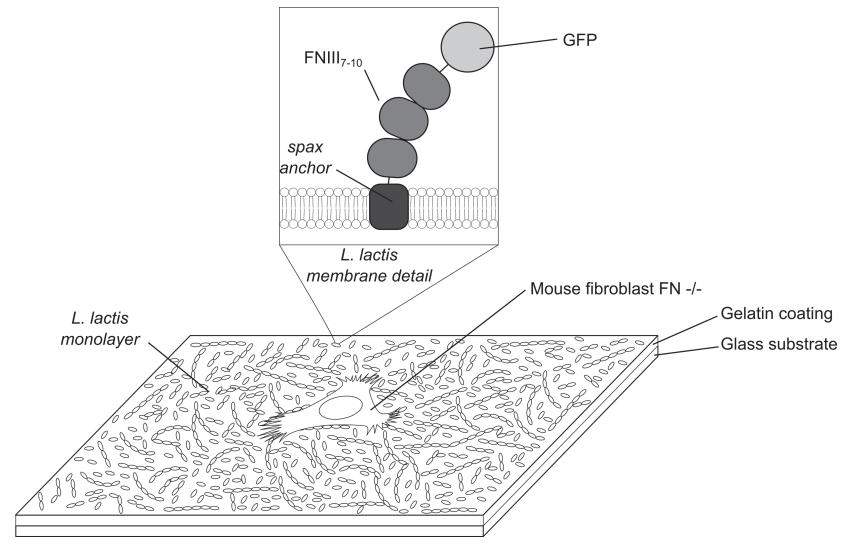

Figure 1. Functional living biointerphases. Non-pathogenic bacteria have been modified to express a fibronectin fragment $\mathrm{FNIII}_{7-10}$ in their membrane (including GFP for identification), and grown to colonize the material surface. Mammalian cells are then cultured on this living biointerphase which triggers cell adhesion and signaling. 


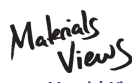

views

www.MaterialsViews.com

a)

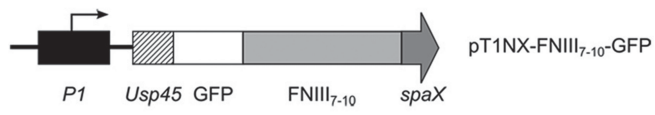

b)

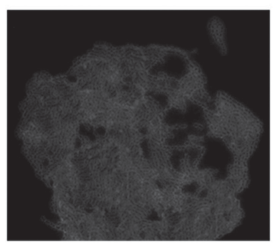

d)

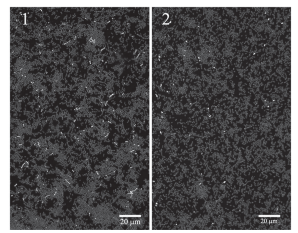

c)

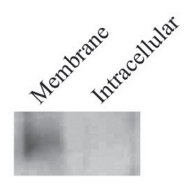

e)

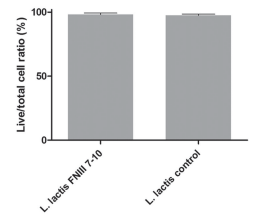

Figure 2. FNIII $7_{7-10}$ expression in L. lactis. a) Plasmid map for $L$. lactis expression of GFP. $\mathrm{FNIII}_{7-10}$. b) Fluorescence microscopy image of GFP-FNIII $I_{7.10}$ expression in L. lactis. A characteristic ring is observed which supports the membrane anchorage of the $\mathrm{FN}$ fragment. $\mathrm{c}$ ) Western istic ring is observed which supports the membrane anchorage of the $\mathrm{FN}$ fragment. c) Western
blot analysis of membrane and intracellular fractions of $L$. lactis. FNIII 7.10 is only found in the blot analysis of membrane and intracellular fractions of $L$. lactis. FNIII ${ }_{7.10}$ is only found in the
membrane fraction, with no detectable levels in the intracellular pool. d) bacterial viability assay. membrane fraction, with no detectable levels in the intracellular pool. d) bacterial viability assay. After 3 hours of culture (1-L. lactis FNIII 7.10 and 2-L. lactis) samples were stained with the Life
Technologies LIVE/DEAD kit for bacteria (SYTO9 permeant green stain and propidium iodide Technologies LIVE/DEAD kit for bacteria (SYTO9 permeant green stain and propidium iodide
non-permeant red stain). e) Quantification by image analysis: both strains showed viability non-permeant red st
higher than $97 \%$.

image $3 .{ }^{[23]}$ In contrast, when fibroblasts are seeded on a layer of the control bacteria (empty pT1NX vector) only rounded cell are found, without any spreading or focal adhesion plaques. This result was expected since there is no adhesion protein at the cell-material interface to trigger cell behavior (Figure 3a image 2). That is to say, cells behave on the control bacteria as if they were seeded directly on the bare material surface (Figure 3a, image 4).

Focal adhesion kinase (FAK) localizes to focal adhesions to activate multiple signaling pathways that regulate cell migration, survival, proliferation, and differentiation. ${ }^{[24-26]}$ We exam ined the phosphorylation of tyrosine-397, the autophosphorylation site in FAK and a binding site for src and PI-3 kinase ${ }^{[27,28}$ by Western blot (Figure 4). Although the band for FAK remains approximately constant, the level of phosphorylation (pFAK) is significantly higher for cells cultured on $\mathrm{FNIII}_{7 \cdot 10^{-}}$expressing

L. lactis whereas fibroblasts cultured on control bacteria exhibited minimal FAK phosphorylation (Figure 4). This result demonstrates that the FNIII $_{7-10}$ displayed on the bacterial membrane can trigger adhesion signalling pathway in contiguous cells. Importantly, FAK phosphorylation levels were equivalent between $\mathrm{FNIII}_{7-10}$-expressing bacteria and synthetic surfaces coated with FN, indicating that the protein displayed on the bacterial surface retains high bioactivity.

In conclusion, we have developed a functional interphase between synthetic materials and cells based on modified bacteria that express a fibronectin fragment $\left(\mathrm{FNIII}_{7.10}\right)$ and display it as a membrane protein. This living interphase supports cell adhesion (focal adhesion formation) and cell signalling (FAK phosphorylation). Moreover, as this interphase is based on a living system, it can be further designed and exploited to provide the spatio-temporal requested proteins and factors to direct cell proliferation and differentiation at the material interface. Taken together, this approach establishes a new paradigm in biomaterial surface functionalization for biomedical applications.

\section{Experimental Section}

Plasmids, primers and cell line: pGFP-C2 plasmid (Clontech) was used to construct a vector containing $\mathrm{FNIII}_{7-10}$ downstream to GFP. FNIII ${ }_{7.10}$ was amplified the plasmid pET15b-FNIII ${ }_{7.10}{ }^{[29]}$ The forward and reverse primers used for FNIII ${ }_{7-10}$ amplification were: F1 (with HindIII restriction site). aggcttaCCATTCTCTCCACCAACAAAC and RI (with Sall restriction site and stop codon) gtcgacttaTTCTGTTCGGTAATTAATGGAAA. PTINX vector was used to clone GFP.FNIII ${ }_{7.10}$ using the following primers F2; (with NgomlV restriction site): GCCGCCATCGCTAAAGCAGAACAACTIT R2 site): GCCCGCATCGCTAAACCACAACAACTTT R2; TTCTCTTCGGTAATTAATCGAAA. Fibronectin-null
FN $\%$ mouse fibroblasts were kindly provided by Prof. Mercedes Costell (University of Valencia, Spain).

Bacterial strains and plasmid extraction: Lactococcus lactis subsp. Bacterial strains and plasmid extraction: Lactococcus lactis subsp.
cremoris $\mathrm{MG}^{2} 1363^{[30]}$ and PTINX containing MG1363 were grown as standing cultures at $30^{\circ} \mathrm{C}$ in $\mathrm{M} 17$ medium (Oxoid, Basingstoke, UK) supplemented with glucose $(0.5 \% \mathrm{v} / \mathrm{v})$ and when necessary, erythromycin $\left(10 \mu \mathrm{g} \mathrm{mL}^{-1}\right)$. For plasmid extraction from $\mathrm{MG} 1363$, a combination of manual protocol[22] and Five Minute Miniprep Kit (Sigma) was applied. After adding ice-cold sodium acetate $(3 \mathrm{M}, \mathrm{pH} 4.8)$ and $15 \mathrm{~min}$ centrifugation at maximum speed, the lysate was transferred to miniprep column and extracted following the manufacturer's protocol.

Preparation of competent cells and electroporation: Competent cells of strain MG1363 was prepared by growing the cells in rich medium containing glycine $(1 \% \mathrm{v} / \mathrm{v}){ }^{[31]}$ Cells were harvested at an $\mathrm{OD}_{60}$ of $0.6-0.8$, resuspended in sucrose $(0.5 \mathrm{~m})$ and glycerol $(10 \% \mathrm{v} / \mathrm{v})$ and then $0.6-0.8$, resuspended in sucrose $(0.5 \mathrm{M})$ and glycerol $(10 \% \mathrm{~V} / \mathrm{V})$ and then frozen at $-80^{\circ} \mathrm{C}$. Electroporation was performed at $2.5 \mathrm{kV}$ using BTX (Harvard Apparatus). In these conditions with desalted DNA, the typical $5 \mathrm{~mL}$ medium (M17, $0.5 \mathrm{M}$ sucrose, $20 \mathrm{mM} \mathrm{MgCl}_{2}, 2 \mathrm{mM} \mathrm{CaCl}_{2}$ ) and 
a)
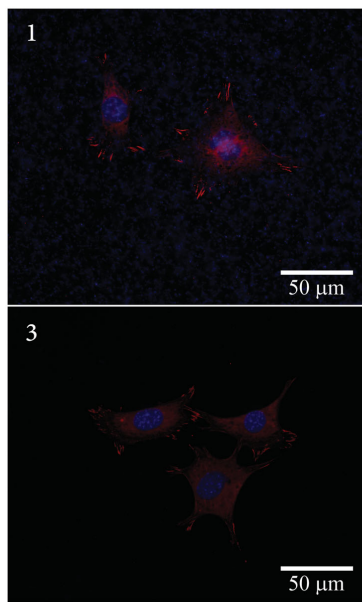

\section{4}

$\overline{50 \mu \mathrm{m}}$

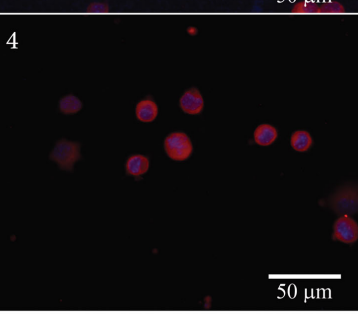

b)

c)
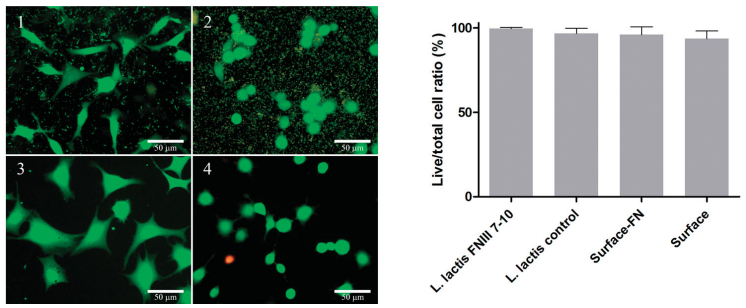

Figure 3. a) FNIII $7-10^{-e x p r e s s i n g ~ b a c t e r i a ~ s u p p o r t ~ c e l l ~ v i a b i l i t y, ~ c e l l ~ a d h e s i o n ~ a n d ~ f o c a l ~ a d h e s i o n ~ a s s e m b l y . ~ F N ~} /$ - fibroblasts were seeded on different interphases and stained for vinculin after $4 \mathrm{~h}$. a1) Cells on modified L. lactis to express FNIII 710 in the membrane. a2) Cells on control L. lactis (empty vector). a3) Cells on a material surface coated with fibronectin. a4) Cells on the bare material surface (without any adhesion protein). b) Fibroblast viability assay. Cells were seeded on different surfaces: b1) L. lactis FNIII 7 -10 monolayer; b2) L. lactis monolayer; b3) FN coated glass and b4) bare material surface, c) After 4 hours cells were stained with $\mathrm{ca}$ ( higher than $93 \%$ for every surface, and higher than $99.5 \pm 0.7 \%$ on $L$. lactis $F N I_{11} I_{7.10}$.

incubated $\left(2 \mathrm{~h}\right.$ at $\left.30^{\circ} \mathrm{C}\right)$. Subsequently the culture was centrifuged resuspended in $0.5 \mathrm{~mL}$ of the later medium and extended on M17-agar resuspended in $0.5 \mathrm{~mL}$ of the later medium and extend

Western cells coresponding (10 $\left.10^{9} \mathrm{~L}^{-1}\right)$. Western blots: Cells corre resuspended in $50 \mu \mathrm{l}$ of washing buffer (Tris/ $\mathrm{HCl}^{-1}(50 \mathrm{mM} \mathrm{pH} 7.5)$ containing sucrose $(0.5 \mathrm{M})$ and lysozyme ( $\left.50 \mathrm{mg} \mathrm{mL}^{-1}\right)$ ). The suspension was incubated $\left(2 \mathrm{~h}\right.$ at $\left.37^{\circ} \mathrm{C}\right)$ then centrifuged at maximum speed.
Supernatant and pellet were separated and resuspended in Laemmli loading buffer $(50 \mathrm{HL})$ and boiled for $5 \mathrm{~min}$ and separated by $10 \%$ SDS-PACE gels. FNIIl was detected by mouse anti-human fibronectin SDS-PACE gels. FNIII $7_{7-10}$ was detected by mouse anti-human fibronectin

Immunofluorescence: Bacteria were seeded $\left(10^{9} \mathrm{cfu} / \mathrm{mL}\right)$ over glass coverslip coated with gelatin $0.1 \%$. After 3 hours, the coverslip was washed with PBS several times to obtain a monolayer. FN- $/$ - fibroblasts 


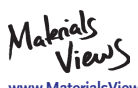

b)
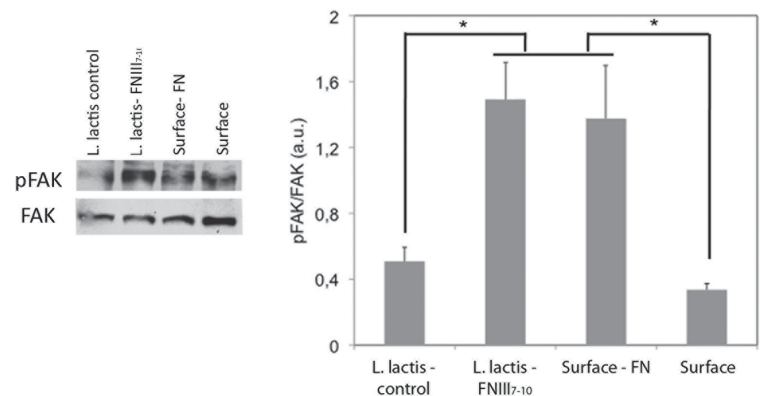

Figure 4. FAK phosphorylation for cells adhering to functional biointerphase. FN $\%$ - fibroblasts were seeded on: modified L. lactis to express FNIII $I_{7-10}$ in the membrane; control L. lactis (empty vector); a material surface coated with fibronectin; bare material surface (without any adhesion protein). a) Representative Western blot for phosphorylated and total tyrosine-397 residue on FAK (pFAK and FAK, respectively). b) Quantification of the fraction of phosphorylated FAK by image analysis of the Western blot bands. Error bars represent the standard deviation of three independent experiments. * stands for $p<0.05$

were seeded on the bacteria in DMEM (Dulbecco's modified eagle medium) without FBS (fetal bovine serum) for 4 hours $\left(1.5 \cdot 10^{4}\right.$ cells well). Cells were fixed and stained with mouse anti-vinculin antibody. A confocal microscopy (Leica TCS SP2 AOBS) was used.

confocal microscopy (Leica TCS SP2 AOBS) was used. FAK phosphorylation: After 3 hours of culture, cells were lysed with
RIPA buffer (Tris-HCl $50 \mathrm{~mm}, 1 \%$ Nonidet P- $40,0.25 \% \mathrm{Na}$ deoxycholate, RIPA buffer (Tris-HCl $50 \mathrm{~mm}, 1 \%$ Nonidet P-40, $0.25 \%$ Na deoxycholate,
$\mathrm{NaCl} 150 \mathrm{~mm}$, EDTA $1 \mathrm{~mm}$ ) supplemented with protease inhibitor $\mathrm{NaCl} 150 \mathrm{~mm}$, EDTA $1 \mathrm{~mm}$ ) supplemented with protease inhibitor
cocktail tablets (Complete, Roche). Proteins were concentrated using cocktail tablets (Complete, Roche). Proteins were concentrated using Microcon YM-30 Centrifugal Filter devices (Millipore) as manufacturer described. To determine FAK protein expression and its phosphorylated form (PFAK), concentrated samples were subjected to 7\% SDS-PAGE ge electrophoresis. Proteins were transferred to a positively charged PVDF membrane (GE Healthcare) using a semidry transfer cell system (BioRad) and blocked by immersion in skimmed milk ( $5 \% \mathrm{w} / \mathrm{v})$ in PBS for $30 \mathrm{~min}$ at room temperature. The blot was incubated with anti-FAK antibody (Upstate) and anti-pFAK antibody (Millipore) diluted 1:2500 in PBS containing Tween $20(0.1 \%)$ and skimmed milk $(2 \%)$. After several hashes wh PBS horsera ish PBS coxidasecojugted $20(0.1 \%$ v/V) and milk (2\%) diluted $1: 50000$ in PBS containing Tween $20(0.1 \% \mathrm{v} / \mathrm{v})$ and milk $(2 \% \mathrm{w} / \mathrm{v})$ for 1 hour at room containin Tween $(0.1 \% \mathrm{~V} / \mathrm{V})$ and milk $(2 \% \mathrm{~W} / \mathrm{V})$, immunoreactive bands were visualized using Supersignal West-femto Maximum Sensitivity Substrate (Thermo Scientific).

Cell viability: After 4 hours of culture, medium was removed and the coverslip were washed three times with PBS, then incubated 45 minutes room temperature with the LIVE/DEAD mammalian cell viability kit (Life Technologies), using calcein AM $(2 \mu \mathrm{m})$ and ethidium homodimer $(2 \mu \mathrm{m})$ in PBS. This kit stains live cells in green and dead cells in red. Cells were observed in epifluorescence microscope and manually counted using at least seven microscope fields at 20x magnification for every surface.

Bacterial viability: Bacteria were seeded $\left(10^{9} \mathrm{cfu} / \mathrm{mL}\right)$ over glass coverslip coated with gelatin $0.1 \%$. Coverslips were washed twice with $\mathrm{NaCl} 0.85 \%$ w/v Then, the $\mathrm{NaCl} 0.85 \%$. Then, the bacterial monolayer was incubated for 30 min using a sYTO $(5 \mu \mathrm{m})$ and propidium iodide $(30 \mu \mathrm{m})$ in $\mathrm{NaCl}$ $0.85 \%$ w/v solution. Aftenwards, coverslips were washed once and four microscope fields at $40 x$ magnification for every strain.

\section{Acknowledgements}

This work was supported by MAT2012-38359-C03-01, MAT2010-10497-E and MAT2009-14695-C04-01.

Received: December 18, 2012 Published online:

[1] J. D. Sipe, Ann. N.Y. Acad. Sci. 2002, 961, 1.

[2] L. Griffith, G. Naughton, G. Naughton, Science 2002, 295, 1009.

[3] F. Grinnell, J. Cell Biol. 1986, 103, 2697

[4] R. Hynes, Cell 2002, 110, 673.

[5] A. García, Biomaterials 2005, 26, 7525 .

[6] S. Mitra, D. Hanson, D. Schlaepfer, D. Hanson, D. Schlaepfer, Not. Rev. Mol. Cell Biol. 2005, 6, 56.

[7] M. Lutolf, P. Gilbert, H. Blau, Nature. 2009, 462, 433

[8] T. Petrie, J. Raynor, D. Dumbauld, T. Lee, S. Jagtap, Sci. Transl. Med. 2010, 2, 45ra60.

[9] H. Makarenkova, M. Hoffman, A. Beenken, A. Eliseenkova, R. Meech, C. Tsau, V. Patel, R. Lang, M. Mohammadi, Sci. Signal. 2009,2 , ra55.

[10] A. K. Silva, C. Richard, M. Bessodes, D. Scherman, O. W. Merten, Biomacromolecules 2009, 10, 9 .

[11] M. P. Lutolf, J. A. Hubbell, Nat. Biotechnol. 2005, 23, 47.

[12] M. S. Hahn, J. S. Miller, J. L. West, Adv Mater. 2006, 18, 2679

[13] J. J. Moon, M. S. Hahn, I. Kim, B. A. Nsiah, J. L. West, Tissue Eng. Part A. 2009, 15, 579.

[14] E. A. Phelps, N. Landazuri, P. M. Thule, W. R. Taylor, A. J. Garcia, Proc. Natl. Acad. Sci. U. S. A. 2010, 107, 3323.

[15] J. Patterson, M. M. Martino, J. A. Hubbell, Mater. Today 2010, 13,

[16] L. G. Bermudez-Humaran, N. G. Cortes-Perez, R. L'Haridon, P. Langella, FEMS Microbiol. Lett. 2008, 280, 144 
[17] N. G. Cortes-Perez, L. F. da Costa Medina, F. Lefevre, P. Langella, L. G. Bermudez-Humaran, Vaccine 2008, 26, 5778.

[18] S. Nouaille, L. A. Ribeiro, A. Miyoshi, D. Pontes, Y. Le Loir S. C. Oliveira, P. Langella, V. Azevedo, Genet. Mol. Res. 2003, 2 S. C.
102.

[19] H. Rawsthorne, K. N. Turner, D. A. Mills, Appl. Environ. Microbiol. 2006, 72, 6088 .

[20] J. Villatoro-Hernandez, M. J. Loera-Arias, A. Gamez-Escobedo, M. Franco-Molina, J. G. Gomez-Gutierrez, H. Rodriguez-Rocha, Y. Gutierrez-Puente, O. Saucedo-Cardenas, J. Valdes-Flores, R. Montes-de-Oca-Luna, Microb.Cell. Fact. 2008, 7, 22.

[21] M. J Gasson, J Bacteriol, 1983, 154, 1 .

[22] D. J. Osullivan, T. R. Klaenhammer, Appl. Environ. Microbiol. 1993 59, 2730.

[23] V. Llopis Hernandez, P. Rico, J. Ballester Beltran, D. Moratal, M. Salmeron Sanchez, PLoS ONE 2011, 6, e19610.
[24] D. Ilic, Y. Furuta, S. Kanazawa, N. Takeda, K. Sobue, N. Nakatsuji, S. Nomura, J. Fujimoto, M. Okada, T. Yamamoto, Nature 1995, 377 539

[25] L. A. Cary, J. F. Chang, J. L. Guan, J. Cell. Sci. 1996, 109, 1787.

[26] S. M. Frisch, K. Vuori, E. Ruoslahti, P. Y. Chan-Hui, J. Cell Biol. 1996 134, 793 .

[27] M. D. Schaller, J. D. Hildebrand, J. D. Shannon, J. W. Fox, R. R. Vines, J. T. Parsons, Mol. Cell. Biol. 1994, 14, 1680.

[28] H. R. Reiske, S. C. Kao, L. A. Cary, J. L. Guan, J. F. Lai, H. C. Chen, J. Biol. Chem. 1999, 274, 12361 .

[29] T.A. Petrie, J. R. Capadona, C.D. Reyes, A. J. García, Biomaterials 2006, 27, 5459

[30] L. Schotte, Enzyme Microbiol. Technol. 2000, 27, 761 [31] H. Holo, I. F. Nes, Appl. Environ. Microbiol. 1989, 55,
3119 . 
OPEN Living biointerfaces based on

SUBJECT AREAS

BIOMEDICAL

ENGINEERING

BIOMATERIALS - CELLS

Received

7 March 2014

Accepted

7 July 2014

Published

28 July 2014

Correspondence and requests for materials should be addressed to

M.S.S. (Manuel.

Salmeron-Sanchez@

glasgow.ac.uk) non-pathogenic bacteria to direct cell differentiation

Aleixandre Rodrigo-Navarro ${ }^{1,4}$, Patricia Rico ${ }^{1}$, Anas Saadeddin ${ }^{2}$, Andres J. Garcia ${ }^{3}$

$\&$ Manuel Salmeron-Sanchez ${ }^{4}$

${ }^{1}$ Center for Biomaterials and Tissue Engineering, Universitat Politécnica de València, Spain, ${ }^{2}$ Abengoa Research, Campus Palmas Altas, Sevilla, Spain, ${ }^{3}$ Woodruff School of Mechanical Engineering, Petit Institute for Bioengineering and Bioscience Georgia Altas, Sevilla, Spain,
Institute of Technology, Atlanta, GA 30332, USA, ${ }^{4}$ Division of Biomedical Engineering, School of Engineering, University of Glasgow, Glasgow G12 8LT, United Kingdom.

Genetically modified Lactococcus lactis, non-pathogenic bacteria expressing the $\mathrm{FNIII}_{7-10}$ fibronectin fragment as a protein membrane have been used to create a living biointerface between synthetic materials and mammalian cells. This FNIII ${ }_{7-10}$ fragment comprises the RGD and PHSRN sequences of fibronectin to bind $\alpha 5 \beta 1$ integrins and triggers signalling for cell adhesion, spreading and differentiation. We used $L$. lactis strain to colonize material surfaces and produce stable biofilms presenting the FNIII 7-10 $_{\text {fragment readily }}$ strain to colonize material surfaces and produce stable biofilms presenting the $\mathrm{FNIII}_{7-10}$ fragment read
available to cells. Biofilm density is easily tunable and remains stable for several days. Murine $\mathrm{C} 2 \mathrm{C} 12$ myoblasts seeded over mature biofilms undergo bipolar alignment and form differentiated myotubes, a process triggered by the FNIII $_{7-10}$ fragment. This biointerface based on living bacteria can be further modified to express any desired biochemical signal, establishing a new paradigm in biomaterial surface functionalisation for biomedical applications.

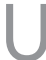

derstanding the behaviour of cells on synthetic surfaces is of foremost interest to engineer microenvirnments that direct cell adhesion, proliferation and differentiation. To favour the interaction with cells, surfaces of synthetic biomaterials have been functionalized with a broad range of proteins, fragments, peptides and growth factors including fibronectin (FN), laminin, vitronectin and others, by using physical and chemical strategies ${ }^{1-3}$. However, these passive coatings can by no means provide the dynamic stimuli required to orchestrate cell responses and organise the formation of a new tissue at the material interface. Significant efforts have focused on engineering materials that recapitulate characteristics of the ECM, such as the presentation of cell adhesive motifs or protease degradable cross-links, in order to direct cellular responses ${ }^{4,5}$. Photoactivable RGD adhesive peptides were used to investigate the effect of the density and time point of ligand presentation on cell adhesion, proliferation and differentiation ${ }^{6}$. Similarly, enzyme-responsive surfaces that present cell adhesive RGD sequences on-demand, that is, by enzymatic hydrolysis of inactive RGD containing precursors that carry cleavable steric blocking groups, have been used to spatiotemporal controlled attachment of cells ${ }^{7}$. However, the development of a cell/material interface able to provide biological stimuli upon demand, a functional dynamic interface between stem cells and synthetic materials, has not been established yet. We hypothesised that nonpathogenic bacteria can colonise the surface of a broad range of synthetic materials and can be genetically modified to constitutively express or secrete the desired adhesive proteins and factors to a living cell population upon external demand. This work shows that non-pathogenic bacteria that constitutively express a fibronectin fragment enhance cell differentiation. However, our long-term goal is to transform this living interface into a dynamic system able to secrete other proteins and growth factors upon demand.

We have recently shown that genetically modified, non-pathogenic bacteria, can play the role of a (living) biointerface between mammalian cells and synthetic biomaterials and we chose Lactococcus lactis subsp. cremoris as host for membrane expression of the fibronectin FNIII $_{7-10}$ fragment ${ }^{8}$. This fragment contains the RGD adhesion motif ( $10^{\text {th }}$ repeat of the type III fragment) and the PHSRN synergy site ( $9^{\text {th }}$ repeat of type III fragment), both of them necessary to promote $\alpha 5 \beta 1$ integrin mediated adhesion ${ }^{9}$. Lactococcus lactis is a gram-positive, nonpathogenic bacterium, with GRAS (Generally Regarded as Safe) status and with low production of exopolysacpathogenic bacterium, with GRAS (Generally Regarded as Safe) status and with low production of exopolysac-
charides, a mandatory condition to ensure the accessibility of the displayed FNIII membrane. Moreover, this low exopolysaccharide production is not an obstacle for this strain to develop stable 


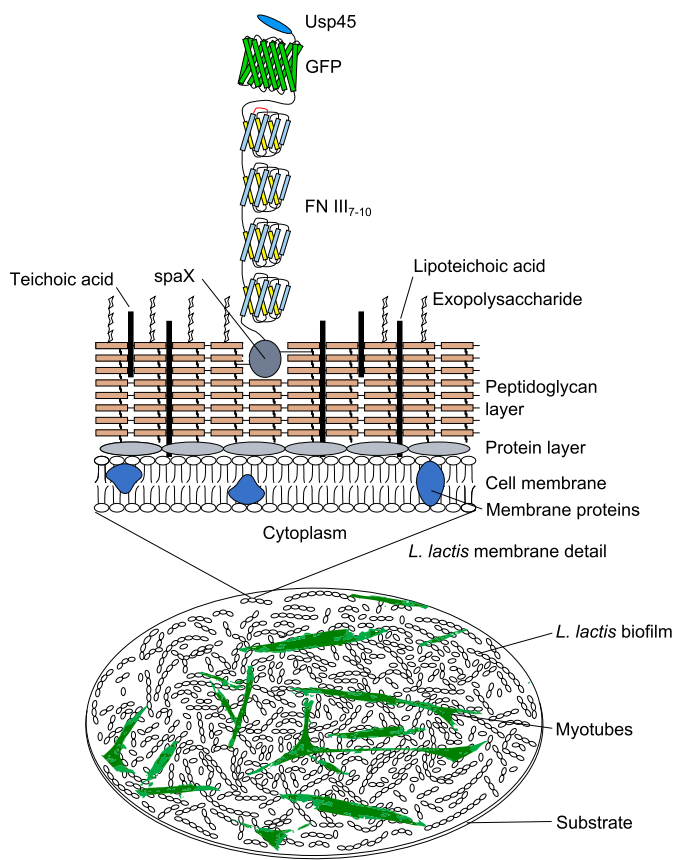

Figure $1 \mid$ Schematic of living biointerfaces. C2C12 murine myoblasts were seeded on top of $L$. lactis biofilms that express a FNIII ${ }_{7-10}$ fragment as a membrane protein. The construct features the Usp45 secretion peptide, GFP and the fibronectin fragment FNIII $_{7-10}$ that contains both RGD (FNIII 10 ) and PHSRN synergy sites ( $\mathrm{FNIII}_{9}$ ). The construct is inserted into the bacterial peptidoglycan layer by the protein $\mathrm{A}$ anchor $(\mathrm{spaX})$. This anchor protein is covalently linked to the tetrapeptides of the peptidoglycan layer. L. lactis strain forms stable biofilms with very low exopolysaccharide production, which granted exposure of FN fragments to mammalian cells. $\mathrm{C} 2 \mathrm{C} 12$ differentiated into myoblasts triggered by the $\mathrm{FNIII}_{7-10}$ fragment displayed on the bacterial membrane.

biofilms: these bacteria firmly attach to synthetic surfaces and establish communities ${ }^{10,11}$. This results in a stable layer of bacteria on the material surface which present FNIII $_{7-10}$ fragments. $^{8}$.

Mammalian cells interact with FN via integrins, a family of transmembrane receptor proteins that anchor them to the ECM. Integrin-mediated adhesion is a complex process that involves the organization of focal adhesion clusters that link the ECM to the cytoskeleton. Focal complexes are mature adhesion sites that contains structural proteins (vinculin, paxilin, talin, tensin) and signalling molecules (FAK, focal adhesion kinase, Src) ${ }^{3,12,13}$. We have previously shown that FN null fibroblasts (FN -/-) adhered on this living biointerface based on L. lactis expressing $\mathrm{FNIII}_{7-10}$, develop focal adhesions and promote FAK-based signalling.

This work investigates the potential of this living interface based on L. lactis expressing a FN fragment as a membrane protein to direct cell differentiation by evaluating myogenic differentiation ${ }^{14}$. As previously reported ${ }^{8}$, a modified L.lactis (MG1363) was engineered to express $\mathrm{FNIII}_{7-10}$ as a membrane protein. The used construct features the Usp45 secretion peptide, GFP and the $\mathrm{FNIII}_{7-10}$ fragment con- taining the RGD adhesion (module $\mathrm{III}_{10}$ ) and PHSRN synergy site (module $\mathrm{III}_{9}$ ). The construct is anchored into the bacterial peptidoglycan layer by the protein A anchor (spaX) from Staphylococcus aureus. This anchor protein is covalently linked to the tetrapeptides of the peptidoglycan layer. L. lactis hardly produces any exopolysaccharide, which granted the availability of the FN fragment to interact with mammalian cells seeded on the bacterial layer (Fig. 1).

\section{Results}

We have first characterised the formation of the L. lactis biofilm on glass, including the amount of FN that is available for cell interaction. Then we have addressed the stability of the biofilm after different days, that results in using a strategy to diminish bacterial metabolism and prevent uncontrolled proliferation. Afterwards, we have explored $\mathrm{C} 2 \mathrm{C} 12$ interactions on this living interface, first in the short-term (cell adhesion, cell morphology) and then in the longterm (differentiation and related signalling).

Characterization of the bacterial-expressed fibronectin. The Usp45 secretion and $\operatorname{spaX}(S$. aureus protein A) anchor signals 
a

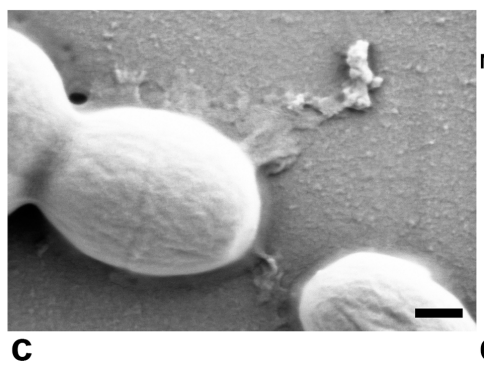

C

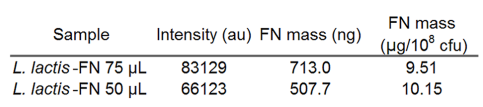

e

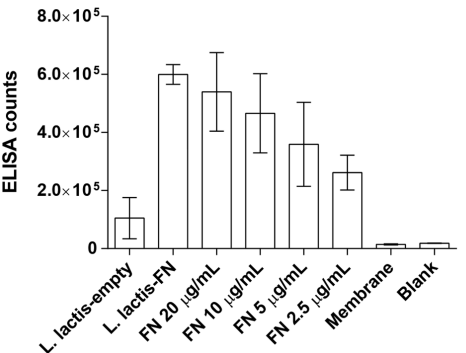

b

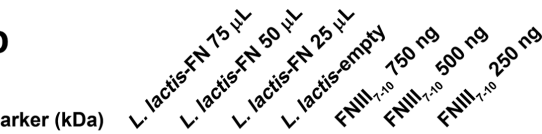

d
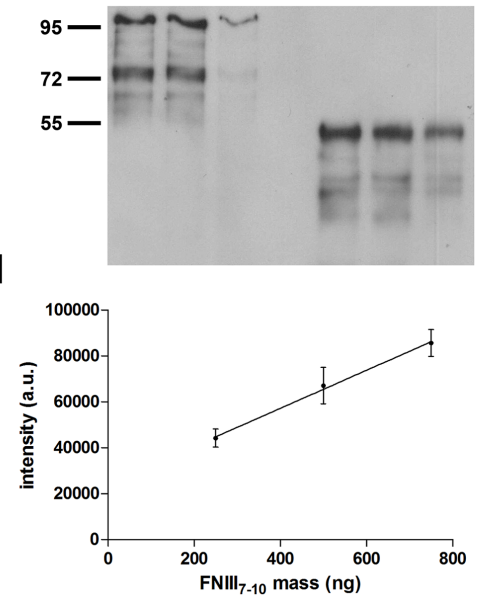

$\mathbf{f}$

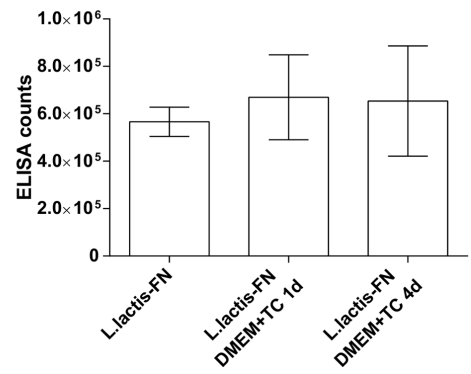

Figure $2 \mid$ Visualisation and quantification of $\mathrm{FNU}_{7-10}$ in the bacterial membrane. (a) Low voltage SEM image of $L$. lactis-FN adhered to a glass surface showing the glycocalyx and the adhesion fimbriae. Scale bar size is $200 \mathrm{~nm}$. (b) - (d) Western blot analysis of membrane fractions of $L$. lactis using protein extracts from 75,50 and $25 \mu \mathrm{L}$ of a stationary phase culture and 750,500 and $250 \mathrm{ng}$ of a purified FNIII $7-10$ fragment as standards (quantification curve shown in d). Proteins isolated from bacteria have higher molecular weight due to GFP, the Usp45 and the spaX fragments (e) Quantification of FNIII $_{7-10}$ on the bacteria membrane using ELISA with HFN7.1 antibody. Biofilm activity is roughly equivalent to a surface coated with a solution of $20 \mu \mathrm{g} /$ $\mathrm{mL}$ of plasma fibronectin $\left(300 \mathrm{ng} / \mathrm{cm}^{2}\right)$. L. lactis-empty shows negligible fibronectin activity (1000 $\mu \mathrm{L}$ of bacterial culture was used both for $L$. lactisempty and L. lactis-FN, that correspond to a surface area coverage of $27.6 \pm 8.5 \%$ ). (f) ELISA of bacterial biofilms (L. lactis-FN) from fresh GM17-E medium and incubated in DMEM with tetracycline $10 \mu \mathrm{g} / \mathrm{mL}$ for 1 and 4 days respectively. ANOVA shows no statistically significant differences between samples. All data presented as mean $\pm \mathrm{SD}$.

efficiently promote the localization of FNIII $_{7-10}$ in the bacterial of each bacterium (Supp Fig. S1) ${ }^{8}$. Fig 2a shows bacterial morphology membrane. We have confirmed the presence of $\mathrm{FNIII}_{7-10}$ by the at high magnification by SEM. Additional SEM and AFM images are tagged GFP, which shows fluorescent rings defining the perimeter included in Supp Fig. S1. We have quantified the amount of FNIII ${ }_{7-10}$ 


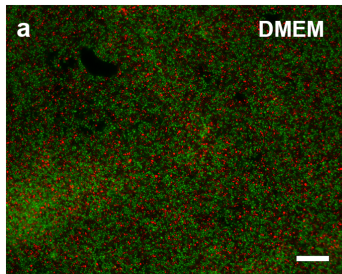

b

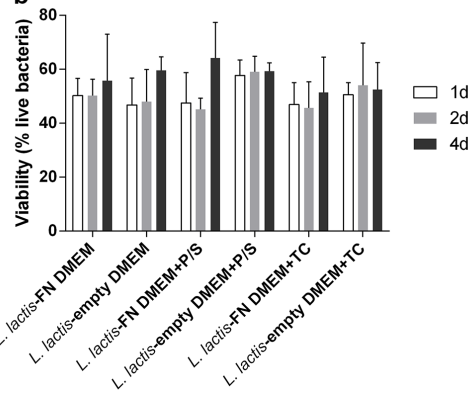

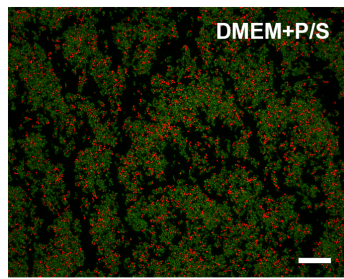

C

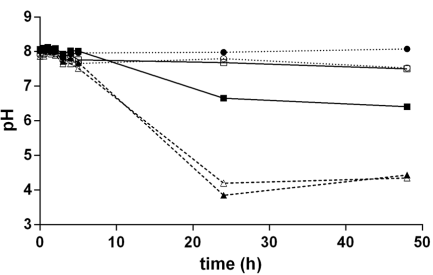

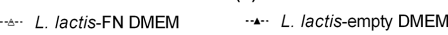

@... L. lactis-FN DMEM+TC $\quad$ •.. L. lactis-empty DMEM+TC

$\rightarrow$ L. lactis-FN DMEM+P/S $\rightarrow$ L. lactis-empty DMEM+P/S

Figure 3 Biofilm metabolism and viability. To assess the metabolism of the bacterial community inside the biofilm in conditions compatible with the culture of $\mathrm{C} 2 \mathrm{C} 12$ cells, biofilms of $L$ lactis-FN and $L$ lactis-empty were produced. Then, GM17-E medium was changed to either DMEM, DMEM with $1 \%$ penicillin/streptomycin (P/S) or DMEM with $10 \mu \mathrm{g} / \mathrm{mL}$ tetracycline (TC). After 1,2 and 4 days of culture in DMEM, DMEM $+\mathrm{P} / \mathrm{S}$ and DMEM + TC, viability was tested using the LIVE/DEAD BacLight bacterial viability kit, where viable bacteria are stained in green and non-viable in red. (a) Representative images after 4 days. Scale bar size is $25 \mu \mathrm{m}$. (b) Image quantification shows that viability is not affected by either the use of antibiotics or the culture time. No statistically significant differences among conditions were found. Data is presented as mean \pm SD. (c) Simultaneously, bacterial metabolism was inferred by measuring the $\mathrm{pH}$ of the medium as a function of time, to assess the production of lactic acid. Addition of tetracycline maintained the $\mathrm{pH}$ stable and above 7.5. The use of $\mathrm{P} / \mathrm{S}$ was enough to maintain the $\mathrm{pH}$ above 6.5. In antibiotic-free DMEM, the $\mathrm{pH}$ dropped to a minimum of 4 due to the transformation of glucose in the medium into lactic acid.

available on $L$. lactis membranes using two techniques that provide complementary information. First, we performed fractionation and Western blot analysis for bacterial membrane proteins and subsequent quantification using a recombinant FNIII $_{7-10}$ fragment as the part of the bacteria lysate ascribed to membrane proteins (Fig. 2b). Image analysis of the Western blot bands reveal that the total amount of FNIII $_{7-10}$ increases as the volume of the sample (number of colonies) does. Based on this, the approximate density of FN fragment per unit volume of bacteria is $0.98 \mu \mathrm{g} / \mathrm{mL}$, which corresponds approximately to $9.8 \mu \mathrm{g} / 10^{8} \mathrm{CFU}$ (Fig. $2 \mathrm{c}$,d). However, considering the role of this living interface in interacting with mammalian cells, is also important to calculate the availability of FNIII $_{7-10}$ after bacteria have been immobilised on a synthetic material. To do so, we have performed an enzyme-linked immunosorbent assay (ELISA) with a monoclonal antibody on high density biofilms, prepared from $1000 \mu \mathrm{L}$ of culture (Fig. 2e). This is a well-established method to probe for structural or conformational changes in adsorbed protein ${ }^{15,16}$. We used the monoclonal HFN7.1 antibody to probe the availability of the flexible linker between the 9th and 10th type III repeats of $\mathrm{FN}^{17}$. Figure $2 \mathrm{e}$ shows the amount of this integrin-binding domain on the surface of the living interface is similar to adsorbing $\mathrm{FN}$ from a solution of concentration $20 \mu \mathrm{g} / \mathrm{mL}$ on glass, a surface density of FN ca. $300 \mathrm{ng} / \mathrm{cm}^{2,18,19}$. As we will use tetracycline containing medium (TC) to maintain a stable biofilm on the material surface during experiments with mammalian cells, and since TC might inhibit bacterial protein expression, we have assessed that there is no influence of TC on FNIII (Fig 2f).

In summary, the engineered living interface presents a high density of FNIII $_{7-10}$ available on the cell surface, seeking to promote focal adhesion organisation and trigger cell fate.

Biofilm formation and stability. We next examined the stability of the living interface on the material surface. This strain, once the biofilm has been established, is able to continue proliferating as long as there is a sufficient supply of nutrients.

L. lactis is a homofermentative strain that metabolises any carbon source found in the medium, glucose in our experiments, to $\mathrm{L}-(+)$ lactic acid, in an anaerobic fashion ${ }^{20}$. This production of lactic acid leads to a decrease in the $\mathrm{pH}$ of the culture medium up to $\sim 4$, seriously compromising the viability of the aboveground cells. Here arises the need to control the $\mathrm{pH}$ of the medium, by inhibiting the bacterial metabolism. We have found that tetracycline used at low concentrations, $10 \mu \mathrm{g} / \mathrm{mL}$, is enough to inhibit the bacterial replication without impacting mammalian cell metabolism ${ }^{21,22}$ (Fig 3 and 
results on cell differentiation later in this work). Tetracycline is broad-spectrum antibiotic that binds to the $30 \mathrm{~S}$ subunit of the microbial ribosomes, inhibiting the protein synthesis by blocking the attachment of the charged aminoacyl-tRNA to the ribosomal A site ${ }^{2}$ Conversely, penicillin acts inhibiting the peptidoglycan cell-wall remodelling, ultimately leading to cell breakdown. As we only intend to maintain the cell population under control, it is counterproductive to promote cell lysis, and, as side effect, the modification of the biofilm morphology. Moreover, tetracycline is more effective controlling the $\mathrm{pH}$ at low concentrations and is nontoxic to mammalian cells ${ }^{21,22}$ (see also our results on cell behaviour afterwards).

Biofilms of different densities were formed on glass and remained stable after several days on the material surface. We have effectively shown that we can control the surface density of bacteria on the material surface by controlling the seeding volume (Supp Fig. S2) We selected high-density bacterial cultures to have the highest possible L. lactis density on the material surface readily available for cell differentiation experiments. We have assessed the stability of the layer of bacteria at different time points up to 4 days. This is the time needed for myogenic differentiation experiment afterwards. Fig. 3 shows live/dead staining for $L$. lactis grown on glass using differen media (DMEM, DMEM + tetracycline (TC), DMEM + penicillin and streptomycin, stated as $\mathrm{P} / \mathrm{S}$ ). After 4 days of culture bacteria viability (measured by the ration of live to total cells) is unaffected by the presence of small amounts of antibiotics in the culture medium and it is maintained at ca. $60 \%$ (Fig. 3b)

The temporal evolution of the $\mathrm{pH}$ in the different media used is shown in Fig. 3c. Only when the culture medium is supplemented with TC, acidification does not occur and the $\mathrm{pH}$ remains stable for four days (Fig 3c). We suggest that this acidification of the culture medium is a consequence of the L. lactis metabolism. As said before, L. lactis is a homofermentative strain that metabolises any suitable carbon source found in the medium - glucose in our experiments - to $\mathrm{L}-(+)$-lactic acid. Then, the production of $\mathrm{L}-(+)$-acid lactic, with a $\mathrm{pK}_{\mathrm{a}}$ of $3.86^{24}$ must be responsible for the acidification of the culture medium. Addition of TC maintains a stable $\mathrm{pH}$, which suggests that no L-lactic acid is produced and that, consequently, bacterial metabolism is inhibited.

The use of antibiotics in the culture medium diminished the density of bacteria on the material surfaces, as it can be inferred from Fig. 3a and we have quantified in Supp Fig. S3. However, even if this is the case, the layer of bacteria that remains on the surface is viable and sufficient to support cell adhesion and cell differentiation, as it is shown afterwards. That is to say, even if the layer of bacteria attained on the material surface is not homogeneous (see e.g. Supp Fig S2), the attained bacterial surface involves the adequate expression of FN for mammalian cell interactions.

Cell morphology, adhesion and differentiation on L. lactis. The density of the biofilm directs area and roundness of mammalian cells. We first studied cell morphology on established biofilms of differen densities on glass (Supp Fig. S2). Both cell area and roundness are directly related to the biofilm density, as shown in fig. 4 . C2C12 cell seeded on biofilms of different densities showed increased are (Fig. 4b), with minimal changes in cell roundness (Fig. 4c). In addition, focal adhesions were formed on cells seeded on $L$. lactisFN biofilms. The number of focal adhesion plaques increased with the density of bacteria on the surface (Supp Fig. S4). These results suggest that L.lactis-FN directs cell adhesion and cell morphology in the short-term, which is necessary before considering other longterm processes such as cell differentiation.

We previously showed that $L$. lactis modified to express FNIII $_{7-10}$ as a membrane protein promotes focal adhesion formation and FAK signalling at similar levels as native $\mathrm{FN}$ in fibroblasts ${ }^{8}$. Now, we assessed the ability of this living interface to support cell differentiation by examining myogenic differentiation ${ }^{25}$. Sarcomeric myosin expression and cell bipolar alignment and fusion into myotubes, markers of myogenesis, were significantly higher on L. lactis modified with FNIII $_{7-10}$ (Fig. 5a) as compared to L. lactis-empty (contro bacteria that do not contain $\mathrm{FNIII}_{7-10}$ ). Surprisingly, myogenic differentiation was higher on the modified $L$. lactis than on native fibronectin and collagen type I, which represents the gold-standard substrate for myogenic differentiation (Fig. 5b) ${ }^{14}$. It is important to emphasise that these differences in myogenic differentiation are no due to differences in the number of cells on the substrates. It is known that a direct correlation between the number of cells on the surface and the level of myogenic differentiation has been found, however the number of cells on the modified bacteria is slightly lower than on the FN and $\mathrm{Col} \mathrm{I}$ controls ( $\mathrm{Fig} 5 \mathrm{c}$ ).

Integrin-mediated cell adhesion triggers a cascade of intracellular signals such as the p38 mitogen-activated protein kinase (p38 MAPK) pathway, which is involved in the myoblast differentiatio process, by promoting the activity of several transcription factors and regulating cell cycle withdrawal ${ }^{26,27}$. An intermediary step between adhesion and downstream targets, including MAPK pathways, is the phosphorylation of $\mathrm{FAK}^{28}$; as a result, FAK phosphorylation a Tyr397 plays a central role during myoblast differentiation in $2 \mathrm{D}$ cultures $^{29,30}$. Initially, FAK phosphorylation at Tyr397 is transiently reduced - contributing to trigger the myogenic genetic programbut it is later activated, as it is central to terminal differentiation into myotubes ${ }^{30}$. In order to study the activation of FAK on the L. lactis expressing $\mathrm{FNIII}_{7-10}$ we examined the phosphorylation of Tyr397 by Western blot. FAK phosphorylation was similar on modified L. lactis and FN-coated glass (Fig 5d e), in good correlation with the high levels of cell differentiation found in this work (Fig 5b).

These results suggest that enhanced cell differentiation can be triggered by FNIII $_{7-10}$ expressed on the membrane of L. lactis. The fact that the same experiments have been done with $L$. lactis-empty strain without significant levels of cell differentiation absolutely confirm FNIII $_{7-10}$ expressed on the bacteria membrane as the trigger of differentiation.

\section{Discussion}

Engineering microenvironments to provide cells with dynamic cues, as occurs in the natural extracellular matrix, is a field of intensive research seeking to direct the differentiation of stem cells and advance in strategies for tissue repair and regeneration ${ }^{31}$. Severa approaches have been explored spanning from the simple functionalisation of material surfaces with cell adhesive motifs to the incorporation of protease-degradable fragments in polymer hydrogels that allow changes in the material structure as cells secrete proteases to remodel the $\mathrm{ECM}^{7,14,32}$. Dynamic surfaces have been engineered to present cell adhesive RGD sequences on-demand ${ }^{6,733}$.

From a different perspective, dynamic cell microenvironment have been engineered to present and release growth factors in sustainable and controlled way to stimulate and support cell differentiation ${ }^{34-40}$. We have recently shown that non-pathogenic bacteria can be genetically modified to establish a functional interface between cells and synthetic materials, and we anticipate that this living interface could be further modified to instruct cells to perform different functions in a highly regulated manner. ${ }^{8}$. As an initial step and proof of concept towards this long-term goal, we engineered ${ }^{8}$ food-grade Lactococcus lactis, a gram-positive bacterium with very low production of lipopolysaccharides (LPS) - previously used for recombinant therapeutic proteins production, therapeutic drug delivery and vaccine production ${ }^{41}$ - to present a fibronectin fragment $\left(\mathrm{FNIII}_{7-10}\right)$ as a membrane protein. $\mathrm{FNIII}_{7-10}$ contains RGD and the PHSRN synergy sequences and promote cell adhesion and differentiation ${ }^{42,43}$. We have previously shown that fibronectin null fibroblasts ( $\mathrm{FN}-/-$ ) adhere, spread and develop focal adhesions on this engineered $L$. lactis expressing $\mathrm{FNIII}_{7-10}$, in a similar way as when seeded directly on a FN coating ${ }^{8}$. 

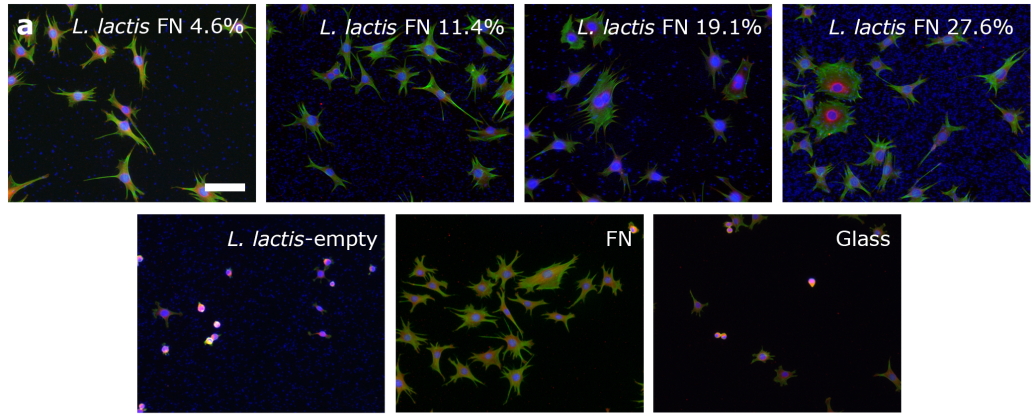

b

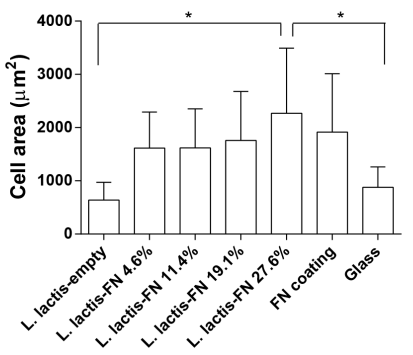

C

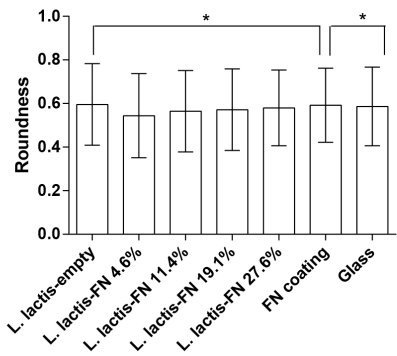

Figure $4 \mid$ Morphological features of $\mathrm{C} 2 \mathrm{C} 12$ myoblasts related to biofilm density. A 3 h culture of $\mathrm{C} 2 \mathrm{C} 12$ cells seeded on top of biofilms of different surface density. Briefly, $10,000 \mathrm{cells} / \mathrm{cm}^{2}$ were seeded on top of L. lactis-FN biofilms of increasing density (covered surface area $4.6 \%, 11.4 \%, 19.1 \%$ and $27.6 \%$ ), and L. lactis-empty biofilm produced with an surface density of $27.6 \%$. Afterwards, cells were stained with a monoclonal anti-vinculin antibody (shown in red), whereas the actin cytoskeleton was stained with phallacidin (in green). Both nuclei of $\mathrm{C} 2 \mathrm{C} 12$ cells and bacterial cells are shown in blue. (a) C2C12 cells seeded over L. lactis-empty biofilm showed no adhesion and remained in their original rounded shape. Cells seeded on L. lactis-FN biofilms showed good adhesion and well-developed focal adhesion plaques and actin cytoskeleton. Scale bar is $100 \mu \mathrm{m}$. (b) Quantification of cell area on the different biointerfaces suggests a correlation between cell area and the surface density of the biofilm. Area and roundness of at least 450 cells were quantified using the ImageJ software. (c), Quantification of cell roundness, defined as roundness $=(4 \cdot$ Area $) /\left(\pi \cdot(\text { major axis })^{2}\right)$. ANOVA test $(\mathrm{N} \geq 400)$ shows statistically significant differences between cells seeded on L.lactis-empty, FN-coated surfaces and glass.

Here, we show that this living interface that constitutively express a FN fragment is able to produce stable biofilms that support cell growth, cell adhesion and cell differentiation. The formation of the biofilm starts when some individual cells adhere to the surface, a process governed by weak non-specific forces - Van der Waals and polar Lewis acid-base interactions $s^{44,45}$. This initial, reversible attachment becomes irreversible after bacteria make use of several cell-wall anchored proteins (CWAP) known as adhesins. In L. lactis, the most prominent ones are the CluA sex factor and the PrtP and NisP proteinases ${ }^{10,46,47}$. These adhesins act modifying the bacterial surface properties and ultimately lead to an irreversible attachment of the bacteria to the surface. After bacteria attachment becomes irreversible, the force required to detach additional bacteria increases and more bacteria are recruited and co-aggregated to the existing ones. Afterwards, these bacteria proliferate and develop the biofilm itself. In this phase, a few hours after the initial irreversible attachment, a stable layer is formed. As L. lactis MG1363 is a strain with a low production of exopolysaccharides, biofilms are usually monolayered, lacking the horizontal stratified structure found in other species ${ }^{48,49}$ Hence, the formation of $L$. lactis biofilms seems limited to a thin layer, usually a monolayer ${ }^{50}$, of strongly attached bacteria to almost any abiotic surface, such as polymers, glass or metallic surfaces. Usually, the adhesion of the bacterium to the substrate is mediated by the bacterial fimbriae, also called adhesion pili $i^{51}$. These fimbriae are also involved in the formation of the bacterial aggregates, as shown in Supp Fig. S1.

Once the biofilm has been successfully established, a need to control its proliferation arises, and we found that the monolayer can be controlled to remain in a stationary phase (using low amount of tetracycline) on the material surface during the time needed to complete the myogenic differentiation process (up to 4 days). We have quantified the amount of $\mathrm{FNIII}_{7-10}$ that is available on the surface of the bacterial and verified that it promotes cell adhesion, signalling and cell differentiation. Overall, this living interface based on non- 

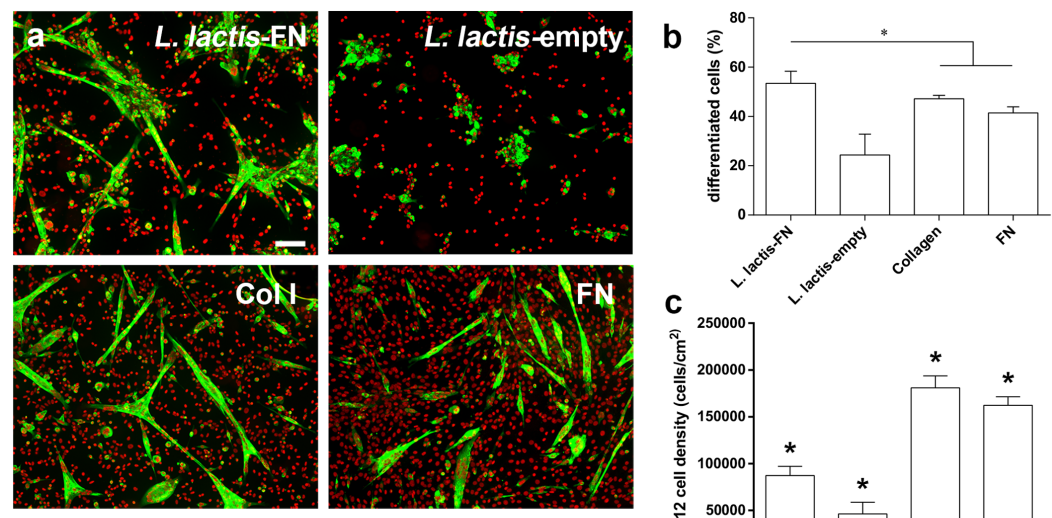

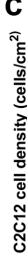
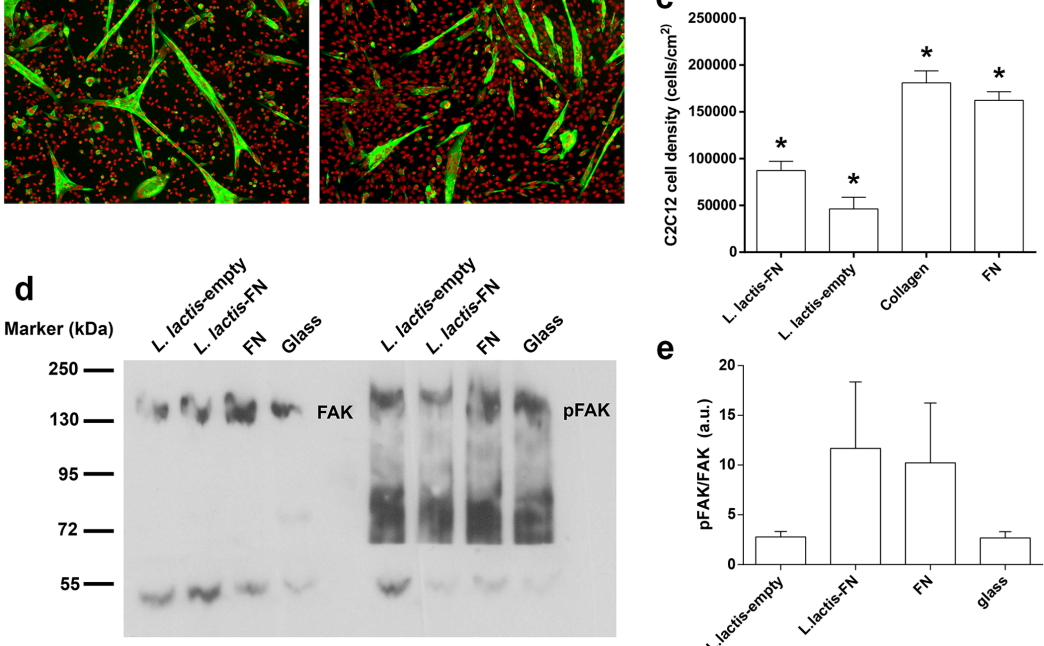

e

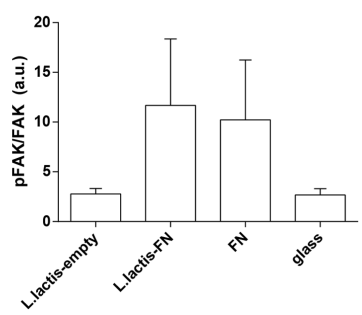

Figure $5 \mid$ Myogenic differentiation and cell signalling on living biointerfaces. (a) Fluorescence staining after 4 days of culture showing sarcomeric myosin-positive cells (green) and cell nuclei (red) on L. lactis-FN, L. lactis-empty, collagen I ( $1 \mathrm{mg} / \mathrm{mL})$ coated glass, and FN (20 $\mu \mathrm{g} / \mathrm{mL})$ coated glass. Scale bar is $25 \mu \mathrm{m}$. (b) Myogenic differentiation as determined by the percentage of sarcomeric myosin-positive cells on the different interfaces. Higher degree of differentiation was found on L. lactis-FN compared to collagen I and FN coated glass. (c) C2C12 cell density on biofilms and control substrates (d) Representative western blot bands for pFAK and FAK on the different biointerfaces. (e) Quantification of western blot bands. ANOVA test shows statistically significant differences between each column. Data is presented as mean \pm SD.

pathogenic bacteria supports myogenic differentiation. Further genetic modification of this living interface is being currently done to engineer a dynamic system able to provide cells different temporal stimuli beyond cell adhesion, such as the delivery of growth factors and other molecules upon external demand. By engineering nonpathogenic bacteria to synthesise proteins and growth factors upon external stimuli, we aim at control the interface between synthetic biomaterials and stem cells to control self-renewal and differentiation, which can be then applied to several strategies to promote tissue repair and regeneration.

\section{Methods}

Genetic modification of L. lactis. The GFP-containing plasmid pGFP-C2 (Clontech) was used to construct a vector contain ing $\mathrm{FNIII}_{7-10}$ downstream to GFP. FNIII
fragment was amplified from the plasmid pET15b- FNIII $_{7-10}$. The forward and reverse primers used for the FNIII7-10 amplification were F1, with HindIII restriction

TCCACCAACAAAC, and R1, with Sall restriction site: gtcgacttaTTCTGTTCGGTAATTAATGGAAA. The lactococcal plasmid PTINX was used to clone the GFP- FNIII NgomIV restriction site gccggcATGGGTAAAGGAGAAGAACTTT; and R2: TTCTGTTCGGTAATTAATGGAAA. Lactococcus lactis MG1363 ${ }^{35}$ containing the PT1NX plasmid was grown as standing culture, in anaerobic conditions, at $30^{\circ} \mathrm{C}$ in M17 medium (Oxoid, Basingstoke, UK) supplemented with glucose $(0.5 \% \mathrm{v} / \mathrm{v}$, Sigma) and erythromycin (10 $\mu \mathrm{g} / \mathrm{mL}$, Sigma-Aldrich) (hereinatter GM17-E). The plasmid extraction was carried using a protocol described elsewheres. Competent $L$ with with glycine $(1 \% \mathrm{~V})$. Cells were harvested when the culture reached an optical $(10 \% \mathrm{v} / \mathrm{v})$ and frozen $-80^{\circ} \mathrm{C}$. BTX electroporator (Harvard A Aparatus). In these conditions, with desalted DNA the typical time constant was 4.5 . Electroporated cells were transferred directly to 
$(2 \mathrm{mM})$ and incubated for $2 \mathrm{~h}$ at $30^{\circ} \mathrm{C}$. The resultant culture was centrifuged, resuspended in $50 \mu \mathrm{L}$ of the later medium and extended on GM17-E agar plates.

Biofilm formation. The protocol to establish a biofilm on the material surface has Briefly, Lactococcus lactis MG1363 containing the PTINX- FNIII $_{7-10}$-GFP plasmid" (hereinafter L. lactis-FN) and L. lactis containi the PT1NX empty vector (L. lactis-empty) were grown as standing cultures in GM1 $\mathrm{E}$ broth at $30^{\circ} \mathrm{C}$. Then, $1 \mu \mathrm{L}$ of each culture was used to streak fresh GM17-E aga plates ( $1 \% \mathrm{w} / \mathrm{v}$ agar). The plates were kept at $30^{\circ} \mathrm{C}$ for $24 \mathrm{~h}$. A single colony from a
GM17-E agar plate was inoculated into sterile $\mathrm{GM} 17-\mathrm{E}$ broth (Oxoid). The culture GM17-E agar plate was inoculated into sterile GM17-E broth (Oxoid). The culture
was grown until $\mathrm{OD}_{660} \sim 0.3$, and then transferred to a P24 multiwell plate containin was grown until $\mathrm{OD}_{660} \sim 0.3$, and then transferred to a P24 multiwell plate containing
sterile glass coverslips in each well, using $300 \mu \mathrm{L}$ and $1000 \mu \mathrm{L}$ respectively in order to produce low and high areal density biofilms. The multiwell plate was sealed with Parafilm and left at $30 \mathrm{C}$ in anaerobic conditions for $48 \mathrm{~h}$. After that, the planktonic (non-adhered) bacteria were removed by shaking the multiwell plate at $150 \mathrm{rpm}$ for $3 \mathrm{~min}$ followed with three washing steps with sterile ultrapure water. In the last wash, the ultrapure water was substituted with for supplemented with $\mathrm{CaCl}_{2}$ and $\mathrm{M}$ (PBS ++ ). The same protocol was used for empty and FN-expressing strains.
.

Biofilm viability and metabolism. For bacterial viability studies, after 1,2 or 4 days, biofilms were gently washed twice with sterile $\mathrm{NaCl} 0.85 \% \mathrm{w} / \mathrm{v}$ solution and incubated for $30 \mathrm{~min}$ using the BacLight LIVE/DEAD kit (Life Technologies), containin SYTO9 $(5 \mu \mathrm{M})$ and propidium iodide $(30 \mu \mathrm{M})$ in $\mathrm{NaCl} 0.85 \% \mathrm{w} / \mathrm{v}$. Afterward SYTO9 $(5 \mu \mathrm{M})$ and propidium iodide $(30 \mu \mathrm{M})$ in $\mathrm{NaCl} 0.85 \% \mathrm{w} / \mathrm{v}$. Afterwards,
samples were washed and mounted using BacLight Oil mounting medium (Life Technologies). Bacteria were counted using Fiji - ImageJ software ${ }^{6}$, using at least fou microscope fields at $40 \times$ magnification for every sample. The viability was determined as the ratio between the viable and total number of bacteria For metabolism analysis, biofilms were prepared following the biofilm formatio protocol. Afterwards, the medium was changed to either DMEM or DMEM containing tetracycline (TC, $10 \mu \mathrm{g} / \mathrm{mL})$ ) or DMEM containing $1 \%$ penicillin-streptomycin $(\mathrm{P} / \mathrm{S})$. Biofilms were kept at $37^{\circ} \mathrm{C}$ in a humidified atmosphere under $5 \% \mathrm{CO}$, and the $\mathrm{pH}$ was monitored as a function of time $(0,0.5,1,1.5,2,3,4,5,24$ and $48 \mathrm{~h})$ using a pH-meter (Eutech Instruments).

AFM and SEM imaging of the biofilms. For SEM imaging, bacterial biofilms were produced as described in the biofilm formation section. Freshly washed biofilms were $4^{\circ} \mathrm{C}$. 4. C. Then, bioflms were washed twice with $\mathrm{PB}$ and dehydrated in an ethanol/water. ethanol step was repeated three times. Afterwards, samples were imm. The ethanol step was repeated three times. Afterwards, samples were immersed twice in
hexamethyldisilazane (Sigma) and air-dried for 10 minutes hexamethyldisilazane (Sigma) and air-dried for 10 minutes ${ }^{37}$. Samples were stored in vacuum until imaging in the microscope. Prior to imaging, samples were sputter-
coated with a $1 \mathrm{~nm}$ layer of platinum and observed in a Zeiss Ultra 55 Field Emissio SEM (Zeiss Microscopy, Germany) with $1 \mathrm{kV}$ of gun acceleration voltage. For AFM, a culture in stationary phase was washed twice with sodium acetate $(100 \mathrm{mM}, \mathrm{pH} 4.8)$ and three millilitres of the resulting bacterial suspension with the same bacterial density as the original culture were filtered through a porous polycarbonate membrane with a mean pore size of $0.8 \mu \mathrm{m}$ (Millipore). The membrane was gently washed with the same sodium acetate solution to remove the non-trapped bacteria, while avoiding dewetting ${ }^{\text {ss. }}$. The wet sample was imaged in a Multimode AFM equipped with a NanoScope III controller from Veeco (Manchester, UK) in QNM mode. Si cantilevers from Veeco were used, with a force constant of $0.7 \mathrm{~N} / \mathrm{n}$ Drive amplitude was $100 \mathrm{mV}$ and amplitude setpoint was $250 \mathrm{mV}$.

Surface density of FN - ELISA. $3 \mathrm{~mL}$ from a $24 \mathrm{~h}$ standing culture of L. lactis-FN and L. lactis-empty grown in sterile GM17-E, with a bacterial density of $10^{7} \mathrm{cfu} / \mathrm{mL}$, were filtered through a porous polycarbonate membrane with a mean pore size of $0.8 \mu \mathrm{m}$ (Isopore, Mapor) $2.5 \mu \mathrm{g} / \mathrm{mL}$ of human plasma fibronectin (Sigma) in PBS ++ for $1 \mathrm{~h}$ at RT and $2.5 \mu \mathrm{g} / \mathrm{mL}$ or human plasma tibronectin (Sigma) in any background signal in the polycarbonate membranes. Membrans were then blocked with $1 \%$ bovine serum albumin (Sigma) in PBS ++ for $1 \mathrm{~h}$ at RT, and incubated for $1 \mathrm{~h}$ at $37^{\circ} \mathrm{C}$ with monoclonal mouse HFN7.1 anti-fibronectin antibody. The primary antibody dilution was $1: 4000$ from a $32 \mu \mathrm{g} / \mathrm{mL}$ antibody stock. After that, samples were washed twice with PBS $++/$ Tween $20(0.5 \% \mathrm{v} / \mathrm{v})$ and incubated with ALP-conjugated donkey anti-mouse secondary antibody (Jackson Immunoresearch) for $1 \mathrm{~h}$ at RT. Samples were washed again twice with PBS ++ Tween $20(0.5 \% \mathrm{v} / \mathrm{v})$, and $400 \mu \mathrm{L}$ of 4 -methylumbelliferyl phosphate $(0.6 \mathrm{mM}$ Sigma) in borax $/ \mathrm{NaOH} \mathrm{pH} 10$ buffer was added. After $45 \mathrm{~min}$ at $37^{\circ} \mathrm{C}$, the supernatant was transferred to a P96 multiwell plate. Fluorescence was measured at $365 / 460 \mathrm{~nm}$ (exctation/enission wavelengths) with a Perkin-Elmer Victor Multilabel Counter (Perkin Elmer).

Surface density of FN - Western blot. Three aliquots of $1.5,1$ and $0.5 \mathrm{~mL}$ from a $24 \mathrm{~h}$ standing culture of both L. lactis $s$ FN and L. lactis-empty strains in GM17-E were lysed using a modified acetone/SDS protocol . Brieny, cells were harvested by we and centrifugd agin. The pellet was trented with $1 \mathrm{~mL}$ of acetone ${ }^{2}-20^{\circ} \mathrm{C}$ for 10 min with $10 \mathrm{~min}$, wh occasiona 5 powder with $100 \mu \mathrm{L}$ of SDS $(1 \% \mathrm{w} / \mathrm{v})$ for 20 min at RT, with occasional vortexing. were pelleted by centrifugation at $7000 \mathrm{~g}$ for $5 \mathrm{~min} .20 \mu \mathrm{L}$ of the supernatan wixed with $20 \mu \mathrm{L}$ of $2 \mathrm{x}$ Laemmli buffer and boiled for $5 \mathrm{~min}$ at $95^{\circ} \mathrm{C}$, and samples were loaded on $10 \%$ SDS-PAGE gels. Simultaneously, 750, 500 and $250 \mathrm{ng} \mathrm{o}$ a purified fragment of $\mathrm{FNIIII}_{7-10}$ were loaded in the same gel as controls. Proteins were transferred to a positively charged PVDF membrane (GE Healthcare) using a semidry transfer cell system (Bio-Rad). Membranes were blocked using 5\% skimmed milk
in PBS for 1 hour at RT and then incubated with the MAB1937 antibody (Millipore) directed against the 8 th type III repeat in human FN diluted 1:1000 in PBS containing Tween $20(0.1 \% \mathrm{v} / \mathrm{v})$ and skimmed milk $(2 \% \mathrm{w} / \mathrm{v})$, overnight, at $4^{\circ} \mathrm{C}$. After everal washes with PBS/Tween $20(0.1 \% \mathrm{v} / \mathrm{v})$, the blot was incubated using horseradish peroxidase-conjugated anti-mouse antibody (GE Healthcare) dilute $1: 50,000$ in PBS/Tween $20(0.1 \% \mathrm{v} / \mathrm{v}) /$ skimmed milk $(2 \% \mathrm{w} / \mathrm{v})$ for $1 \mathrm{~h}$ at RT. inmunoreative basds were vis lized using the ECL Plus Westen blot the (CE Healthcare)

C2C12-biofilm co-culture. C2C12 cells (American Type Culture Collection) wer maintained in DMEM medium with $20 \%$ Foetal Bovine Serum (FBS) and 1\% penicillin-streptomycin. Then, they wore seeded or f $3 \mathrm{~T}^{\circ} \mathrm{C}$ in a bioflms at thosere medium was changed to DMEM with $1 \%$ ITS (insulin-transferrin-selenium $3 \mathrm{~h}$, the Technologies) and tetracycline (10 $\mathrm{\mu g} / \mathrm{mL}$, Sigma-Aldrich) to maintain the Technologies) and tetracycline $(10 \mu \mathrm{g} / \mathrm{mL}$, Sigma-Aldrich) to maintain the
proliferation of the bacteria under control and prevent the acidification of the culture proliferation of the bacteria under control and prevent the acidification of the culture
medium by lactic acid production. The culture was kept for 4 days at $37^{\circ} \mathrm{C}$ and $5 \%$ $\mathrm{CO}_{2}$ in a humidified atmosphere.

mmunofluorescence. Cultures were fixed at $4{ }^{\circ} \mathrm{C}$ with $70 \%$ ethanol, $37 \%$ formaldehyde and glacial acetic acid $(20: 2: 1)$ for $15 \mathrm{~min}$ and then blocked with $5 \%$ goat serum in PBS++ for $1 \mathrm{~h}$ at RT. The samples were incubated with MF-20 antibody against sarcomeric myosin (Developmental Studies Hybridoma Bank, University of Iowa, USA) at $1: 250$ dilution in PBS + + and $5 \%$ goat serum, followed by two washes with PBS++/Tween $20(0.5 \% \mathrm{v} / \mathrm{v})$ and another blocking step with $5 \%$ goat serum in PBS++ for $10 \mathrm{~min}$ at RT. Then were washed twice with PBS++1 Tween $20(0.5 \% \mathrm{v} / \mathrm{v})$ and incubated with rabbit anti-mouse Cy3-conjugated secondary antibody (Jackson Immunoresearch) at 1:200 dilution in PBS + + with 5\% goat serum. Samples were then washed three times with PBS $++/$ Tween $20(0.5 \% \mathrm{v} /$ v), mounted with Vectashield-DAPI, and observed under an epifluorescence microscope (Nikon Eclipse 80i).

Images from the fluorescence microscope (DAPI channel - nuclei, and Cy3 channel - sarcomeric myosin) of the $\mathrm{C} 2 \mathrm{C} 12$ culture were acquired at $10 \times$ magnification, transformed to an 8-bit grayscale bitmap (Fiji - Image) software) and segmented using the Trainable Weka Segmentation plugin to create a binary mask, for both analysis command. Then, the segmented DAPI channel image was subtracted from analysis command. Then, the segmented DAPI channel image was subtracted fro assigned to subtracting the non-differentiated nuclei from the total nuclei count.

For vinculin and actin visualisation, a slightly different protocol was used. Cell fixation was performed using formalin for $30 \mathrm{~min}$ at $4^{\circ} \mathrm{C}$. Then cells were blocked with $1 \%$ BSA in PBS ++. A monoclonal anti-vinculin antibody (Sigma), diluted
$1: 400$ in BSA $1 \% /$ PBS + + was used as primary antibody. The incubation lasted 1 hour at RT. Then, cells were washed twice with PBS $++/$ Tween $20(0.5 \% \mathrm{v} / \mathrm{v})$, and incubated with rabbit anti-mouse Cy3 conjugated (Jackson Immunoresearch), $1: 200$ dilution, with FITC-conjugated phallacidin (Life Technologies) diluted 1:100 in 1\% BSA/PBS ++/Tween $20(0.5 \% \mathrm{v} / \mathrm{v})$. The secondary antibody was incubated 1 hour at $\mathrm{RT}$ in absence of light. Cells were washed three times with PBS/Tween $20(0.5 \% \mathrm{v} / \mathrm{v})$ and mounted with Vectashield-DAPI (Vector Laboratories).

FAK phosphorylation. After 3 hours of culture, cells were lysed with RIPA buffer (Tris-HCl $50 \mathrm{mM}, 1 \%$ Nonidet P-40, $0.25 \% \mathrm{Na}$ deoxycholate, $150 \mathrm{mM} \mathrm{NaCl}, 1 \mathrm{mM}$ EDTA) supplemented with protease inhibitor cocktail tablets (Complete, Roche). Proteins were concentrated using Microcon YM-30 Centrifugal Filter devices (Millipore) as manufacturer described. To determine FAK protein expression and its Tyr397 phosphorylated form (pFAK), concentrated samples were subjected to 7\% SDS-PAGE gel electrophoresis. Proteins were transferred to a positively charged PVDF membrane (GE Healthcare) using a semidry transfer cell system (Bio-Rad) and blocked by immersion in skimmed milk $(5 \% \mathrm{w} / \mathrm{v})$ in PBS for $1 \mathrm{~h}$ at room temperature. The blot was incubated with anti-FAK antibody (Upstate) and anti-pFAK antibody Millipore) diluted 1.2500 in PBS containing Tween $20(0.1 \%)$ and skimmed milk ( horseradish peroxidase-conjugated antibody (GE Healthcare) diluted 1:50000 in several washes with PBS containing Tween $(0.1 \% \mathrm{v} / \mathrm{v})$ and milk $(2 \% \mathrm{w} / \mathrm{v})$, immunoreactive bands were visualized using Supersignal West-femto Maximum Sensitivity Substrate (Thermo Scientific).

Statistical analysis. All data presented in this paper are shown as mean \pm SD

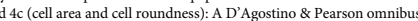
normality test was performed, finding that the data do not follow a Gaussian

SCIENTIFIC REPORTS | 4 : 5849 | DOI: 10.1038/srep05849 
distribution. Then, a non-parametric ANOVA followed by a Kruskal-Wallis (Dunn) multiple comparison test was performed, with $\mathrm{p}=0.05$.

Figure $5 \mathrm{~b}$ and $5 \mathrm{e}$, corresponding to the $\mathrm{C} 2 \mathrm{C} 12$ differentiation assay and cell density respectively: A D'Agostino \& Pearson omnibus normality test was done finding that the data follows a Gaussian distribution. Then, a one-way ANOVA with $\mathrm{p}=0.05$ followed by a Tukey multiple column comparison test was performed.

1. Sipe, J. D. Tissue engineering and reparative medicine. Ann N Y Acad Sci 961, 1-9 (2002)

2. Griffith, L., Naughton, G. \& Naughton, G. Tissue engineering--current challeng and expanding opportunities. Science (80-) 295, 1009 (2002).

3. Grinnell, F. Focal adhesion sites and the removal of substratum-boun fibronectin. J Cell Biol 103, 2697-2706 (1986).

4. Lutolf, M., Gilbert, P. \& Blau, H. Designing materials to direct stem-cell fate. Nature 462, 433-441 (2009).

5. Petrie, T., Raynor, J., Dumbauld, D., Lee, T. \& Jagtap, S. Multivalent IntegrinSpecific Ligands Enhance Tissue Healing and Biomaterial Integration. Sci Trans Med 2, 45 ra60 (2010)

6. Weis, S., Lee, T. T., del Campo, A. \& García, A. J. Dynamic cell-adhesive microenvironments and their effect on myogenic differentiation. Acta Biomater 9, 8059-66 (2013)

Todd, S. J., Scurr, D. J., Gough, J. E., Alexander, M. R. \& Ulijn, R. V. Enzymeactivated RGD ligands on functionalized poly(ethylene glycol) monolaye

8. Saadeddin, A. et al. Functional living biointerphases. Adv Healthc Mater 2, 1213-8 (2013).

9. Aota, S., Nomizu, M. \& Yamada, K. M. The short amino acid sequence Pro-HisSer-Arg-Asn in human fibronectin enhances cell-adhesive function. J Biol Chem 269, 24756-61 (1994)

10. Habimana, O. et al. Positive role of cell wall anchored proteinase PrtP in adhesion of lactococci. BMC Microbiol 7, 36 (2007). 11. Mercier, C. et al. Positive role of peptidoglycan breaks in lactococcal biofilm
formation. Mol Microbiol 46, 235-43 (2002).

12. García, A. J. Get a grip: integrins in cell-biomaterial interactions. Biomaterials 26 7525-9 (2005)

3. Hynes, R. O. Integrins: Bidirectional, Allosteric Signaling Machines. Cell 110, 673-687 (2002).

14. García, A. J., Vega, M. D. \& Boettiger, D. Modulation of cell proliferation and differentiation through substrate-dependent changes in fibronectin conformation. Mol Biol Cell 10, 785-98 (1999).

15. Ugarova, T. P. et al. Conformational transitions in the cell binding domain of fibronectin. Biochemistry 34, 4457-4466 (1995).

16. McClary, K. B., Ugarova, T. \& Grainger, D. W. Modulating fibroblast adhesion spreading, and proliferation using self-assembled monolayer films of alkylthiolates on gold. J Biomed Mater Res 50, 428-439 (2000).

17. Schoen, R. C., Bentley, K. L. \& Klebe, R. J. Monoclonal antibody against human fibronectin which inhibits cell attachment. Hybridoma 1, 99-10 (1982)

18. Keselowsky, B. G., Collard, D. M. \& García, A. J. Surface chemistry modulates fibronectin conformation and directs integrin binding and specificity to contro cell adhesion. J Biomed Mater Res A 66, 247-59 (2003).

19. Salmerón-Sánchez, M. et al. Role of material-driven fibronectin fibrillogenesis in cell differentiation. Biomaterials 32, 2099-105 (2011).

20. Oliveira, A. P., Nielsen, J. \& Förster, J. Modeling Lactococcus lactis using a genome-scale flux model. BMC Microbiol 5, 39 (2005).

21. Rivadeneira, J., Di Virgilio, A. L., Audisio, M. C., Boccaccini, A. R. \& Gorustovich A. A. Evaluation of antibacterial and cytotoxic effects of nano-sized bioactive glass/collagen composites releasing tetracycline hydrochloride. J Appl Microbio

22. Bacon, J. A., Linseman, D. A. \& Raczniak, T. J. In vitro cytotoxicity of tetracyclines and aminoglycosides in LLC-PK(1), MDCK and Chang continuous cell lines.

Toxicol In Vitro 4, 384-8 (1990).
23. Connell, S. R., Tracz, D. M., Nierhaus, K. H. \& Taylor, D. E. Ribosomal protection proteins and their mechanism of tetracycline resistance. Antimicrob Agents

24. Dawson, R. Data for biochemical research (Oxford University Press, Oxford,

25. Sabourin, L. A. \& Rudnicki, M. A. The molecular regulation of myogenesis. Clin Genet 57, 16-25 (2001)

. Mancini, A. et al. Regulation of myotube formation by the actin-binding factor drebrin. Skelet Muscle 1, 36 (2011).

27. Sastry, S. K. et al. Quantitative changes in integrin and focal adhesion signaling regulate myoblast cell cycle withdrawal. J Cell Biol 144, 1295-1309 (1999). signaling: A side mechanism in cytotoxicity. Toxicology 245, 1-10 (2008). signaling: A side mechanism in cytotoxicity. Toxicology 245, 1-10 (2008)
. Clemente, C. F. M. Z., Corat, M. A. F., Saad, S. T. O. \& Franchini, K. G. 9. Clemente, C. F. M. Z., Corat, M. A. F., Saad, S. T. O. \& Franchini, K. G. Physiol Regul Integr Comp Physiol 289, R862-R870 (2005).
30. Quach, N. L. \& Rando, T. A. Focal adhesion kinase is essential for costamerogenesis in cultured skeletal muscle cells. Dev Biol 293, 38-52 (2006)

31. Kirschner, C. M., Alge, D. L., Gould, S. T. \& Anseth, K. S. Clickable, Photodegradable Hydrogels to Dynamically Modulate Valvular Interstitial Cell Phenotype. Adv Healthc Mater (2014) doi:10.1002/adhm.201300288.

32. Khetan, S. et al. Degradation-mediated cellular traction directs stem cell fate in covalently crosslinked three-dimensional hydrogels. Nat Mater 12, 458-65 (2013).

33. Ulijn, R. V. Enzyme-responsive materials: a new class of smart biomaterials. J Mater Chem 16, 2217 (2006).

34. Makarenkova, H. et al. Differential interactions of FGFs with heparan sulfate control gradient formation and branching morphogenesis. Sci Signal 2, ra55 (2009)

Silva, A. K., Richard, C., Bessodes, M., Scherman, D. \& Merten, O. W. Growth factor delivery approaches in hydrogels. Biomacromolecules 10, 9-18 (2009).

6. Lutolf, M. P. \& Hubbell, J. A. Synthetic biomaterials as instructive extracellular $47-55(2005)$

37. Hahn, M. S., Miller, J. S. \& West, J. L. Three-dimensional biochemical and biomechanical patterning of hydrogels for guiding cell behavior. Adv Mater 18 $2679-+(2006)$.

38. Moon, J. J., Hahn, M. S., Kim, I., Nsiah, B. A. \& West, J. L. Micropatterning of poly(ethylene glycol) diacrylate hydrogels with biomolecules to regulate and guide endothelial morphogenesis. Tissue Eng A 15, 579-585 (2009).

39. Phelps, E. A., Landazuri, N., Thule, P. M., Taylor, W. R. \& García, A. J. Bioartificia matrices for therapeutic vascularization. Proc Natl Acad Sci U SA 107, 3323-3328 (2010)

40. Patterson, J., Martino, M. M. \& Hubbell, J. A. Biomimetic materials in tissue engineering. Mater Today 13, 14-22 (2010).

41. Cortes-Perez, N. G., da Costa Medina, L. F., Lefevre, F., Langella, P. \& BermudezHumaran, L. G. Production of biologically active CXC chemokines by Lactococcus lactis: evaluation of its potential as a novel mucosal vaccine adjuvant.

. Cutler, S. M. \& García, A. J. Engineering cell adhesive surfaces that direct integrin $\alpha 5 \beta 1$
$1759-1770$ (2003).

43. Rico, P. Gonźlez-García, C. Petrie, T. A., García, A. J \& Salmerón-Sánchez, M. Molecular assembly and biological activity of a recombinant fragment of fibronectin (FNIII7-10) on poly(ethyl acrylate). Colloids Surfaces B Biointerfaces 78, 310-316 (2010)

44. Van Oss, C. J., Good, R. J. \& Chaudhury, M. K. The role of van der Waals forces and hydrogen bonds in "hydrophobic interactions" between biopolymers and low energy surfaces. J Colloid Interface Sci 111, 378-390 (1986).

45. Van Loosdrecht, M. C., Lyklema, J., Norde, W., Schraa, G. \& Zehnder, A. J. Electrophoretic mobility and hydrophobicity as a measured to predict the initial steps of bacterial adhesion. Appl Environ Microbiol 53, 1898-1901 (1987).

46. Godon, J.-J., Jury, K., Shearman, C. A. \& Gasson, M. J. The Lactococcus lactis sexfactor aggregation gene cluA. Mol Microbiol 12, 655-663 (1994)

47. Giaouris, E., Chapot-Chartier, M.-P. P. \& Briandet, R. Surface physicochemical analysis of natural Lactococcus lactis strains reveals the existence of hydrophob and low charged strains with altered adhesive properties. Int J Food Microbiol 131

48. Gulot, E. et al. Heterogeneity of diffusion inside microbial biofilms determined by fuorescence correlation spectroscopy under two-photon excitation. Photochen

9. Habimana, O., Meyrand, M., Meylheuc, T., Kulakauskas, S. \& Briandet, R. Genetic . . network of knitted chains. Appl Environ Microbiol 74: no mushrooms but . Appl Environ Microbiol 74, 4491-4497 (2008). 1. Oxaran, V. et al. Pilus biogenesis in Lactococcus lactis: molecular characterization 2. Petrie, T. A., Capadona, J. R., Reyes, C. D. \& García, A. J. Integrin specificity an enhanced cellular activities associated with surfaces presenting a recombinant fibronectin fragment compared to RGD supports. Biomaterials 27, 5459-70 (2006)

53. Schotte, L. Secretion of biologically active murine interleukin- 10 by Lactococcus lactis. Enzyme Microb Technol 27, 761-765 (2000).

54. Burmolle, M. et al. Enhanced biofilm formation and increased resistance to antimicrobial agents and bacterial invasion are caused by synergistic interaction in multispecies biofilms. Appl Environ Microbiol 72, 3916-3923 (2006).

55. Zaidi, A. H., Bakkes, P. J., Krom, B. P., van der Mei, H. C. \& Driessen, A. J. M. Cholate-stimulated biofilm formation by Lactococcus lactis cells. Appl Enviro Microbiol 77, 2602-10 (2011)

6. Schindelin, J. et al. Fiji: an open-source platform for biological-image analysis. Nat

57. Araujo, J. C. Comparison of hexamethyldisilazane and critical point drying analysis of anaerobic biofilms and granular sludge. $J$ Elbctor (2003). Dufrêne, Y. F. Atomic force microscopy and chemical force microscopy of
microbial cells. Nat Protoc 3,1132-8 (2008).

SCIENTIFIC REPORTS | $4: 5849$ | DOI: 10.1038/srep05849 
59. Bhaduri, S. Modification of an acetone-sodium dodecyl sulfate disruption method for cellular protein extraction from neurotoxigenic Clostridium botulinum. Foodborne Pathog Dis 9, 172-4 (2012).

\section{Acknowledgments}

The support from ERC through HeallnSynergy 306990 is acknowledged.

\section{Author contributions}

A.R.N. P.R., A.S., A.J.G. and M.S.S. analysed the data. A.R.N. and M.S.S. wrote the pape

\section{Additional information}

Supplementary information accompanies this paper at http://www.nature.com/

Competing financial interests: The authors declare no competing financial interests.

How to cite this article: Rodrigo-Navarro, A., Rico, P., Saadeddin, A., Garcia, A.J. \& Salmerón-Sánchez, M. Living biointerfaces based on non-pathogenic bacteria to direct cell differentiation. Sci. Rep. 4, 5849; DOI:10.1038/srep05849 (2014).

(c) (1) (3) This work is licensed under a Creative Commons Attribution-NonCommercialNoDerivs 4.0 International License. The images or other third party material in this article are included in the article's Creative Commons license, unless indicated otherwise in the credit line; if the material is not included under the Creative Commons license, users will need to obtain permission from the license holder in order to reproduce the material. To vew a copy of this hicense, nis beptl 



\section{References}

[1] Robert Langer and Joseph P Vacanti. Tissue engineering. Science (New York, N.Y.) 260.5110 (May 1993), pp. 920-6

[2] David F. Williams. On the mechanisms of biocompatibility. Biomaterials 29.20 (July 2008), pp. 2941-53. DOI: $10.1016 / \mathrm{j}$. biomaterials . 2008.04 .023

[3] Lakshmi S. Nair and Cato T. Laurencin. Biodegradable polymers as biomaterials. Progress in Polymer Science 32.8-9 (Aug. 2007), pp. 762798. DOI: $10.1016 / \mathrm{j}$. progpolymsci. 2007.05.017

[4] Kazutoshi Takahashi and Shinya Yamanaka. Induction of pluripotent stem cells from mouse embryonic and adult fibroblast cultures by defined factors. Cell 126.4 (Aug. 2006), pp. 663-76. DoI: 10.1016/j . cell.2006.07.024

[5] Keisuke Okita, Naoki Nagata and Shinya Yamanaka. Immunogenicity of induced pluripotent stem cells. Circulation research 109.7 (Sept. 2011), pp. 720-1. DOI: 10.1161/RES. Ob013e318232e187

[6] Ryoko Araki et al. Negligible immunogenicity of terminally differentiated cells derived from induced pluripotent or embryonic stem cells. Nature 494.7435 (Feb. 2013), pp. 100-4. DOI: 10.1038/nature11807

[7] Hideyuki Okano and Shinya Yamanaka. iPS cell technologies: significance and applications to CNS regeneration and disease. Molecular brain 7.1 (Jan. 2014), p. 22. DOI: 10.1186/1756-6606-7-22

[8] J D Sipe. Tissue engineering and reparative medicine. ANNALS OF THE NEW YORK ACADEMY OF SCIENCES 961 (2002). Ed. by J D Sipe, C A Kelley and L A McNicol, pp. 1-9 
[9] Linda G Griffith and Gail Naughton. Tissue engineering-current challenges and expanding opportunities. Science (New York, N.Y.) 295.5557 (Feb. 2002), pp. 1009-14. DOI: 10.1126/science. 1069210

[10] F Grinnell. Focal adhesion sites and the removal of substratum-bound fibronectin. The Journal of cell biology 103.6 Pt 2 (1986), pp. 26972706. DOI: $10.1083 /$ jcb.103.6.2697

[11] Andrés J García. Get a grip: integrins in cell-biomaterial interactions. Biomaterials 26.36 (Dec. 2005), pp. 7525-9

[12] Richard O. Hynes. Integrins: Bidirectional, Allosteric Signaling Machines. Cell 110.6 (Sept. 2002), pp. 673-687. DOI: 10.1016/S00928674(02) 00971-6

[13] Raquel Vaz et al. Fibronectin promotes migration, alignment and fusion in an in vitro myoblast cell model. Cell and tissue research 348.3 (June 2012), pp. 569-78. DOI: $10.1007 / \mathrm{s} 00441-012-1364-1$

[14] Simone Weis et al. Dynamic cell-adhesive microenvironments and their effect on myogenic differentiation. Acta biomaterialia 9.9 (Sept. 2013), pp. 8059-66. DOI: $10.1016 /$ j.actbio.2013.06.019

[15] Simon J Todd et al. Enzyme-activated RGD ligands on functionalized poly(ethylene glycol) monolayers: surface analysis and cellular response. Langmuir : the ACS journal of surfaces and colloids 25 (2009), pp. 7533-7539. DOI: 10.1021/la900376h

[16] M P Lutolf and J A Hubbell. Synthetic biomaterials as instructive extracellular microenvironments for morphogenesis in tissue engineering. Nature biotechnology 23.1 (2005), pp. 47-55. DOI: 10.1038/nbt1055

[17] Udo Wegmann et al. Complete genome sequence of the prototype lactic acid bacterium Lactococcus lactis subsp. cremoris MG1363. Journal of bacteriology 189.8 (Apr. 2007), pp. 3256-70. DOI: 10 . 1128/JB . 01768-06

[18] Daniel M Linares, Jan Kok and Bert Poolman. Genome sequences of Lactococcus lactis MG1363 (revised) and NZ9000 and comparative physiological studies. Journal of bacteriology 192.21 (Nov. 2010), pp. 5806-12. DOI: 10.1128/JB.00533-10

[19] Mohammed Bahey-El-Din, Brendan T Griffin and Cormac Gm Gahan. Nisin inducible production of listeriolysin $\mathrm{O}$ in Lactococcus lactis NZ9000. Microbial cell factories 7.1 (Jan. 2008), p. 24. DOI: 10.1186/ 1475-2859-7-24 
[20] Noora Sirén et al. A new and efficient phosphate starvation inducible expression system for Lactococcus lactis. Applied microbiology and biotechnology 79.5 (July 2008), pp. 803-10. DOI: 10.1007/s00253008-1484-4

[21] Soren M Madsen et al. Molecular characterization of the $\mathrm{pH}$-inducible and growth phase-dependent promoter P170 of Lactococcus lactis. Molecular Microbiology 32.1 (Apr. 1999), pp. 75-87. DOI: 10.1046/j . 1365-2958.1999.01326.x

[22] Dongdong Mu et al. Zirex: a novel zinc-regulated expression system for Lactococcus lactis. Applied and environmental microbiology 79.14 (July 2013), pp. 4503-8. DOI: 10.1128/AEM . 00866-13

[23] P G de Ruyter, O P Kuipers and W M de Vos. Controlled gene expression systems for Lactococcus lactis with the food-grade inducer nisin. Applied and environmental microbiology 62.10 (Oct. 1996), pp. 3662-7

[24] Igor Mierau et al. Optimization of the Lactococcus lactis nisin-controlled gene expression system NICE for industrial applications. Microbial cell factories 4 (May 2005), p. 16. DoI: 10.1186/1475-2859-4-16

[25] a R Raha et al. Cell surface display system for Lactococcus lactis: a novel development for oral vaccine. Applied microbiology and biotechnology 68.1 (July 2005), pp. 75-81. DOI: 10.1007/s00253-004-1851-8

[26] Jennifer L Owen, Bikash Sahay and Mansour Mohamadzadeh. New generation of oral mucosal vaccines targeting dendritic cells. Current opinion in chemical biology 17.6 (Dec. 2013), pp. 918-24. DOI: 10 . 1016/j.cbpa. 2013.06.013

[27] N G Cortes-Perez et al. Production of biologically active CXC chemokines by Lactococcus lactis: evaluation of its potential as a novel mucosal vaccine adjuvant. Vaccine 26.46 (2008), pp. 5778-5783. DOI: 10 . 1016/ j. vaccine. 2008.08.044

[28] Dafeng Song and Qing Gu. Surface expression of Helicobacter pylori urease subunit $B$ gene $E$ fragment on Lactococcus lactis by means of the cell wall anchor of Staphylococcus aureus protein A. Biotechnology letters 31.7 (July 2009), pp. 985-9. DOI: 10 . 1007 / s10529-0099965-9

[29] J Villatoro-Hernandez et al. Secretion of biologically active interferongamma inducible protein-10 (IP-10) by Lactococcus lactis. Microbial cell factories 7 (2008), p. 22. DOI: 10.1186/1475-2859-7-22 
[30] S Nouaille et al. Heterologous protein production and delivery systems for Lactococcus lactis. Genetics and molecular research: GMR 2.1 (2003), pp. $102-111$

[31] Sarah M. Cutler and Andres J Garcia. Engineering cell adhesive surfaces that direct integrin $\alpha 5 \beta 1$ binding using a recombinant fragment of fibronectin. Biomaterials 24.10 (2003), pp. 1759-1770. DOI: 10.1016/ S0142-9612(02) 00570-7

[32] M. Quirynen et al. Clinical relevance of the influence of surface free energy and roughness on the supragingival and subgingival plaque formation in man. 1994. DOI: $10.1016 / 0927-7765$ (94)80014-6

[33] Yasunori Tanji et al. Structural analysis of a biofilm which enhances carbon steel corrosion in nutritionally poor aquatic environments. Journal of Bioscience and Bioengineering 88 (1999), pp. 551-556. DOI: 10 . 1016/S1389-1723(00)87674-4

[34] E. J. Bouwer and A. J B Zehnder. Bioremediation of organic compounds - Putting microbial metabolism to work. 1993. DoI: 10.1016/01677799 (93) 90159-7

[35] Jacqueline A. Macdonald and Bruce E. Rittmann. Performance standards for in situ bioremediation. Environmental Science \& Technology 27.10 (Sept. 1993), pp. 1974-1979. DOI: 10.1021/es00047a002

[36] Ignatius Wahyu Marjaka et al. Augmentation of self-purification capacity of sewer pipe by immobilizing microbes on the pipe surface. Biochemical Engineering Journal 15 (2003), pp. 69-75. DOI: 10 . 1016/S1369703X (02) 00182-1

[37] KATSUTOSHI HORI et al. Isolation, Characterization and Application to Off-Gas Treatment of Toluene-Degrading Bacteria. JOURNAL OF CHEMICAL ENGINEERING OF JAPAN 34.9 (May 2001), pp. 1120-1126. DOI: $10.1252 /$ jcej . 34.1120

[38] Manuel Espinosa-Urgel, Amparo Salido and Juan Luis Ramos. Genetic analysis of functions involved in adhesion of Pseudomonas putida to seeds. Journal of Bacteriology 182 (2000), pp. 2363-2369. DOI: 10. 1128/JB.182.9.2363-2369.2000

[39] Harivony Rakotoarivonina et al. Adhesion to cellulose of the Grampositive bacterium Ruminococcus albus involves type IV pili. Microbiology 148 (2002), pp. 1871-1880 
[40] A. M. Raichur et al. Flocculation and flotation of coal by adhesion of hydrophobic Mycobacterium phlei. Colloids and Surfaces B: Biointerfaces 8 (1996), pp. 13-24. DOI: 10.1016/S0927-7765 (96) 01312-4

[41] M C van Loosdrecht et al. Bacterial adhesion: A physicochemical approach. Microbial ecology 17.1 (Jan. 1989), pp. 1-15. DOI: 10.1007/ BF02025589

[42] Paul C Hiemenz and Raj. Rajagopalan. Principles of colloid and surface chemistry. English. New York, 1997

[43] C. J. Van Oss et al. The role of van der Waals forces and hydrogen bonds in "hydrophobic interactions" between biopolymers and low energy surfaces. Journal of Colloid and Interface Science 111.2 (1986), pp. 378390. DOI: $10.1016 / 0021-9797$ (86) 90041-X

[44] Albert T. Poortinga et al. Electric double layer interactions in bacterial adhesion to surfaces. Surface Science Reports 47.1 (June 2002), pp. 132. DOI: 10.1016/S0167-5729(02)00032-8

[45] Y H An and R J Friedman. Concise review of mechanisms of bacterial adhesion to biomaterial surfaces. Journal of biomedical materials research 43 (1998), pp. 338-348. DOI: 10.1002/ (SICI) 1097-4636(199823) 43:3<338: : AID- JBM16>3.0.CO;2-B

[46] M. Katsikogianni and Y. F. Missirlis. Concise review of mechanisms of bacterial adhesion to biomaterials and of techniques used in estimating bacteria-material interactions. 2004. DOI: 10 .1002/ (sici) 1097 4636 (199823) 43:3<338: : aid-jbm16>3.0.co;2-b

[47] K. C. Marshall and R. H. Cruickshank. Cell surface hydrophobicity and the orientation of certain bacteria at interfaces. Archiv für Mikrobiologie 91.1 (1973), pp. 29-40. DOI: 10.1007/BF00409536

[48] Huub H M Rijnaarts et al. Reversibility and mechanism of bacterial adhesion. Colloids and Surfaces B Biointerfaces 4 (1995), pp. 5-22. DOI: 10.1016/0927-7765 (94)01146-V

[49] A Zita and M Hermansson. Effects of bacterial cell surface structures and hydrophobicity on attachment to activated sludge flocs. Applied and environmental microbiology 63 (1997), pp. 1168-1170

[50] Anna Zita and Malte Hermansson. Determination of bacterial cell surface hydrophobicity of single cells in cultures and in wastewater in situ. FEMS Microbiology Letters 152 (1997), pp. 299-306. DOI: 10.1016/ S0378-1097 (97) 00214-0 
[51] Ann Cathrin Olofsson, Anna Zita and Malte Hermansson. Floc stability and adhesion of green-fluorescent-protein-marked bacteria to flocs in activated sludge. Microbiology 144 (1998), pp. 519-528. DOI: 10. 1099/00221287-144-2-519

[52] C.J. van Oss. Hydrophobicity of biosurfaces: Origin, quantitative determination and interaction energies. 1995. DOI: 10.1016/0927-7765 (95) 01217-7

[53] C J Van Oss. The forces involved in bioadhesion to flat surfaces and particles: Their determination and relative roles. 1991. DOI: 10.1080/ 08927019109378192

[54] Carel J Van Oss. Energetics of Cell-Cell and Cell-Biopolymer Interactions. Cell Biophysics 14 (1989), pp. 1-16. DOI: 10.1007/BF02797387

[55] C.J. van Oss. Acid?base interfacial interactions in aqueous media. 1993. DOI: $10.1016 / 0927-7757$ (93) 80308-2

[56] C J van Oss, M K Chaudhury and R J Good. Monopolar surfaces. Advances in colloid and interface science 28 (1987), pp. 35-64. DOI: 10.1016/0001-8686(87)80008-8

[57] Hisao Morisaki et al. The effect of motility and cell-surface polymers on bacterial attachment. Microbiology 145.10 (Oct. 1999), pp. 2797-2802

[58] Hisao Morisaki et al. The effect of motility and cell-surface polymers on bacterial attachment. Microbiology 145 (1999), pp. 2797-2802

[59] S. Takashima and H. Morisaki. Surface characteristics of the microbial cell of Pseudomonas syringae and its relevance to cell attachment. Colloids and Surfaces B: Biointerfaces 9.3-4 (July 1997), pp. 205-212. DOI: $10.1016 / \mathrm{S} 0927-7765$ (97)00023-4

[60] J R Reid and T Coolbear. Altered specificity of lactococcal proteinase $\mathrm{p}(\mathrm{i})$ (lactocepin I) in humectant systems reflecting the water activity and salt content of cheddar cheese. Applied and environmental microbiology 64.2 (Feb. 1998), pp. 588-93

[61] Yves Le Loir et al. Protein secretion in Lactococcus lactis : an efficient way to increase the overall heterologous protein production. Microbial cell factories 4.1 (Jan. 2005), p. 2. DOI: 10.1186/1475-2859-4-2

[62] Jean-Jacques Godon et al. The Lactococcus lactis sex-factor aggregation gene cluA. Molecular Microbiology 12.4 (May 1994), pp. 655-663. DOI: $10.1111 / \mathrm{j} .1365-2958$.1994.tb01053.x 
[63] Hongliang Luo, Kai Wan and HH Hua H Wang. High-frequency conjugation system facilitates biofilm formation and pAMbeta1 transmission by Lactococcus lactis. Applied and environmental microbiology 71.6 (June 2005), pp. 2970-2978. DOI: 10.1128/AEM .71 .6.2970-2978. 2005

[64] Olivier Habimana et al. Positive role of cell wall anchored proteinase PrtP in adhesion of lactococci. BMC microbiology 7 (Jan. 2007), p. 36. DOI: $10.1186 / 1471-2180-7-36$

[65] June R Scott and Dorothea Zähner. Pili with strong attachments: Grampositive bacteria do it differently. Molecular microbiology 62.2 (Oct. 2006), pp. 320-30. DOI: $10.1111 / j .1365-2958.2006 .05279$. $\mathrm{x}$

[66] Efstathios Giaouris, Marie-Pierre Pierre Chapot-Chartier and Romain Briandet. Surface physicochemical analysis of natural Lactococcus lactis strains reveals the existence of hydrophobic and low charged strains with altered adhesive properties. International journal of food microbiology 131.1 (Apr. 2009), pp. 2-9. DOI: 10.1016/j . i jfoodmicro. 2008.09 .006

[67] Rodney M. Donlan and J. William Costerton. Biofilms: Survival mechanisms of clinically relevant microorganisms. 2002. DOI: 10.1128/CMR . 15.2.167-193.2002

[68] Trevor Roger Garrett, Manmohan Bhakoo and Zhibing Zhang. Bacterial adhesion and biofilms on surfaces. Progress in Natural Science 18.9 (Sept. 2008), pp. 1049-1056. DOI: 10.1016/j .pnsc. 2008. 04.001

[69] Carel J Van Oss et al. Interfacial Lifshitz-van der Waals and polar interactions in macroscopic systems. Chemical Reviews 88 (1988), pp. 927941. DOI: $10.1021 / \mathrm{cr} 00088 \mathrm{a} 006$

[70] Steven S. Branda et al. Biofilms: The matrix revisited. 2005. Dor: 10 . 1016/j.tim. 2004.11.006. arXiv: 3556

[71] D. Seyer et al. Proteomic comparison of outer membrane protein patterns of sessile and planktonic Pseudomonas aeruginosa cells. 2005. DOI: 10 . $1017 /$ S1479050505001638

[72] Michel Vert et al. Terminology for biorelated polymers and applications (IUPAC Recommendations 2012). Pure and Applied Chemistry 84.2 (Jan. 2012), pp. 377-410. DOI: 10.1351/PAC-REC-10-12-04

[73] Ross C Wilson and Jennifer A Doudna. Molecular mechanisms of RNA interference. Annual review of biophysics 42 (Jan. 2013), pp. 217-39. DOI: $10.1146 /$ annurev-biophys-083012-130404 
[74] Ryszard Kole, Adrian R Krainer and Sidney Altman. RNA therapeutics: beyond RNA interference and antisense oligonucleotides. Nature reviews. Drug discovery 11.2 (Feb. 2012), pp. 125-40. DOI: 10.1038/nrd3625

[75] Trygve Tollefsbol. Biological aging : methods and protocols. Totowa N.J.: Humana Press, 2007

[76] P G de Ruyter, O P Kuipers and W M de Vos. Controlled gene expression systems for Lactococcus lactis with the food-grade inducer nisin. Applied and environmental microbiology 62 (1996), pp. 3662-3667

[77] Rita M. Hickey, R. Paul Ross and Colin Hill. Controlled Autolysis and Enzyme Release in a Recombinant Lactococcal Strain Expressing the Metalloendopeptidase Enterolysin A. Applied and Environmental Microbiology 70 (2004), pp. 1744-1748. DOI: 10.1128/AEM. 70 .3.17441748.2004

[78] Igor Mierau and Michiel Kleerebezem. 10 years of the nisin-controlled gene expression system (NICE) in Lactococcus lactis. Applied microbiology and biotechnology 68.6 (Oct. 2005), pp. 705-17. DOI: 10.1007/ s00253-005-0107-6

[79] Noora Sirén et al. 'A new salt inducible expression system for Lactococcus lactis'. 2009

[80] W M de Vos. Gene expression systems for lactic acid bacteria. Current opinion in microbiology 2.3 (June 1999), pp. 289-95. DOI: 10.1016/ S1369-5274 (99) 80050-2

[81] New products. TOPO TA Cloning. Biofutur 40 (2006), pp. 1-35. DOI: 10.1016/S0294-3506 (99) 80491-8

[82] Lena K. Petersen and R. Steven Stowers. A Gateway Multisite recombination cloning toolkit. PLOS ONE 6 (2011). DOI: 10.1371/journal. pone. 0024531 . arXiv: 19326203

[83] Anton V. Bryksin and Ichiro Matsumura. Overlap extension PCR cloning: A simple and reliable way to create recombinant plasmids. BioTechniques 48 (2010), pp. 463-465. DOI: $10.2144 / 000113418$

[84] Anthony N Warrens, Michael D Jones and Robert I Lechler. Splicing by overlap extension by PCR using asymmetric amplification: an improved technique for the generation of hybrid proteins of immunological interest. Gene 186.1 (1997), pp. 29-35 
[85] Daniel G Gibson et al. Enzymatic assembly of DNA molecules up to several hundred kilobases. Nature methods 6 (2009), pp. 343-345. DOI: $10.1038 /$ nmeth .1318

[86] Velupillai M Ramesh, Scott E Bingham and Andrew N Webber. A simple method for chloroplast transformation in Chlamydomonas reinhardtii. Methods in molecular biology (Clifton, N.J.) 274 (Jan. 2004), pp. 301-7. DOI: $10.1385 / 1-59259-799-8: 301$

[87] L Predajňa, A Nagyová and Z Subr. Simple and efficient biolistic procedure for the plant transfection with cDNA clones of RNA viruses. Acta virologica 54.4 (Jan. 2010), pp. 303-6

[88] P L Felgner et al. Lipofection: a highly efficient, lipid-mediated DNAtransfection procedure. Proceedings of the National Academy of Sciences of the United States of America 84.21 (Nov. 1987), pp. 7413-7

[89] J H Felgner et al. Enhanced gene delivery and mechanism studies with a novel series of cationic lipid formulations. The Journal of biological chemistry 269.4 (Jan. 1994), pp. 2550-61

[90] R Y Tsien. The green fluorescent protein. Annual review of biochemistry 67 (Jan. 1998), pp. 509-44. DOI: 10.1146/annurev . biochem. 67 . 1.509

[91] I Sattler et al. Cloning, sequencing, and expression of the uroporphyrinogen III methyltransferase cobA gene of Propionibacterium freudenreichii (shermanii). J. Bacteriol. 177.6 (Mar. 1995), pp. 1564-1569

[92] Drew Endy. Foundations for engineering biology. Nature 438 (2005), pp. 449-453. DOI: $10.1038 /$ nature 04342

[93] Tom Knight. Idempotent Vector Design for Standard Assembly of Biobricks. Structure (2003), pp. 1-11. DOI: http://hdl . handle.net/1721. $1 / 21168$

[94] Reshma P Shetty, Drew Endy and Thomas F Knight. Engineering BioBrick vectors from BioBrick parts. Journal of biological engineering 2 (Jan. 2008), p. 5. DOI: $10.1186 / 1754-1611-2-5$

[95] Huimin Zhao. Synthetic biology tools and applications. Amsterdam ;;Boston : 2013

[96] Timothy S Gardner and Kristy Hawkins. Synthetic biology: evolution or revolution? A co-founder's perspective. Current opinion in chemical biology 17.6 (Dec. 2013), pp. 871-7. DOI: 10.1016/j . cbpa. 2013. 09.013 
[97] Thomas Kuhlman et al. Combinatorial transcriptional control of the lactose operon of Escherichia coli. Proceedings of the National Academy of Sciences of the United States of America 104.14 (Apr. 2007), pp. 60438. DOI: $10.1073 /$ pnas. 0606717104

[98] Oliver Purcell et al. A comparative analysis of synthetic genetic oscillators. Journal of the Royal Society, Interface / the Royal Society 7.52 (Nov. 2010), pp. 1503-24. DOI: 10.1098/rsif .2010.0183

[99] Vijai Singh. Recent advancements in synthetic biology: current status and challenges. Gene 535.1 (Feb. 2014), pp. 1-11. DOI: 10.1016/j . gene.2013.11.025

[100] Subhayu Basu et al. A synthetic multicellular system for programmed pattern formation. Nature 434.April (2005)

[101] Mayuree Chanasakulniyom et al. Expression of membrane-associated proteins within single emulsion cell facsimiles. The Analyst 137.13 (July 2012), pp. 2939-43. DOI: 10.1039/c2an35047e

[102] Jing Zhao et al. Biomimetic and bioinspired membranes: Preparation and application. Progress in Polymer Science 39.9 (Sept. 2014), pp. 16681720. DOI: $10.1016 / \mathrm{j}$. progpolymsci . 2014.06.001

[103] Yue-xiao Shen et al. Biomimetic membranes: A review. Journal of Membrane Science 454 (Mar. 2014), pp. 359-381. DOI: 10 . 1016/j . memsci . 2013.12.019

[104] Benjamin Lewin. Cells. Sudbury Mass.: Jones and Bartlett Publishers, 2007

[105] Ioannis Vakonakis and Iain D Campbell. Extracellular matrix: from atomic resolution to ultrastructure. Current opinion in cell biology 19.5 (Oct. 2007), pp. 578-83. DOI: 10.1016/j . ceb. 2007.09.005

[106] Melinda Larsen et al. The matrix reorganized: extracellular matrix remodeling and integrin signaling. Current opinion in cell biology 18.5 (Oct. 2006), pp. 463-71. DOI: 10.1016/j . ceb. 2006.08.009

[107] Xiaoming Zhou et al. Fibronectin fibrillogenesis regulates three-dimensional neovessel formation. Genes \& development 22.9 (May 2008), pp. 123143. DOI: $10.1101 / \mathrm{gad} .1643308$

[108] Purva Singh, Cara Carraher and Jean E Schwarzbauer. Assembly of fibronectin extracellular matrix. Annual review of cell and developmental biology 26 (Jan. 2010), pp. 397-419. DOI: 10.1146/annurevcellbio-100109-104020 
[109] Harvey Lodish. Molecular cell biology. New York ;Houndmills Basingstoke Hampshire: W.H. Freeman and Company ;;Macmillan Higher Education, 2013

[110] Gloria A Di Lullo et al. Mapping the ligand-binding sites and diseaseassociated mutations on the most abundant protein in the human, type I collagen. The Journal of biological chemistry 277.6 (Feb. 2002), pp. 4223-31. DOI: 10.1074/jbc. M110709200

[111] G Karsenty and R W Park. Regulation of type I collagen genes expression. International reviews of immunology 12.2-4 (Jan. 1995), pp. 177-85

[112] Yuri I. Veklich et al. Carboxyl-terminal portions of the $\alpha$ chains of fibrinogen and fibrin: Localization by electron microscopy and the effects of isolated $\alpha \mathrm{C}$ fragments on polymerization. Journal of Biological Chemistry 268 (1993), pp. 13577-13585

[113] Takako Sasaki, Reinhard Fässler and Erhard Hohenester. Laminin: The crux of basement membrane assembly. 2004. DOI: 10.1083 / jcb . 200401058

[114] Chris D. Madsen and Nicolai Sidenius. The interaction between urokinase receptor and vitronectin in cell adhesion and signalling. 2008. DOI: 10 . 1016/j.ejcb.2008.02.003

[115] Richard O Hynes. Fibronectins. English. New York: Springer-Verlag, 1990

[116] Scott Freeman. Biological science. 2014

[117] Allison L Berrier and Kenneth M Yamada. Cell - Matrix Adhesion. Journal of Cellular Physiology 213 (2007), pp. 565-573. DOI: 10.1002/JCP

[118] Barbara D. Boyan et al. Role of material surfaces in regulating bone and cartilage cell response. Biomaterials 17 (1996), pp. 137-146. DOI: 10.1016/0142-9612(96)85758-9

[119] K. Anselme. Osteoblast adhesion on biomaterials. Biomaterials 21.7 (Apr. 2000), pp. 667-681. DOI: 10.1016/S0142-9612(99)00242-2

[120] C S Izzard and L R Lochner. Cell-to-substrate contacts in living fibroblasts: an interference reflexion study with an evaluation of the technique. Journal of cell science 21 (1976), pp. 129-159

[121] E Zamir and B Geiger. Molecular complexity and dynamics of cell-matrix adhesions. Journal of cell science 114 (2001), pp. 3583-3590 
[122] S K Sastry and K Burridge. Focal adhesions: a nexus for intracellular signaling and cytoskeletal dynamics. Experimental cell research 261.1 (Nov. 2000), pp. 25-36. DOI: 10.1006/excr.2000.5043

[123] M Abercrombie and G.A. Dunn. Adhesions of fibroblasts to substratum during contact inhibition observed by interference reflection microscopy. Experimental Cell Research 92.1 (Apr. 1975), pp. 57-62. DOI: 10.1016/0014-4827 (75)90636-9

[124] Lindsay Ramage. Integrins and extracellular matrix in mechanotransduction. 2011. DOI: http://dx.doi.org/10.2147/CHC.S21829

[125] K. Rottner, A. Hall and J. V. Small. Interplay between Rac and Rho in the control of substrate contact dynamics. Current Biology 9 (1999), pp. 640-648. DOI: 10.1016/S0960-9822 (99)80286-3

[126] C D Nobes and A Hall. Rho, rac, and cdc42 GTPases regulate the assembly of multimolecular focal complexes associated with actin stress fibers, lamellipodia, and filopodia. Cell 81 (1995), pp. 53-62. Dor: 10.1016/0092-8674(95) 90370-4

[127] E Zamir et al. Dynamics and segregation of cell-matrix adhesions in cultured fibroblasts. Nature cell biology 2 (2000), pp. 191-196. DOI: $10.1038 / 35008607$

[128] E Zamir et al. Molecular diversity of cell-matrix adhesions. Journal of cell science 112 ( Pt 1 (1999), pp. 1655-1669

[129] Bruce Alberts. Molecular biology of the cell. New York: Garland Science, 2002, 389a-389a

[130] D C Han, L G Rodriguez and J L Guan. Identification of a novel interaction between integrin beta1 and 14-3-3beta. Oncogene 20.3 (Jan. 2001), pp. 346-57. DOI: $10.1038 / \mathrm{sj}$. onc. 1204068

[131] S K Hanks et al. Focal adhesion protein-tyrosine kinase phosphorylated in response to cell attachment to fibronectin. Proceedings of the National Academy of Sciences of the United States of America 89.18 (Sept. 1992), pp. 8487-8491. DOI: 10.1073/pnas.89.18.8487

[132] M D Schaller et al. pp125FAK a structurally distinctive protein-tyrosine kinase associated with focal adhesions. Proceedings of the National Academy of Sciences of the United States of America 89.11 (June 1992), pp. 5192-5196. DOI: 10.1073/pnas.89.11.5192 
[133] Gordon W McLean et al. The role of focal-adhesion kinase in cancer - a new therapeutic opportunity. Nature reviews. Cancer 5.7 (July 2005), pp. 505-515. DOI: $10.1038 / \mathrm{nrc1647}$

[134] Datsun A Hsia et al. Differential regulation of cell motility and invasion by FAK. The Journal of cell biology 160.5 (Mar. 2003), pp. 753-767. DOI: $10.1083 /$ jcb. 200212114

[135] Tang-Long Shen et al. Conditional knockout of focal adhesion kinase in endothelial cells reveals its role in angiogenesis and vascular development in late embryogenesis. The Journal of cell biology 169.6 (June 2005), pp. 941-52. DOI: $10.1083 /$ jcb. 200411155

[136] J Thomas Parsons. Focal adhesion kinase: the first ten years. Journal of cell science 116.Pt 8 (Apr. 2003), pp. 1409-16

[137] Satyajit Mitra et al. Focal adhesion kinase: in command and control of cell motility. Nature reviews.Molecular cell biology 6.1 (2005), pp. 56-68. DOI: $10.1038 / \mathrm{nrm} 1549$

[138] Rickmer Braren et al. Endothelial FAK is essential for vascular network stability, cell survival, and lamellipodial formation. Journal of Cell Biology 172 (2006), pp. 151-162. DOI: 10.1083/jcb. 200506184

[139] Hilary E. Beggs et al. FAK deficiency in cells contributing to the basal lamina results in cortical abnormalities resembling congenital muscular dystrophies. Neuron 40 (2003), pp. 501-514. DOI: 10.1016/S08966273(03)00666-4

[140] Jill M Dunty et al. FERM domain interaction promotes FAK signaling. Molecular and cellular biology 24 (2004), pp. 5353-5368. DOI: 10 . 1128/MCB . 24 . 12.5353-5368. 2004

[141] Lee Ann Cooper, Tang-Long Shen and Jun-Lin Guan. Regulation of focal adhesion kinase by its amino-terminal domain through an autoinhibitory interaction. Molecular and cellular biology 23 (2003), pp. 80308041. DOI: 10.1128/MCB . 23.22.8030-8041.2003

[142] Lee Ann Cohen and Jun Lin Guan. Residues within the first subdomain of the FERM-like domain in focal adhesion kinase are important in its regulation. Journal of Biological Chemistry 280 (2005), pp. 8197-8207. DOI: $10.1074 /$ jbc . M412021200 
[143] D D Schlaepfer, M A Broome and T Hunter. Fibronectin-stimulated signaling from a focal adhesion kinase-c-Src complex: involvement of the Grb2, p130cas, and Nck adaptor proteins. Molecular and cellular biology 17 (1997), pp. 1702-1713

[144] P J Ruest et al. Phosphospecific antibodies reveal focal adhesion kinase activation loop phosphorylation in nascent and mature focal adhesions and requirement for the autophosphorylation site. en. Cell growth \& differentiation : the molecular biology journal of the American Association for Cancer Research 11.1 (Jan. 2000), pp. 41-8

[145] James D. Owen et al. Induced Focal Adhesion Kinase (FAK) Expression in FAK-Null Cells Enhances Cell Spreading and Migration Requiring Both Auto- and Activation Loop Phosphorylation Sites and Inhibits Adhesion-Dependent Tyrosine Phosphorylation of Pyk2. Mol. Cell. Biol. 19.7 (July 1999), pp. 4806-4818

[146] R. Pankov. Fibronectin at a glance. Journal of Cell Science 115.20 (Oct. 2002), pp. 3861-3863. DOI: 10.1242/jcs. 00059

[147] Heyu Ni et al. Plasma fibronectin promotes thrombus growth and stability in injured arterioles. Proceedings of the National Academy of Sciences of the United States of America 100.5 (Mar. 2003), pp. 2415-9. DOI: $10.1073 /$ pnas. 2628067100

[148] J. Cho and Deane F. Mosher. Role of fibronectin assembly in platelet thrombus formation. Journal of thrombosis and haemostasis : JTH 4.7 (July 2006), pp. 1461-1469. DOI: 10.1111/j . 1538-7836 . 2006. 01943.x

[149] Yong Mao and Jean E Schwarzbauer. Fibronectin fibrillogenesis, a cell-mediated matrix assembly process. Matrix biology : journal of the International Society for Matrix Biology 24.6 (Sept. 2005), pp. 389-99. DOI: $10.1016 / j$.matbio. 2005.06 .008

[150] Michael Leiss et al. The role of integrin binding sites in fibronectin matrix assembly in vivo. Current opinion in cell biology 20.5 (Oct. 2008), pp. 502-7. DOI: 10.1016/j.ceb.2008.06.001

[151] Yong Mao and Jean E. Schwarzbauer. Fibronectin fibrillogenesis, a cellmediated matrix assembly process. 2005. DOI: $10.1016 / \mathrm{j}$. matbio . 2005.06 .008

[152] J. E. Schwarzbauer. Fibronectin: From gene to protein. 1991. DOI: 10. 1016/0955-0674(91)90051-Y 
[153] J L Guan and R O Hynes. Lymphoid cells recognize an alternatively spliced segment of fibronectin via the integrin receptor alpha 4 beta 1 . Cell 60.1 (Jan. 1990), pp. 53-61

[154] E C Williams et al. Fibronectin. Effect of disulfide bond reduction on its physical and functional properties. The Journal of biological chemistry 258.9 (May 1983), pp. 5911-4

[155] K Sakai, T Fujii and T Hayashi. Cell-free formation of disulfide-bonded multimer from isolated plasma fibronectin in the presence of a low concentration of SH reagent under a physiological condition. Journal of biochemistry 115.3 (Mar. 1994), pp. 415-21

[156] T Vartio. Disulfide-bonded polymerization of plasma fibronectin in the presence of metal ions. The Journal of biological chemistry 261.20 (July 1986), pp. 9433-7

[157] D F Mosher and R B Johnson. In vitro formation of disulfide-bonded fibronectin multimers. The Journal of biological chemistry 258.10 (May 1983), pp. 6595-601

[158] Y Chen, L Zardi and D M Peters. High-resolution cryo-scanning electron microscopy study of the macromolecular structure of fibronectin fibrils. Scanning 19.5 (Aug. 1997), pp. 349-55

[159] DMP Peters et al. Conformation of Fibronectin Fibrils Varies: Discrete Globular Domains of Type III Repeats Detected. Microscopy and microanalysis : the official journal of Microscopy Society of America, Microbeam Analysis Society, Microscopical Society of Canada 4.4 (July 1998), pp. 385-396

[160] M Vuento et al. Spontaneous and polyamine-induced formation of filamentous polymers from soluble fibronectin. European journal of biochemistry / FEBS 105.1 (Mar. 1980), pp. 33-42

[161] M Vuento, E Salonen and P Riepponen. Interaction of polyamines with proteins of human plasma: a preferential aggregation of fibrinogen and fibronectin (cold insoluble globulin). Biochimie 62.1 (Jan. 1980), pp. 99-104

[162] F Jilek and H Hörmann. Fibronectin (cold-insoluble globulin), VI. Influence of heparin and hyaluronic acid on the binding of native collagen. Hoppe-Seyler's Zeitschrift für physiologische Chemie 360.4 (Apr. 1979), pp. 597-603 
[163] H Richter, C Wendt and H Hörmann. Aggregation and fibril formation of plasma fibronectin by heparin. Biological chemistry Hoppe-Seyler 366.5 (May 1985), pp. 509-14

[164] A Morla, Z Zhang and E Ruoslahti. Superfibronectin is a functionally distinct form of fibronectin. Nature 367.6459 (Jan. 1994), pp. 193-6. DOI: $10.1038 / 367193 \mathrm{a} 0$

[165] D C Hocking, R K Smith and P J McKeown-Longo. A novel role for the integrin-binding III-10 module in fibronectin matrix assembly. The Journal of cell biology 133.2 (Apr. 1996), pp. 431-44

[166] Klára Briknarová et al. Anastellin, an FN3 fragment with fibronectin polymerization activity, resembles amyloid fibril precursors. Journal of molecular biology 332.1 (Sept. 2003), pp. 205-15

[167] C Zhong et al. Rho-mediated contractility exposes a cryptic site in fibronectin and induces fibronectin matrix assembly. The Journal of cell biology 141.2 (Apr. 1998), pp. 539-51

[168] G Baneyx and V Vogel. Self-assembly of fibronectin into fibrillar networks underneath dipalmitoyl phosphatidylcholine monolayers: role of lipid matrix and tensile forces. Proceedings of the National Academy of Sciences of the United States of America 96.22 (Oct. 1999), pp. 12518-23

[169] O S Ejim, G W Blunn and R A Brown. Production of artificial-orientated mats and strands from plasma fibronectin: a morphological study. Biomaterials 14.10 (Aug. 1993), pp. 743-8

[170] R A Brown, G W Blunn and O S Ejim. Preparation of orientated fibrous mats from fibronectin: composition and stability. Biomaterials 15.6 (May 1994), pp. 457-64

[171] B Wòjciak-Stothard et al. Adhesion, orientation, and movement of cells cultured on ultrathin fibronectin fibers. In vitro cellular \& developmental biology. Animal 33.2 (Feb. 1997), pp. 110-7

[172] Z Ahmed, S Underwood and R A Brown. Nerve guide material made from fibronectin: assessment of in vitro properties. Tissue engineering 9.2 (Apr. 2003), pp. 219-31. DOI: 10.1089/107632703764664693

[173] Z Ahmed and R A Brown. Adhesion, alignment, and migration of cultured Schwann cells on ultrathin fibronectin fibres. Cell motility and the cytoskeleton 42.4 (Jan. 1999), pp. 331-43. DOI: 10.1002/ (SICI) 1097-0169(1999) 42:4<331: :AID-CM6>3 . 0 . CO;2-7 
[174] William C Little et al. Assay to mechanically tune and optically probe fibrillar fibronectin conformations from fully relaxed to breakage. Matrix biology : journal of the International Society for Matrix Biology 27.5 (June 2008), pp. 451-61. DOI: 10.1016/j . matbio.2008.02.003

[175] Enrico Klotzsch et al. Fibronectin forms the most extensible biological fibers displaying switchable force-exposed cryptic binding sites. Proceedings of the National Academy of Sciences of the United States of America 106.43 (Oct. 2009), pp. 18267-72. DOI: 10.1073/pnas . 0907518106

[176] Nadine Pernodet et al. Fibronectin fibrillogenesis on sulfonated polystyrene surfaces. Journal of biomedical materials research. Part A 64.4 (Mar. 2003), pp. 684-92. DOI: 10.1002/jbm.a.10394

[177] Delphine Pellenc, Hugues Berry and Olivier Gallet. Adsorption-induced fibronectin aggregation and fibrillogenesis. Journal of colloid and interface science 298.1 (June 2006), pp. 132-44. DOI: 10.1016/j . jcis . 2005.11 .059

[178] Valentin Nelea and Mari T Kaartinen. Periodic beaded-filament assembly of fibronectin on negatively charged surface. Journal of structural biology 170.1 (Apr. 2010), pp. 50-9. DOI: 10.1016/j . jsb. 2010.01. 009

[179] Adam W Feinberg and Kevin Kit Parker. Surface-initiated assembly of protein nanofabrics. Nano letters 10.6 (June 2010), pp. 2184-91. DOI: $10.1021 / \mathrm{nl100998p}$

[180] Manuel Salmerón-Sánchez et al. Role of material-driven fibronectin fibrillogenesis in cell differentiation. Biomaterials 32 (2011), pp. 20992105. DOI: $10.1016 / \mathrm{j}$. biomaterials . 2010.11.057

[181] K. Ichihara-Tanaka et al. Matrix assembly of recombinant fibronectin polypeptide consisting of amino-terminal $70 \mathrm{kDa}$ and carboxyl-terminal 37 kDa regions. FEBS Letters 299 (1992), pp. 155-158. DOI: 10.1016/ 0014-5793 (92) 80236-A

[182] J Sottile et al. Five type I modules of fibronectin form a functional unit that binds to fibroblasts and Staphylococcus aureus. The Journal of biological chemistry 266.20 (July 1991), pp. 12840-3

[183] E Ruoslahti. RGD and other recognition sequences for integrins. Annual review of cell and developmental biology 12 (Jan. 1996), pp. 697-715. DOI: 10.1146/annurev.cellbio.12.1.697 
[184] J L Sechler, S A Corbett and J E Schwarzbauer. Modulatory roles for integrin activation and the synergy site of fibronectin during matrix assembly. Molecular biology of the cell 8.12 (Dec. 1997), pp. 2563-73

[185] K Wennerberg et al. Beta 1 integrin-dependent and -independent polymerization of fibronectin. The Journal of cell biology 132.1-2 (Jan. 1996), pp. 227-38

[186] C Wu et al. Integrin activation and cytoskeletal interaction are essential for the assembly of a fibronectin matrix. Cell 83.5 (Dec. 1995), pp. 71524

[187] K J Johnson et al. The compact conformation of fibronectin is determined by intramolecular ionic interactions. The Journal of biological chemistry 274.22 (May 1999), pp. 15473-9

[188] Atsuko Yoneda et al. Fibronectin matrix assembly requires distinct contributions from Rho kinases I and -II. Molecular biology of the cell 18.1 (Jan. 2007), pp. 66-75. DOI: 10.1091/mbc.E06-08-0684

[189] A Hall. Rho GTPases and the control of cell behaviour. Biochemical Society transactions 33.Pt 5 (Nov. 2005), pp. 891-5. DOI: 10.1042/ BST20050891

[190] K J Langenbach and J Sottile. Identification of protein-disulfide isomerase activity in fibronectin. The Journal of biological chemistry 274.11 (Mar. 1999), pp. 7032-8

[191] Michael D. Pierschbacher and Erkki Ruoslahti. Cell attachment activity of fibronectin can be duplicated by small synthetic fragments of the molecule. en. Nature 309.5963 (May 1984), pp. 30-33. DOI: 10.1038/ 309030a0

[192] E Ruoslahti and M. Pierschbacher. New perspectives in cell adhesion: RGD and integrins. Science 238.4826 (Oct. 1987), pp. 491-497. DOI: 10.1126/science. 2821619

[193] E F Plow et al. The effect of Arg-Gly-Asp-containing peptides on fibrinogen and von Willebrand factor binding to platelets. Proceedings of the National Academy of Sciences of the United States of America 82.23 (Dec. 1985), pp. 8057-61

[194] T K Gartner and J S Bennett. The tetrapeptide analogue of the cell attachment site of fibronectin inhibits platelet aggregation and fibrinogen binding to activated platelets. The Journal of biological chemistry 260.22 (Oct. 1985), pp. 11891-4 
[195] S Suzuki et al. Complete amino acid sequence of human vitronectin deduced from cDNA. Similarity of cell attachment sites in vitronectin and fibronectin. The EMBO journal 4 (1985), pp. 2519-2524

[196] A L Main et al. The three-dimensional structure of the tenth type III module of fibronectin: an insight into RGD-mediated interactions. Cell 71 (1992), pp. 671-678. DOI: 10 . 1016/0092-8674 (92) 90600-H

[197] Craig D. Dickinson et al. Crystal structure of the tenth type III cell adhesion module of human fibronectin. Journal of Molecular Biology 236 (1994), pp. 1079-1092. DOI: 10.1016/0022-2836 (94)900132

[198] A M de Vos, M Ultsch and A A Kossiakoff. Human growth hormone and extracellular domain of its receptor: crystal structure of the complex. Science (New York, N.Y.) 255 (1992), pp. 306-312. DoI: 10.1126/ science. 1549776

[199] D J Leahy et al. Structure of a fibronectin type III domain from tenascin phased by MAD analysis of the selenomethionyl protein. Science (New York, N.Y.) 258 (1992), pp. 987-991. DOI: 10.1126/science. 1279805

[200] A H Huber et al. Crystal structure of tandem type III fibronectin domains from Drosophila neuroglian at 2.0 A. Neuron 12 (1994), pp. 717-731. DOI: 10.1016/0896-6273(94)90326-3

[201] S Aota, M Nomizu and K M Yamada. The short amino acid sequence ProHis-Ser-Arg-Asn in human fibronectin enhances cell-adhesive function. The Journal of biological chemistry 269.40 (Oct. 1994), pp. 24756-61

[202] R D Bowditch et al. Identification of a novel integrin binding site in fibronectin. Differential utilization by beta 3 integrins. The Journal of biological chemistry 269 (1994), pp. 10856-10863

[203] A. A. Kossiakoff et al. Variability of conformations at crystal contacts in BPTI represent true low-energy structures: Correspondence among lattice packing and molecular dynamics structures. Proteins: Structure, Function and Genetics 14 (1992), pp. 65-74. DOI: 10 . 1002/prot . 340140108

[204] J S Richardson. The anatomy and taxonomy of protein structure. Advances in protein chemistry 34 (1981), pp. 167-339. DOI: 10.1016/ S0065-3233(08)60520-3 
[205] Alan D. Welman and Ian S. Maddox. Exopolysaccharides from lactic acid bacteria: perspectives and challenges. Trends in Biotechnology 21.6 (2003), pp. 269-274

[206] S Salminen and A Von Wright. Lactic acid bacteria: microbiological and functional aspects. 2004

[207] a Bolotin et al. The complete genome sequence of the lactic acid bacterium Lactococcus lactis ssp. lactis IL1403. Genome research 11.5 (May 2001), pp. 731-53. DOI: 10.1101/gr.169701

[208] H Rawsthorne, K N Turner and D A Mills. Multicopy integration of heterologous genes, using the lactococcal group II intron targeted to bacterial insertion sequences. Applied and Environmental Microbiology 72.9 (2006), pp. 6088-6093. DOI: 10.1128/AEM.02992-05

[209] Arsalan Haseeb Zaidi. 'Biofilm development and toxic compound resistance in Lactococcus lactis '. Thesis. Rijksuniversiteit Groningen, 2011

[210] Carine Mercier et al. Positive role of peptidoglycan breaks in lactococcal biofilm formation. Molecular microbiology 46.1 (Oct. 2002), pp. 235-43

[211] Aleixandre Rodrigo-Navarro et al. Living biointerfaces based on nonpathogenic bacteria to direct cell differentiation. Scientific reports 4 (Jan. 2014), p. 5849. DOI: 10.1038/srep05849

[212] L Steidler et al. Functional display of a heterologous protein on the surface of Lactococcus lactis by means of the cell wall anchor of Staphylococcus aureus protein A. Applied and environmental microbiology 64.1 (Jan. 1998), pp. 342-5

[213] N R Waterfield et al. The Isolation of Lactococcal Promoters and their use in Investigating Bacterial Luciferase Synthesis in Lactococcus-Lactis. Gene 165.1 (Nov. 1995), pp. 9-15. DoI: 10.1016/0378-1119(95) 00484-N

[214] M van Asseldonk et al. Cloning of usp45, a gene encoding a secreted protein from Lactococcus lactis subsp. lactis MG1363. Gene 95.1 (Oct. 1990), pp. 155-60

[215] L. Schotte et al. Secretion of biologically active murine interleukin-10 by Lactococcus lactis. Enzyme and Microbial Technology 27.10 (Dec. 2000), pp. 761-765. DOI: 10.1016/S0141-0229(00)00297-0

[216] Anas Saadeddin et al. Functional living biointerphases. Advanced Healthcare Materials 2.9 (Sept. 2013), pp. 1213-8. DOI: 10 .1002/adhm . 201200473 
[217] S K Mazmanian, H Ton-That and O Schneewind. Sortase-catalysed anchoring of surface proteins to the cell wall of Staphylococcus aureus. Molecular microbiology 40.5 (June 2001), pp. 1049-57

[218] C. Ton-That et al. XPS and AFM surface studies of solvent-cast PS/PMMA blends. 2001. DOI: 10.1016/S0032-3861(00)00448-1

[219] Kathleen W. Clancy, Jeffrey A. Melvin and Dewey G. McCafferty. Sortase transpeptidases: insights into mechanism, substrate specificity, and inhibition. 2010. DOI: 10.1002/bip. 21472

[220] O Schneewind, A Fowler and K F Faull. Structure of the cell wall anchor of surface proteins in Staphylococcus aureus. Science (New York, N.Y.) 268.5207 (Apr. 1995), pp. 103-6

[221] J Rodríguez. Heterologous production of bacteriocins by lactic acid bacteria. International Journal of Food Microbiology 80.2 (Jan. 2003), pp. 101-116. DOI: $10.1016 /$ S0168-1605(02)00153-8

[222] Shujie Liu et al. Immune responses elicited in mice with recombinant Lactococcus lactis expressing F4 fimbrial adhesin FaeG by oral immunization. Veterinary research communications 34.6 (Aug. 2010), pp. 491502. DOI: $10.1007 / \mathrm{s} 11259-010-9418-\mathrm{x}$

[223] D J Lane et al. Rapid determination of 16S ribosomal RNA sequences for phylogenetic analyses. Proceedings of the National Academy of Sciences of the United States of America 82 (1985), pp. 6955-6959. DOI: 10. 1073/pnas.82.20.6955

[224] M. D. Collins, A. M. Williams and S. Wallbanks. The phylogeny of Aerococcus and Pediococcus as determined by 16S rRNA sequence analysis: Description of Tetragenococcus gen. nov. FEMS Microbiology Letters 70 (1990), pp. 255-262. DOI: 10 . 1016/S0378-1097(05) 80004-7

[225] S Wallbanks et al. 16S rRNA sequence determination for members of the genus Carnobacterium and related lactic acid bacteria and description of Vagococcus salmoninarum sp. nov. International journal of systematic bacteriology 40 (1990), pp. 224-230. DOI: 10.1099/00207713-403-224

[226] M D Collins et al. Taxonomic studies on some leuconostoc-like organisms from fermented sausages: description of a new genus Weissella for the Leuconostoc paramesenteroides group of species. The Journal of applied bacteriology 75 (1993), pp. 595-603 
[227] M D Collins et al. 16S ribosomal ribonucleic acid sequence analyses of lactococci and related taxa. Description of Vagococcus fluvialis gen. nov., sp. nov. The Journal of applied bacteriology 67 (1989), pp. 453-460

[228] R W Bentley, J A Leigh and M D Collins. Intrageneric structure of Streptococcus based on comparative analysis of small-subunit rRNA sequences. International journal of systematic bacteriology 41 (1991), pp. 487-494. DOI: 10.1099/00207713-41-4-487

[229] Y Kawamura et al. Determination of 16S rRNA sequences of Streptococcus mitis and Streptococcus gordonii and phylogenetic relationships among members of the genus Streptococcus. International journal of systematic bacteriology 45 (1995), pp. 406-408. DOI: $10.1099 /$ 00207713-45-4-882a

[230] A. M. Williams, U. M. Rodrigues and M. D. Collins. Intrageneric relationships of Enterococci as determined by reverse transcriptase sequencing of small-subunit rRNA. Research in Microbiology 142 (1991), pp. 67-74. DOI: 10.1016/0923-2508(91) 90098-U

[231] M D Collins et al. Phylogenetic analysis of the genus Listeria based on reverse transcriptase sequencing of 16S rRNA. International journal of systematic bacteriology 41 (1991), pp. 240-246. DOI: 10 . 1099/ 00207713-41-2-240

[232] A J Martinez-Murcia, N M Harland and M D Collins. Phylogenetic analysis of some leuconostocs and related organisms as determined from large-subunit rRNA gene sequences: assessment of congruence of small- and large-subunit rRNA derived trees. The Journal of applied bacteriology 74 (1993), pp. 532-541

[233] Seppo. Salminen. Lactic acid bacteria : microbiological and functional aspects. English. Boca Raton: CRC Press, Taylor \& Francis, 2012

[234] DM Engesser and WP Hammes. Non-heme catalase activity of lactic acid bacteria. Systematic and applied microbiology (1994)

[235] G Wolf et al. Heme-dependent catalase activity of lactobacilli. International journal of food microbiology 12 (1991), pp. 133-140. DOI: 10.1016/0168-1605(91) 90062-T

[236] R Whittenbury. Biochemical characteristics of Streptococcus species. Society for Applied Bacteriology symposium series 7 (Jan. 1978), pp. 5169 
[237] R Whittenbury. Hydrogen Peroxide Formation and Catalase Activity in the Lactic Acid Bacteria. J Gen Microbiol 35 (1964), pp. 13-26. DoI: 10. 1099/00221287-35-1-13

[238] D G Bryan-Jones and R Whittenbury. Haematin-dependent oxidative phosphorylation in Streptococcus faecalis. Journal of general microbiology 58 (1969), pp. 247-260. DOI: 10. 1099/00221287-58-2-247

[239] Philippe Gaudu et al. Respiration capacity and consequences in Lactococcus lactis. Antonie van Leeuwenhoek, International Journal of General and Molecular Microbiology 82 (2002), pp. 263-269. DOI: 10.1023/A: 1020635600343

[240] T W Ritchey and H W Seely. Distribution of cytochrome-like respiration in streptococci. Journal of general microbiology 93 (1976), pp. 195-203. DOI: $10.1099 / 00221287-93-2-195$

[241] Jutta Meisel, Gudrun Wolf and Walter P. Hammes. Heme-Dependent Cytochrome Formation in Lactobacillus maltaromicus. Systematic and Applied Microbiology 17.1 (Mar. 1994), pp. 20-23. DOI: $10.1016 /$ S0723-2020 (11) 80026-3

[242] P Duwat et al. Respiration capacity of the fermenting bacterium Lactococcus lactis and its positive effects on growth and survival. Journal of bacteriology 183 (2001), pp. 4509-4516. DOI: 10.1128/JB.183.15. 4509-4516. 2001

[243] M. Stahl et al. Restriction Endonuclease Patterns and Multivariate Analysis as a Classification Tool for Lactobacillus spp. International Journal of Systematic Bacteriology 40.2 (Apr. 1990), pp. 189-193. Dor: 10.1099/00207713-40-2-189

[244] A. T. Bull, D. C. Ellwood and C. Ratledge. 'Microbial technology: current state, future prospects.' English. Microbial technology: current state, future prospects. Cambridge University Press., 1979

[245] J Thompson. Lactose metabolism in Streptococcus lactis: phosphorylation of galactose and glucose moieties in vivo. Journal of bacteriology 140 (1979), pp. 774-785

[246] David W. Russell and J Sambrook. Molecular cloning: a laboratory manual. 2001 
[247] D J Osullivan, T R Klaenhammer and D J O'sullivan. Rapid Mini-Prep Isolation of High-Quality Plasmid Dna from Lactococcus and Lactobacillus Spp. Applied and Environmental Microbiology 59.8 (Aug. 1993), pp. 2730-2733

[248] B E Terzaghi and W E Sandine. Improved medium for lactic streptococci and their bacteriophages. Applied microbiology 29.6 (June 1975), pp. 807-13

[249] Mette Burmø lle et al. Enhanced biofilm formation and increased resistance to antimicrobial agents and bacterial invasion are caused by synergistic interactions in multispecies biofilms. Applied and environmental microbiology 72.6 (June 2006), pp. 3916-3923. DOI: 10.1128/ AEM. 03022-05

[250] Saumya Bhaduri. Modification of an acetone-sodium dodecyl sulfate disruption method for cellular protein extraction from neurotoxigenic Clostridium botulinum. en. Foodborne pathogens and disease 9.2 (Feb. 2012), pp. 172-4. DOI: $10.1089 /$ fpd. 2011.0979

[251] Johannes Schindelin et al. Fiji: an open-source platform for biologicalimage analysis. 2012. DOI: 10.1038/nmeth . 2019

[252] Bu"lent Sankur. Survey over image thresholding techniques and quantitative performance evaluation. Journal of Electronic Imaging 13.1 (Jan. 2004), p. 146. DOI: 10.1117/1.1631315

[253] Mark Hall et al. The WEKA Data Mining Software : An Update. SIGKDD Explorations 11 (2009), pp. 10-18. DOI: 10.1145/1656274.1656278

[254] Matthias Lutolf, Penney Gilbert and Helen Blau. Designing materials to direct stem-cell fate. Nature 462.7272 (2009), pp. 433-441. DOI: 10.1038/nature08602

[255] Timothy A Petrie et al. Integrin specificity and enhanced cellular activities associated with surfaces presenting a recombinant fibronectin fragment compared to RGD supports. Biomaterials 27.31 (Nov. 2006), pp. 5459-70. DOI: 10.1016/j.biomaterials.2006.06.027

[256] J. C. Araujo. Comparison of hexamethyldisilazane and critical point drying treatments for SEM analysis of anaerobic biofilms and granular sludge. Journal of Electron Microscopy 52.4 (Sept. 2003), pp. 429-433. DOI: $10.1093 /$ jmicro/52.4.429 
[257] Yves F Dufrêne. Atomic force microscopy and chemical force microscopy of microbial cells. Nature protocols 3.7 (Jan. 2008), pp. 1132-8. DOI: $10.1038 /$ nprot .2008 .101

[258] T P Ugarova et al. Conformational transitions in the cell binding domain of fibronectin. Biochemistry 34 (1995), pp. 4457-4466

[259] K B McClary, T Ugarova and D W Grainger. Modulating fibroblast adhesion, spreading, and proliferation using self-assembled monolayer films of alkylthiolates on gold. Journal of biomedical materials research 50 (2000), pp. 428-439. DOI: 10.1002/(SICI) 1097-4636(20000605) $50: 3<428$ : :AID-JBM18>3.0.CO;2-H[pii]

[260] J Rivadeneira et al. Evaluation of antibacterial and cytotoxic effects of nano-sized bioactive glass/collagen composites releasing tetracycline hydrochloride. Journal of applied microbiology (Feb. 2014), pp. 1-9. DOI: $10.1111 /$ jam. 12476

[261] J A Bacon, D A Linseman and T J Raczniak. In vitro cytotoxicity of tetracyclines and aminoglycosides in LLC-PK(1), MDCK and Chang continuous cell lines. Toxicology in vitro : an international journal published in association with BIBRA 4.4-5 (Jan. 1990), pp. 384-8

[262] Sean R Connell et al. Ribosomal protection proteins and their mechanism of tetracycline resistance. Antimicrobial agents and chemotherapy 47 (2003), pp. 3675-3681. DOI: 10.1128/AAC . 47 .12 .36753681.2003

[263] Patricia Rico et al. Substrate-induced assembly of fibronectin into networks: influence of surface chemistry and effect on osteoblast adhesion. Tissue engineering. Part A 15.11 (Nov. 2009), pp. 3271-81. DOI: 10.1089/ten. TEA.2009.0141

[264] Régis Stentz et al. Controlled expression of CluA in Lactococcus lactis and its role in conjugation. Microbiology (Reading, England) 150.Pt 8 (Aug. 2004), pp. 2503-12. DOI: 10.1099/mic.0.27149-0

[265] Ming Luo and Jun-Lin Guan. Focal adhesion kinase: a prominent determinant in breast cancer initiation, progression and metastasis. Cancer letters 289 (2010), pp. 127-139. DOI: 10.1016/j. canlet.2009. 07. 005 
[266] M D Schaller et al. Autophosphorylation of the focal adhesion kinase, pp125FAK, directs SH2-dependent binding of pp60src. Molecular and cellular biology 14.3 (1994), pp. 1680-1688. DOI: 10.1128/MCB . 14 3.1680. Updated

[267] Annalisa Mancini et al. Regulation of myotube formation by the actinbinding factor drebrin. Skeletal muscle 1.1 (Jan. 2011), p. 36. DOI: 10.1186/2044-5040-1-36

[268] Candice Cabane et al. Regulation of C2C12 myogenic terminal differentiation by MKK3/p38alpha pathway. American journal of physiology. Cell physiology 284.3 (Mar. 2003), pp. C658-66. DOI: 10.1152/ajpcell. 00078.2002

[269] Aviad Keren, Yael Tamir and Eyal Bengal. The p38 MAPK signaling pathway: a major regulator of skeletal muscle development. Molecular and cellular endocrinology 252.1-2 (June 2006), pp. 224-30. DOI: 10. $1016 /$ j.mce. 2006.03 .017

[270] Frederic Lluís et al. Regulation of skeletal muscle gene expression by p38 MAP kinases. Trends in cell biology 16.1 (Jan. 2006), pp. 36-44. DOI: $10.1016 / j . t c b .2005 .11 .002$

[271] JW Han et al. Promyogenic function of Integrin/FAK signaling is mediated by Cdo, Cdc42 and MyoD. Cellular signalling 23.7 (July 2011), pp. 1162-9. DOI: 10.1016/j.cellsig.2011.03.001

[272] L A Cary and J L Guan. Focal adhesion kinase in integrin-mediated signaling [In Process Citation]. Front Biosci 4 (1999), pp. D102-13

[273] M D Schaller. Biochemical signals and biological responses elicited by the focal adhesion kinase. Biochimica et biophysica acta 1540.1 (July 2001), pp. 1-21

[274] Nadia K Zouq et al. FAK engages multiple pathways to maintain survival of fibroblasts and epithelia: differential roles for paxillin and p130Cas. Journal of cell science 122.Pt 3 (Feb. 2009), pp. 357-67. DOI: 10.1242/ jcs. 030478

[275] Navaline L Quach et al. Focal adhesion kinase signaling regulates the expression of caveolin 3 and beta1 integrin, genes essential for normal myoblast fusion. Molecular biology of the cell 20.14 (July 2009), pp. 3422-35. DOI: 10.1091/mbc.E09-02-0175 
[276] Inbal Wortzel and Rony Seger. The ERK Cascade: Distinct Functions within Various Subcellular Organelles. Genes \& cancer 2 (2011), pp. 195209. DOI: $10.1177 / 1947601911407328$

[277] G Manning et al. The protein kinase complement of the human genome. Science (New York, N.Y.) 298 (2002), pp. 1912-1934. DOI: 10.1126/ science. 1075762

[278] Robert Roskoski. ERK1/2 MAP kinases: structure, function, and regulation. Pharmacological research : the official journal of the Italian Pharmacological Society 66.2 (Aug. 2012), pp. 105-43. DOI: 10.1016/ j.phrs.2012.04.005

[279] Robert Roskoski. RAF protein-serine/threonine kinases: Structure and regulation. 2010. DOI: 10.1016/j.bbrc. 2010.07.092

[280] Seunghee Yoon and Rony Seger. The extracellular signal-regulated kinase: Multiple substrates regulate diverse cellular functions. 2006. DOI: 10 . 1159/000094762

[281] Zhen Xiang Liu et al. Hepatocyte growth factor induces ERK-dependent paxillin phosphorylation and regulates paxillin-focal adhesion kinase association. Journal of Biological Chemistry 277 (2002), pp. 1045210458. DOI: $10.1074 / \mathrm{jbc} . \mathrm{M} 107551200$

[282] Arnold I. Caplan. Adult mesenchymal stem cells for tissue engineering versus regenerative medicine. 2007. DOI: $10.1002 / \mathrm{jcp} .21200$

[283] J Sanchez-Ramos et al. Adult bone marrow stromal cells differentiate into neural cells in vitro. Experimental neurology 164 (2000), pp. 247256. DOI: $10.1006 /$ exnr . 2000.7389

[284] C. Toma et al. Human mesenchymal stem cells differentiate to a cardiomyocyte phenotype in the adult murine heart. Circulation 105 (2002), pp. 93-98. DOI: 10.1161/hc0102.101442

[285] Morayma Reyes et al. Origin of endothelial progenitors in human postnatal bone marrow. Journal of Clinical Investigation 109 (2002), pp. 337346. DOI: $10.1172 /$ JCI200214327

[286] Timothy Petrie et al. Multivalent Integrin-Specific Ligands Enhance Tissue Healing and Biomaterial Integration. Science translational medicine 2.45 (2010), 45ra60. DoI: 10.1126/scitranslmed. 3001002

[287] D Ilić et al. Reduced cell motility and enhanced focal adhesion contact formation in cells from FAK-deficient mice. Nature 377.6549 (1995), pp. 539-544. DOI: $10.1038 / 377539 a 0$ 
[288] L A Cary, J F Chang and J L Guan. Stimulation of cell migration by overexpression of focal adhesion kinase and its association with Src and Fyn. Journal of Cell Science 109 ( Pt 7.Pt 7 (1996), pp. 1787-1794

[289] S M Frisch et al. Control of adhesion-dependent cell survival by focal adhesion kinase. The Journal of cell biology 134.3 (1996), pp. 793-799

[290] H R Reiske et al. Requirement of phosphatidylinositol 3-kinase in focal adhesion kinase-promoted cell migration. The Journal of biological chemistry 274.18 (1999), pp. 12361-12366

[291] A. J. Garcia, M. D. Vega and D. Boettiger. Modulation of Cell Proliferation and Differentiation through Substrate-dependent Changes in Fibronectin Conformation. Molecular Biology of the Cell 10.3 (Mar. 1999), pp. 785-798. DOI: $10.1091 / \mathrm{mbc} \cdot 10.3 .785$

[292] E G Hayman and E Ruoslahti. Distribution of fetal bovine serum fibronectin and endogenous rat cell fibronectin in extracellular matrix. The Journal of cell biology 83.1 (Oct. 1979), pp. 255-9

[293] Chelsea M Kirschner et al. Clickable, Photodegradable Hydrogels to Dynamically Modulate Valvular Interstitial Cell Phenotype. Advanced healthcare materials (Jan. 2014). DOI: 10.1002/adhm. 201300288

[294] Sudhir Khetan et al. Degradation-mediated cellular traction directs stem cell fate in covalently crosslinked three-dimensional hydrogels. Nature materials 12 (2013), pp. 458-65. DOI: 10.1038/nmat3586

[295] Rein V. Ulijn. Enzyme-responsive materials: a new class of smart biomaterials. en. Journal of Materials Chemistry 16.23 (June 2006), p. 2217. DOI: $10.1039 / \mathrm{b} 601776 \mathrm{~m}$

[296] Helen Makarenkova et al. Differential interactions of FGFs with heparan sulfate control gradient formation and branching morphogenesis. Science Signaling 2.88 (2009), ra55. DOI: 10.1126/scisignal. 2000304

[297] A K Silva et al. Growth factor delivery approaches in hydrogels. Biomacromolecules 10.1 (2009), pp. 9-18. DOI: 10.1021/bm801103c

[298] Mariah S Hahn, Jordan S Miller and Jennifer L West. Three-dimensional biochemical and biomechanical patterning of hydrogels for guiding cell behavior. Advanced Materials 18.20 (2006), pp. 2679-+. DOI: 10 . 1002/adma . 200600647 
[299] J J Moon et al. Micropatterning of poly(ethylene glycol) diacrylate hydrogels with biomolecules to regulate and guide endothelial morphogenesis. Tissue engineering.Part A 15.3 (2009), pp. 579-585. DOI: 10 . 1089/ten.tea. 2008.0196

[300] E A Phelps et al. Bioartificial matrices for therapeutic vascularization. Proceedings of the National Academy of Sciences of the United States of America 107.8 (2010), pp. 3323-3328. DOI: 10.1073/pnas . 0905447107

[301] Jennifer Patterson, Mikael M Martino and Jeffrey A Hubbell. Biomimetic materials in tissue engineering. Materials Today 13.1-2 (2010), pp. 14 22

[302] Patricia Rico et al. Molecular assembly and biological activity of a recombinant fragment of fibronectin (FNIII7?10) on poly(ethyl acrylate). Colloids and Surfaces B: Biointerfaces 78.2 (2010), pp. 310-316

[303] M C van Loosdrecht et al. Electrophoretic mobility and hydrophobicity as a measured to predict the initial steps of bacterial adhesion. Applied and environmental microbiology 53 (1987), pp. 1898-1901

[304] E Gulot et al. Heterogeneity of diffusion inside microbial biofilms determined by fluorescence correlation spectroscopy under two-photon excitation. Photochemistry and photobiology 75.6 (June 2002), pp. 570578

[305] Olivier Habimana et al. Genetic features of resident biofilms determine attachment of Listeria monocytogenes. Applied and environmental microbiology 75 (2009), pp. 7814-7821. DOI: 10.1128/AEM.01333-09

[306] Aurélie Rieu et al. Listeria monocytogenes EGD-e biofilms: no mushrooms but a network of knitted chains. Applied and environmental microbiology 74 (2008), pp. 4491-4497. DOI: 10.1128/AEM.00255-08

[307] Virginie Oxaran et al. Pilus biogenesis in Lactococcus lactis: molecular characterization and role in aggregation and biofilm formation. PloS one 7.12 (Jan. 2012). Ed. by Indranil Biswas, e50989. DOI: 10.1371/ journal.pone.0050989

[308] P. H. Pilkington et al. FUNDAMENTALS OF IMMOBILISED YEAST CELLS FOR CONTINUOUS BEER FERMENTATION: A REVIEW. Journal of the Institute of Brewing 104.1 (Jan. 1998), pp. 19-31. DOI: $10.1002 / \mathrm{j}$. 2050-0416.1998.tb00970.x 
[309] Y Kourkoutas et al. Immobilization technologies and support materials suitable in alcohol beverages production: a review. Food Microbiology 21.4 (Aug. 2004), pp. 377-397. DOI: 10.1016/j.fm. 2003.10.005

[310] Jose M Guisan. Immobilization of Enzymes and Cells 2nd edition. 2nd

[311] Hideto Tsuji and Yoshito Ikada. Blends of aliphatic polyesters. II. Hydrolysis of solution-cast blends from poly(L-lactide) and poly ( $\epsilon$-caprolactone) in phosphate-buffered solution. Journal of Applied Polymer Science 67.3 (1998), pp. 405-415

[312] James Lunt. Large-scale production, properties and commercial applications of poly lactic acid polymers. Polymer Degradation and Stability 59.1-3 (1998), pp. 145-152

[313] Donald Garlotta. A literature review of poly (lactic acid). Journal of Polymers and the Environment 9.2 (2001)

[314] Yanling Cheng et al. Polylactic acid (PLA) synthesis and modifications: A review. Frontiers of Chemistry in China 4 (2009), pp. 259-264. DOI: 10.1007/s11458-009-0092-x

[315] Ann-Christine Albertsson and IndraK. Varma. Degradable Aliphatic Polyesters. English. Vol. 157. Advances in Polymer Science. Berlin, Heidelberg: Springer Berlin Heidelberg, Feb. 2002, pp. 1-40. DOI: 10.1007/ 3-540-45734-8

[316] Astrid J R Lasprilla et al. Poly-lactic acid synthesis for application in biomedical devices - a review. Biotechnology advances 30.1 (2012), pp. 321-8. DOI: 10.1016/j . biotechadv. 2011.06.019

[317] J. Doshi and D.H. Reneker. Electrospinning process and applications of electrospun fibers. Conference Record of the 1993 IEEE Industry Applications Conference Twenty-Eighth IAS Annual Meeting (1993). DOI: 10.1109/IAS. 1993.299067

[318] Zheng Ming Huang et al. A review on polymer nanofibers by electrospinning and their applications in nanocomposites. Composites Science and Technology 63 (2003), pp. 2223-2253. DOI: 10 . 1016/S02663538(03) 00178-7

[319] Dan Li and Younan Xia. Electrospinning of nanofibers: Reinventing the wheel? 2004. DOI: 10.1002/adma. 200400719

[320] S. N. Reznik et al. Transient and steady shapes of droplets attached to a surface in a strong electric field. 2004. DOI: 10.1017/S0022112004000679 
[321] G. Taylor. Electrically Driven Jets. 1969. DOI: 10.1098/rspa. 1969. 0205

[322] Darrell H. Reneker et al. Bending instability of electrically charged liquid jets of polymer solutions in electrospinning. Journal of Applied Physics 87 (2000), pp. 4531-4547. DOI: 10.1063/1.373532

[323] Y. M. Shin et al. Electrospinning: A whipping fluid jet generates submicron polymer fibers. Applied Physics Letters 78 (2001), pp. 11491151. DOI: $10.1063 / 1.1345798$

[324] Seema Agarwal, Andreas Greimer and Joachin H. Wendorff. Electrospinning of manmade and biopolymer nanofibers - Progress in techniques, materials, and applications. Advanced Functional Materials 19 (2009), pp. 2863-2879. DOI: 10.1002/adfm . 200900591

[325] Andreas Greiner and Joachim H. Wendorff. Electrospinning: A fascinating method for the preparation of ultrathin fibers. 2007. DOI: 10.1002/ anie. 200604646

[326] D. H. Reneker et al. Electrospinning of Nanofibers from Polymer Solutions and Melts. 2007. DOI: 10.1016/S0065-2156(07)41002-X

[327] C. Ton-That et al. Effects of Annealing on the Surface Composition and Morphology of PS/PMMA Blend. Macromolecules 33 (2000), pp. 84538459. DOI: $10.1021 / \mathrm{ma} 000792 \mathrm{~h}$

[328] P Müller-Buschbaum et al. The control of thin film morphology by the interplay of dewetting, phase separation and microphase separation. 2005. DOI: $10.1088 / 0953-8984 / 17 / 9 / 006$

[329] M Geoghegan. Wetting at polymer surfaces and interfaces. 2003. DOI: 10.1016/S0079-6700(02)00080-1 